CIVIL ENGINEERING STUDIES

Illinois Center for Transportation Series No. 20-002

UILU-ENG-2020-2002

ISSN: 0197-9191

\title{
Work Zone Safety Performance on Illinois State Routes
}

\author{
Prepared by \\ Kerrie Schattler \\ Sadit Maharjan \\ Audrey Hawkins \\ Krishnanand Maillacheruvu \\ Bradley University
}

Research Report No. FHWA-ICT-20-001

A report of the findings of

ICT PROJECT R27-186

Correlation between Work Zone Exposure and Work Zone-Related Fatal and A-Injury Crashes

https://doi.org/10.36501/0197-9191/20-002

Illinois Center for Transportation

January 2020 



\section{TECHNICAL REPORT DOCUMENTATION PAGE}

\begin{tabular}{|c|c|c|c|c|c|}
\hline $\begin{array}{l}\text { 1. Report No. } \\
\text { FHWA-ICT-20-001 }\end{array}$ & \multicolumn{3}{|c|}{$\begin{array}{l}\text { 2. Government Accession No. } \\
\text { N/A }\end{array}$} & \multicolumn{2}{|l|}{$\begin{array}{l}\text { 3. Recipient's Catalog No. } \\
\text { N/A }\end{array}$} \\
\hline \multicolumn{4}{|l|}{ 4. Title and Subtitle } & \multicolumn{2}{|l|}{$\begin{array}{l}\text { 5. Report Date } \\
\text { January } 2020\end{array}$} \\
\hline \multicolumn{4}{|c|}{ Work Zone Safety Performance on Illinois State Routes } & \multicolumn{2}{|c|}{$\begin{array}{l}\text { 6. Performing Organization Code } \\
\text { N/A }\end{array}$} \\
\hline \multicolumn{4}{|c|}{$\begin{array}{l}\text { 7. Authors } \\
\text { Kerrie L. Schattler (https://orcid.org/0000-0003-4184-8318), Sadit Maharjan } \\
\text { (https://orcid.org/0000-0001-9460-8276), Audrey Hawkins, Krishnanand Maillacheruvu } \\
\text { (https://orcid.org/0000-0002-8995-2029) }\end{array}$} & \multicolumn{2}{|c|}{$\begin{array}{l}\text { 8. Performing Organization Report No. } \\
\text { ICT } 20-002 \\
\text { UILU-ENG-2020-2002 }\end{array}$} \\
\hline \multirow{2}{*}{\multicolumn{4}{|c|}{$\begin{array}{l}\text { 9. Performing Organization Name and Address } \\
\text { Illinois Center for Transportation } \\
\text { Department of Civil and Environmental Engineering } \\
\text { University of Illinois at Urbana-Champaign } \\
205 \text { North Mathews Avenue, MC- } 250 \\
\text { Urbana, IL } 61801\end{array}$}} & \multicolumn{2}{|l|}{$\begin{array}{l}\text { 10. Work Unit No. } \\
\text { N/A }\end{array}$} \\
\hline & & & & \multicolumn{2}{|l|}{$\begin{array}{l}\text { 11. Contract or Grant No. } \\
\text { R27-186 }\end{array}$} \\
\hline \multirow{2}{*}{\multicolumn{2}{|c|}{$\begin{array}{l}\text { 12. Sponsoring Agency Name and Address } \\
\text { Illinois Department of Transportation (SPR) } \\
\text { Bureau of Material and Physical Research } \\
\text { 126 East Ash Street } \\
\text { Springfield, IL } 62704\end{array}$}} & & & \multicolumn{2}{|c|}{$\begin{array}{l}\text { 13. Type of Report and Period Covered } \\
\text { Final Report } 2 / 1 / 18-1 / 31 / 20\end{array}$} \\
\hline & & & & \multicolumn{2}{|c|}{ 14. Sponsoring Agency Code } \\
\hline \multicolumn{6}{|c|}{$\begin{array}{l}\text { 15. Supplementary Notes } \\
\text { Conducted in cooperation with the U.S. Department of Transportation, Federal Highway Administration. } \\
\text { https://doi.org/10.36501/0197-9191/20-002 }\end{array}$} \\
\hline \multicolumn{6}{|c|}{ 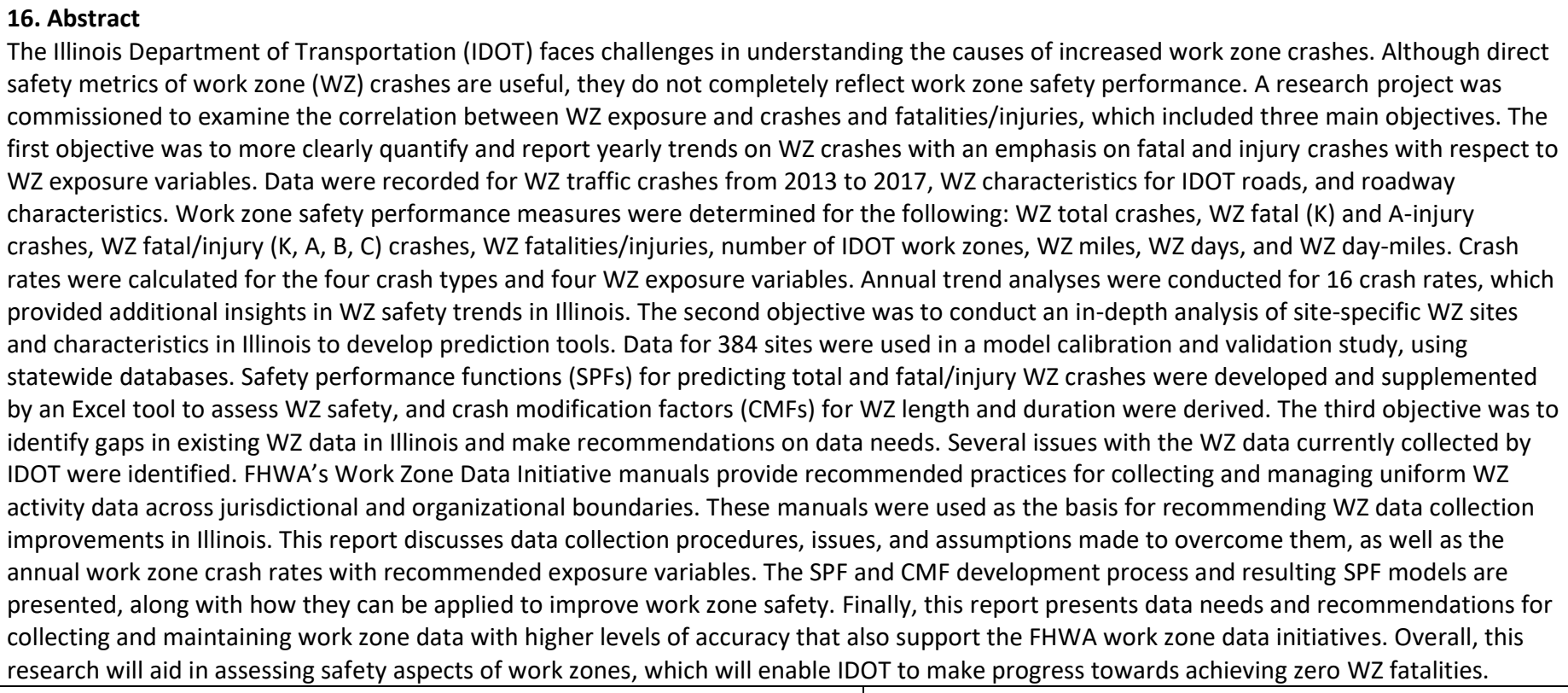 } \\
\hline \multicolumn{3}{|c|}{$\begin{array}{l}\text { 17. Key Words } \\
\text { Work Zone Safety, Work Zone Crashes, Work Zone Exposure Variables, } \\
\text { Length, Duration, Work Zone Crash Rates, Safety Performance Functions, } \\
\text { Crash Modification Factors }\end{array}$} & \multicolumn{3}{|c|}{$\begin{array}{l}\text { 18. Distribution Statement } \\
\text { No restrictions. This document is available through the } \\
\text { National Technical Information Service, Springfield, VA } 22161 .\end{array}$} \\
\hline \multicolumn{2}{|l|}{$\begin{array}{l}\text { 19. Security Classif. (of this report) } \\
\text { Unclassified }\end{array}$} & \multicolumn{2}{|l|}{$\begin{array}{l}\text { 20. Security } \\
\text { Unclassified }\end{array}$} & $\begin{array}{l}\text { 21. No. of Pages } \\
75+\text { appendices }\end{array}$ & $\begin{array}{l}\text { 22. Price } \\
N / A\end{array}$ \\
\hline
\end{tabular}

Form DOT F 1700.7 (8-72)

Reproduction of completed page authorized 



\section{ACKNOWLEDGMENT, DISCLAIMER, MANUFACTURERS' NAMES}

This publication is based on the results of ICT-R27-186: Correlation between Work Zone Exposure and Work Zone-Related Fatal and A-Injury Crashes. ICT-R27-186 was conducted in cooperation with the Illinois Center for Transportation; the Illinois Department of Transportation; and the U.S.

Department of Transportation, Federal Highway Administration.

Members of the Technical Review Panel (TRP) were the following:

- Juan Pava (TRP Chair), IDOT

- Kyle Armstrong, IDOT

- Mark Blankenship, IDOT

- $\quad$ Mike Copp, IDOT

- Anna Ghidina, IDOT

- Paul Gurklys, IDOT

- Dean Mentjes, FHWA

- Marshall Metcalf, IDOT

- Carlos Munoz, IDOT

- Susan Stitt, IDOT

- Megan Swanson, IDOT

- Kyle Videgar, IDOT

The contents of this report reflect the view of the authors, who are responsible for the facts and the accuracy of the data presented herein. The contents do not necessarily reflect the official views or policies of the Illinois Center for Transportation, the Illinois Department of Transportation, or the Federal Highway Administration. This report does not constitute a standard, specification, or regulation. 


\section{EXECUTIVE SUMMARY}

The Illinois Department of Transportation (IDOT) faces challenges in understanding the causes for increased work zone crashes. Although direct safety metrics such as the number of work zone fatal and A-injury crashes are available, they do not completely reflect work zone safety performance. Three objectives were established for this research. The first objective is to more clearly quantify and report yearly trends on work zone crashes and injuries with an emphasis on fatal and A-injury crashes with respect to work zone exposure variables such as number of work zones, work zone length, and work zone duration. The second objective is to conduct an in-depth analysis of site-specific work zone sites and characteristics in Illinois to develop prediction tools such as safety performance functions (SPFs) and crash modification factors (CMFs) to assess work zone safety. The third objective is to identify gaps in existing work zone data in Illinois and make recommendations on data needs. Overall, this research will aid in assessing safety aspects of work zones, which will enable IDOT to make progress towards improving safety and reducing fatalities and serious injuries in work zones.

\section{Work Zone Safety Performance Measures}

The three performance measures that were used to quantify work zone safety in Illinois are (1) traffic crash frequencies, (2) exposure variables, and (3) crash rates.

Data from three main sources were obtained from IDOT to analyze work zone safety performance in Illinois from 2013 to 2017. They are the traffic crash, lane closure, and roadway network databases. The three databases were fused to obtain work zone information in terms of traffic crash frequencies and work zone exposure variables in Illinois. Annual work zone frequencies were obtained and trend analyses were conducted for all roads and IDOT roads for the following crash types: total work zone (WZ) crashes, WZ fatal (K) and A-injury crashes, WZ fatal/injury $(K, A, B, C)$ crashes, and WZ fatalities/injuries.

WZ exposure variables were only available for IDOT roads. Thus, annual trends of work zone exposure variables were quantified for IDOT roads only from 2013 to 2017 for the following: number of IDOT work zones, WZ miles, WZ days, and WZ day-miles.

Crash rates were then calculated for the four work zone crash types and four exposure variables. Annual trend analyses were conducted for 16 crash rates for IDOT roads from 2013 to 2017, which revealed that WZ exposure variables and crash rates do provide additional insights into WZ safety performance and should continue to be collected in the future.

\section{Site-Specific Work Zone Analysis}

For the site-specific work zone analysis, data for 384 work zone sites were used in a model calibration and validation study, using multiple statewide databases. SPFs were developed to predict total work zone crashes (for all crash severities $-K, A, B, C$, and property damage only [PDO]) and work zone fatal/injury crashes (K-, A-, B-, and C-injury crashes). 


\section{Safety Performance Functions}

Twelve data elements for each of the 384 work zone sites were queried from three IDOT sources: the traffic crash, lane closure, and road network databases. The 12 data elements included work zone crash, operational, and characteristic data, as well as non-work-zone crashes, geometry, and characteristics. The characteristics of the 384 work zone sites were compiled and analyzed using the IBM SPSS statistical analysis software. Assuming an underlying Poisson/negative binomial distribution, which is a common assumption in modeling traffic crashes per the Highway Safety Manual, SPF models were then developed to predict crashes using variables that were found to have a statistically significant influence on work zone total crashes and fatal/injury crashes.

Three statistically significant models were developed for total work zone crashes and one for work zone fatal/injury crashes. Statistically significant results for a work zone K-A crash model specifically could not be developed, and thus was not able to be included in this research.

The 384 work zone sites were initially divided into a calibration group or a validation group. The calibration data set included 256 randomly selected work zone sites. The four resulting variables of the 12 considered that were found to have a statistically significant impact on crashes were work zone duration (D), work zone length (L), annual average daily traffic (AADT), and the product of nonwork-zone speed limit and work zone speed limit (NWZ SL x WZ SL).

The remaining 128 sites were used to develop validation models. Analyses were conducted to confirm the models developed with the calibration data set through comparisons with the validation models. Such analyses included analysis of cumulative residual (CURE) plots, goodness-of-fit statistical tests, and comparison of individual variable coefficients, standard errors, and $p$-values between the calibration and validation data sets.

The results of these analyses identified which of the three resulting total work zone crash SPF models was superior and that the fatal/injury work zone model was validated. Once the general form of the total and fatal/injury work zone models were validated, the two subsets were combined to develop the final values of the coefficients for the SPF variables in each model, using the pooled set consisting of all 384 sites. A statistical analysis of the observed and predicted work zone crashes was conducted. The results indicated a nonsignificant difference, which means that the models were accurately able to predict work zone total and fatal/injury crashes. All statistical analyses were conducted at $95 \%$ level of confidence. The recommended SPF models are as follows:

$$
\begin{gathered}
\mu_{\text {Total }}=e^{-7.049} \times D^{0.904} \times L^{0.317} \times A A D T^{0.486} \times e^{-0.0004(N W Z S L \times W Z S L)} \\
\mu_{\text {Fatal } / \text { Injury }}=e^{-2.872} \times D^{0.812} \times L^{0.323} \times e^{-0.0005(N W Z S L \times W Z S L)}
\end{gathered}
$$

A Monte Carlo simulation analysis was conducted to determine the relative impact of the variables in each of the total and fatal/injury work zone SPFs models. Both the total and fatal/injury work zone crash models revealed that the variables with the highest relative impact were NWZ SL x WZ SL, followed by work zone duration. 


\section{Excel Tool for SPF Calculations}

An Excel tool was developed to facilitate the ease of the calculations for the SPFs and assess safety performance of work zones in Illinois. A user can analyze a single work zone, or up to three work zone alternatives at a time. The tool includes a tutorial worksheet, which explains the basic components of a work zone and descriptions of the color-coding schemes for data input, and a Work Zone Safety Performance-Analysis using the Work Zone SPFs worksheet. In the latter worksheet, a user would input data and the results would be generated for total and fatal/injury work zone crashes per WZ duration.

\section{Crash Modification Factors}

CMFs were extracted from the SPF coefficients for total WZ crashes for work zone length (0.317) and work zone duration (0.904), and for fatal/injury work zone crashes for length (0.323) and duration (0.812). The CMFs developed for IDOT work zones were compared with those developed in the past by other authors, which revealed similarities for duration. Differences in the CMF for WZ length were observed, which may be due to the minimum work zone length considered in the data samples.

\section{Work Zone Data Needs}

Several issues with the work zone data currently collected by IDOT were identified. FHWA's Work Zone Data Initiative manuals provide recommended practice for collecting and managing uniform work zone activity data across jurisdictional and organizational boundaries. These manuals were used as the basis for developing recommendations in a tiered priority list of work zone data improvement needs in Illinois.

The following is the suggested high-priority list for improving the quality of work zone data in Illinois.

\section{Priority 1 Work Zone Variables}

- For number of work zones: identifier, project ID, project event ID

- For work zone duration: actual start date/time, actual end date/time

- For work zone length: actual begin location, actual end location

- Other critical exposure variables:
- AADT
- Work zone average daily traffic
- Speed limit of road under normal conditions
- Work zone speed limit
- Functional classification of road 


\section{TABLE OF CONTENTS}

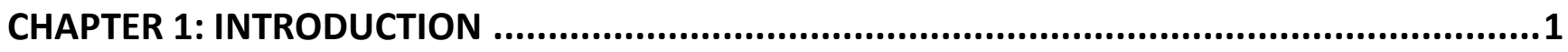

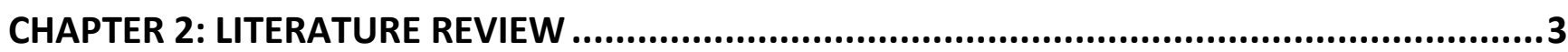

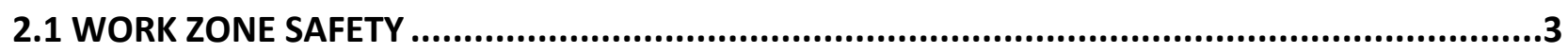

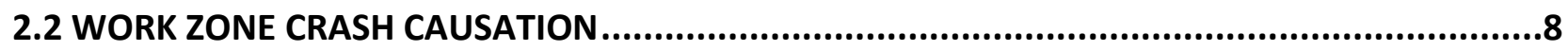

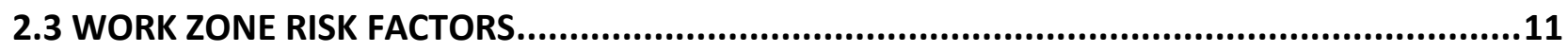

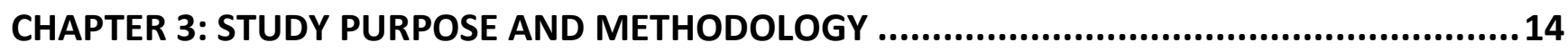

3.1 WORK ZONE SAFETY PERFORMANCE MEASURES ..........................................................14

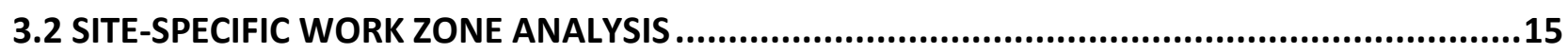

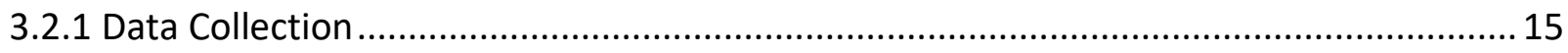

3.2.2 Detailed Work Zone Crash Analysis ............................................................................. 16

3.2.3 Safety Performance Function Modeling Process ........................................................ 17

3.3 WORK ZONE DATA NEEDS.............................................................................................18

CHAPTER 4: WORK ZONE SAFETY PERFORMANCE MEASURES .....................................19

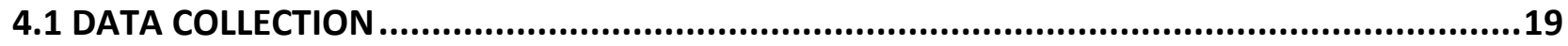

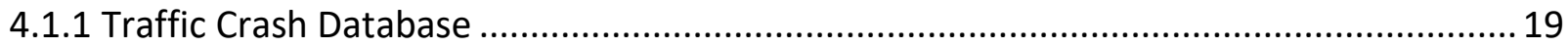

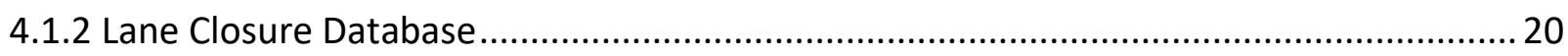

4.1.3 Roadway Network Database.................................................................................... 20

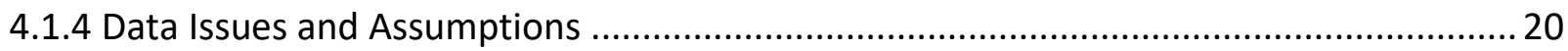

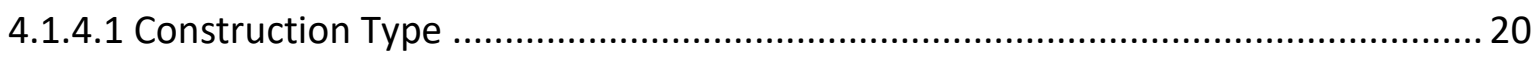

4.1.4.2 Contract Number ........................................................................................... 21

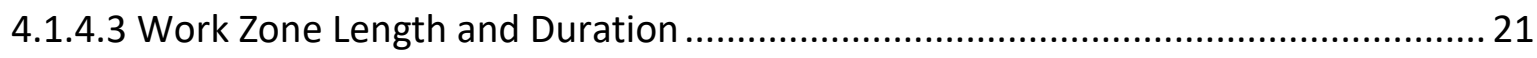

4.1.5 Methodology for Extracting Work Zone Exposure Data.................................................. 22

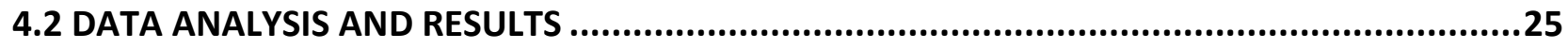

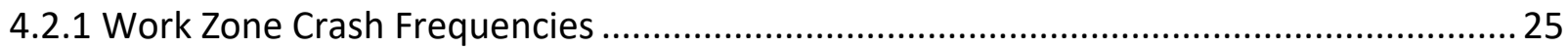

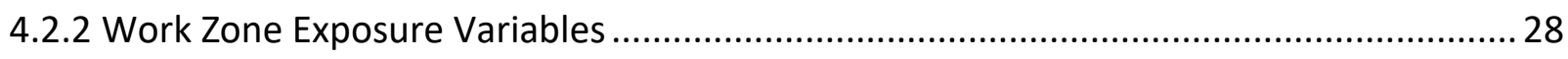

4.2.3 Work Zone Crash Rates.................................................................................................. 30

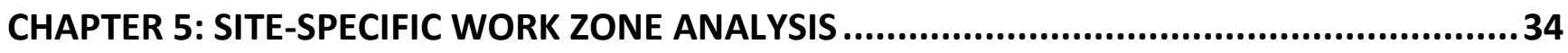

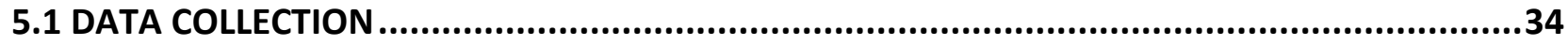




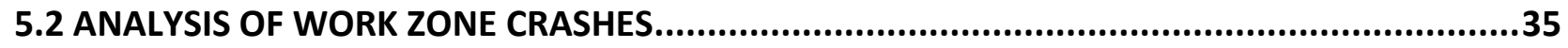

5.3 SAFETY PERFORMANCE FUNCTION CALIBRATION AND VALIDATION.................................35

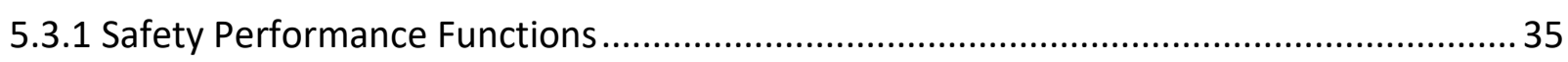

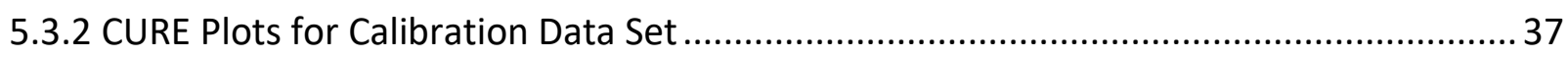

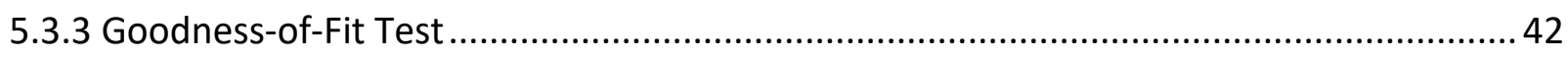

5.3.4 Comparison of Coefficients-Calibration versus Validation Data Sets ............................ 43

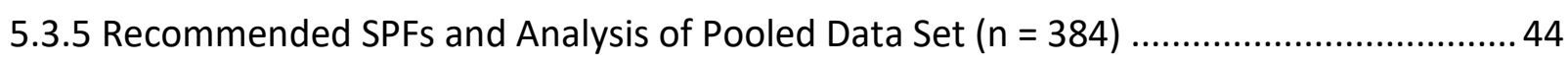

5.3.6 Comparison of Observed and Predicted Work Zone Crashes .......................................... 46

5.3.7 Relative Impact of Parameters in SPF Regression Equations-Monte Carlo .................... 47

CHAPTER 6: METHODOLOGY FOR WORK ZONE SAFETY .................................................5 52

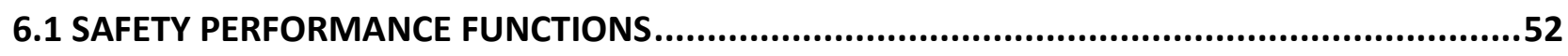

6.1.1 SPF Example for Comparison of Work Zone Alternatives ................................................. 53

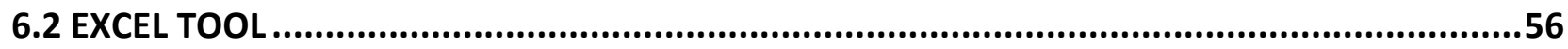

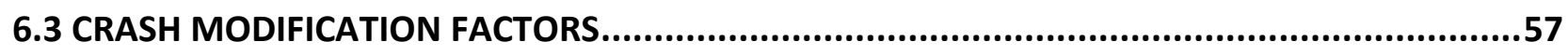

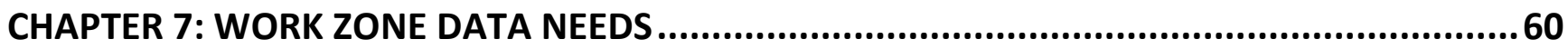

7.1 IDOT'S EXISTING DATA FOR WORK ZONE INFORMATION ..............................................61

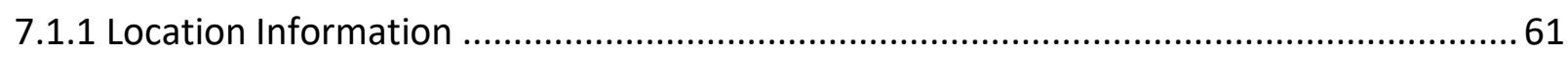

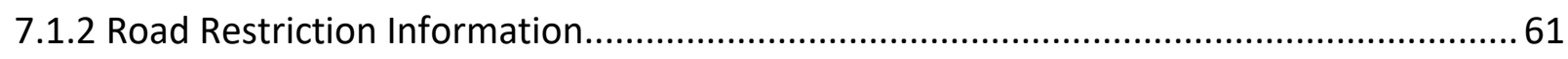

7.2 RECOMMENDATIONS FOR WORK ZONE DATA COLLECTION.........................................63

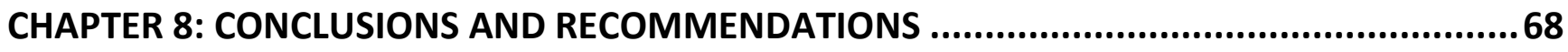

8.1 WORK ZONE SAFETY PERFORMANCE MEASURES .............................................................68

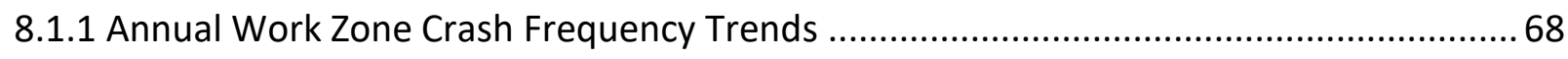

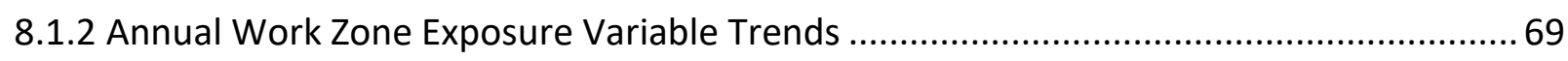

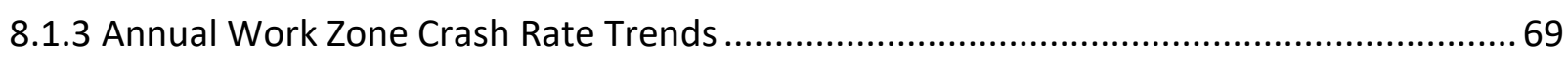

8.2 SITE-SPECIFIC WORK ZONE ANALYSIS ...............................................................................

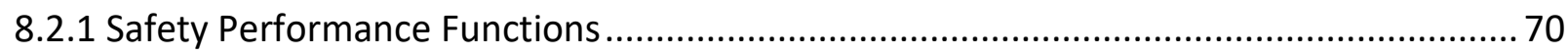

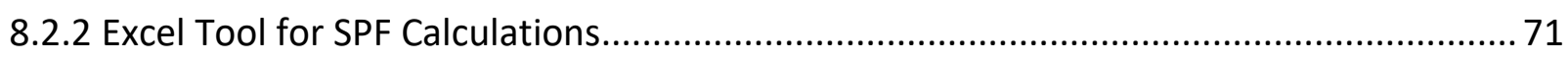

8.2.3 Crash Modification Factors .......................................................................................... 71

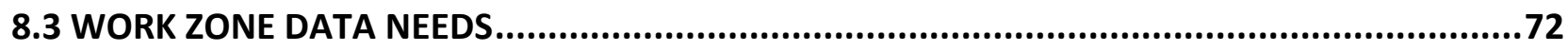

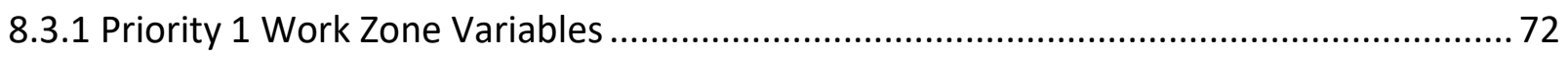


APPENDIX A: ILLUSTRATIONS OF ISSUES AND ASSUMPTIONS FOR NO. WORK ZONES, LENGTH, AND DURATION FOR SEGMENT AND POINT DATABASES...................................76

APPENDIX B: ANNUAL WORK ZONE CRASH FREQUENCIES, EXPOSURE VARIABLES, AND CRASH RATES FOR IDOT ROADS 2013-2017

APPENDIX C: DETAILS OF 384 SITE-SPECIFIC WORK ZONES .93

APPENDIX D: SCREEN CAPTURES OF THE EXCEL TOOL. 123

APPENDIX E: IDOT'S ROAD RESTRICTION INFORMATION FORM OPER 2410 126 


\section{LIST OF ACRONYMS}

\begin{tabular}{|c|c|}
\hline AASHTO & American Association of State Highway and Transportation Officials \\
\hline AADT & Annual average daily traffic \\
\hline ADT & Average daily traffic \\
\hline AIC & Akaike's Information Criterion \\
\hline ASCE & American Society of Civil Engineers \\
\hline BIC & Bayesian Information Criterion \\
\hline CMF & Crash modification factor \\
\hline $\mathrm{CMH}$ & Cochran-Mantel-Haenszel \\
\hline $\mathrm{CN}$ & Condition numbers \\
\hline CSI & Crash severity index \\
\hline CURE & Cumulative residual \\
\hline DOT & Department of Transportation \\
\hline FHWA & Federal Highway Administration \\
\hline GIS & Geographic Information System \\
\hline HSM & Highway Safety Manual \\
\hline IDOT & Illinois Department of Transportation \\
\hline LOC & Level of confidence \\
\hline MAD & Mean absolute deviation \\
\hline MASD & Mean absolute scaled deviation \\
\hline MENB & Measurement error negative binomial \\
\hline MPB & Mean predicted bias \\
\hline MOT & Maintenance of traffic \\
\hline NCHRP & National Cooperative Highway Research Program \\
\hline NHWZSP & National Highway Work Zone Safety Program \\
\hline NWZ SL $\times W Z S L$ & Product of non-work-zone and work zone speed limits \\
\hline OPER 2410 & Road restriction form used to create IDOT's lane closure database \\
\hline PDO & Property damage only \\
\hline SPF & Safety performance function \\
\hline TRP & Technical Review Panel \\
\hline TTC & Temporary traffic control \\
\hline VATraffic & Virginia Traffic Information Management System \\
\hline VDOT & Virginia Department of Transportation \\
\hline VMT & Vehicle miles traveled \\
\hline WisLCS & Wisconsin Lane Closure System \\
\hline WZ & Work zone \\
\hline WZAD & Work zone activity data \\
\hline WZDI & Work Zone Data Initiative \\
\hline
\end{tabular}




\section{CHAPTER 1: INTRODUCTION}

Historically, safety in work zones has been a major concern to transportation professionals, regulatory and law enforcement agencies, construction companies and their workers, maintenance crews, utility companies, and the motoring public at large. Over the past few years, work zone crashes have increased by $38 \%$ in the US from 67,887 in 2013 to 94,000 in 2017 . Additionally, work zone fatal crashes in the US increased by $3 \%$, while fatal crashes outside of work zones decreased by 1.5\% from 2016 to 2017 (FHWA, 2019a, 2019b).

The Federal Highway Administration (FHWA) established the National Highway Work Zone Safety Program (NHWZSP) to enhance safety and operational efficiency of highway work zones for highway users (FHWA, 2019b). One of the four components of the NHWZSP is to "Improve Evaluation of Work Zones." Through safety evaluation and performance measure assessment, an agency can analyze crash trends, identify safety deficiencies, and develop countermeasures to alleviate work zone crashes and injuries. Work zone safety evaluation also helps to measure the benefits of current safety practices.

Current Federal Regulations (23 CFR 630 Subpart J) encourage states to collect and analyze both safety and mobility data to address work zone impacts at an agency level. Work zone evaluation involves developing performance measures, encouraging widespread use of measures, tracking measures over time, and using the findings to identify and make improvements. Performance measures can help agencies assess if and how their work zone safety policies, processes, and procedures are working well or should be improved (Ullman et al., 2013).

Historically, work zone mobility data has been widely tracked by agencies, and many tools are available to assist in quantifying and analyzing mobility data. However, research on assessing the safety performance of work zones is limited. Crash modification factors (CMFs) and safety prediction models for work zones are provided in the Highway Safety Manual (HSM) (Khattak et al., 2002; AASHTO, 2010) that account for the effects of project length and duration on crash frequency as compared with normal road operations. The crash data used to derive the CMFs in the HSM are from one state, California. Since the publication of the HSM, a few studies have been conducted to calibrate or update CMFs in Missouri, Indiana, and Michigan (Sun, et al., 2014; Venugopal \& Tarko, 2000; Rista et al., 2017).

In 2014, as a part of the Smart Work Zone Deployment Initiative, researchers in Missouri calibrated the HSM's work zone CMFs for duration and length for the Midwest region (Sun et al., 2014). Similar research was conducted in 2000 in Indiana to develop CMFs for work zone duration and length (Venugopal \& Tarko, 2000). Research conducted in Michigan examined the safety impacts of temporary traffic-control strategies on freeways, including shoulder closures, lane closures, and lane shifts (Rista et al., 2017). The authors found that "crash rates increase more rapidly in work zones that are shorter in length or duration. Single-lane closures, multilane closures, and lane shifts were associated with an increase in crashes, whereas shoulder closures did not show a significant difference compared with similar, non-work-zone conditions" (Rista et al., 2017, p. 1). A comparison of the CMFs from this past research shows that CMFs for work zone length in miles varies from 0.58 
in the Missouri study (Sun et al., 2014) to 0.82 in the Michigan study (Rista et al., 2017), while the CMFs for project duration in days varies from 0.90 in the Michigan study (Rista et al., 2017) to 1.11 in the California study (Khattak et al., 2002; AASHTO, 2010).

Many state departments of transportation, including the Illinois Department of Transportation (IDOT), face challenges in understanding the causes in increased work zone crashes. Although direct safety metrics such as the number of work zone fatal and A-injury crashes are available, they do not completely reflect work zone safety performance. Three objectives were established for this research. The first objective is to quantify and report statewide work zone safety performance measures and yearly trends for work zone crashes/injuries and exposure variables such as work zone length, duration, and number of work zones, using available data. The second objective is to conduct an in-depth analysis of site-specific work zone sites and characteristics in Illinois to develop prediction tools, such as SPFs and CMFs, to assess work zone safety. The third objective is to identify gaps in existing work zone data in Illinois and make recommendations on data needs.

This report contains the following chapters:

Chapter 2-Literature Review

Chapter 3-Study Purpose and Methodology

Chapter 4-Work Zone Safety Performance Measures

Chapter 5-Site-Specific Work Zone Analysis

Chapter 6-Methodology for Work Zone Safety

Chapter 7-Work Zone Data Needs

Chapter 8-Conclusions and Recommendations 


\section{CHAPTER 2: LITERATURE REVIEW}

To assess the work zone safety performance on Illinois state routes, an in-depth literature review was conducted. This search was conducted through web-based queries and queries through specific search engines such as the Transportation Research Board Publication Index, the Transportation Research Information Services, the American Society of Civil Engineers' Journal of Transportation Engineering, the Institute of Transportation Engineers Library, and others. Various journals, papers, reports, and other documents were reviewed. A summary of the findings of these documents is divided into the following topics: work zone safety, work zone crash causation, and work zone risk factors.

\subsection{WORK ZONE SAFETY}

A study by Kweon et al. (2016) developed safety performance measures for work zones in Virginia. Previously, the Virginia Department of Transportation (VDOT) used the number of fatalities and serious injuries in work zone crashes as safety performance measures. However, this does not account for exposure measures such as length and duration. Therefore, the authors conducted a study to determine whether increases in work zone crashes were due to underlying safety issues or the increasing quantity of work zones.

To accomplish this, the VDOT crash database and the Virginia Traffic Information Management System (VaTraffic) were combined. Count measures were found using the crash database, while exposure measures were found using the VaTraffic database. A traffic-monitoring system and roadway inventory databases were also used to obtain additional information. Three of the four databases used (the crash database, traffic-monitoring system, and roadway inventory databases) are subsets of the VDOT Roadway Network System.

The analysis involved visual examinations, correlation analysis, and regression analysis. During the analysis, the research team faced three issues with their data. First, there were differences in how work zone events were coded. For example, in a multiday pavement-marking project, a separate work zone ID would sometimes be created for each day of the advancing project. This would create multiple work zone IDs for one project. However, sometimes just one work zone ID was assigned to an entire pavement-marking project. Because these could not be recorded using a consistent method, the work zone counts were affected in some regions.

Second, some issues arose while matching traffic crashes to respective work zones. The crash and work zone were considered a match when "the location of the crash lies within the bounds of the work zone and the time of the crash is within the specified time period of the work zone" (Kweon et al., 2016, p. 10). However, the matching success rate was only $20 \%$ unless additional time-consuming algorithms were used. Therefore, the work zone crash and event data were not matched very well at a project level. However, the data could still be used for exposure and rate measure calculations at a district, region, and state level. The third data issue was that it was not possible to obtain the traffic volume data at a work zone. It is extremely difficult to record these volumes during a construction project. Therefore, they excluded any traffic volumes from their analysis. 
Ultimately, the following count and exposure measures were used (Kweon et al., 2016):

- Count: total WZ crash count, total person count involved in WZ crashes, fatal and injury WZ crash count, and fatality and injury count involved in WZ crashes.

- Exposure: WZ count, WZ-miles, WZ-hours, and WZ-hour-miles.

Using these count and exposure measures, crash rates (crashes per work zone, crashes per WZ-hour, crashes per WZ-mile, etc.) were tested using a linearity condition through regression analysis for three road types (all roads, interstate highways, and non-interstate highways) and four temporal levels of crashes (annual, biannual, quarterly, and monthly).

The authors concluded that "four performance measures are appropriate for monitoring and evaluating the statewide safety performance of work zones and eight summary measures are appropriate for obtaining further insights and understanding with regard to statewide safety issues at work zones in Virginia" (Kweon et al., 2016, p. 27). Figure 2.1 shows the recommended performance and summary measures. The study concluded that the exposure measures are critical when evaluating the safety of a work zone and the exposure measures should reflect both duration and length for the best results.

\begin{tabular}{|c|c|c|}
\hline \multicolumn{2}{|r|}{ Measures of Work Zone Safety } & Type \\
\hline \multicolumn{3}{|c|}{ Recommended for Performance Measures } \\
\hline 1 & Total Crashes & \multirow[t]{2}{*}{ Count Measure } \\
\hline 2 & Fatal and Injury Crashes & \\
\hline 3 & Crashes per Work Zone-Hour-Mile & \multirow[t]{2}{*}{ Rate Measure } \\
\hline 4 & Fatal and Injury Crashes per Work Zone-Hour-Mile & \\
\hline \multicolumn{3}{|c|}{ Recommended for Summary Measures } \\
\hline 1 & Fatal and Injury Crash Victims & Count Measure \\
\hline 2 & Work Zones & \multirow[t]{4}{*}{ Exposure Measure } \\
\hline 3 & Work Zone-Hours & \\
\hline 4 & Work Zone-Miles & \\
\hline 5 & Work Zone-Hour-Miles & \\
\hline 6 & Crashes per Work Zone & \multirow[t]{3}{*}{ Rate Measure } \\
\hline 7 & Crashes per Work Zone-Hour & \\
\hline 8 & Fatal and Injury Crashes per Work Zone & \\
\hline \multicolumn{3}{|c|}{ Not Recommended for Performance or Summary Measures } \\
\hline 1 & Total Crash Victims & Count Measure \\
\hline 2 & Fatal and Injury Crashes per Work Zone-Hour & \multirow[t]{4}{*}{ Rate Measure } \\
\hline 3 & Fatal and Injury Crashes per Work Zone-Mile & \\
\hline 4 & Fatal and Injury Victims per Work Zone & \\
\hline 5 & Fatal and Injury Victims per Work Zone-Hour-Mile & \\
\hline
\end{tabular}

Figure 2.1. Recommended measures of work zone safety in Virginia (Source: Kweon et al., 2016).

Another study by Kweon et al. (2017) provides details of the process used in Virginia to fuse the crash and roadway databases to determine work zone crash rate measures. For the analysis, four data sources were used, which contained crash data, roadway inventory data, traffic volume data, and roadway activities data (Kweon et al., 2017).

The exposure measures obtained from the data were split into four temporal categories: yearly, biyearly, quarterly, and monthly. These were found for three road types: all roads, interstate highways, and non-interstate highways. This resulted in 192 regression models based on statewide 
data. Conclusions were made from the regression analyses that were found to be statistically significant. First, although the databases contained imperfect data, it was still possible to find exposure measures from them. Another conclusion was that interstate and non-interstate highways had significantly different safety performance measures. This implies that this data should always be analyzed separately. Next, rate measures involving three characteristics of work zones (total number, duration, and length) seem to be better than those involving two characteristics (Kweon et al., 2017).

A study by Cheng et al. (2012) analyzed work zones by integrating crash and lane-closure data so that more conclusions could be made on the overall safety of a given work zone. Another goal of this study was to develop a method of integrating crash and lane-closure data efficiently. The data sources used in this study were the Wisconsin Lane Closure System (WisLCS) and the Wisconsin crash database.

The matching of work zone crashes and line segments had to satisfy two requirements. First, the crash had to happen during the time of the work zone. Secondly, the crash had to happen in the impact area of the work zone. Figure 2.2 shows the diagram used for location matching. If the crash happened on the same route as the work zone, then it needed to be in between the start and end of the closure (with an additional 0.25-mi buffer zone upstream and downstream). If the crash happened on an intersecting road, then the road had to be between the start and end point of the zone. If the crash happened on a ramp, then the ramp beginning and end needed to be between the start and end of the work zone (Cheng et al., 2012).

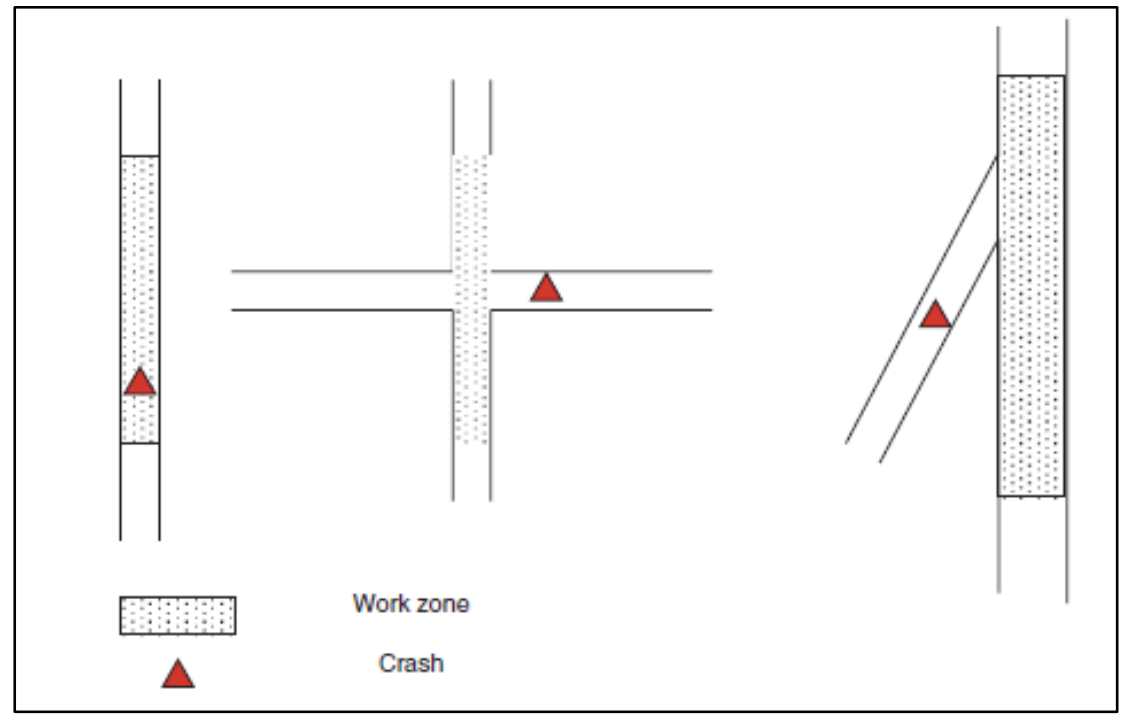

Figure 2.2. Locations of work zones and crashes (Source: Cheng et al., 2012).

Using this matching algorithm, $82.3 \%$ of the total crashes, or 1,262 crashes, were matched and analyzed. Of these matched crashes, most occurred inside the work zone. Of the remaining matched crashes, those occurring upstream of the work zone were four times as frequent as those occurring downstream. A total of 255 work zone coded crashes were not matched with a lane closure. The researchers determined that each was caused by one of three errors: crash mapping errors, local work zones, or report coding errors (Cheng et al., 2012). 
Various attributes of crashes and lane closures (such as crash severity and crash rates) were compared to determine what combination of attributes may be the most unsafe. However, no actual model resulted for analyzing the likelihood of a crash based on given work zone information. The researchers did conclude that three possible actions could be taken to improve work zone data (Cheng et al., 2012, p. 24):

1. "An alternative way to identify work zone-related crashes that does not rely solely on the police crash report.

2. The ability to monitor work zone safety on a systematic level and within the lane closure approval process.

3. The ability to bring more detailed information about specific work zones to the analysis."

Although they were able to merge the lane closure and crash data fairly well, the authors believe that any one of these actions could bring about better work zone safety analyses (Cheng et al., 2012).

Another study by Cheng et al. (2015) provides details for the data integration process used to combine crash and real-time traffic and lane closure data for analysis. The sources that were integrated were statewide lane closure data, police crash reports, and ITS traffic detector data (Cheng et al., 2015). Additionally, the Wisconsin Lane Closure System, WisLCS, was analyzed individually during this study. All data systems used were available in the Wisconsin Transportation Portal. The process of data integration is outlined as three tasks: "(1) obtain the work zone length and actual duration, (2) find all crashes that occurred near or within work zones and all ITS detectors that are located upstream, within or downstream of those work zones, and (3) calculate the actual vehicle mile traveled (VMT) for work zones" (Cheng et al., 2015, p. 5).

First, to obtain the work zone lengths, the beginning highway mileage was subtracted from the end highway mileage. If the work zone was represented as a point instead of a segment, then a distance of $0.25 \mathrm{mi}$ was assigned to it. The WisLCS also categorized their lane closures into four duration types: daily/nightly, weekly, continuous, and long term. These were accounted for while calculating duration; however, the primary method was subtracting the start date from the end date. Lastly, work zone VMT was calculated by multiplying the length of the work zone by the total volume of traffic that traveled through the work zone while it was active. This volume was obtained using volume, speed, and occupancy detectors.

From 2009 to 2012, there were 20,425 work zones with reliable traffic data and nearby detectors during work zone periods that were used in the authors' study. Of these, 1,564 work zones had at least one crash occur within them. In Wisconsin, a total of 4,273 work zone crashes occurred from 2009 and 2012, while 2,054 crashes occurred in the sample of 1,564 work zones. In the end, the researchers believe that they were able to create a "successful alignment of previously disparate data sources to a common linear referencing system" (Cheng et al., 2015, p. 16).

The authors then calculated work zone crash rates using actual VMT as the exposure variable and conducted a comprehensive review of statewide work zone safety. The authors concluded that: "(1) different work zone settings have different impacts on the crash rate and crash severity, and (2) 
planned work zones with shorter duration, and fewer lanes closed are generally safer than unplanned, longer and more lanes closed ones" (Cheng et al., 2015, p. 16).

Research conducted by Rista et al. (2017) compared different work zone traffic-control strategies. The lane-closure types included in this comparison are shoulder closures, lane closures, and lane shifts. The specific characteristics evaluated were segment length, duration, traffic volume AADT, and closure type. Data for this study was collected during two separate time periods: during the construction period and the same time period from the prior year (when no construction was taking place) (Rista et al., 2017).

The sources of the data included the Michigan DOT's lane closure reports, AADT estimates, and the Michigan state police traffic crash database. The data was analyzed using Poisson and negative binomial modeling. The results of the analysis showed significant increases in crashes from pre-work zone to work zone conditions for lane closures and lane shifts. This was especially true if a single-lane closure occurred on a four-lane highway, with two lanes in each direction. However, they concluded that there was no significant increase when the closure type was a closed shoulder (Rista et al., 2017).

The authors' research also examined the impacts of changes in traffic volumes, work zone length, and duration. The average effect of AADT was 1.10, indicating that increases in annual average traffic volumes results in increased crashes. The average effect of work zone length was 0.82 , and the average effect of work zone duration was 0.90. The authors concluded that "crash risk is highest at short-duration work zones and tends to level off over time" (Rista et al., 2017, p. 91). In the analysis of Michigan's work zones, a number of shorter projects (with a minimum of three days) were analyzed. The authors also stated that drivers traveling through longer work zones in place over a longer duration may acclimatize themselves to a work zone over time and over longer distances (Rista et al., 2017).

The study by Ullman et al. (2008) compared the driver risk associated with nighttime versus daytime work zones. This research evaluated management practices that increase the safety and mobility of work zones and provided recommendations regarding work zone crash reporting to improve the available data. The main sources of data used in this study were the New York State DOT crash database and the work zone activity and crash databases for 64 projects located in California, North Carolina, Ohio, and Washington.

First, the authors concentrated on the New York State DOT database for road closure and crash information for work zones on freeways and expressways. They analyzed time of crash as occurring during the day or night, crash severity, contributing factors, and other crash and road closure characteristics. In this database, crashes occurring in work zones between 6 a.m. and 6 p.m. were coded as daytime crashes and those occurring between 6 p.m. and 6 a.m. were coded as nighttime crashes. The data were collected from 2000 to 2005 and over 3,400 crashes were included in the analysis. The crash data were then organized by daytime and nighttime crashes, and chi-square tests of independence were performed to determine if the differences in the distributions of daytime and nighttime work zone crashes were statistically significant. A summary of the authors' key findings include (1) "About half of daytime work zone traffic crashes and $60 \%$ of nighttime work zone crashes 
on New York State DOT freeways and expressways occur during traffic lane closures, (2) there appears to be little difference in traffic crash severity between daytime and nighttime work operations, and (3) rear-end collisions comprise a smaller proportion of work zone traffic crashes at night work zone operations than during daytime operations" (Ullman et al., 2008, p. 13).

For the second component of the study, after evaluating the data from the 64 projects in California, North Carolina, Ohio, and Washington, multiple conclusions about the differences between daytime and nighttime work zones were made. First, when the work was being performed at night and no temporary lane closures were used, severe crashes increased by $41.4 \%$ from non-work-zone conditions. In comparison, daytime work zones with the same conditions experienced a $17.4 \%$ increase from non-work-zone conditions. This is possibly due to poor lighting and glare during the night, more equipment and material being delivered in and out of the work area at night, and common issues that drivers have at night regardless of a work zone (Ullman et al., 2008). Also, there were statistically significant increases in property damage only (PDO) crashes at night when the work was inactive and there were no lane closures. This may be due to the same issues stated above. Another finding by the authors was that there was an increased cost of work zone crashes for daytime work compared to nighttime work, which means that the public is experiencing more safety risks driving through daytime construction (Ullman et al., 2008).

Another aspect mentioned by Ullman et al. (2008) involves strategies that can be used to improve the safety of work zones. Based on the AASHTO Strategic Highway Safety Plan and a comprehensive NCHRP publication on work zone safety, the following strategies were identified to increase safety:

- "Improve maintenance and construction practices to reduce work zone duration and to reduce the number of work zones that are required

- Utilize full-time roadway closure for construction operations

- Utilize time-related contract provisions to reduce construction duration

- Use nighttime road work

- Use demand management programs to reduce volumes through work zones

- Design future work zone capacity into new or reconstructed highways" (Ullman et al., 2008, p. 35).

\subsection{WORK ZONE CRASH CAUSATION}

A study by Akepati and Dissanayake (2011) was conducted to improve the understanding of work zone crash causes by analyzing crash data during a five-year period (2002 to 2006). The study was performed in states under the Smart Work Zone Deployment Initiative, including lowa, Kansas, Missouri, Nebraska, and Wisconsin. A total of 44,004 crashes out of the 44,678 available in the database were able to be analyzed. Some issues arose with this data such as a lack of consistency among states and lack of available exposure measures. These issues narrowed the crash characteristics that were considered. Chi-square tests of independence were performed to determine whether a variety of variables (light condition, road condition, driver gender, etc.) had a significant 
impact on the crash severity. Of the 15 variables analyzed, the only one that was statistically insignificant was the impact of the road surface condition on work zone crash severity.

A few of the major findings from this study were that $50 \%$ of the work zone crashes occur in the activity area, whereas the safest area of a work zone was before the first warning sign. Also, the most predominant collision type was rear-end crashes. In addition to this, the highest percentage of work zone crashes occurred in those with a lane closure. The authors also suggested that crash report forms be reviewed to improve future analyses, as they contain more information on work zones. Some of the additions they recommended were crash location within work zone, length of work zone, and status of work zone being active or inactive (Akepati \& Dissanayake, 2011).

The study by Clark and Fontaine (2015) analyzed crashes that were coded as work zone crashes per the police crash report form. The goal was to determine whether the crashes being coded as work zone crashes were actually related to a work zone. This was done by individually studying Virginia work zone crash data for two years. The specific steps used for analyzing crash reports is as follows:

- "Review crash report narratives to identify if the work zone influenced the likelihood or severity of a crash

- Identify the major factors that contributed to crashes influenced by the work zone and the chain of events that led to the crash, and

- Using this information, identify areas where DOTs should invest greater resources in work zone planning and safety" (Clark \& Fontaine, 2015, p. 62).

For the sample, crash types that represented at least $10 \%$ of the total crashes were considered. This left $94.8 \%$ of the total 6,774 work zone crashes to be analyzed. These crashes occurred between 2011 and 2012. Information was compiled into three categories: total crashes, work zone-coded crashes, and work zone directly related crashes. The work zone directly related crashes were determined by examining police crash reports. Factors that caused the crash to fall into this category were:

- "A work zone vehicle or piece of equipment was struck,

- The crash narrative directly referred to a work zone feature,

- The crash narrative directly indicated that the work zone created changes in flow or speed

- The narrative indicated a specific driver response to the work zone" (Clark \& Fontaine, 2015, p. 63).

After the analysis, $23 \%$ of the total 6,424 coded crashes were placed into the directly related work zone category. The traffic crashes were further analyzed and subcategorized by cause to determine how work zones influence crashes. Some examples include stopping or slowing because of the work zone, unauthorized work zone entry, and confusion because of work zone traffic control.

The authors concluded that many work zone crashes are caused because of driver behavior, which cannot be fixed by the DOT. However, some improvements that could be made include placing 
emphasis on improving traffic congestion on interstate work zones and improving traffic control so drivers know when to merge. The authors recommended improvements to the crash report forms for data purposes. This is because they had to manually analyze so much of the report to receive proper data for work zones crashes (Clark \& Fontaine, 2015).

A study by Yang et al. (2013) identified work zone risk factors through the estimation of a crash frequency model using crashes and characteristics of 60 site-specific work zones in New Jersey. The authors proposed a measurement error (ME) model integrated with the negative binomial (NB) model, called the MENB, to overcome issues related to work zone length. Many work zone lengths change during the duration of the project and that variability could decrease the accuracy of the models developed. They obtained crash data from the New Jersey DOT database and the work zone length was determined "using the length from the work zone project file, and employing spatialtemporal diagrams of work zone crash data" (Yang et al., 2013, p. 193). Figure 2.3 shows a sample spatial-temporal diagram used in the Yang et al. study.

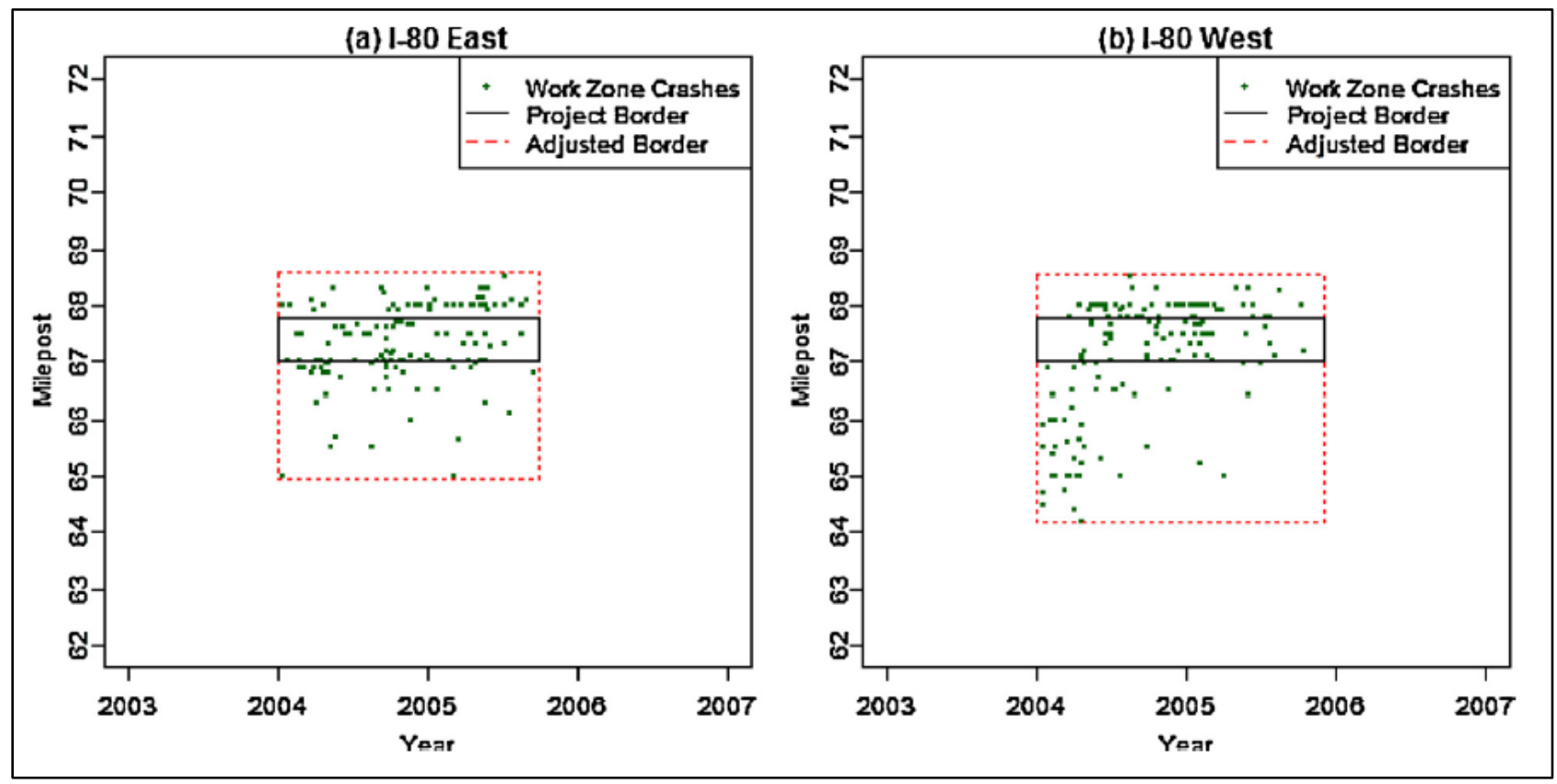

Figure 2.3. Sample spatial-temporal distribution of work zone crashes (Source: Yang et al., 2013).

The work zone length obtained from the New Jersey DOT database was inaccurate and did not reflect the actual length during the road work. This is because lengths are recorded prior to the start of the project and changes could occur during the project, which are not reflected in the data. Also, the spatial-temporal method of determining the length of the work zone was inaccurate because it was based on crashes that occurred in the vicinity of the work zone. Because crashes are random, this estimation is not the best way of determining work zone length.

The authors used measurement errors in the modeling process to help reduce the variability imposed by work zone length. A model with a MENB was created for the analysis. Comparing the results of the model with and without the MENB showed that the MENB model achieved more accurate results. 
The authors emphasize that although this model can be used to account for measurement errors and improve the overall results, it does not rectify the issue with low-quality data being collected.

Therefore, engineers should still strive for more accurate data collection methods for work zone data (Yang et al., 2013).

\subsection{WORK ZONE RISK FACTORS}

The study by Li and Bai (2008) developed crash severity index (CSI) models to predict the likelihood of fatal crashes occurring in a given work zone. They identified risk factors of past work zones and then used the chi-square test and Cochran-Mantel-Haenszel $(\mathrm{CMH})$ statistics to determine the significance. The crash data was obtained from the Kansas DOT and included 85 fatal and 604 injury crashes. The dates of the fatal crashes ranged from 1998 to 2004, while the dates of the injury crashes ranged from 2003 to 2004. The data collection process also included analyzing crash report forms to clarify unclear or missing information. Figure 2.4 shows the significant risk factors for the work zone crash data analyzed.

\begin{tabular}{|rlll|}
\hline No. & Risk factor & Abbr, & Selection step \\
\hline 1 & Age & AG & First step \\
2 & Light condition & LC & First step \\
3 & Vehicle type & VT & First step \\
4 & Road class & RC & First step \\
5 & Road character & RCH & First step \\
6 & Number of lanes & LN & First step \\
7 & Speed limit & SL & First step \\
8 & Surface type & SUR & First step \\
9 & None/inoperative traffic control & NTC & First step \\
10 & Flagger & FL. & First step \\
11 & Stop sign/signal & ST & First step \\
12 & Disregarded traffic control & DTC & First step \\
13 & Following too close & FC & First step \\
14 & Crash time & CT & Second step \\
15 & Special feature & SF & Second step \\
16 & Area information & AI & Second step \\
17 & Alcohol/drug impairment & AL & Third step \\
18 & Exceeded posted speed limits or too & SP & Third step \\
& fast for conditions & & \\
\hline
\end{tabular}

Figure 2.4. Selected work zone risk factors (Source: Li \& Bai, 2008).

Using the CSI models, the authors were able to accurately predict most crash severity outcomes for given work zones and thus recommend the use of the CSI models when designing a work zone. This will help create countermeasures for high-risk work zones to prevent crashes from occurring. One issue with the model is that it does not accurately predict fatal crashes. This may be due to a much smaller sample of fatal crashes than severe injury crashes. The authors recommended further research on this topic to develop a model that can also accurately predict fatal work zone crashes (Li \& Bai, 2008). 
Another study by Li and Bai (2009) used the CSI models developed in their previous work to analyze work zone crashes to identify risk factors that could increase the probability of a fatality in a severe work zone crash. Severe and fatal crashes occurring between 1998 and 2004 and injury crashes occurring between 2003 and 2004 were considered in the study. The data analysis included chisquare testing, $\mathrm{CMH}$ statistics, and relevant historical data to identify significant risk factors involved in a fatal work zone crash. Additionally, a frequency analysis and logistic regression were used to analyze the impact of the specific risk factors.

In total, 85 fatal crashes (1998-2004) and 620 injury crashes (2003-2004) occurring on Kansas highway work zones were analyzed in the study. When unclear or missing information was present for crashes in this database, the police crash report forms were reviewed for clarification. Many significant risk factors were identified. First, people in the age ranges of 65+ and 35-44 were more likely to be in a fatal work zone crash. Also, fatal work zone crashes were more likely to occur in poor lighting conditions. This resulted in the recommendation of better illumination of work zones during the night to reduce confusion. Lastly, rural two-lane highways and urban highways with speed limits over $60 \mathrm{mph}$ were more likely to have fatal work zone crashes. Overall, the study by Li and Bai was able to provide insights into what work zone characteristics could pose a significant risk for drivers.

The research conducted by McAvoy et al. (2011) used a driving simulator to determine the most hazardous primary and precipitating factors involved in a work zone crash. The primary factors that were evaluated included roadway type, traffic density, and work zone type. The precipitating factors were ones that could cause either driver behavior or roadway characteristics to change in a way that initiated a work zone crash. A driving simulator was used in the study to eliminate the subjectivity that is often present in crash data.

The driving simulator, a DS-600c Research Simulator, was located at Cleveland State University in Ohio. To obtain data, drivers were maneuvered through various work zone types and road condition scenarios in the simulated environment. Figure 2.5 outlines the various configurations that were tested as a part of this study.

The focus group consisted of 45 participants who lived in the Cleveland metropolitan area and used the freeways during their commute. Their ages ranged from 18 to 49 years, with $75.6 \%$ male and $24.4 \%$ female. The data from this simulation found that the most hazardous precipitating factors were a stopped work truck and a braking car. Also, the driving situation that was found to be most hazardous was a combination of divided roadways, low-density traffic conditions, and a lane closure. Drivers tended to have the most difficulty when there were many lane deviations because of a lane closure and there were moderate traffic conditions present. The researchers emphasized that although these findings are interesting, they are not real-life situations, so more research should be conducted to confirm the findings (McAvoy et al., 2011). 


\begin{tabular}{|lllll|}
\hline Work Zone & & & & \\
Number & Road Type & Traffic Density & Work Zone Type & Precipitating Factor \\
\hline 1 & Divided & Low & Lane closure & Stopped truck in work zone \\
2 & Divided & Low & Lane closure & Cone knocked over in travel lane \\
3 & Divided & Low & Shoulder work & Slow-moving car in work zone \\
4 & Divided & Low & Shoulder work & Barrel encroaching on travel lane \\
5 & Divided & Moderate & Lane closure & Braking truck \\
6 & Divided & Moderate & Lane closure & Worker in roadway \\
7 & Divided & Moderate & Shoulder work & Stopped car in work zone \\
8 & Divided & Moderate & Shoulder work & Sign encroaching on travel lane \\
9 & Divided & High & Lane closure & Slow-moving truck \\
10 & Divided & High & Lane closure & Cone encroaching on travel lane \\
11 & Divided & High & Shoulder work & Braking car \\
12 & Divided & High & Shoulder work & Barrel knocked over in travel lane \\
13 & Undivided & Low & Lane closure & Braking car \\
14 & Undivided & Low & Lane closure & Cone encroaching on travel lane \\
15 & Undivided & Low & Shoulder work & Braking truck \\
16 & Undivided & Low & Shoulder work & Barrel knocked over in travel lane \\
17 & Undivided & Moderate & Lane closure & Slow-moving car in work zone \\
18 & Undivided & Moderate & Lane closure & Cone knocked over in travel lane \\
19 & Undivided & Moderate & Shoulder work & Stopped truck in work zone \\
20 & Undivided & Moderate & Shoulder work & Barrel encroaching on travel lane \\
21 & Undivided & High & Lane closure & Stopped car in work zone \\
22 & Undivided & High & Lane closure & Sign encroaching on travel lane \\
23 & High & Shoulder work & Slow-moving truck \\
24 & High & Shoulder work & Worker in roadway \\
\hline & Unded & S & & \\
\hline
\end{tabular}

Figure 2.5. Work zone scenarios (Source: McAvoy et al., 2011). 


\section{CHAPTER 3: STUDY PURPOSE AND METHODOLOGY}

IDOT faces challenges in understanding the causes of increased work zone crashes. Although the direct safety metrics such as the number of work zone fatal and A-injury crashes are available, they do not completely reflect work zone safety performance. Three objectives were established for this research. The first objective is to more clearly quantify and report yearly trends on work zone crashes and injuries with an emphasis on fatal and A-injury crashes with respect to work zone exposure variables such as number of work zones, work zone length, and work zone duration. The second objective is to conduct an in-depth analysis of site-specific work zone sites and characteristics in Illinois to develop prediction tools, such as SPFs and CMFs, to assess work zone safety. The third objective is to identify gaps in existing work zone data in Illinois and make recommendations on data needs. The following sections provide an overview of the methodologies used for each objective.

\subsection{WORK ZONE SAFETY PERFORMANCE MEASURES}

The three performance measures that were used to quantify work zone safety in Illinois are traffic crash frequencies, exposure variables, and crash rate measures.

Data from three main sources were obtained from IDOT to analyze work zone safety performance in Illinois from 2013 to 2017. They are:

- $\quad$ Traffic crash database, in GIS (geographic information system) from 2013 to 2017.

- Lane closure databases (OPER 2410) for points and segments that document road restrictions on IDOT roads.

- Roadway network database, containing the base map and attributes of roads in Illinois.

The three databases were fused to obtain work zone information in terms of traffic crash frequencies and work zone exposure variables in Illinois. Annual work zone frequencies were obtained, and trend analyses were prepared for all roads and for IDOT roads for the following crash types:

1. Total work zone (WZ) crashes

2. WZ fatal $(K)$ and $A$-injury crashes

3. $W Z$ fatal and injury $(K, A, B, C)$ crashes

4. WZ fatalities and injuries (number of persons injured or killed in work zone crashes)

Exposure variables were only available for IDOT roads. Thus, annual trends of work zone exposure variables were quantified for IDOT roads only for 2013 to 2017 for the following:

1. Number of work zones

2. WZ miles

3. WZ-days

4. WZ day-miles 
Crash rates were then calculated for the four work zone crash types and four exposure variables. Annual trend analyses were then prepared for the following 16 crash rates for IDOT roads from 2013 to 2017:

1. WZ total crashes per work zone

2. Fatalities and injuries per work zone

3. Fatal and injury crashes per work zone

4. K-A WZ crashes per work zone

5. WZ total crashes per work zone-mile

6. Fatalities and injuries per work zone-mile

7. Fatal and injury crashes per work zone-mile

8. K-A WZ crashes per work zone-mile

9. WZ total crashes per work zone-day

10. Fatalities and injuries per work zone-day

11. Fatal and injury crashes per work zone-day

12. K-A WZ crashes per work zone-day

13. WZ total crashes per 100,000 work zone-day-miles

14. Fatalities and injuries per 100,000 work zone-day-miles

15. Fatal and injury crashes per 100,000 work zone-day-miles

16. K-A WZ crashes per 100,000 work zone-day-miles

\subsection{SITE-SPECIFIC WORK ZONE ANALYSIS}

For the site-specific work zone analysis, data for 384 work zone sites were used in a model calibration and validation study, using statewide databases. SPFs were developed assuming an underlying Poisson/negative binomial distribution to predict total work zone crashes (for all crash severities $-K$, A, B, C, and PDO) and work zone fatal/injury crashes (K-fatal, and A-, B-, and C-injury crashes).

\subsubsection{Data Collection}

Data for each of the 384 work zone sites were queried from the three IDOT sources: the traffic crash, lane closure, and road network databases. The following data were recorded:

1. IDOT district number and functional classification

2. Work zone duration (number of days)

3. Work zone length (miles)

4. AADT, vehicles per day

5. Number of lanes reduced

6. Speed limit, non-work-zone speed limit (miles per hour)

7. Work zone speed limit (miles per hour)

8. Work zone crashes and injuries-crash frequency by severity per work zone days (confirmed, likely, probable work zone crashes) for

a. K-A work zone crashes

b. Fatal/injury work zone crashes $(K, A, B, C)$

c. Total work zone crashes (all severities $-K, A, B, C, P D O$ )

9. Pre-construction crash frequency (same duration as respective work zone with no overlap) 
10. Number of intersections/ramps in work zone

11. Type of road closure (lane reduction/closure, ramp closed, one-way traffic with flaggers, intermittent road work, one-way traffic with temporary signals, shoulder work, intersection restrictions, shoulder/bridge/road closed, etc.)

12. Work zone crash frequency per work zone days (workers not present and workers present)

The contract identification numbers of the work zones were used to access the maintenance of traffic (MOT) plans and additional data was extracted, such as type of road closure, work zone speed limit, and other information. Historic AADT values were obtained from IDOT's Traffic Count Database System and represent the non-work-zone traffic volumes in vehicles per day.

The lengths of the work zones were estimated from the lane closure database and were supposed to represent the length from the advance warning area to the termination area. However, work zone lengths were not consistently recorded per this definition among the districts in Illinois. To account for this inconsistency, a 0.25 -mi buffer was applied upstream and downstream of the work zone segments and the crashes were queried over this distance.

The statewide traffic crash database consists of information from Illinois Traffic Crash Report SR 1050. In 2013, work zone fields were added to the SR 1050 crash report form, including: if a crash occurs in a work zone, the type of work zone (construction, maintenance, utility, or other), and whether workers were present at the time of the crash. The statewide traffic crash database was used to query crash data for the site-specific locations over the duration from 2013 to 2017. The crash report forms were also downloaded and analyzed for the 384 sites to correct coding errors common on these forms.

In addition to obtaining and analyzing traffic crash data for crashes occurring within the work zone, the pre-construction crash frequency was also collected and analyzed for the same duration (same months and days) but for the previous non-work-zone time period, with no overlap.

\subsubsection{Detailed Work Zone Crash Analysis}

An in-depth crash analysis was performed for all 384 work zone sites from 2013 to 2017 to reduce the effects of coding errors reported on the traffic crash report forms. The analysis of crashes did not rely on the recorded attribute of whether the crash occurred in a work zone, as it did not clearly indicate if the coded work zone crash was because of the presence of the work zone. Based on information from the crash report form narratives, crashes were aggregated into the four categories listed below as a part of a more detailed crash analysis. These categories were developed to provide additional flexibility and accuracy during the modeling process.

1. Confirmed Work Zone Crash was marked "as a work zone crash" by the reporting police officer, and there was evidence in the narrative that supported that the crash did in fact occur in a work zone. Such evidence reported in the narrative section of the crash report form included: 
- Stopping/slowing due to the work zone (queue, merging), flagger, advance warning sign

- Changing lanes due to lane closure

- Limited sight distance or confusion because of work zone traffic controls or activities

- Vehicle entering or exiting a work zone

- Avoiding crash with work zone device/barrier or with another vehicle

2. Likely Work Zone Crash was marked "as a work zone crash" on the crash report form but may not show evidence in the narrative section that associates the crash with the work zone. Although such crashes were reported to have occurred in the work zone area, they may have been influenced by additional factors such as driver health issues, cell phone usage, vehicle issues, distraction inside the vehicle, weather condition, animals, etc.

3. Probable Work Zone Crash was marked "not as a work zone crash" on the crash report form but had work zone-related evidence in the narratives, as listed above.

4. Not a Work Zone Crash was marked as "not a work zone crash" and did not have any evidence in the narrative that it occurred in a work zone, yet the crash matched with the length and duration query.

\subsubsection{Safety Performance Function Modeling Process}

The work zone crashes, work zone characteristics, site characteristics, traffic volumes, and operational features of the 384 work zone sites were compiled and analyzed using the IBM SPSS statistical analysis software. Assuming an underlying Poisson/negative binomial distribution, which is a common assumption in modeling traffic crashes per the HSM (AASHTO, 2010), SPF models were then developed to predict crashes using variables that were found to have a statistically significant influence on work zone crashes.

Three statistically significant models were developed for total work zone crashes and one for work zone fatal/injury crashes. Statistically significant results for a work zone K-A crash model specifically could not be developed, and thus was not able to be included in this research.

The 384 work zone sites were initially divided into a calibration group or a validation group. The calibration data set included 256 randomly selected work zone sites. The resulting variables of the 12 considered that were found to have a statistically significant impact on work zone crashes were:

- Work zone duration

- Work zone length

- AADT

- Product of non-work-zone speed limit and work zone speed limit

The remaining 128 sites were used to develop validation models. Analyses were conducted to confirm the models developed with the calibration data set through comparisons with the validation data sets and models. Such analyses include: 
- Analysis of cumulative residual (CURE) plots

- Goodness-of-fit statistics

- Comparison of individual variable coefficients, standard errors, and p-values between the calibration and validation data sets.

The results of these analyses identified which of the three resulting total work zone crash SPF models was superior and that the fatal/injury work zone model was validated. Once the general form of the total and fatal/injury work zone models were validated, the two subsets were combined to develop the final values of the coefficients for the SPF variables in each model, using the pooled set consisting of all 384 sites. A statistical analysis of the observed and predicted work zone crashes was conducted, and the results were not significant, meaning that the models were accurately able to predict work zone crashes and injuries. All statistical analyses were conducted at $95 \%$ level of confidence.

To further explore the total and fatal/injury work zone SPFs, a Monte Carlo simulation analysis was performed to determine the relative impact of the variables in each model. Details are contained in chapter 5 .

CMFs were extracted from the SPF coefficients for total crashes for work zone length and work zone duration. Comparisons of the CMFs developed for Illinois roads were compared with those developed by other authors.

Methodologies and examples on how to use the SPFs and CMFs developed as a part of this research are presented in chapter 6 . An Excel tool was also developed to apply the SPFs using varying work zone lengths and durations. These methodologies and tools can be used by work zone planners when designing the MOT plans to identify which work zone layout and staging will result in fewer work zone crashes and injuries.

\subsection{WORK ZONE DATA NEEDS}

Several issues with the work zone data currently collected by IDOT were identified. Even at the inception of the research project, the Technical Review Panel (TRP) and IDOT engineers were aware of the work zone data quality issues. Thus, an additional objective was incorporated into this project to identify data needs and to provide recommendations on how work zone data may be collected in the future to improve its accuracy. The following tasks were performed to accomplish the work zone data need objective as a part of this research.

- Identify current IDOT data collection methods for work zone variables.

- Review FHWA's Work Zone Data Initiative (WZDI), which developed a recommended practice for collecting and managing uniform work zone activity data across jurisdictional and organizational boundaries.

- Provide recommendations on how critical work zone variables should be collected and maintained by IDOT that are consistent with FHWA's WZDI. 


\section{CHAPTER 4: WORK ZONE SAFETY PERFORMANCE MEASURES}

Three performance measures were used to quantify work zone safety in Illinois: traffic crash frequencies, exposure variables, and traffic crash rates. Traffic crash frequencies provide a direct count measure of work zone safety in Illinois. Exposure variables provide information of the change in characteristics of work zone such as duration and length. Crash rates provide a combination of the count and exposure measures and the safety impact per unit exposure.

\subsection{DATA COLLECTION}

Data from three main sources were obtained from IDOT to analyze work zone safety performance in Illinois from 2013 to 2017. They are:

- Traffic crash database in GIS from 2013 to 2017, containing data from the SR1050 traffic crash report forms in Illinois.

- Lane closure databases (OPER 2410) for points and segments that document road restrictions on IDOT roads. This information is used to inform the Illinois motoring public of road obstructions and restrictions at any given time and is available on GIS maps on the internet.

- Roadway network database, containing the base map and attributes of roads in Illinois.

The three databases were fused to obtain work zone information in terms of traffic crash frequencies and work zone exposure variables in Illinois.

\subsubsection{Traffic Crash Database}

The Illinois statewide traffic crash database in ArcGIS for a five-year period (2013 to 2017) was used to query work zone crashes. The traffic crash report form SR 1050 from 2013 onwards contains work zone attributes (Figure 4.1) and asks the following questions to be answered and recorded:

- Did the crash occur in a work zone (yes/no)?

- If yes, what was the type of work zone (construction, maintenance, utility, unknown)?

- Were workers present (yes/no)?

The corresponding fields in IDOT's crash database for the work zone attributes are identified as WorkZone, WorkZoneTy, and WorkersPre, respectively. In addition to these key work zone attributes, other information is available from the police crash report forms such as location, date and time of the crash, crash characteristics (collision type, severity, vehicle direction, and maneuver), and environmental factors such as lighting, weather, and surface condition. 


\section{SR 1050 KEY CHANGES Effective January 1, 2013}

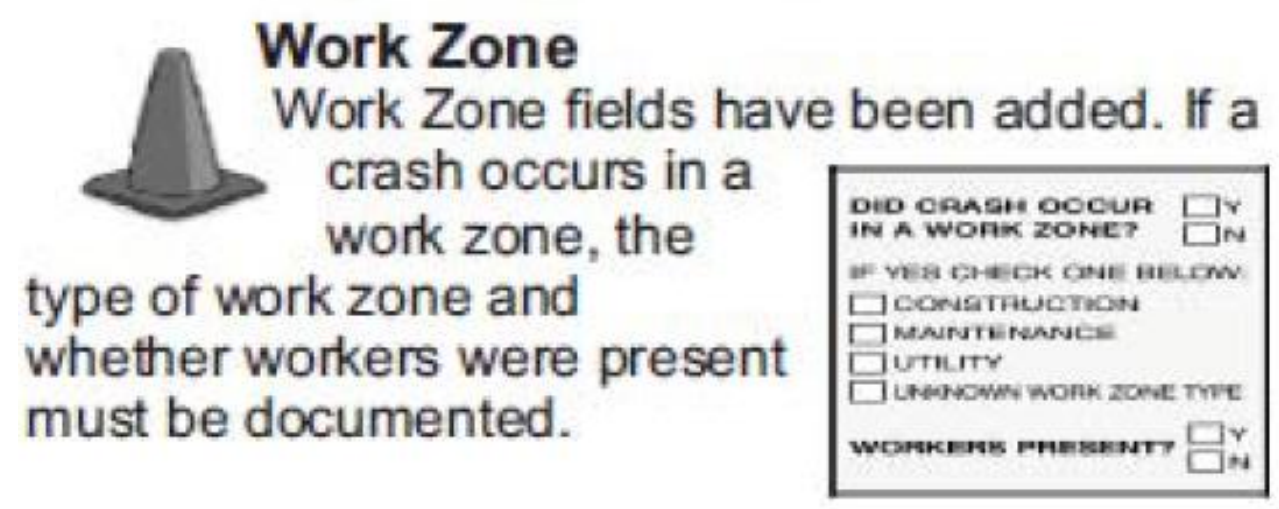

Figure 4.1. Work zone attribute in police crash report form (SR 1050).

\subsubsection{Lane Closure Database}

The lane closure database, OPER 2410, contains records of road closures and restrictions under IDOT's jurisdiction. It contains information such as contract number of the project, start and end dates, from and to location of the work zones, route name and direction, type of construction (lane reduction/lane closure, intermittent road work, one-way traffic with flaggers/temporary signals, etc.), number of lanes closed, suggestions to motorists, and other information. Two databases were available for segments and points. The segment database contained information on work zones over a recorded roadway segment. The point database contained data for spot road closures for smaller projects such as bridge painting, bridge repair, structure replacement, drainpipe repair, etc.

\subsubsection{Roadway Network Database}

IDOT's roadway network database contains a base map of all roads in Illinois. The key attributes extracted from this database include functional classification, speed limits, AADT, road names, etc. Additional information for site-specific work zones, when needed, were obtained from IDOT's maintenance of traffic plans.

\subsubsection{Data Issues and Assumptions}

While preparing the data for the analysis, several data issues were identified with the lane closure database. This is primarily because the purpose of the OPER 2410 form is to notify the traveling public of obstructions and restrictions on IDOT roads at any given time. It was not intended to provide detailed information on work zones. The following provides a summary of the data issues, assumptions, and resolutions made as a part of this research.

\subsubsection{Construction Type}

The information on type of construction that correspond to the attribute name "ConstructionType" in the database contains 15 categories: bridge closed, closed due to flooding, intermittent roadwork, 
intersection restrictions, lane reduction/lane closures, one-way traffic with flaggers, one-way traffic with temporary signals, permanent restriction, railroad closed, ramp closed, rest area closed, road closed, shoulder closed, temporary changes, and weight station closed. Categories closed because of flooding, permanent restriction, railroad closed, rest area closed, temporary changes, and weight station closed did not represent work zones. These categories were eliminated from the analysis in this study, as per approval from the TRP.

\subsubsection{Contract Number}

Another issue identified was the variability in work zone contract data. Some contract numbers represented a single work zone entry while some had multiple work zone entries associated with it. The multiple work zone entries associated to one contract number contained unique work zone events as well as duplicates. The Bradley University research team categorized these issues into six situations for work zone segments and three situations for point work zones. Assumptions were made to convert these varying data recordings into one consistent method of recording. The list of assumptions for segments and points were sent to the TRP and were subsequently reviewed and approved including the TRP's feedback. Table 4.1 lists the situations and assumptions for exposure variable counts. For the Point database issues, situations 1 and 2 had corresponding e-plans available, and the length of the work zones could be validated. For the records in situation 3, where no e-plans were available, lengths had to be estimated. Detailed illustrations for the situations and assumptions are included in Appendix A.

\subsubsection{Work Zone Length and Duration}

The lengths of the work zone segments were calculated by measuring the length between the start and end points in GIS. The duration of the work zone was calculated as the difference in start and end date as recorded in the lane closure database. In some cases, the duration of the work zone may not be accurate for multiyear projects, but because of lack of information about inactive durations of the work zones such as winter shutdowns, the entire duration of the project was considered as the work zone duration.

Table 4.1. Situations and Assumptions for Segment and Point Lane Closure Data

\begin{tabular}{|c|l|l|}
\hline No. & \multicolumn{1}{|c|}{ Situation/Issue } & \multicolumn{1}{|c|}{ Assumption for Count } \\
\hline For Work Zone Segments & 1 entry with 1 contract ID, 1 Length, and 1 Duration & $\begin{array}{l}\text { Count as 1 work zone with recorded length and } \\
\text { duration }\end{array}$ \\
\hline 1 & $\begin{array}{l}2 \text { entries with same contract ID, same route, } \\
\text { different route directions (EB/WB, NB/SB), same } \\
\text { location, same length and duration }\end{array}$ & $\begin{array}{l}\text { Count as 1 work zone with recorded length and } \\
\text { duration }\end{array}$ \\
\hline 3 & $\begin{array}{l}\text { 2 or more entries with same contract ID, same route } \\
\text { and direction, different locations/ different lengths, } \\
\text { and same duration }\end{array}$ & $\begin{array}{l}\text { Count as 1 work zone, sum the individual lengths, } \\
\text { and use recorded duration }\end{array}$ \\
\hline 4 & $\begin{array}{l}\text { Multiple entries with same contract ID, different } \\
\text { routes/locations, \& different dates }\end{array}$ & $\begin{array}{l}\text { Count as separate work zones and use recorded } \\
\text { lengths and durations }\end{array}$ \\
\hline 5 & $\begin{array}{l}2 \text { or more entries with same contract ID, same } \\
\text { route/location, and different durations }\end{array}$ & $\begin{array}{l}\text { Count as separate work zones unless the end date } \\
\text { of one is the start date of the next }\end{array}$ \\
\hline 6 & Ramp Closures & Excluded \\
\hline
\end{tabular}




\begin{tabular}{|c|l|l|}
\hline No. & \multicolumn{1}{|c|}{ Situation/Issue } & \multicolumn{1}{|c|}{ Assumption for Count } \\
\hline For Point Work Zones & $\begin{array}{l}\text { 2 or more points close in distance (a mile or less a } \\
\text { part) over a bridge/culvert }\end{array}$ & $\begin{array}{l}\text { Count as single work zone if the duration match up, } \\
\text { else count as different work zones }\end{array}$ \\
\hline 2 & 2 or more points more than one mile apart & $\begin{array}{l}\text { Count as multiple work zones, each with their } \\
\text { individual lengths and durations }\end{array}$ \\
\hline $3 a$ & $\begin{array}{l}\text { Length-if no e-plans are available } \\
\text { Bridge/culvert project }\end{array}$ & $\begin{array}{l}\text { Structure length measured from Google maps + 0.25 } \\
\text { mi upstream and downstream to account for lane } \\
\text { losure taper length }\end{array}$ \\
\hline $3 b$ & $\begin{array}{l}\text { Length-if no e-plans are available } \\
\text { Road project }\end{array}$ & $\begin{array}{l}\text { Length assumed as } 1,000^{\prime} \text { if located on an Interstate, } \\
\text { and 500' for non-Interstate }\end{array}$ \\
\hline $3 c$ & $\begin{array}{l}\text { Length-if no e-plans are available } \\
\text { At-grade rail-highway crossing }\end{array}$ & Length assumed as 500' \\
\hline
\end{tabular}

\subsubsection{Methodology for Extracting Work Zone Exposure Data}

Figure 4.2 provides an example of the output from the statewide computerized GIS lane closure database, illustrating the methodology to obtain the exposure variable of number of work zones. This procedure is currently a manual process and is incredibly labor intensive.

The first step was sorting and grouping the records by district and work zone contract number (Figure 4.2a). Once this was done, the assumptions from Table 4.1 were applied to each contract to determine the number of work zone count for each contract as well as the work zone durations and lengths (Figure 4.2b). Application of the assumptions were done manually by visually inspecting the records in GIS and by checking the maintenance of traffic plans from IDOT's e-plans. Durations and lengths for each contract number were analyzed, and the total project duration and final length of the project were calculated (Figure 4.2c).

\begin{tabular}{|c|c|c|c|c|c|c|c|c|}
\hline A & B & c & D & E & $\mathrm{F}$ & G & $\mathrm{H}$ & I \\
\hline ID $\quad 7$ & ContractNumber $-\mathrm{T}$ & Contractor & ContractValue $\nabla$ & Contact & ContactNu & District & County $=$ & NearTo \\
\hline \{38BD6EA| & 62187 & Lorig Construction Co & 3739138.15 & Michael Rinaldi & $(224) 358-8911$ & & 1 LAKE & Waucon \\
\hline \{05CBO00F & 62187 & Lorig Construction & 3739138.15 & Michael Rinaldi & 224-358-8911 & & 1 LAKE & Waucon \\
\hline \{BE11521[ & 62195 & Martam Construction C & 9617630.44 & Ron Stemler & $(847) 846-242$ & & 1 KANE & St Charle \\
\hline \{491A216/ & 62268 & Plote Constructon & 25281880 & Troy Wancket & $(630) 878-212$ & & 1 MCHENRY & $\bar{C}$ Crystal L \\
\hline$\{88640 \mathrm{~A} 8 \mathrm{C}$ & 62268 & Plote Constructon & 25281880 & Troy Wancket & $(630) 878-212$ & & 1 MCHENRY & Crystal L \\
\hline \{4BFA2BE\} & 62268 & Plote Constructon & 25281880 & Troy Wancket & (630)878-212: & & 1 MCHENRY & Crystal L \\
\hline \{EBD578FF & 62268 & Plote Constructon & 25281880 & Troy Wancket & (630)878-212: & & 1 MCHENRY & Crystal L \\
\hline [64B5E2DC & 62407 & Plote Construction & 4386092.84 & Francisco Abreu & $847-846-4373$ & & $1 \mathrm{KANE}$ & Gilberts \\
\hline \{87B9BF6E & 62410 & Martam Construction $\mathrm{C}$ & 9617630.44 & Ron Stemler & $(847) 846-242$ & & 1 KANE & $\overline{\text { St Charle }}$ \\
\hline \{FDEFC12 & 62410 & Martam Construction $\mathrm{C}$ & 9617630.44 & Ron Stemler & (847)846-242: & & 1 KANE & St Charle \\
\hline \{4ADBF71: & 62420 & K-Five & 26019371.43 & John Clinnin & $630-918-8823$ & & 1 DUPAGE & Warrenv \\
\hline$\{77907535$ & 62420 & K-Five & 26019371.43 & John Clinnin & $630-918-8823$ & & 1 DUPAGE & Warrenv \\
\hline \{F7BBF6DI & 62420 & K-Five & 26019371.43 & John Clinnin & $630-918-8823$ & & 1 DUPAGE & Warrens \\
\hline \{38D1FAD & 62420 & K-Five & 26019371.43 & John Clinnin & $630-918-8823$ & & 1 DUPAGE & Warrent \\
\hline \{EFF5432A & 62517 & Plote Constructon & 22880978 & Troy Wancket & $(630) 878-212$ & & 1 MCHENRY & Crystal L \\
\hline \{B1A2DA6 & 62517 & Plote Constructon & 22880978 & Troy Wancket & (630)878-212: & & 1 MCHENRY & Crystal L \\
\hline$\overline{\text { \{CB8COA1: }}$ & 62537 & RW Dunteman & 101489282 & Eric Norland & $847-433-7112$ & & 1 MCHENRY & $\overline{\text { Crystal L }}$ \\
\hline \{EE2977BF & 62537 & RW Dunteman & 101489282 & Eric Norland & $847-433-7112$ & & 1 MCHENRY & Crystal L \\
\hline
\end{tabular}

Figure 4.2. Example of work zone exposure data extraction. 


\begin{tabular}{|c|c|c|c|c|c|c|c|c|c|c|c|c|}
\hline B & C & \multirow{2}{*}{ d } & E & \multirow[t]{2}{*}{ J } & \multirow[t]{2}{*}{ K } & \multirow{2}{*}{\multicolumn{2}{|c|}{$\mathbf{R}$}} & s & \multirow{2}{*}{$t$} & \multirow[t]{2}{*}{$\mathbf{U}$} & $y$ & \multirow[t]{2}{*}{ w } \\
\hline & & & & & & & & & & & $\sqrt{7}$ & \\
\hline ContractNumb -1 & OBJECT - & COUNT - & Route1 $=$ & District -1 & County $\mathbf{T}$ & NearTo $=$ & StartDate - & EndDate - & Duratic.-1 & Project Duratio $=$ & Lengt -1 & \multirow{2}{*}{$\begin{array}{c}\text { Final Length } \\
1.2794 \\
\end{array}$} \\
\hline $61 \mathrm{~A} 90$ & 2284 & 1 & \multicolumn{2}{|c|}{ Gabriel Avens } & 1 LAKE & Zion & $6 / 9 / 2015$ & $8 / 14 / 2015$ & 67 & $4 \quad 67$ & 1.27939 & \\
\hline $61 \mathrm{A94}$ & 3300 & \multirow{4}{*}{1} & vo12 & 1 & 1 LAKE & Lake Zuric & $2 / 16 / 2016$ & $6 / 30 / 2016$ & 136 & \multirow{4}{*}{256} & \multirow{4}{*}{$\begin{array}{l}0.15125 \\
\text { (c) }\end{array}$} & \multirow[t]{2}{*}{0.1512} \\
\hline $61 \mathrm{A94}$ & 3301 & & vo12 & 1 & 1 LAKE & Lake Zuric & $2 / 16 / 2016$ & $6 / 30 / 2016$ & 136 & & & \\
\hline $61 \mathrm{A94}$ & 2792 & & vo12 & 1 & 1 LAKE & Lake Zuric & $8 / 3 / 2015$ & $11 / 30 / 2015$ & 120 & & & - \\
\hline $61 \mathrm{A94}$ & 2793 & & vo12 & 1 & 1 LAKE & Lake Zuric & $8 / 3 / 2015$ & $11 / 30 / 2015$ & 120 & & & \\
\hline 61801 & 2192 & \multirow{2}{*}{2} & Park Street & 1 & 1 DUPAGE & Winfield & $5 / 26 / 2015$ & $7 / 15 / 2015$ & 51 & \multirow{2}{*}{102} & 0.32378 & 0.3238 \\
\hline 61801 & 2193 & & \multicolumn{2}{|l|}{ Washington d } & 1 DUPAGE & Winfield & $5 / 26 / 2015$ & $7 / 15 / 2015$ & 51 & & $6.84 E-02$ & 0.0684 \\
\hline 61806 & 2363 & 1 & \multicolumn{2}{|l|}{ Dempster Stru } & $1 \mathrm{COOK}$ & Evanston & $9 / 1 / 2015$ & $7 / 29 / 2016$ & 333 & 333 & 0.39163 & 0.3916 \\
\hline 61811 & 2167 & 1 & Oak Street & 1 & 1 DUPAGE & Hinsdale & $5 / 15 / 2015$ & $12 / 30 / 2015$ & 230 & 230 & 0.17437 & 0.1744 \\
\hline 61812 & 2162 & 1 & 5043 & 1 & $1 \mathrm{COOK}$ & Palos Hts & $5 / 11 / 2015$ & $10 / 1 / 2015$ & 144 & 144 & 1.22454 & 1.2245 \\
\hline 61820 & 2684 & 1 & Powis Road & 1 & 1 DUPAGE & Wayne & $7 / 13 / 2015$ & $8 / 31 / 2015$ & 50 & so & 1.33598 & 1.3360 \\
\hline 61842 & 5607 & 1 & 5058 & 1 & $1 \mathrm{COOK}$ & Rolling $\mathrm{M}_{\mathrm{n}}$ & $4 / 25 / 2016$ & $8 / 1 / 2016$ & 99 & 99 & 1.21881 & 1.2188 \\
\hline 61859 & 1616 & & 5043 & 1 & $1 \mathrm{COOK}$ & Palos Hts & $10 / 5 / 2015$ & $10 / 31 / 2015$ & 27 & & 0.29462 & 0.2946 \\
\hline 61859 & 1615 & 3 & 5083 & 1 & 1 COOK & Palos Hts & $11 / 9 / 2015$ & $11 / 30 / 2015$ & 22 & 64 & 0.48899 & 0.4890 \\
\hline 61859 & 1617 & & 127 th Street & 1 & $1 \mathrm{COOK}$ & Palos Hts & $10 / 26 / 2015$ & $11 / 9 / 2015$ & 15 & & 0.95688 & 0.9569 \\
\hline 61876 & 3930 & 2 & Ridge Road & & $1 \mathrm{COOK}$ & Lansing & $5 / 1 / 2016$ & $11 / 30 / 2016$ & 214 & & $4.55 E-02$ & 0.0455 \\
\hline 61876 & 3920 & 2 & 5083 & & $1 \mathrm{COOK}$ & Lansing & $5 / 1 / 2016$ & $11 / 30 / 2016$ & 214 & 428 & 0.02758 & 0.0276 \\
\hline 61878 & 4275 & & 5064 & 1 & $1000 K$ & Melrose P & $2 / 21 / 2017$ & $6 / 30 / 2017$ & 130 & & 1.76439 & 2.7491 \\
\hline 61878 & 4282 & & 5064 & 1 & 1 COOK & Melrose $P$ & $2 / 21 / 2017$ & $6 / 30 / 2017$ & 130 & & 1.76422 & \\
\hline 61878 & 4281 & & 5064 & 1 & 1 COOK & Melrose P & $2 / 21 / 2017$ & $6 / 30 / 2017$ & 130 & & 0.99015 & \\
\hline 61878 & 4276 & 2 & 5064 & 1 & 1 COOK & Melrose P & $2 / 21 / 2017$ & $6 / 30 / 2017$ & 130 & 237 & 0.98472 & \\
\hline 61878 & 5604 & 2 & 5064 & 1 & 1 COOK & Melrose P & $5 / 13 / 2016$ & $8 / 27 / 2016$ & 107 & 237 & 1.76534 & 2.7610 \\
\hline
\end{tabular}

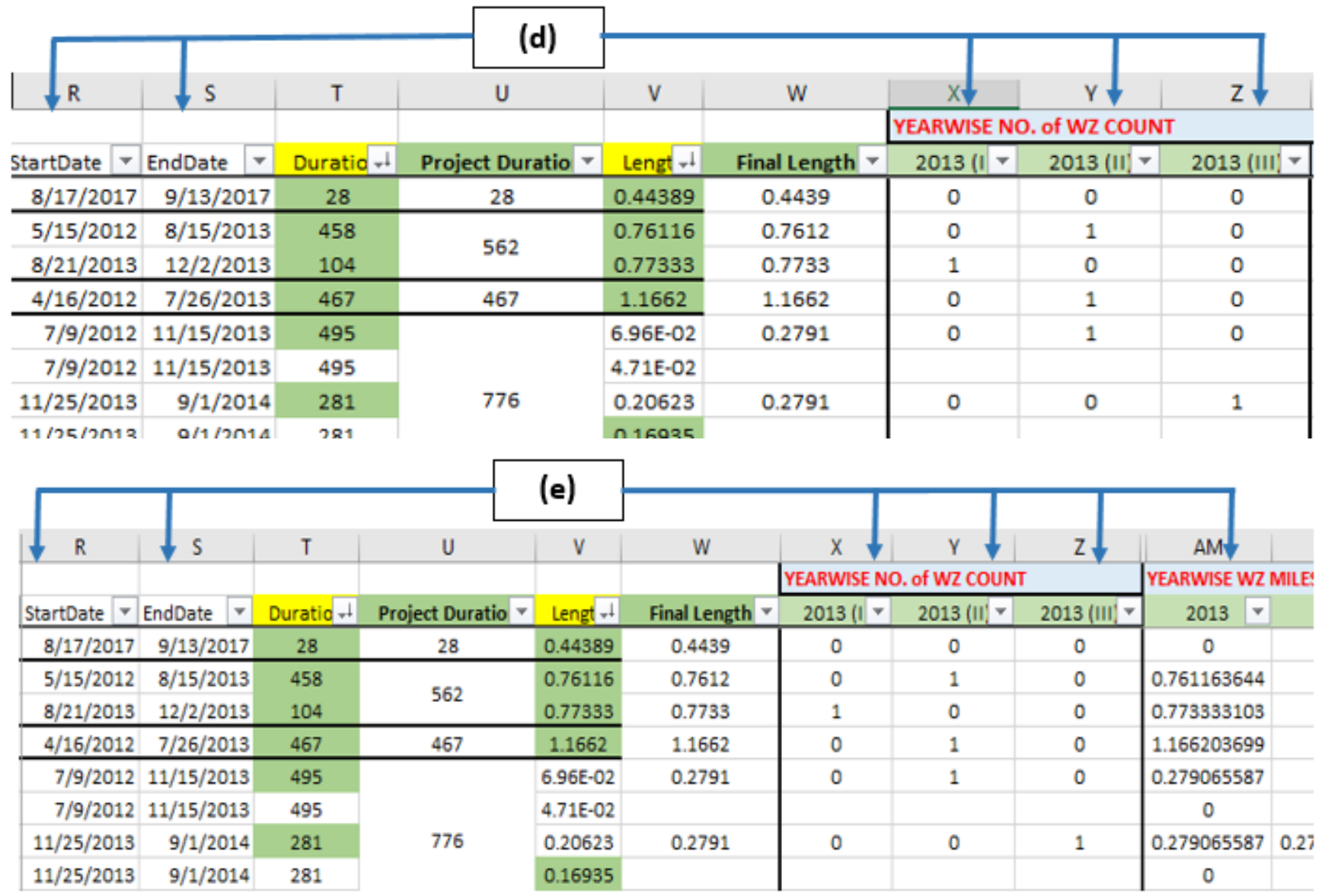

Figure 4.2. Example of work zone exposure data extraction (continued). 


\begin{tabular}{|c|c|c|c|c|c|c|c|c|c|c|c|}
\hline \multirow[t]{2}{*}{$\nabla R$} & s & $\mathbf{T}$ & $\mathbf{U}$ & $\mathrm{v}$ & W & $x \downarrow$ & $r \sqrt{1}$ & 2 & AM & $A R \downarrow$ & AS \\
\hline & & & & & & \multicolumn{3}{|c|}{ YEARWISE NO. of WZ COUNT } & YEARWISE WZ & \multicolumn{2}{|c|}{ YYEARWISW WZ DAYS (FO } \\
\hline StartDate $\mathbf{P}$ & EndDate - & Duratio..t & Project Duratio $\mathrm{v}$ & Lenet at & Final Length $=$ & $2013(1)$ & $2013($ III) - & 2013 (III) & $2013=$ & $2013 \mathrm{~V}$ & 2014 \\
\hline $8 / 2 / 2016$ & $8 / 31 / 2016$ & 30 & 30 & 0.7404 & 0.7404 & 0 & 0 & 0 & 0 & & \\
\hline $3 / 22 / 2012$ & $4 / 1 / 2014$ & 741 & \multirow{4}{*}{814} & 2.76379 & 2.8386 & 0 & 1 & 0 & 2.838570331 & 365 & 91 \\
\hline $9 / 12 / 2012$ & $4 / 1 / 2014$ & 567 & & 0.07478 & & & & & 0 & & \\
\hline $4 / 4 / 2014$ & $6 / 15 / 2014$ & 73 & & 2.82987 & 2.9871 & 0 & 0 & 0 & 0 & & 73 \\
\hline $4 / 4 / 2014$ & $6 / 15 / 2014$ & 73 & & 0.15727 & & & & & 0 & & \\
\hline $5 / 15 / 2012$ & $8 / 15 / 2013$ & 458 & \multirow{2}{*}{562} & 0.76116 & 0.7612 & 0 & 1 & 0 & 0.761163644 & 227 & \\
\hline $8 / 21 / 2013$ & $12 / 2 / 2013$ & 104 & & 0.77333 & 0.7733 & 1 & 0 & 0 & 0.773333103 & 104 & \\
\hline $4 / 16 / 2012$ & $7 / 26 / 2013$ & 467 & 467 & 1.1662 & 1.1662 & 0 & 1 & 0 & 1.166203699 & 207 & \\
\hline $7 / 9 / 2012$ & $11 / 15 / 2013$ & 495 & \multirow{4}{*}{776} & 6.96E-02 & 0.2791 & 0 & 1 & 0 & 0.279065587 & 319 & \\
\hline $7 / 9 / 2012$ & $11 / 15 / 2013$ & 495 & & $4.71 E-02$ & & & & & 0 & & \\
\hline $11 / 25 / 2013$ & $9 / 1 / 2014$ & 281 & & 0.20623 & 0.2791 & 0 & 0 & 1 & 0.279065587 & 37 & 244 \\
\hline $11 / 25 / 2013$ & $9 / 1 / 2014$ & 281 & & 0.16935 & & & & & 0 & & \\
\hline
\end{tabular}

Figure 4.2. Example of work zone exposure data extraction (continued).

After the output was organized in this manner, additional fields were created (Figure $4.2 \mathrm{~d}$ ) to count the annual number of work zone, work zone length (miles), and work zone duration (days). The work zone start and end date ranges were broken down into three cases:

1. Starting and ending in the year of interest

2. Starting before a year of interest and ending in/after the year of interest

3. Starting in the year of interest and ending in a different year

The nested "IF" functions were used to represent the three cases that returned 1 (true) or 0 (false) for the given condition. For example, if 2013 was the year of interest, then the Excel formulas used for 2013(a), 2013(b), and 2013(c) were as follows:

1. $2013($ I) $=$ IF (AND (Start Date $>=$ DATEVALUE ("1/1/2013"), End Date<=DATEVALUE ("12/31/2013")),1,0)

2. $2013($ II) $=$ IF (AND (Start Date $<$ DATEVALUE ("01/01/2013"), End Date $>=$ DATEVALUE ("01/01/2013")),1,0)

3. $2013($ III) $=$ IF (AND (Start Date $>=$ DATEVALUE ("01/01/2013"), Start Date<=DATEVALUE ("12/31/2013"), End Date>DATEVALUE ("12/31/2013")),1,0)

The annual count of work zone length was based on the results from the categories listed above. The final length of the work zone was counted in the year it occurred if one of the above three cases were true (Figure 4.2e). For example, for the year 2013, this was computed using the Excel expression:

$$
=((\text { Final Length } \times 2013(I))+(\text { Final Length } \times 2013(I I))+(\text { Final Length } \times 2013(I I I))
$$


Work zone duration was computed based on the output of the above three cases of work zone date range. The count of work zone days (Figure 4.2f) was calculated using the following Excel expression for 2013:

$$
\begin{gathered}
=\mathrm{IF}(2013(\mathrm{I})=1 \text {, Duration, IF }(2013(\mathrm{II})=1, \mathrm{IF}(\text { End Date }>\text { DATE }(2013,12,31), 365, \text { (End Date-(DATE } \\
(2013,1,1))+1)), \operatorname{IF}(2013(\mathrm{III})=1,((\operatorname{DATE}(2013,12,31))-\text { StartDate+1)," "))). }
\end{gathered}
$$

Finally, once these steps were completed for all the years from 2013-2017, the exposure columns were summed to find the total work zone exposures (count, length, and duration).

\subsection{DATA ANALYSIS AND RESULTS}

\subsubsection{Work Zone Crash Frequencies}

The statewide work zone crash and injury frequencies were quantified by querying the statewide traffic crash database for crashes marked as a "Yes" for a work zone crash. Queries were made for all roads in Illinois and for those roads under IDOT jurisdiction. The roadway network database consists of attribute (JUR_TYPE) that indicates which agency has jurisdictional responsibility of a highway or roadway. The crash database was overlaid with the road network database, and queries were made based on the jurisdiction type attribute to obtain four work zone crash count measures on IDOT roads:

1. Total work zone (WZ) crashes

2. WZ fatal $(K)$ and $A$-injury crashes

3. WZ fatal and injury $(K, A, B, C)$ crashes

4. WZ fatalities and injuries

It was necessary to query the work zone crashes for IDOT roads specifically, because the work zone exposure variables are only available for IDOT roads.

Figures 4.3 through 4.6 show the annual trends of work zone crash frequencies for total WZ crashes, WZ K-A injury crashes, WZ fatal and injury crashes, and WZ fatalities and injuries, respectively, for 2013 to 2017, for all roads and IDOT roads. 


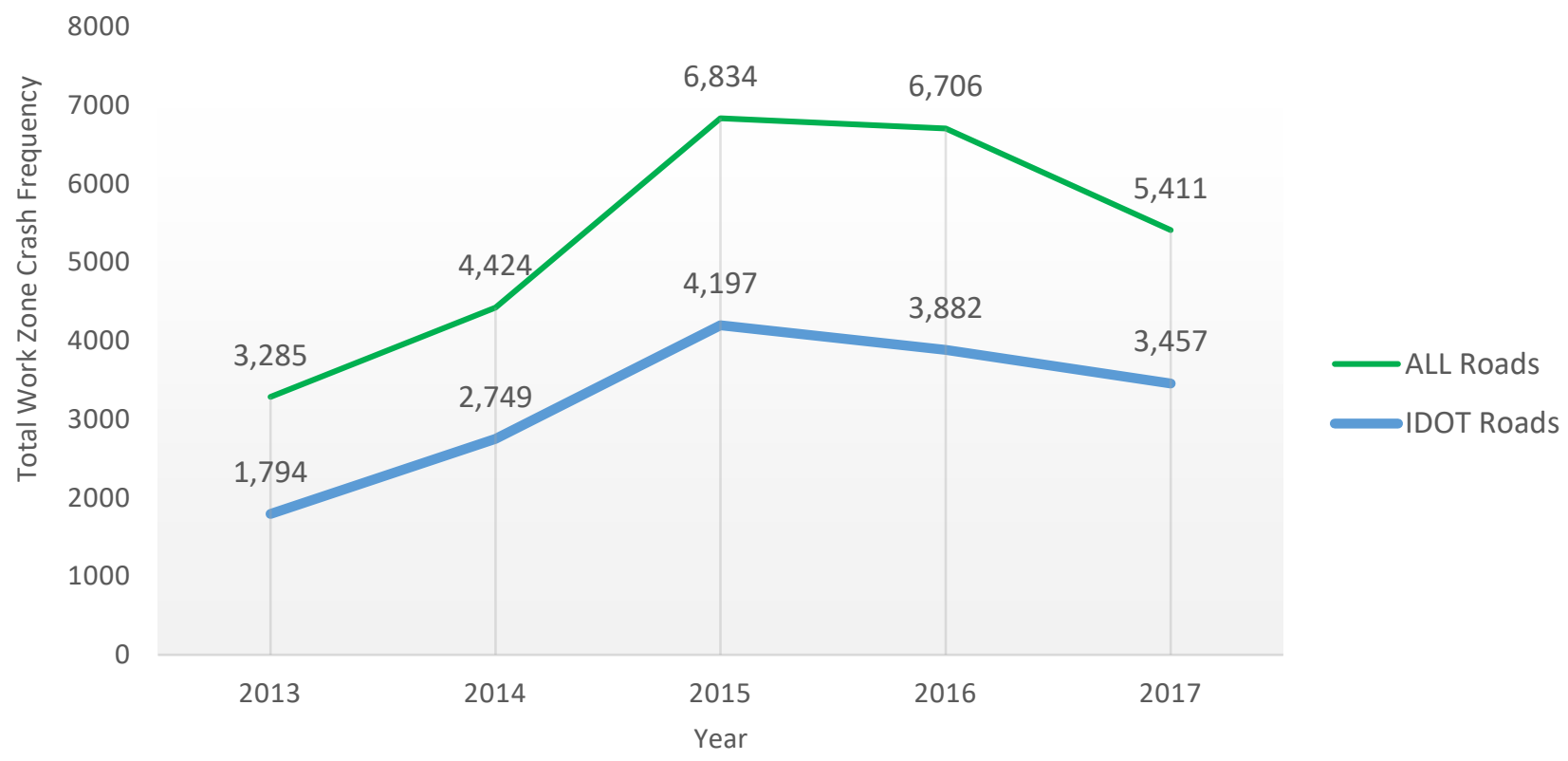

Figure 4.3. Total work zone crashes-all severities.

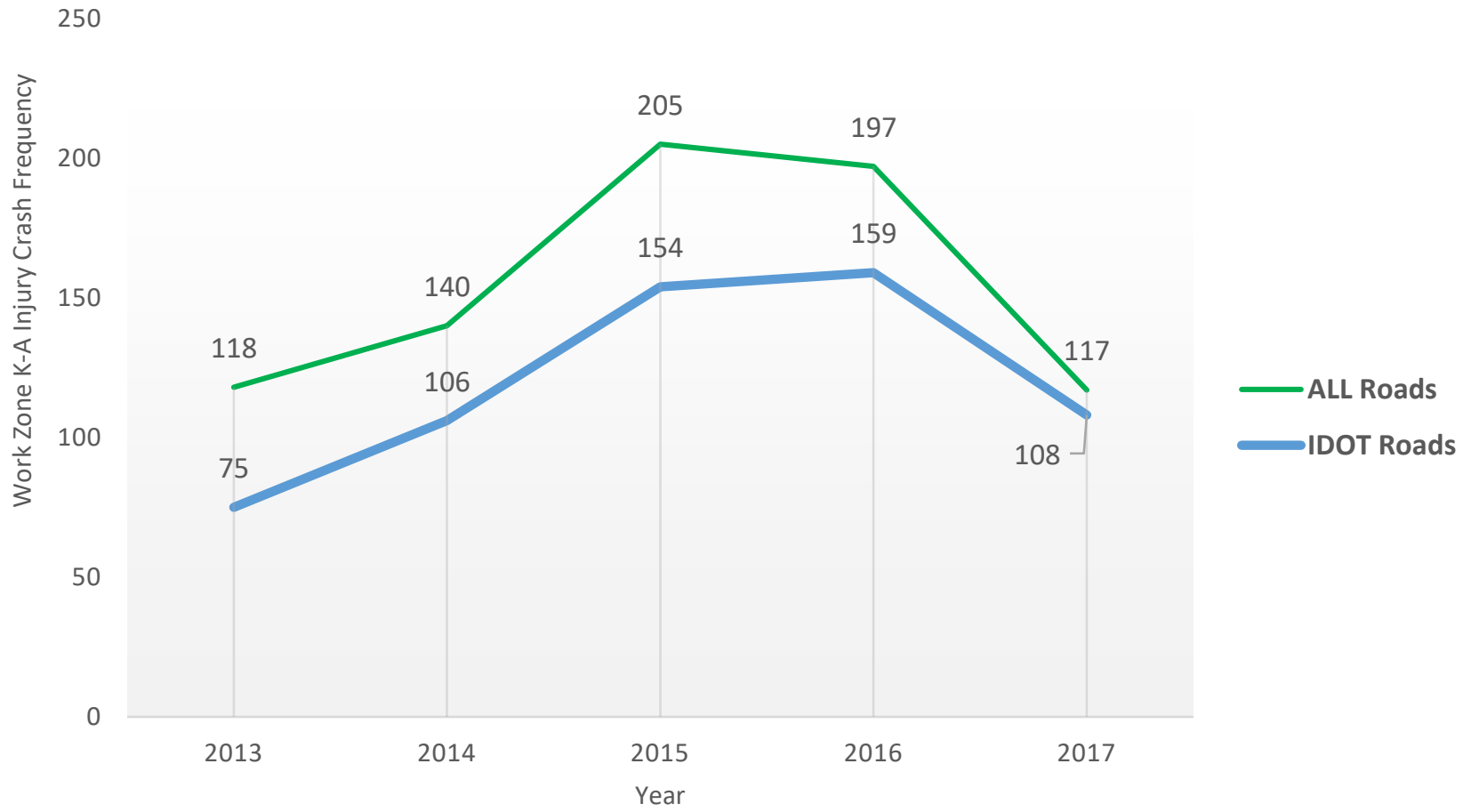

Figure 4.4. Work zone K-A injury crashes. 


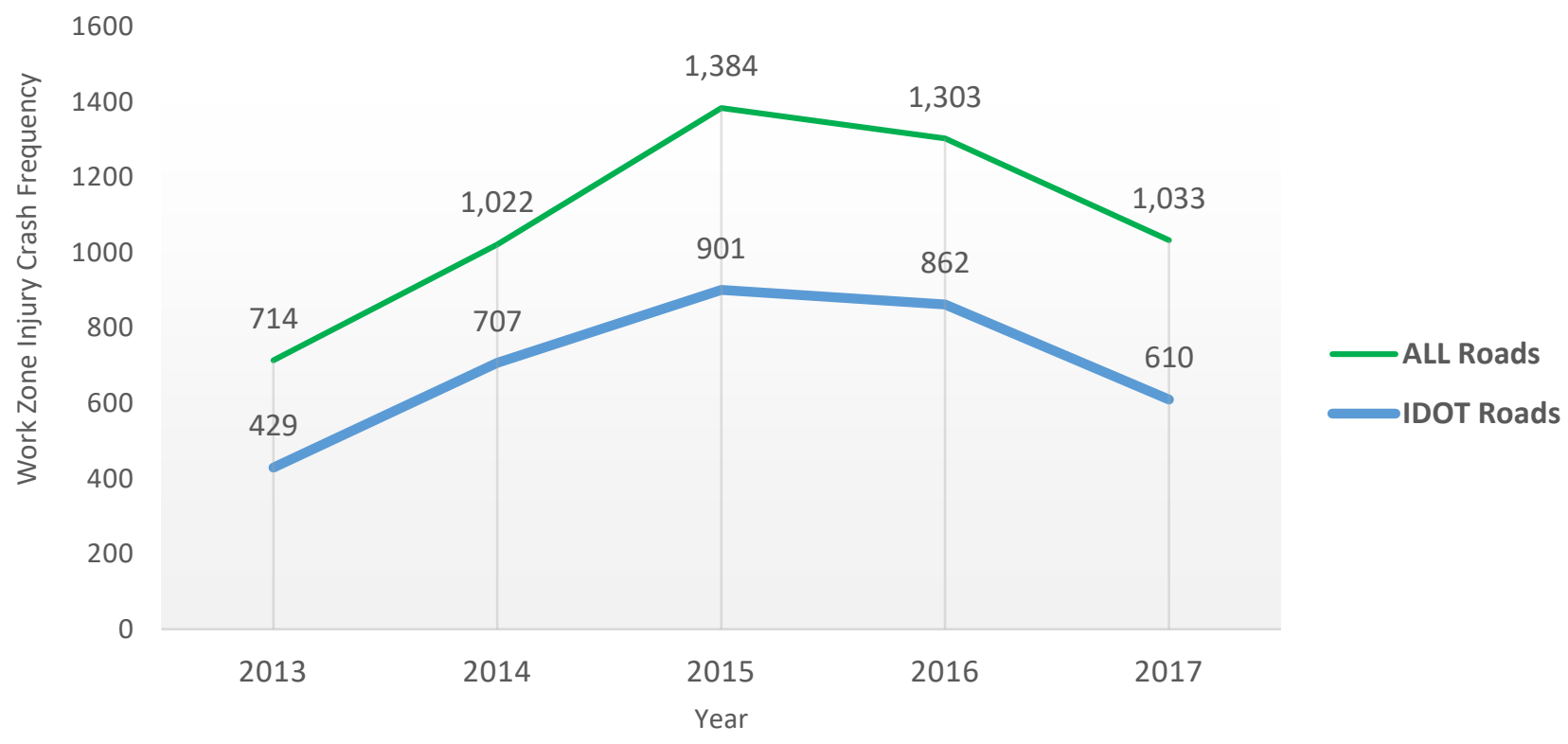

Figure 4.5. Work zone fatal/injury crashes (K, A, B, and C).

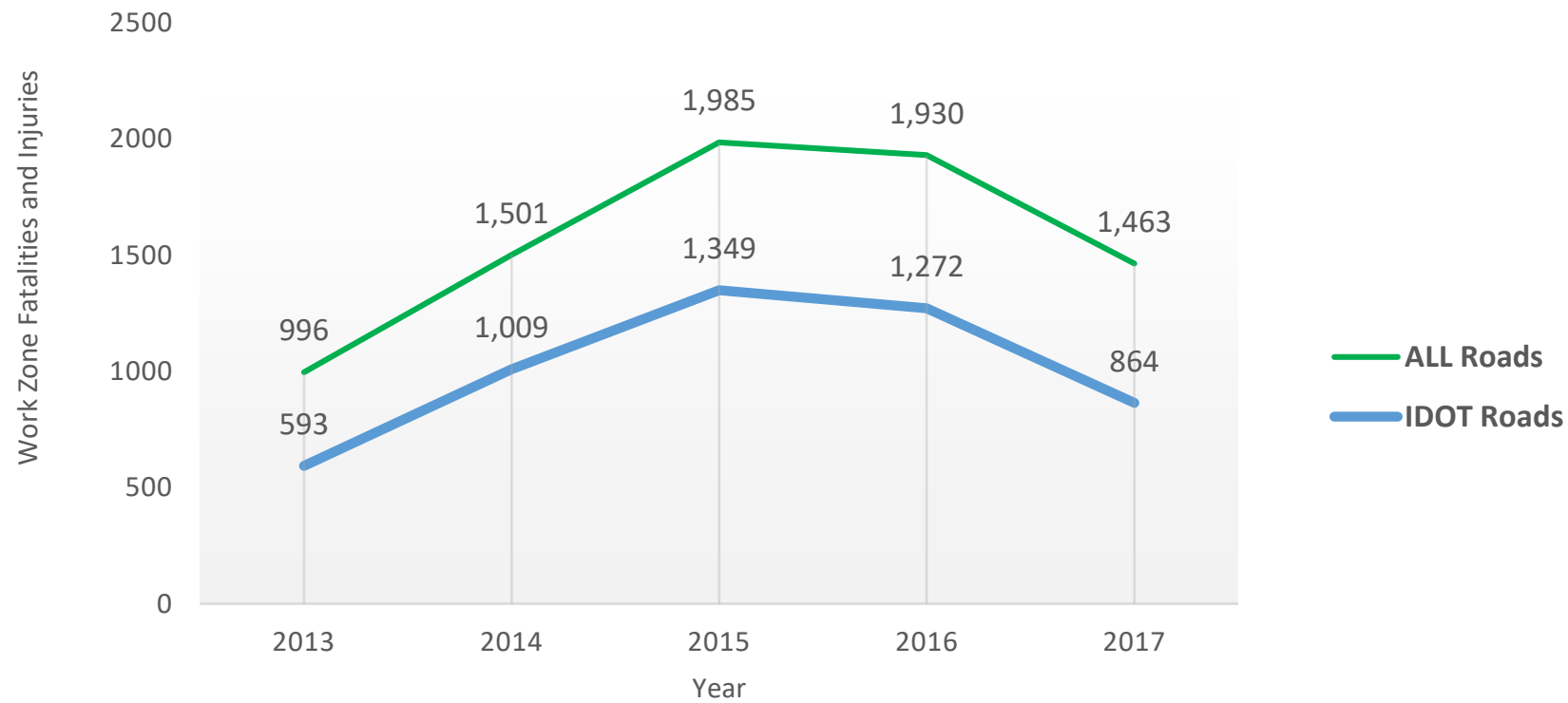

Figure 4.6. Work zone fatalities and injuries. 
Observation of the work zone crash trends show that work zone crash frequency increased from 2013 to 2015 and then decreased for 2016 and 2017 across all crash categories and roads (IDOT and All roads). The lowest work zone crash and injury frequencies were observed in 2017.

A comparison of the proportion of work zone crashes occurring on IDOT roads versus all roads from 2013 to 2017 range from $55 \%$ to $64 \%$ for total crashes and $64 \%$ to $92 \%$ for $\mathrm{K}-\mathrm{A}$ crashes.

\subsubsection{Work Zone Exposure Variables}

The assumptions discussed in Table 4.1 were applied on IDOT's OPER 2410 lane closure databases (segments and points) to calculate annual numbers of four exposure measures for work zones on IDOT roads:
a. Number of work zones
b. Work zone miles
c. Work zone days
d. Work zone day-miles

Figures 4.7 through 4.10 show the annual trends of the work zone exposure variables, respectively, for number of IDOT work zones, work zone miles, work zone days, and work zone day-miles from 2013 to 2017.

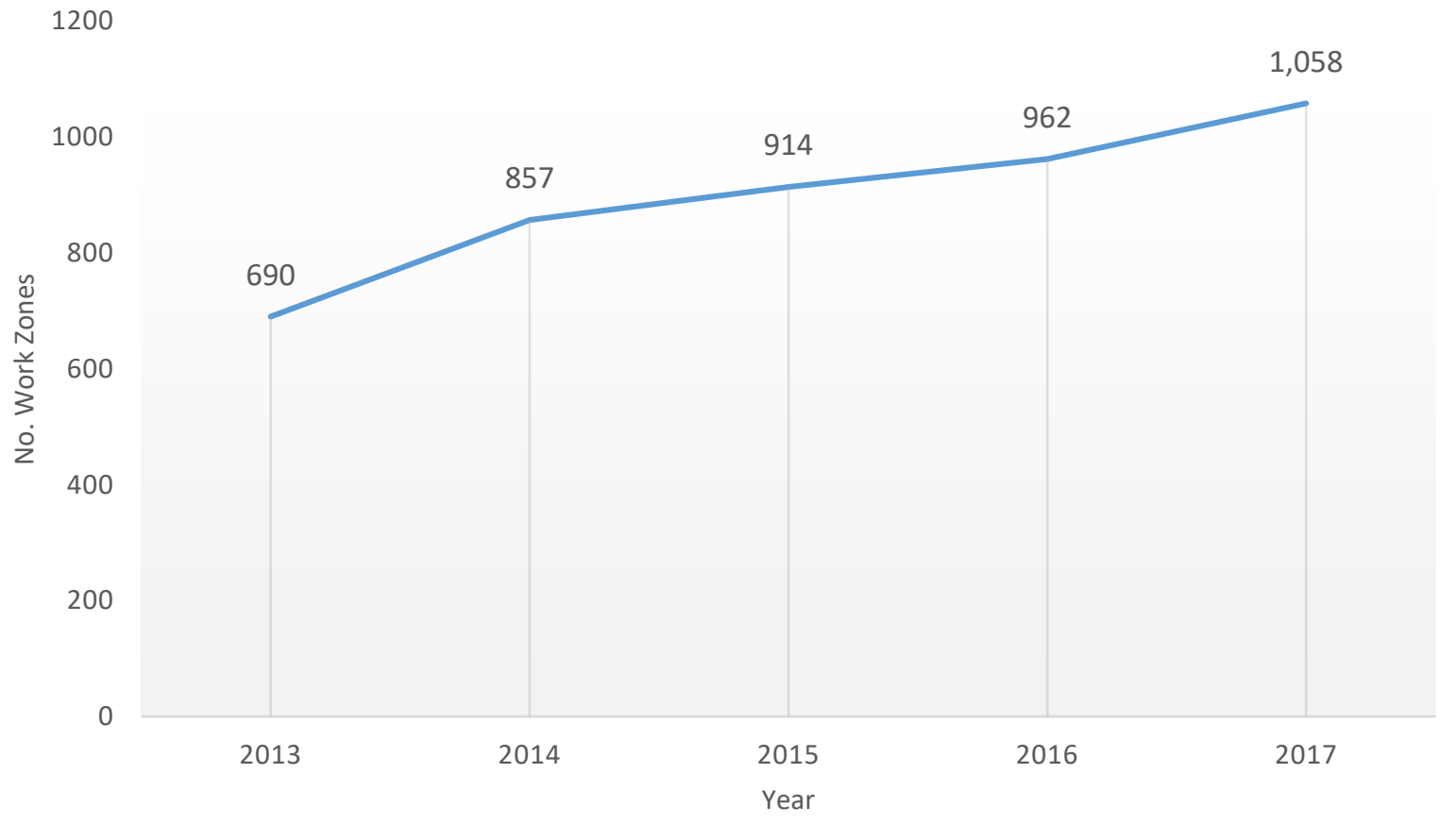

Figure 4.7. Annual number of work zones-IDOT roads. 


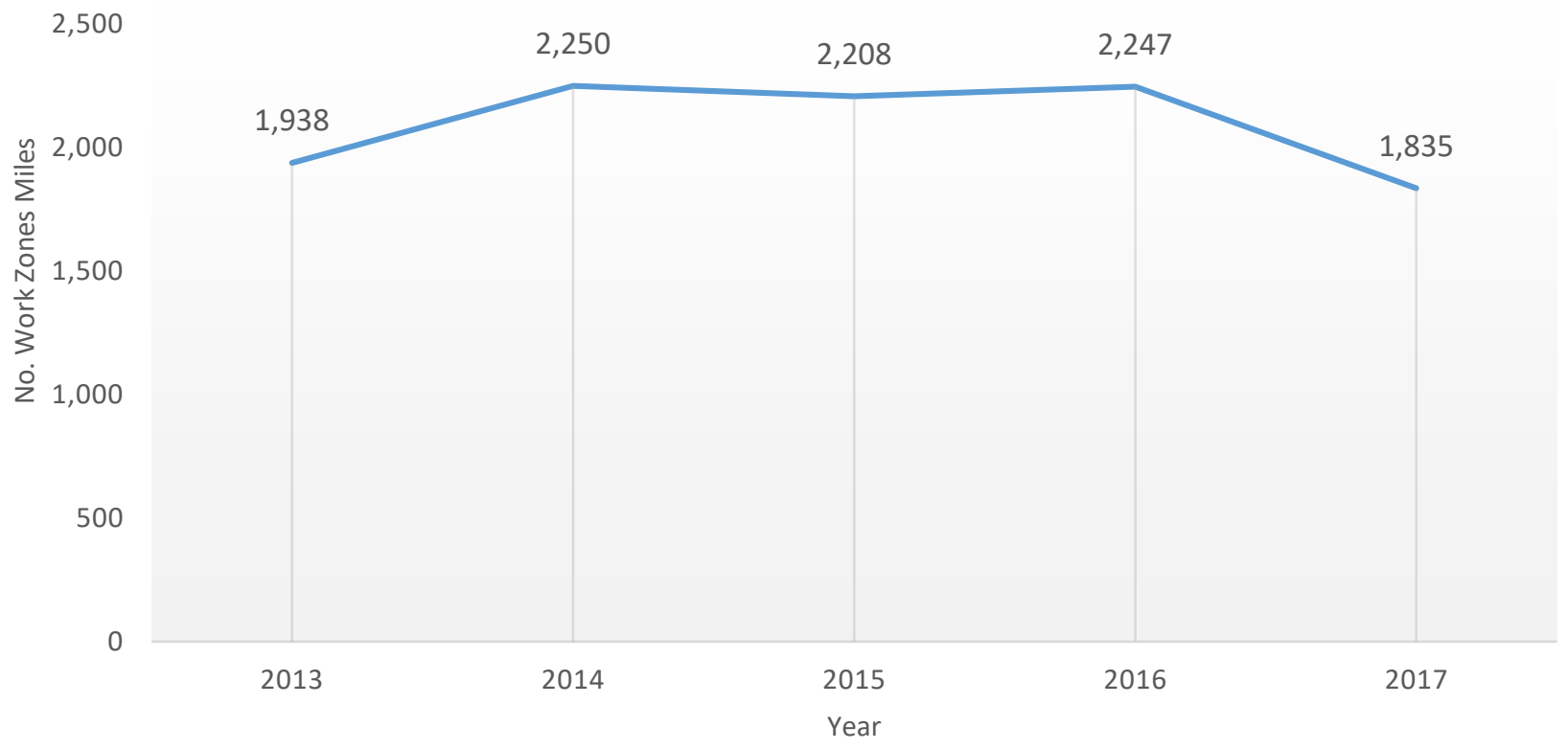

Figure 4.8. Annual number of work zone miles-IDOT roads.

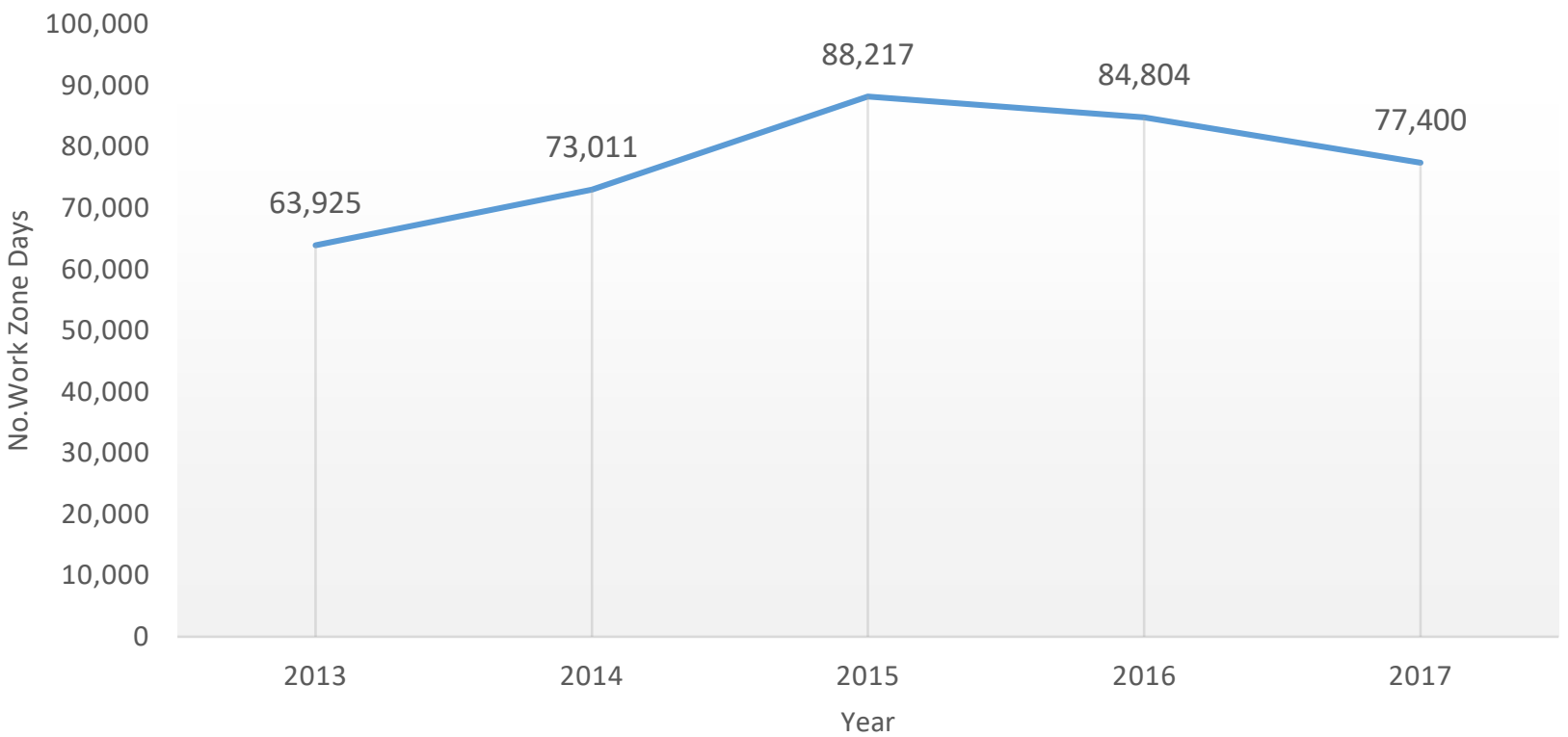

Figure 4.9. Annual number of work zone days-IDOT roads. 


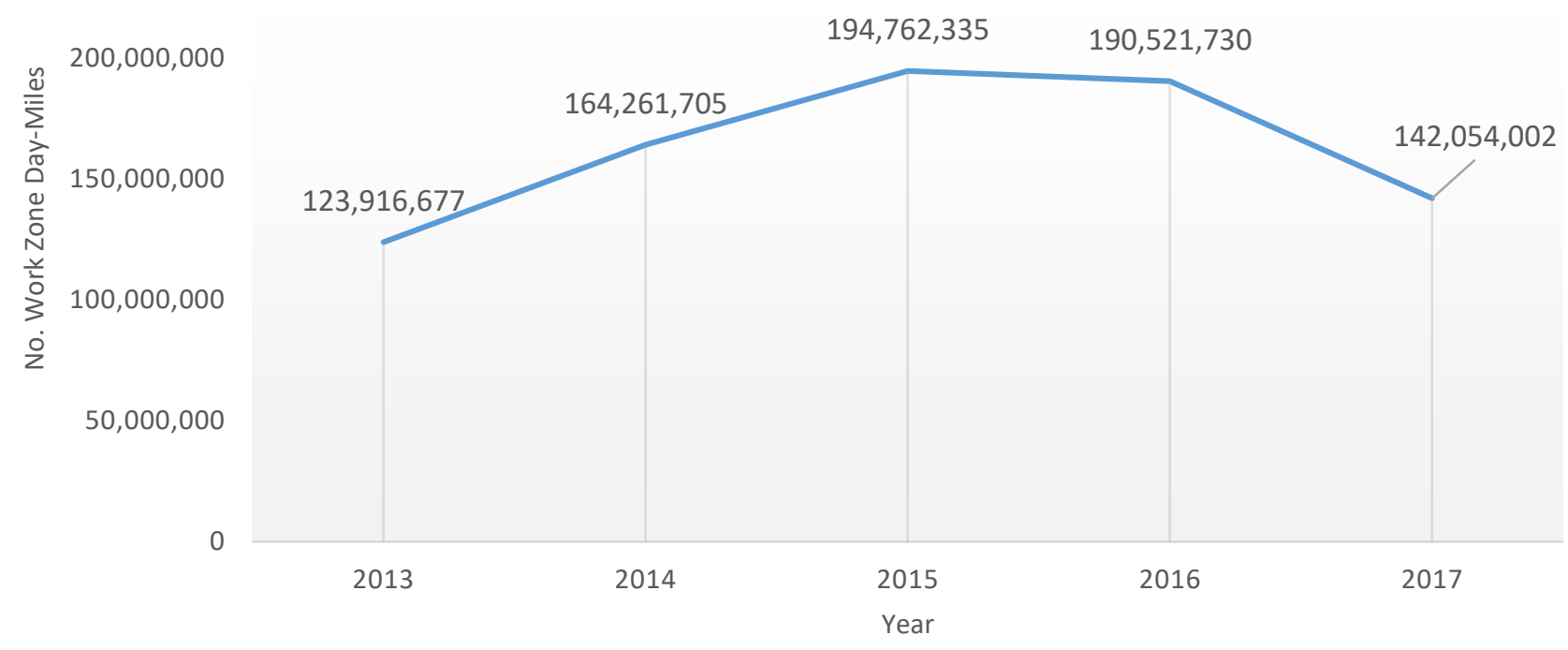

Figure 4.10. Annual number of work zone day-miles-IDOT roads.

The work zone exposure trends reveal that the annual number of IDOT work zones increased steadily from 690 in 2013 to 1,058 in 2017. The annual number of IDOT work zone miles was relatively constant from 2014 to 2016 at 2,250 to 2,247 mi, while in 2017, the work zone miles decreased to 1,835 . In terms of total annual work zone duration, the number of work zone days increased from 2013 to 2015 and decreased in 2016 and 2017. The trends for annual IDOT work zone day-miles also increased from 2013 to 2015 and decreased in 2016 and 2017.

\subsubsection{Work Zone Crash Rates}

Figures 4.11 to 4.14 depict the annual work zone crash rates for the four crash categories and four work zone variables from 2013 to 2017 for IDOT roads. 

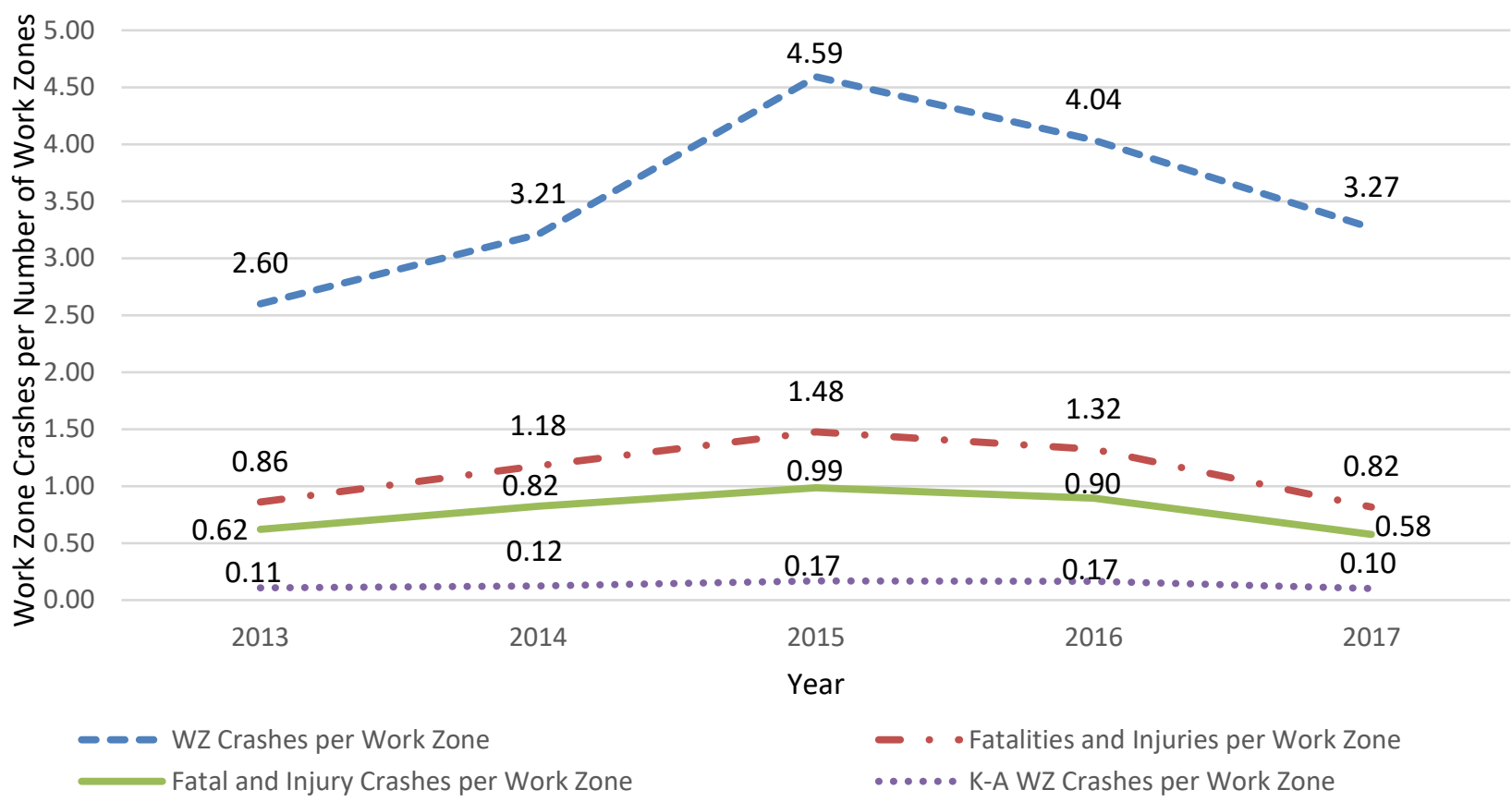

Figure 4.11. Work zone crash rate per number of work zones.

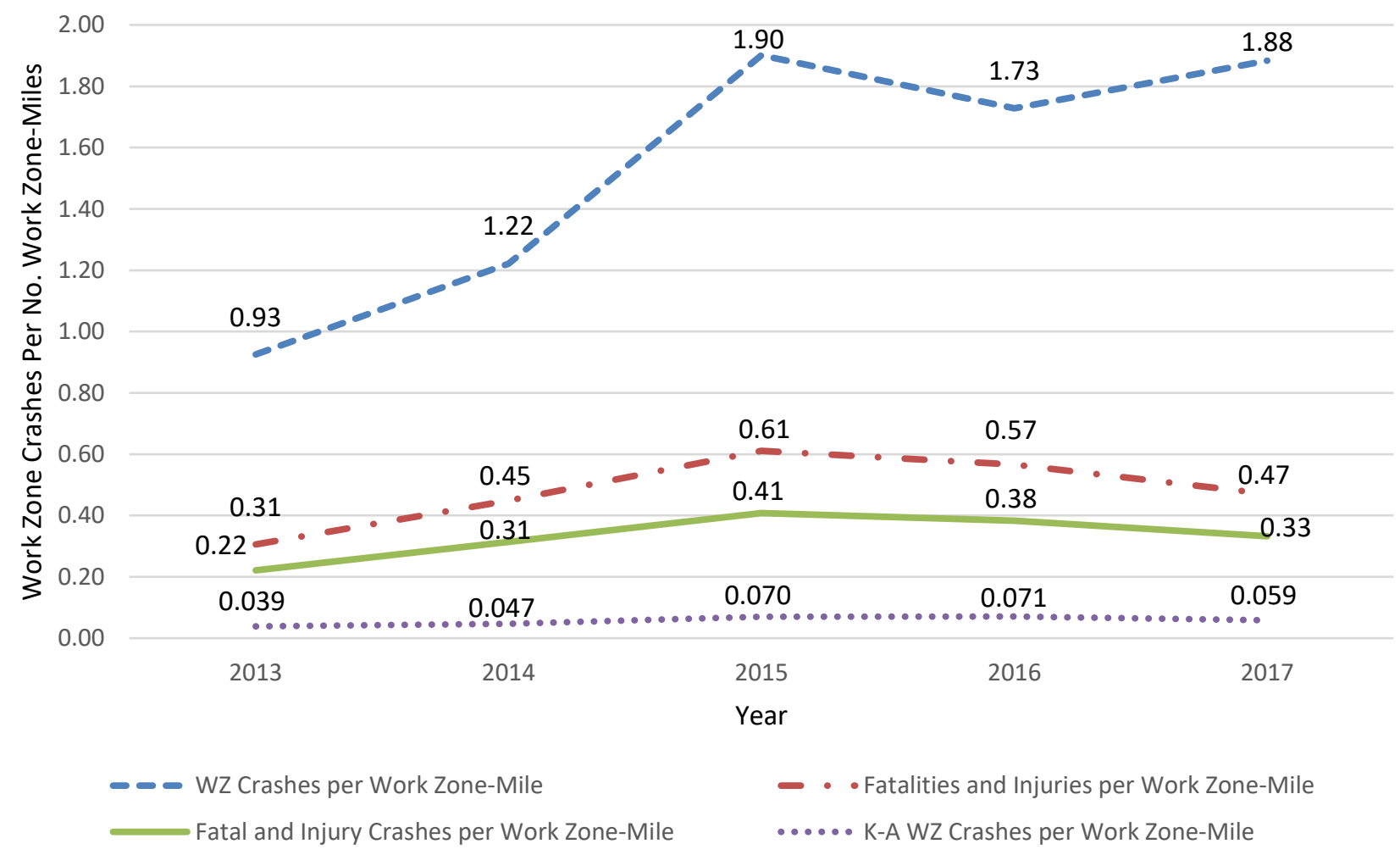

Figure 4.12. Work zone crash rate per work zone-mile. 


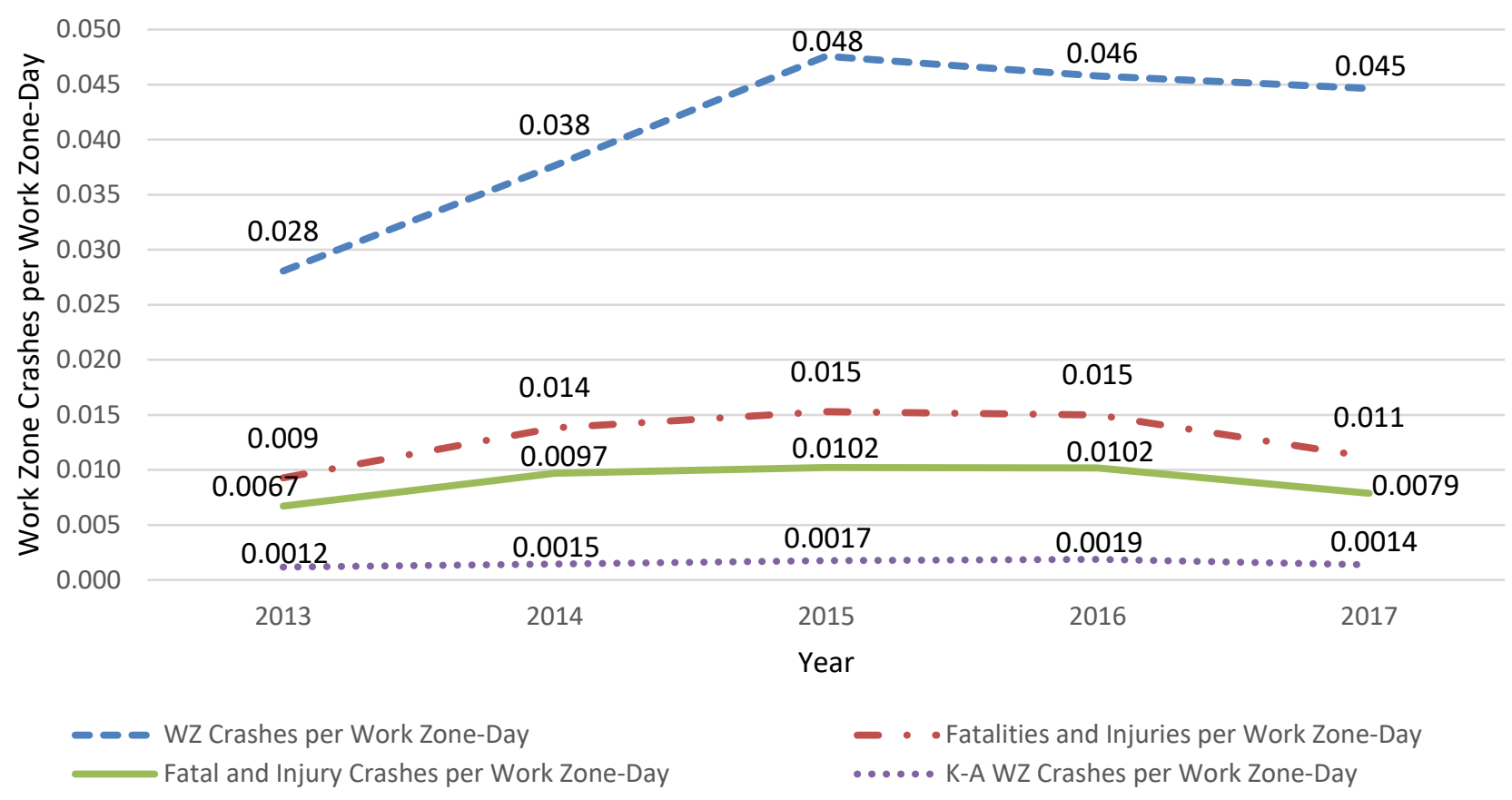

Figure 4.13. Work zone crash rate per work zone-day.

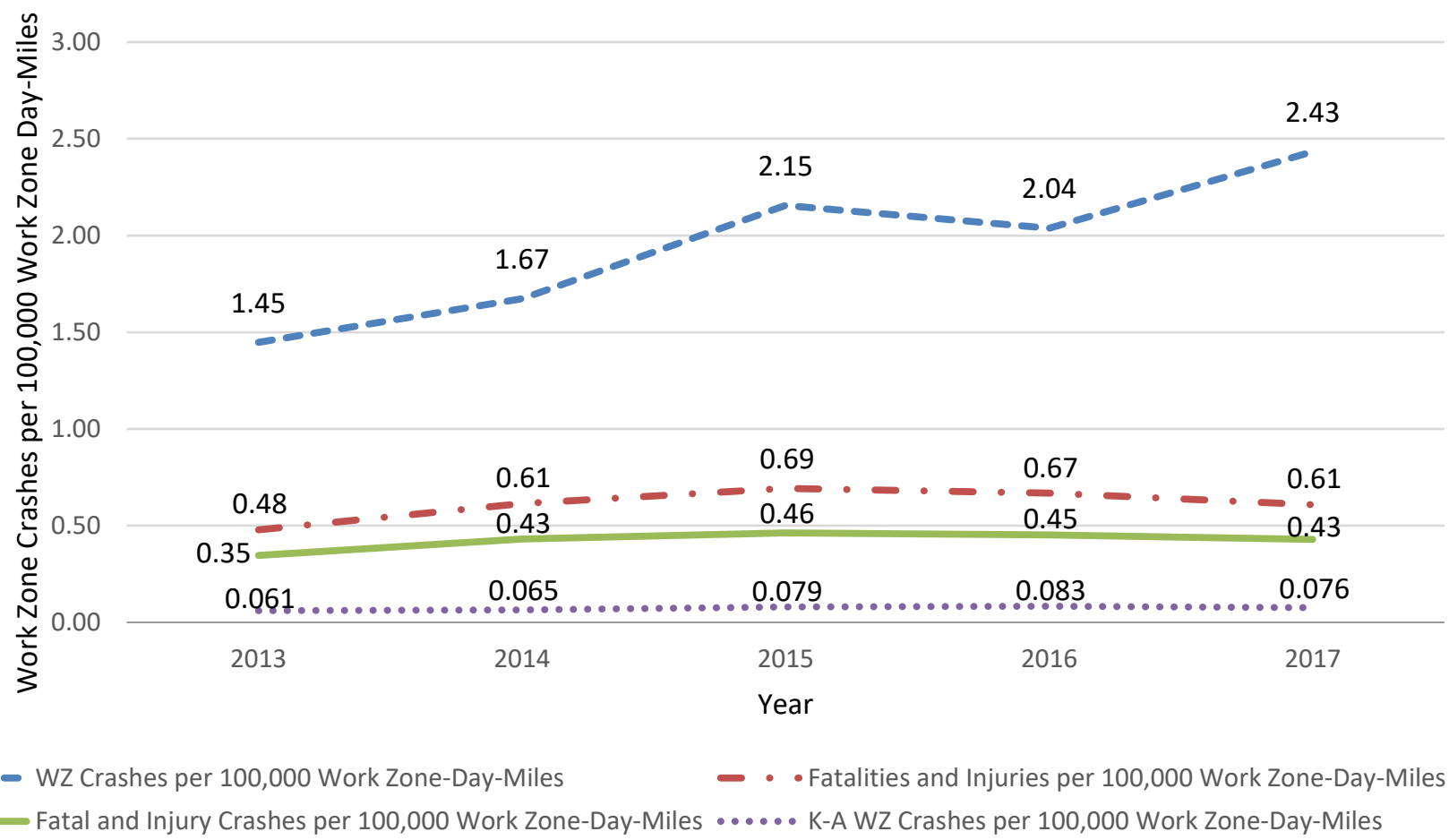

Figure 4.14. Work zone crash rate per 100,000 work zone day-miles. 
The following observations can be made for IDOT work zone crash rates:

- For work zone crashes per number of work zones, in general, an increasing trend was observed for the four crash severity categories from 2013 to 2015, with decreasing rates in 2016 and 2017. The lowest annual rates over the analysis period were observed in 2017 for fatalities and injuries per work zone, fatal and injury crashes per work zone, and K-A crashes per work zone.

- For work zone crashes per work zone mile, the total work zone crash rate increased from 0.93 in 2013 to 1.90 in 2015, the rate decreased to 1.73 in 2016, and then increased to 1.88 in 2017. The rates based on fatalities and injuries per work zone mile and fatal and injury crashes per work zone mile increased from 2013 to 2015 and then decreased in 2016 and 2017. The KA work zone crashes per work zone mile increased from 2013 to 2016 but decreased in 2017.

- For work zone crashes per work zone day, the total work zone crash rate increased from 2013 to 2015 (from 0.028 to 0.048 ) and then decreased slightly to 0.046 and 0.045 in 2016 and 2017 , respectively. The rates based on fatalities and injuries per work zone day and fatal and injury crashes per work zone day increased from 2013 to 2015, remained constant in 2016, and then decreased in 2017. The K-A work zone crashes per work zone day increased from 2013 to 2016 but then decreased in 2017.

- For work zone crashes per $\mathbf{1 0 0 , 0 0 0}$ work zone day-miles, the total work zone crash rate increased from 2013 to 2015 (from 1.45 to 2.15), then decreased 2.04 in 2016, and increased again to 2.43 in 2017. The rates based on fatalities and injuries per 100,000 work zone daymiles and fatal and injury crashes per 100,000 work zone day-miles increased from 2013 to 2015 and then decreased in 2016 and 2017. The K-A work zone crashes per 100,000 work zone day-miles increased from 2013 to 2016 but then decreased in 2017.

- Overall, from 2016 to 2017, 14 of the 16 of the work zone crash and injury rates decreased. The two exceptions where increases were observed from 2016 to 2017 were for total work zone crashes per work zone mile and total work zone crashes per 100,000 day-miles.

The trend analysis of work zone crash frequencies and crash rates reveals that the work zone exposure variables do provide additional insights into work zone safety performance and should continue to be collected in the future. Even though the lane closure databases contained imperfect data, it was still possible to find exposure measures from them through the manual process documented in this report. Improvements to collecting more accurate work zone exposure variables will help in automating the extraction of work zone crash and exposure data and make the process easier to conduct in the future.

Details of the work zone crash frequencies, work zone exposure variables, and crash rates for each year from 2013 to 2017 are included in Appendix B. 


\section{CHAPTER 5: SITE-SPECIFIC WORK ZONE ANALYSIS}

Information from the Illinois traffic crash, lane closure, and road network databases were linked using GIS geoprocessing tools and structure query language. The key data elements from the Illinois statewide traffic crash database used to process, match, and locate work zone crashes include crash date, location ( $X$ and $Y$ coordinates), route name, and vehicle direction. The key data elements of the lane closure database for Illinois roads used in this research include start and end date, starting and ending location of the work zone, route, and route direction of the work zone. A work zone crash was considered to be successfully matched if the crash location and date of crash was within the work zone length and duration, and if the route and vehicle direction of the crash matched with route and closure direction of the work zone between these two databases and GIS layers.

Work zone segments with matching fatal and A-injury crashes were first selected for inclusion in the site-specific work zone analysis. Additional matching was conducted to identify work zone segments with B- and C-injury crashes and property damage only (PDO) crashes. This resulted in the total sample of 384 work zone sites for the site-specific analysis.

In the case of injury crashes, traffic crash severity is defined as follows: $\mathrm{K}$ represents a fatal crash, $\mathrm{A}$ represents a crash with an incapacitating injury, B represents a crash with a non-incapacitating injury, and $\mathrm{C}$ represents a crash with a possible injury.

The total sample of 384 work zone sites were randomly divided into two categories, one for model calibration and the other for model validation. Two-thirds of the data ( 256 sites) were used for model calibration and the remaining one-third (128 sites) was used for model validation.

\subsection{DATA COLLECTION}

Data for the 384 work zone sites were queried from three IDOT sources: the traffic crash, lane closure, and roadway network (base map) databases. Data collection included work zone crashes and injuries, pre-work zone crashes and injuries, duration, length, functional classification, speed limit, work zone speed limit, AADT, number of lanes, number of lanes reduced, type of road closure, activity type, and type of work zone. The contract identification numbers of the work zones were used to access the maintenance of traffic plans and additional data on type of project and work zone speed limits. Historic AADT values were obtained from IDOT's Traffic Count Database System and represent the non-work-zone traffic volumes in vehicles per day.

The lengths of the work zones were estimated from the lane closure database and consisted of the length from the advance warning area to the termination area. However, lengths were not consistently recorded for work zones among the districts in Illinois. To account for this inconsistency, a 0.25-mi buffer was applied upstream and downstream of the work zone segments, and the crashes were queried in this distance. This buffer is similar to work zone length buffers of 0.25 and $0.5 \mathrm{mi}$ used in other studies (Khattak et al., 2002; Sun et al., 2014; Cheng et al., 2015). A 0.25-mi buffer was used in this study because detailed information for work zone lengths was available from the MOT plans for most sites. 
In addition to obtaining and analyzing traffic crash data for crashes occurring within the work zone, the pre-construction crash frequency was also collected and analyzed for the same duration (same months and days) but for the previous non-work-zone time period, with no overlap. The preconstruction crash frequencies provide a basis for comparing how the presence of work zone changes the crash pattern compared to normal roadway conditions.

\subsection{ANALYSIS OF WORK ZONE CRASHES}

The statewide traffic crash database consists of information from Illinois Traffic Crash Report SR 1050. In 2013, work zone fields were added to the RS 1050 crash report form, including if a crash occurs in a work zone, the type of work zone (construction, maintenance, utility, or other), and whether workers were present at the time of the crash. In this research an in-depth crash analysis was performed for all 384 work zone sites from 2013 to 2017 to reduce the effects of coding errors reported on the traffic crash report forms.

The analysis of crashes did not rely on the recorded attribute of whether the crash occurred in a work zone, as it did not clearly indicate if the coded work zone crash was due to the presence of the work zone. For each work zone site, the police traffic crash report forms were downloaded and then a detailed crash analysis was conducted. By carefully reviewing the information from crash report narratives, crashes were aggregated into four categories as a part of a more detailed crash analysis (as previously defined in chapter 3 ):

1. Confirmed work zone crash

2. Likely work zone crash

3. Probable work zone crash

4. Not a work zone crash

These categories were developed to provide increased accuracy in quantifying work zone crashes and provided additional flexibility during the modeling process.

\subsection{SAFETY PERFORMANCE FUNCTION CALIBRATION AND VALIDATION}

A SPF is an equation that estimates the average number of crashes per unit time at a location as a function of exposure and other characteristics. SPFs are used to predict crash frequency for a given set of site conditions or to compare the safety performance of a specific site under various conditions. They are also used to explain the correlation between work zone crashes and specific work zone exposures.

\subsubsection{Safety Performance Functions}

The work zone characteristics, other geometric characteristics, crash history, and traffic volumes of the 256 work zone sites comprising the calibration data set and the 128 work zone sites comprising the validation data set were compiled and analyzed using the IBM SPSS statistical analysis software. Details of the crash data, traffic volume, and other characteristics for the calibration sites can be found in Appendix C. Work zone crashes and injuries were the dependent variables. Twelve independent variables were considered in the regression/modeling analysis: pre-construction crashes 
and injuries, work zone duration, length of work zone, functional classification, speed limit, work zone speed limit, AADT, number of lanes, number of lanes reduced, type of road closure, activity type, and type of work zone. Assuming an underlying Poisson/negative binomial distribution, which is a common assumption in modeling traffic crashes per the HSM (AASHTO, 2010), SPF models were then developed to predict crashes using variables that were found to have a statistically significant influence on crashes.

Following the iterative process, three SPF models were developed to predict total work zone crashes, and one model was developed to predict work zone fatal/injury crashes (K-fatal and A-, B-, and Cinjury crashes). All three models are considered viable models because the overall regression equations were statistically significant and the variable coefficients were also significant at $95 \%$ level of confidence or higher. Equations 1, 2, 3, and 4 show the general form of the SPFs developed.

$$
\begin{array}{lr}
\mu_{\text {Total }}=e^{\alpha} \times D^{\beta_{1}} \times L^{\beta_{2}} & \text { Model 1 (1) } \\
\mu_{\text {Total }}=e^{\alpha} \times D^{\beta_{1}} \times L^{\beta_{2}} \times A A D T^{\beta_{3}} & \text { Model 2 (2) } \\
\mu_{\text {Total }}=e^{\alpha} \times D^{\beta_{1}} \times L^{\beta_{2}} \times A A D T^{\beta_{3}} \times e^{\beta_{4} *(N W Z S L \times W Z S L)} & \text { Model 3 (3) } \\
\mu_{\text {Fatal/Injury }}=e^{\alpha} \times D^{\beta_{1}} \times L^{\beta_{2}} \times e^{\beta_{3} *(N W Z S L \times W Z S L)} & \text { Fatal/Injury Model (4) }
\end{array}
$$

where,

$\mu_{\text {Total }}=$ Average predicted work zone crashes (confirmed, likely, probable)

$\mu_{\text {Fatal/Injury }}=$ Average predicted work zone injury crashes (confirmed, likely, probable) for K, A, $B$, and $C$ crashes combined

$D=$ Duration of the work zone (end date - start date +1 ) (days)

$L=$ Length of the work zone (miles)

AADT = Annual average daily traffic (vehicles/day)

NWZ SL = Non-work-zone speed limit (mph)

WZ SL = Work zone speed limit (mph)

NWZ SL $\times$ WZ SL = Product of non-work-zone and work zone speed limits

$\alpha=$ Regression model intercept

$\beta_{1}, \beta_{2}, \beta_{3}, \beta_{4}=$ Regression coefficients

Tables 5.1 and 5.2 show the coefficients, standard error, and overdispersion factors for the SPFs developed, using the calibration data set of 256 sites and the validation data set with 128 sites for total work zone crashes (Table 5.1) and fatal/injury work zone crashes (Table 5.2). The estimated parameters are for the logarithmic transformation of the variables work zone duration, length, and AADT. 
Table 5.1. Variable Coefficients for SPFs Developed for Total Work Zone Crashes

\begin{tabular}{|c|c|c|c|c|c|c|}
\hline \multirow[b]{2}{*}{ Model } & \multicolumn{5}{|c|}{ Regression Coefficients } & \multirow[b]{2}{*}{$\begin{array}{c}\text { Overdispersion } \\
\text { Parameter, k } \\
\text { (St. Error) }\end{array}$} \\
\hline & $\begin{array}{l}\text { Intercept } \\
\qquad(\alpha) \\
\text { (St. Error) } \\
\text { (P-Value) }\end{array}$ & $\begin{array}{l}\text { Coefficient } \\
\quad\left(\beta_{1}\right) \\
\text { Duration } \\
\text { (St. Error) } \\
\text { (P-Value) }\end{array}$ & $\begin{array}{c}\text { Coefficient } \\
\left(\beta_{2}\right) \\
\text { Length } \\
\text { (St. Error) } \\
\text { (P-Value) }\end{array}$ & $\begin{array}{c}\text { Coefficient } \\
\left(\beta_{3}\right) \\
\text { AADT } \\
\text { (St. Error) } \\
\text { (P-Value) }\end{array}$ & $\begin{array}{c}\left.\text { Coefficient ( } \beta_{4}\right) \\
\text { NWZ×WZ SL } \\
\text { (St. Error) } \\
\text { (P-Value) }\end{array}$ & \\
\hline $\begin{array}{c}\text { Calibration } \\
\text { Model } 1 \\
n=256\end{array}$ & $\begin{array}{c}-2.444 \\
(0.4062) \\
(<0.001)\end{array}$ & $\begin{array}{c}0.781 \\
(0.0726) \\
(<0.001)\end{array}$ & $\begin{array}{c}0.170 \\
(0.0443) \\
(<0.001)\end{array}$ & NA & NA & $\begin{array}{c}0.768 \\
(0.0744)\end{array}$ \\
\hline $\begin{array}{c}\text { Calibration } \\
\text { Model } 2 \\
n=256\end{array}$ & $\begin{array}{c}-6.977 \\
(0.8130) \\
(<0.001) \\
\end{array}$ & $\begin{array}{c}0.743 \\
(0.0695) \\
(<0.001) \\
\end{array}$ & $\begin{array}{c}0.150 \\
(0.0421) \\
(<0.001) \\
\end{array}$ & $\begin{array}{c}0.469 \\
(0.0741) \\
(<0.001) \\
\end{array}$ & NA & $\begin{array}{c}0.663 \\
(0.0663)\end{array}$ \\
\hline $\begin{array}{c}\text { Calibration } \\
\text { Model } 3 \\
n=256\end{array}$ & $\begin{array}{c}-6.119 \\
(0.8049) \\
(<0.001) \\
\end{array}$ & $\begin{array}{c}0.725 \\
(0.0680) \\
(<0.001) \\
\end{array}$ & $\begin{array}{c}0.329 \\
(0.0566) \\
(<0.001) \\
\end{array}$ & $\begin{array}{c}0.464 \\
(0.0708) \\
(<0.001) \\
\end{array}$ & $\begin{array}{l}-0.00035 \\
(0.0001) \\
(<0.001) \\
\end{array}$ & $\begin{array}{c}0.596 \\
(0.0620)\end{array}$ \\
\hline $\begin{array}{c}\text { Validation } \\
\text { Model } 1 \\
n=128\end{array}$ & $\begin{array}{c}-4.888 \\
(0.6640) \\
(<0.001)\end{array}$ & $\begin{array}{c}1.277 \\
(0.1108) \\
(<0.001)\end{array}$ & $\begin{array}{c}0.153 \\
(0.0670) \\
(0.05)\end{array}$ & NA & NA & $\begin{array}{c}1.055 \\
(0.0744)\end{array}$ \\
\hline $\begin{array}{c}\text { Validation } \\
\text { Model } 2 \\
n=128\end{array}$ & $\begin{array}{c}-9.007 \\
(1.3597) \\
(<0.001) \\
\end{array}$ & $\begin{array}{c}1.155 \\
(0.1131) \\
(<0.001) \\
\end{array}$ & $\begin{array}{c}0.179 \\
(0.0666) \\
(0.01)\end{array}$ & $\begin{array}{c}0.475 \\
(0.1385) \\
(<0.001)\end{array}$ & NA & $\begin{array}{c}0.978 \\
(0.1214)\end{array}$ \\
\hline $\begin{array}{c}\text { Validation } \\
\text { Model } 3 \\
n=128\end{array}$ & $\begin{array}{c}-7.585 \\
(1.3031) \\
(<0.001)\end{array}$ & $\begin{array}{c}1.079 \\
(0.1136) \\
(<0.001)\end{array}$ & $\begin{array}{c}0.339 \\
(0.0711) \\
(<0.001)\end{array}$ & $\begin{array}{c}0.466 \\
(0.1279) \\
(<0.001)\end{array}$ & $\begin{array}{l}-0.00044 \\
(0.0001) \\
(<0.001)\end{array}$ & $\begin{array}{c}0.871 \\
(0.1114)\end{array}$ \\
\hline
\end{tabular}

$N A=$ Not Available

Table 5.2. Variable Coefficients for SPFs Developed for Fatal/Injury Work Zone Crashes

\begin{tabular}{|c|c|c|c|c|c|}
\hline \multirow[b]{2}{*}{ Model } & \multicolumn{5}{|c|}{ Regression Coefficients } \\
\hline & $\begin{array}{c}\text { Intercept ( } \alpha) \\
\text { (St. Error) } \\
\text { (P-Value) }\end{array}$ & $\begin{array}{c}\left.\text { Coefficient ( } \beta_{1}\right) \\
\text { Duration } \\
\text { (St. Error) } \\
\text { (P-Value) }\end{array}$ & $\begin{array}{c}\text { Coefficient }\left(\boldsymbol{\beta}_{2}\right) \\
\text { Length } \\
\text { (St. Error) } \\
\text { (P-Value) }\end{array}$ & $\begin{array}{c}\text { Coefficient } \\
\left(\beta_{3}\right) \\
\text { NWZ×WZ SL } \\
\text { (St. Error) } \\
\text { (P-Value) }\end{array}$ & $\begin{array}{c}\text { Overdispersion } \\
\text { Parameter, k } \\
\text { (St. Error) }\end{array}$ \\
\hline $\begin{array}{l}\text { Calibration Model } \\
\qquad n=256\end{array}$ & $\begin{array}{c}-1.824 \\
(0.5900) \\
(0.005)\end{array}$ & $\begin{array}{c}0.572 \\
(0.096) \\
(<0.001)\end{array}$ & $\begin{array}{c}0.312 \\
(0.0817) \\
(<0.001)\end{array}$ & $\begin{array}{c}-0.00042 \\
(0.0001) \\
(<0.001)\end{array}$ & $\begin{array}{c}0.880 \\
(0.1405)\end{array}$ \\
\hline $\begin{array}{l}\text { Validation Model } \\
\qquad n=128\end{array}$ & $\begin{array}{c}-4.371 \\
(1.0548) \\
(<0.001) \\
\end{array}$ & $\begin{array}{c}1.110 \\
(0.1570) \\
(<0.001) \\
\end{array}$ & $\begin{array}{c}0.342 \\
(0.1066) \\
(<0.001) \\
\end{array}$ & $\begin{array}{c}-0.001 \\
(0.0001) \\
(0.05)\end{array}$ & $\begin{array}{c}1.269 \\
(0.2285)\end{array}$ \\
\hline
\end{tabular}

\subsubsection{CURE Plots for Calibration Data Set}

To determine how the residuals are distributed with respect to the independent variables and in comparing multiple alternative SPFs, CURE plots were used. Hauer recommends the use of CURE plots to obtain further insight into whether the selected appropriate functional form was reasonable (Hauer, 2004; Srinivasan \& Bauer, 2013). The general concept is that for a model of the appropriate functional form and to have a good fit, the CURE plot is expected to oscillate randomly about zero 
(such that the mean of all the residuals is 0 ). The following are the steps involved in making CURE plots:

- Step 1: For the sites used to calibrate the SPF, obtain the Pearson residuals (or the scaled residuals) from SPSS or calculate the raw residual divided by the square root of the variance as follows (Equation 5):

$$
\text { res }=\sum_{i: x_{i} \leq j} \frac{\left(y_{i}-\hat{y}_{i}\right)}{\sqrt{\hat{y}_{i}+K \hat{y}_{i}^{2}}}
$$

where,

$$
\begin{aligned}
& y_{i}=\text { observed crash frequency at site } i \\
& \hat{y}_{i}=\text { estimated/predicted mean accident count at site number } i \text { (according to the model) } \\
& K=\text { overdispersion parameter of the model } \\
& N=\text { sample size to which the model is applied }
\end{aligned}
$$

- Step 2: Sort the data set in increasing order of an explanatory variable of interest.

- Step 3: Calculate the cumulative residuals (CURE) for each observation.

- Step 4: Calculate squared of the residuals $\left(\right.$ res $\left.^{2}\right)$ for each site.

- Step 5: Calculate the cumulative of the squared residuals, $\sigma^{2}(n)$.

- Step 6: Sum the squared residuals, $\sigma^{2}(N)$.

- Step 7: Estimate the variance of the CURE/ random walk, $\sigma^{* 2}$ (Equation 6).

$$
\sigma *^{2}=\sigma^{2}(\mathrm{n})\left[1-\frac{\sigma^{2}(n)}{\sigma^{2}(N)}\right]
$$

- Step 8: For each site, calculate the $95 \% \mathrm{Cl}$ of $\pm 2 \sqrt{\sigma *^{2}}$.

- Step 9: Plot, CURE from step 3, lower and upper limits from step 7 on the $y$-axis against the explanatory variable of interest on the $\mathrm{x}$-axis.

Figures 5.1 through 5.4 show the CURE plot for the dependent variables of (a) duration, (b) length, (c) AADT, and (d) NWZ $\times W Z S L$, respectively, for the calibration SPF models (with $n=256$ ) for total work zone crashes. 


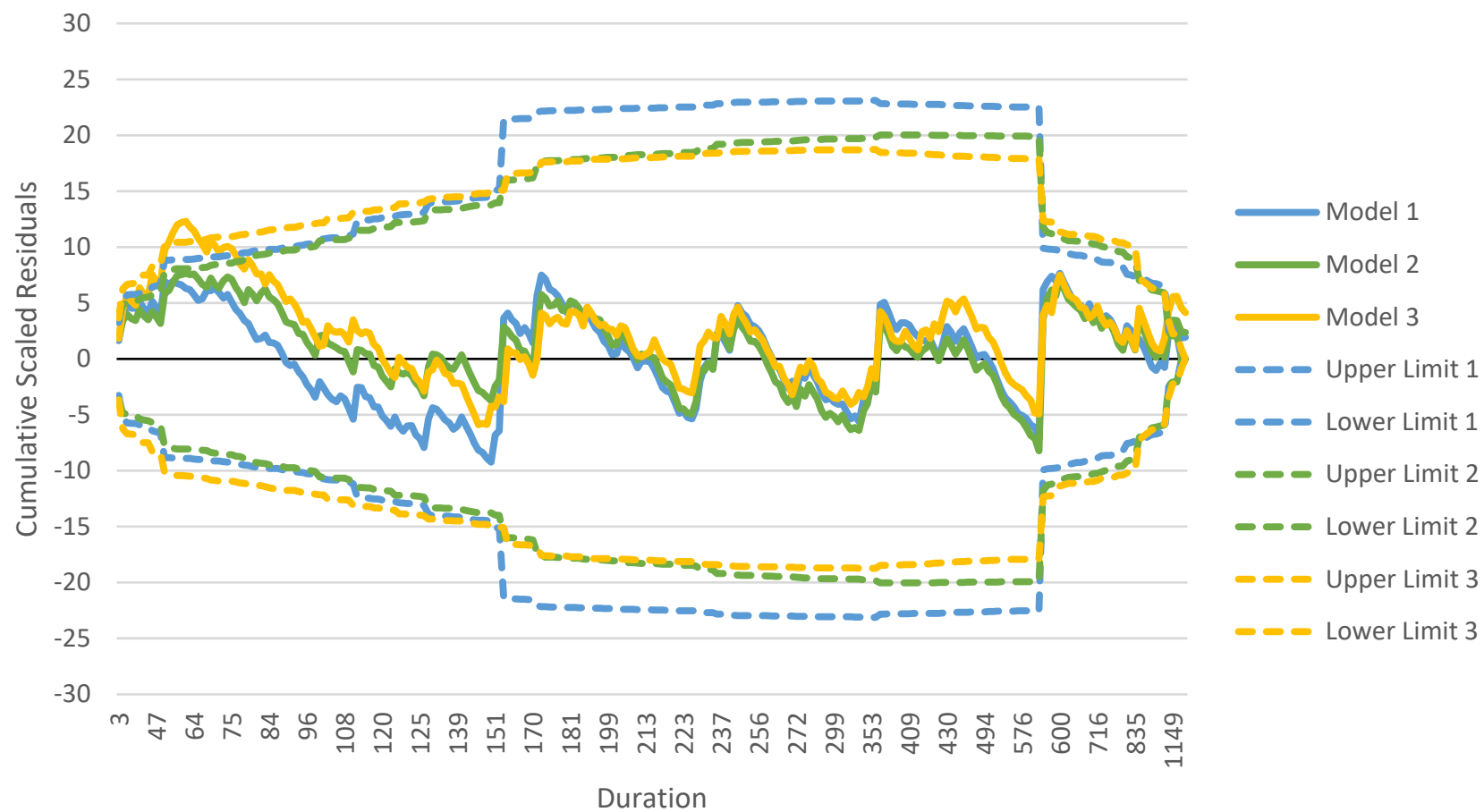

Figure 5.1. CURE plots for "duration" for total work zone crashes.

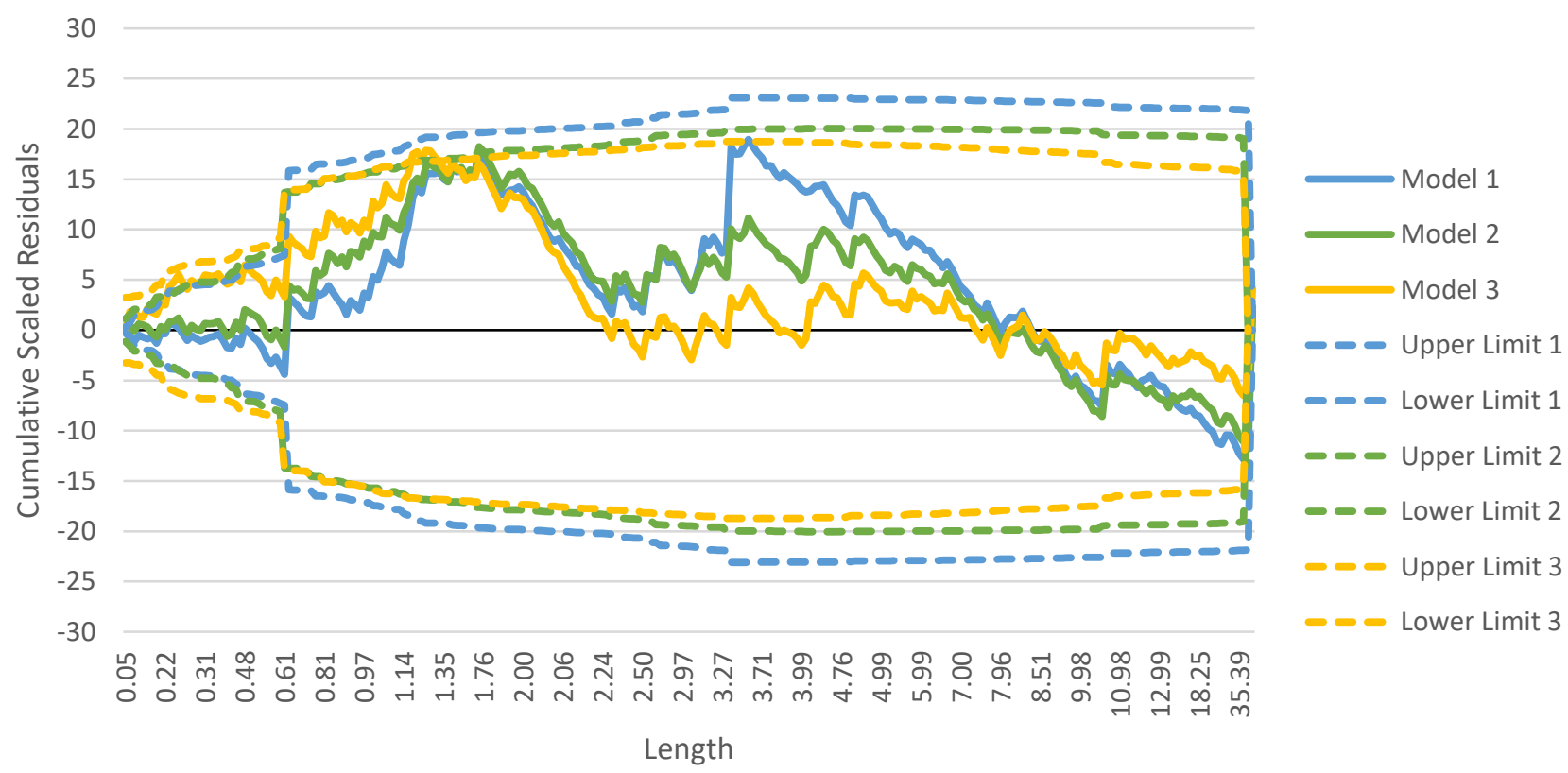

Figure 5.2. CURE plots for "length" for total work zone crashes. 


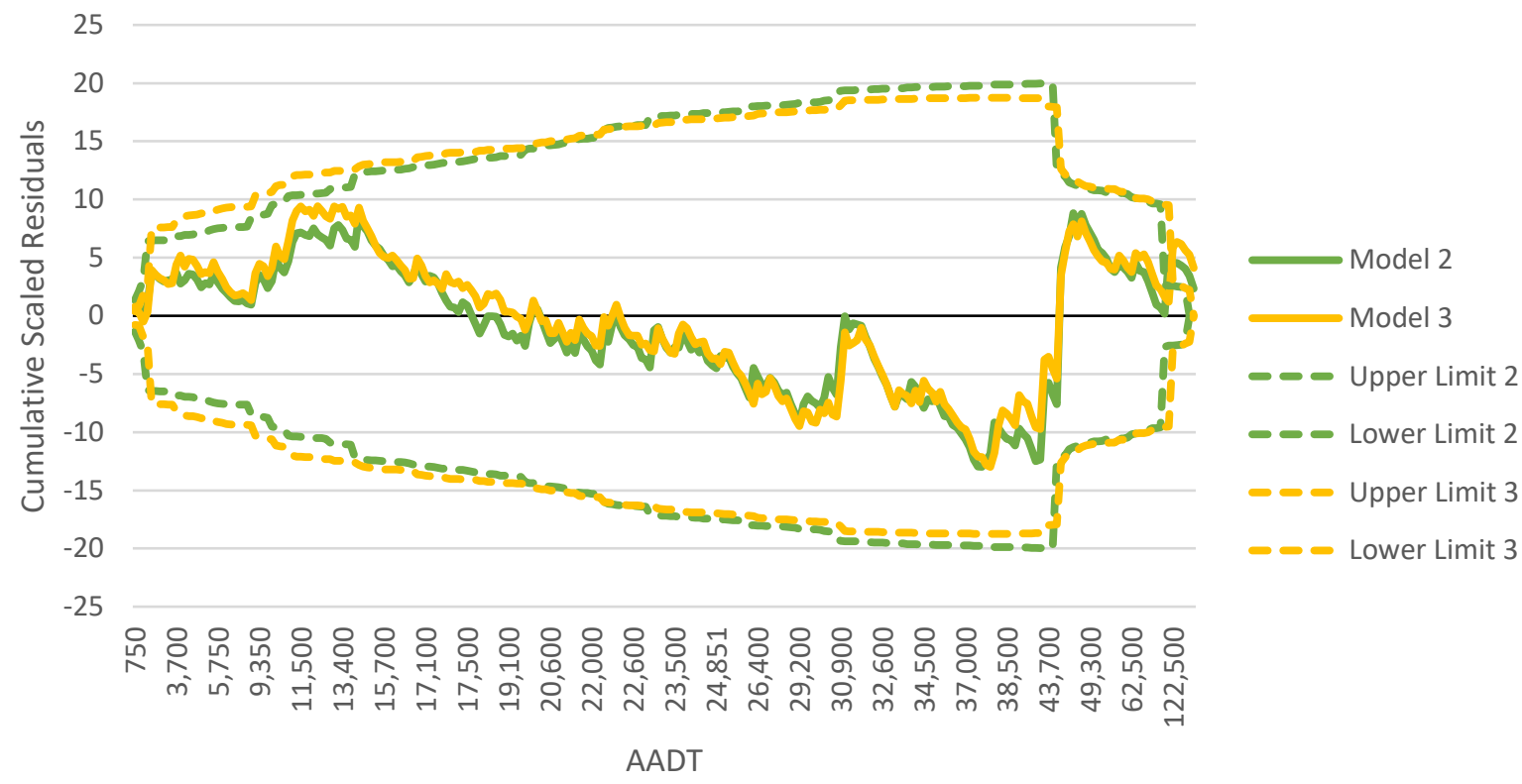

Figure 5.3. CURE plots for "AADT" for total work zone crashes.

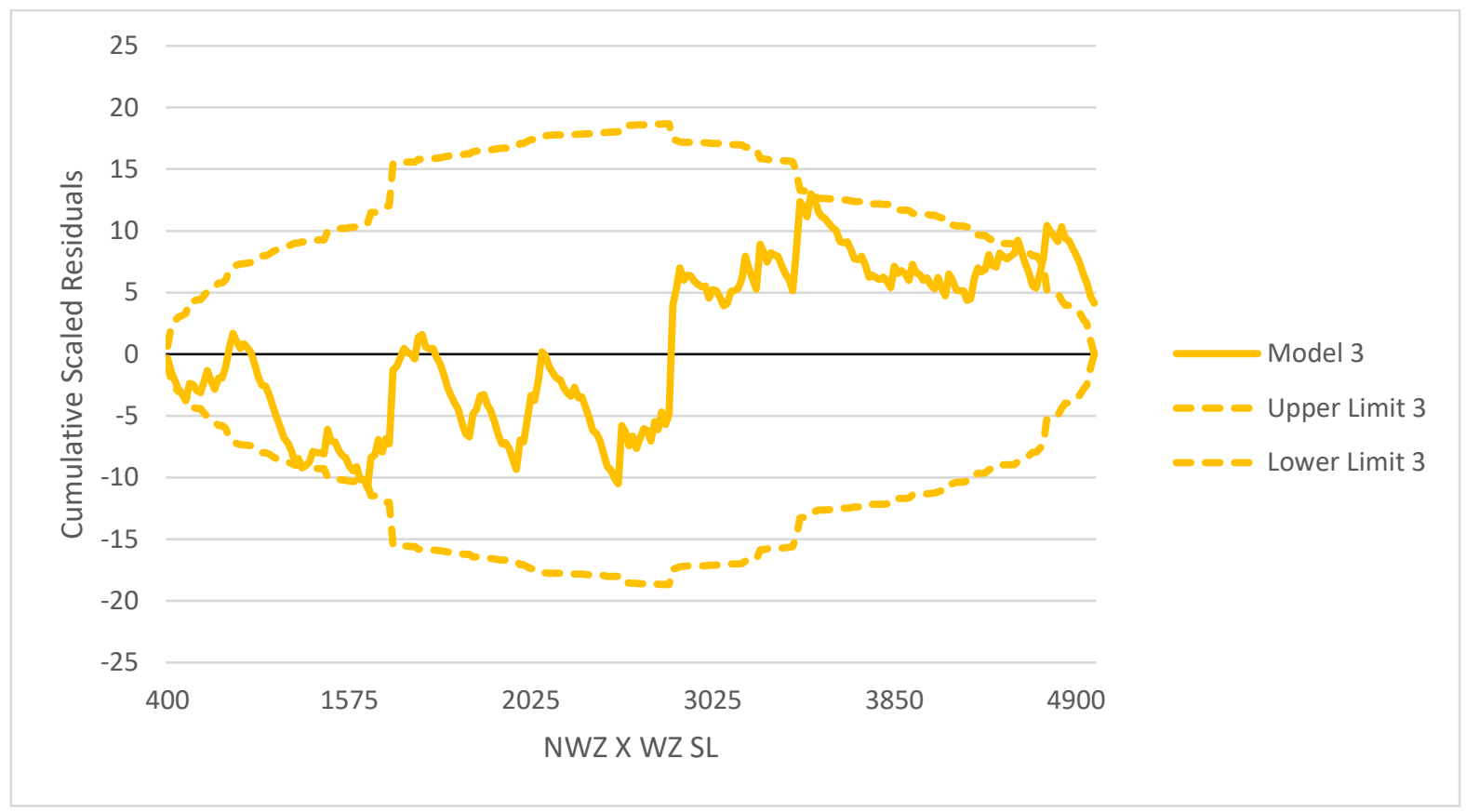

Figure 5.4. CURE plots for “NWZ SL $\times$ WZ SL" for total work zone crashes.

A consistent upward drift of the cumulative residuals within a particular range of exposure variables indicates that the SPF model is underpredicting the crashes. A consistent downward drift within a particular range of exposure variables indicates that the SPF model is overpredicting the crashes. Despite underprediction and overprediction for some exposure variable ranges, the CURE plots for Model 1, Model 2, and Model 3 from Figures 5.1 through 5.4 are essentially random and are within 
the confidence limits of \pm 2 standard deviations ( $\sigma)$. The upward drift of the CURE for the dependent variable of "Length" from the $2.29 \mathrm{mi}$ to $7.96 \mathrm{mi}$ range was observed for Model 1 and Model 2. But, Model 3 showed a marked improvement in comparison with a lower CURE deviation. Further, the CURE better oscillated about zero in Model 3 for the work zone "Length" variable.

Figures 5.5 through 5.7 are the CURE plots that show the distribution of residuals with respect to the independent variables for the work zone fatal/injury crash SPF. Despite underprediction and overprediction for some exposure variable ranges, the CURE plots for the fatal/injury SPF are essentially random and are within the confidence limits of $\pm 2 \sigma$.

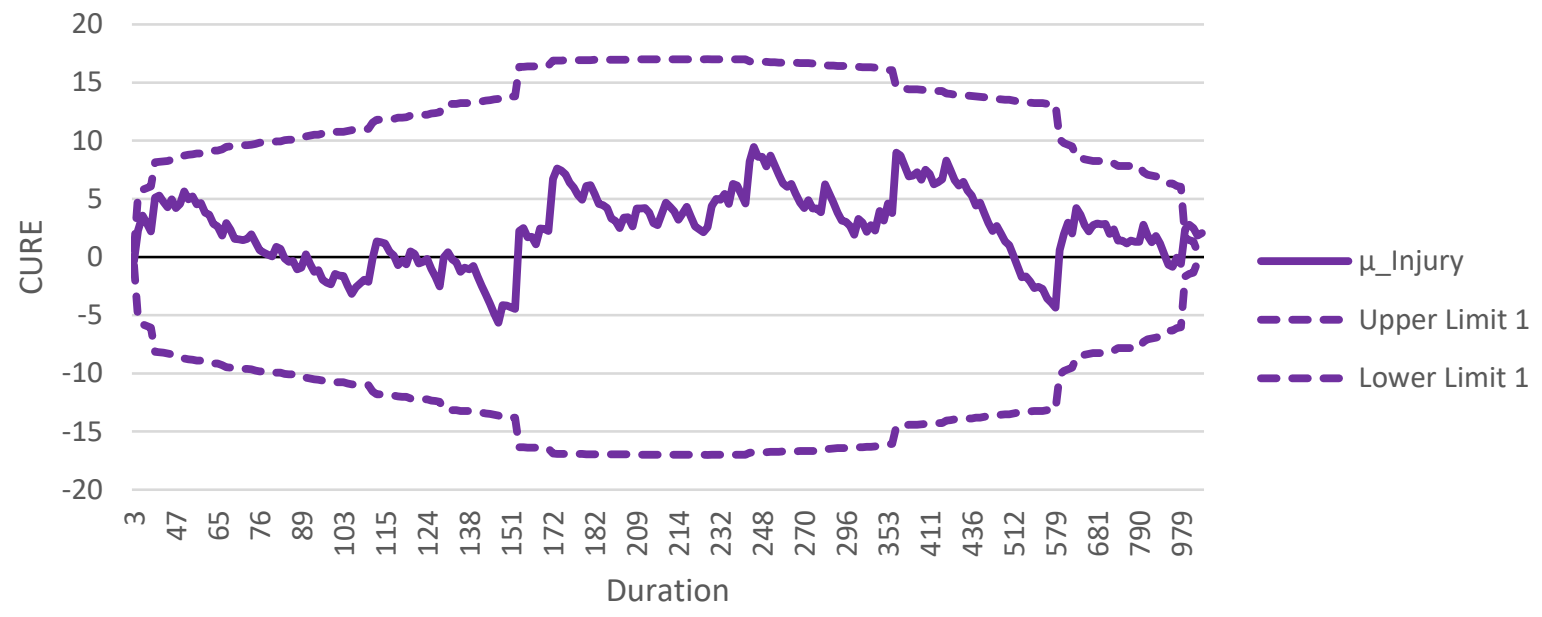

Figure 5.5. CURE plot for "duration" for fatal/injury work zone crashes.

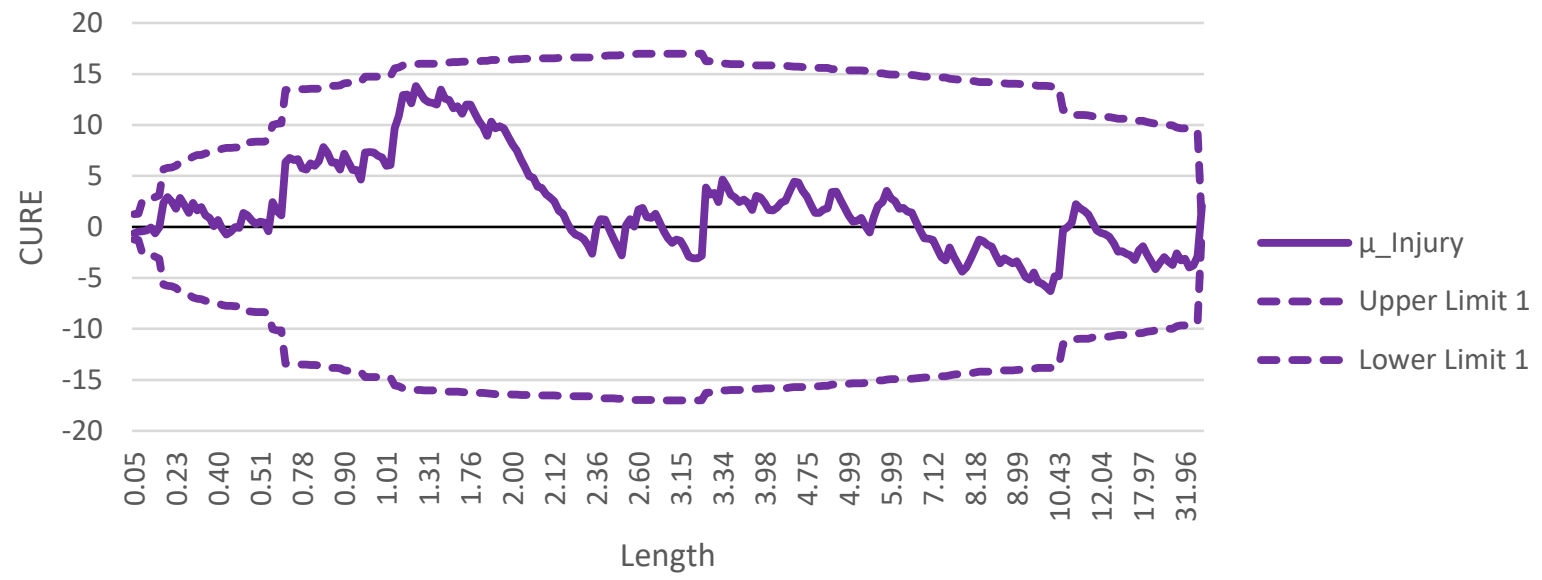

Figure 5.6. CURE plot for "length" for fatal/injury work zone crashes. 


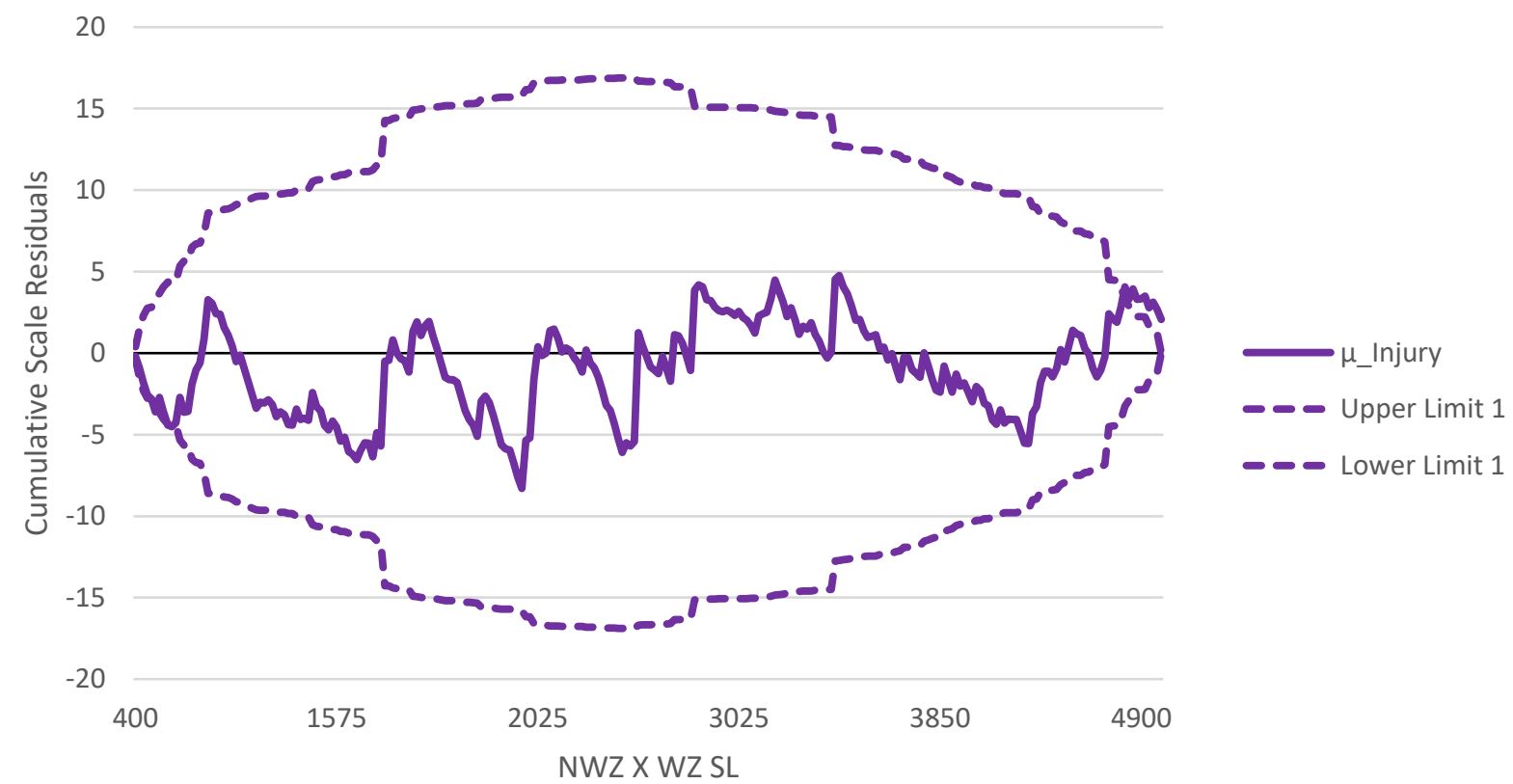

Figure 5.7. CURE plot for NWZ SL $\times$ WZ SL for fatal/injury work zone crashes.

\subsubsection{Goodness-of-Fit Test}

To compare the total and fatal/injury work zone crash prediction models in terms of overall goodness of fit to the calibrated data, the following assessment measures were used (Srinivasan \& Bauer, 2013; Garber \& Rivera, 2010): the overdispersion parameter, Pearson chi-square/degrees of freedom, Akaike's Information Criterion (AIC), and Bayesian Information Criterion (BIC) (Table 5.3). To test the transferability of the calibrated SPFs to the validation data, the mean absolute deviation (MAD), the mean predicted bias (MPB), the mean absolute scaled deviation (MASD), the Pearson product moment correlation ( $r$ ), and the Freeman-Tukey R-squared measures were used (Table 5.3).

Analysis of the results in Table 5.3 indicate that total work zone crash Model 3 is the preferred model, as compared to Model 1 and Model 2 for the following reasons.

Based on Calibration Data-Total Work Zone Crashes:

- The goodness-of-fit statistics indicate that in terms of the overdispersion parameter, Model 3 is preferred over Models 1 and 2. It has the least overdispersion parameter of 0.596 for the calibration data. A lower overdispersion parameter means smaller variance and consequently lower standard error.

- The Pearson chi-square/degrees of freedom for Model 3 is closer to one, showing a better fit.

- The Pearson product moment correlation coefficient for Model 3 on calibration is 0.535, which is the highest of all the models, indicating higher linear association between observed and predicted data. 
- The smaller AIC and BIC values for Model 3 also confirm the finding that it is superior to Model 1 and Model 2. Low AIC and BIC indicates a lower degree of information lost by the model (or less unexplained variation in the dependent variable and exposure variables) and indicate better in-sample fit.

Table 5.3. Goodness-of-Fit Statistics for Calibration Data and Validation Data for Total and Fatal/Injury Work Zone Crash Models

\begin{tabular}{|c|c|c|c|c|c|}
\hline \multirow{2}{*}{ Goodness of Fit for Calibration Data } & \multicolumn{3}{|c|}{ Total Work Zone Crash Models } & \multirow{2}{*}{$\begin{array}{l}\text { Fatal/Injury Work } \\
\text { Zone Crash Model }\end{array}$} & \multirow{2}{*}{$\begin{array}{l}\text { Desirable } \\
\text { Condition }\end{array}$} \\
\hline & Model 1 & Model 2 & Model 3 & & \\
\hline No. of Sites & 256 & 256 & 256 & 256 & \\
\hline Overdispersion & 0.768 & 0.663 & 0.596 & 0.880 & Lower value \\
\hline Pearson chi-square/degrees of freedom & 2.125 & 1.601 & 1.405 & 1.153 & Close to 1.0 \\
\hline Pearson Product Moment Correlation ( $r$ ) & 0.4182 & 0.4281 & 0.5345 & 0.495 & Higher value \\
\hline Akaike's Information Criterion (AIC) & 1532.816 & 1497.073 & 1478.678 & 905.722 & Lower value \\
\hline Bayesian Information Criterion (BIC) & 1546.997 & 1514.799 & 1499.949 & 923.448 & Lower value \\
\hline \multirow{2}{*}{ Goodness of Fit for Validation Data } & \multicolumn{3}{|c|}{ Total Work Zone Crash Models } & Fatal/Injury Work & Desirable \\
\hline & Model 1 & Model 2 & Model 3 & Zone Crash Model & Condition \\
\hline No of Sites & 128 & 128 & 128 & 128 & \\
\hline Mean Absolute Deviation (MAD) & 17.016 & 16.504 & 16.211 & 3.44 & Lower value \\
\hline Mean Prediction Bias (MPB) & 10.303 & 10.849 & 10.116 & 1.72 & Lower value \\
\hline Mean Absolute Scaled Deviation (MASD) & 1.35 & 1.39 & 1.24 & 1.03 & Lower value \\
\hline Pearson Product Moment Correlation ( $r$ ) & 0.45 & 0.46 & 0.61 & 0.543 & Higher value \\
\hline Freeman-Tukey $\mathrm{R}^{2}$ & 0.23 & 0.26 & 0.35 & 0.26 & Higher value \\
\hline
\end{tabular}

Based on Validation Data-For Total Work Zone Crashes:

- From the validation data, Model 3 had the lowest average magnitude of variability of prediction (i.e., mean absolute deviation-MAD of 16.21 and mean prediction bias MPB of 10.12).

- Model 3 had the highest $r$ value of 0.61 , indicating better external validation.

For the fatal/injury work zone model, the overdispersion parameter for the calibration data was found to be 0.88 . Also, the Pearson chi-square/degrees of freedom for the model is 1.153 (close to one), showing a good fit. The Pearson product moment correlation ( $r$ ) for the calibration model was 0.54 , which is higher than that of the calibration data of 0.26 . The low values of MAD, MPB, and MASD of 3.44,1.72, and 1.03, respectively, confirm a good fit.

\subsubsection{Comparison of Coefficients-Calibration versus Validation Data Sets}

In an ideal scenario, the variables found in the calibrated SPFs would be confirmed as statistically significant variables using the validation data, and the model coefficients would perfectly match with 
the calibrated model coefficients. Tables 5.1 and 5.2 show the parameter estimates obtained from calibration and validation datasets for the total and fatal/injury work zone crash models, respectively.

All variables from the calibrated SPFs were also found to be statistically significant in the validation dataset. However, the statistical significance of all variable coefficients in the validation dataset was best for total work zone crash Model 3 (P-value $<0.001)$. The variable coefficients, as expected, were not exactly the same because of differences in the calibration and validation datasets. A direct comparison of variable coefficient ratio between the calibrated SPFs and that from the validation data for the models is presented in Table 5.4 for total and fatal/injury work zone crashes.

Table 5.4. Variable Coefficient Ratios between the Calibration and Validation Models

\begin{tabular}{|c|c|c|c|c|}
\hline \multirow{3}{*}{ Parameter } & \multicolumn{4}{|c|}{ Coefficient Ratio } \\
\hline & \multicolumn{3}{|c|}{ Total Work Zone Crash Models } & \multirow{2}{*}{$\begin{array}{c}\text { Fatal/Injury } \\
\text { Work Zone } \\
\text { Crash } \\
\text { Model }\end{array}$} \\
\hline & Model 1 & Model 2 & Model 3 & \\
\hline$\alpha$ (Intercept Coefficient) & 0.5 & 0.775 & 0.807 & 0.417 \\
\hline Duration Coefficient & 0.612 & 0.666 & 0.672 & 0.515 \\
\hline Length Coefficient & 1.11 & 0.838 & 0.971 & 0.910 \\
\hline AADT Coefficient & NA & 0.987 & 1.040 & NA \\
\hline NWZ×WZ SL Coefficient & NA & NA & 0.795 & 0.733 \\
\hline
\end{tabular}

NA $=$ Not Applicable

The variable coefficient ratios for the total work zone crash Model 3 are larger and closer to the value of 1.0, indicating a close agreement between the validation and calibration coefficients for Model 3.

For the fatal/injury work zone crash model, the variable coefficient ratio of 0.91 and 0.733 shows close agreement between the coefficient values for length and NWZ×WZ SL, respectively because they are closer to the value of 1.0. The duration coefficient and intercept coefficient ratio of 0.515 and 0.417 , respectively, are not as close to 1.0 and thus do not indicate as close of an agreement.

\subsubsection{Recommended SPFs and Analysis of Pooled Data Set $(n=384)$}

The results of individual variable coefficient comparison, goodness-of-fit statistics, and CURE plot analysis indicated that total work zone crash Model 3 is the best model of the three considered in this study. However, the comparatively large difference in the coefficient for the variable work zone "Duration" from the calibration to the validation datasets suggests that the sampling of the calibration data was not robust enough to represent all work zone duration conditions. To further evaluate the robustness of Model 3, the entire data set of 384 work zone sites (i.e., the pooled dataset, $n=384$ ) was used to re-estimate the predictor variable coefficients. Table 5.5 shows the variable coefficients for Model 3 using the pooled data set. Similarly, modeling for fatal/injury work zone crashes using the pooled data set was conducted, and the results are also shown in Table 5.5. 
Table 5.5. Variable Coefficients for Recommended SPFs-Pooled Data Set $(n=384)$

\begin{tabular}{|c|c|c|c|c|c|c|}
\hline \multirow[b]{2}{*}{$\begin{array}{c}\text { Enhanced } \\
\text { Models }\end{array}$} & \multicolumn{5}{|c|}{ Regression Coefficients } & \multirow[b]{2}{*}{$\begin{array}{c}\text { Overdispersion } \\
\text { Parameter, k } \\
\text { (St. Error) }\end{array}$} \\
\hline & $\begin{array}{l}\text { Intercept } \\
\quad(\alpha) \\
\text { (St. Error) } \\
\text { (P-Value) }\end{array}$ & $\begin{array}{l}\text { Duration } \\
\text { Coefficient } \\
\text { (St. Error) } \\
\text { (P-Value) }\end{array}$ & $\begin{array}{c}\text { Length } \\
\text { Coefficient } \\
\text { (St. Error) } \\
\text { (P-Value) }\end{array}$ & $\begin{array}{c}\text { AADT } \\
\text { Coefficient } \\
\text { (St. Error) } \\
\text { (P-Value) }\end{array}$ & $\begin{array}{c}\text { NWZ×WZ SL } \\
\text { Coefficient } \\
\text { (St. Error) } \\
\text { (P-Value) }\end{array}$ & \\
\hline $\begin{array}{c}\text { Total WZ } \\
\text { Crashes } \\
\text { Model } 3\end{array}$ & $\begin{array}{c}-7.049 \\
(0.6982) \\
(<0.001)\end{array}$ & $\begin{array}{c}0.904 \\
(0.0588) \\
(<0.001)\end{array}$ & $\begin{array}{c}0.317 \\
(0.0436) \\
(<0.001)\end{array}$ & $\begin{array}{c}0.486 \\
(0.0643) \\
(<0.001)\end{array}$ & $\begin{array}{c}-0.0004 \\
(0.0001) \\
(<0.001)\end{array}$ & $\begin{array}{c}0.739 \\
(0.058)\end{array}$ \\
\hline $\begin{array}{c}\text { Fata/Injury } \\
\text { Model }\end{array}$ & $\begin{array}{c}-2.872 \\
(0.5306) \\
(<0.001)\end{array}$ & $\begin{array}{c}0.812 \\
(0.0822) \\
(<0.001)\end{array}$ & $\begin{array}{c}0.323 \\
(0.0658) \\
(<0.001)\end{array}$ & NA & $\begin{array}{c}-0.0005 \\
(0.0001) \\
(<0.0001)\end{array}$ & $\begin{array}{c}1.105 \\
(0.1258)\end{array}$ \\
\hline
\end{tabular}

NA $=$ Not Available

The recommended SPF models for predicting work zone crashes and injuries on IDOT state routes and freeways are as follows in Equation 7 and Equation 8:

$$
\begin{aligned}
& \mu_{\text {Total }}=e^{-7.049} \times D^{0.904} \times L^{0.317} \times A A D T^{0.486} \times e^{-0.0004(N W Z S L \times W Z S L)} \\
& \mu_{\text {Fatal/Injury }}=e^{-2.872} \times D^{0.812} \times L^{0.323} \times e^{-0.0005(N W Z S L \times W Z S L)}
\end{aligned}
$$

The standard error of the coefficients helps measure the quality of an SPF and represents the ability of an SPF to predict crashes accurately. A small standard error indicates that the SPF predicts crashes accurately. As shown in Table 5.5, the standard errors are small, with values ranging from 0.0001 to 0.6982. The P-values are also very small < 0.001, indicating a 99.9\% level of confidence (LOC) for the coefficients.

The overdispersion parameters ( $\mathrm{k}$ ) were derived from the negative binomial modeling process. Traffic crashes are typically assumed to follow a Poisson distribution, where the mean and variance are equal. If the mean and variance of the crashes are not equal, then the negative binomial model is used to account for this overdispersion. The overdispersion parameters were 0.739 for the total work zone crash model and 1.105 for the fatal/injury work zone crash model.

The estimated parameters for total and fatal/injury work zone crashes are for the logarithmic transformation of the variables work zone duration, length, and AADT, respectively. As such, the estimated log-transformed model parameters directly indicate the elasticity of the corresponding independent variable with respect to the dependent variable. From the final total work zone crash model results, crashes were found to increase at an average of $0.90 \%$ for every $1 \%$ increase in work zone duration. For the effect of work zone length, crashes would increase by an average of $0.32 \%$ for every $1 \%$ increase in work zone length. Similarly, a $1 \%$ increase in AADT leads to an increase of $0.49 \%$ in the number of total work zone crashes. AADTs are typically higher during non-work-zone conditions as compared to work zone conditions. Hence, the increase in crashes predicted by AADT criterion is likely and underestimate. 
Although the SPFs include the variable NWZ SL x WZ SL, it is expected that IDOT's policy for setting work zone speed limits will be used. The SPFs are not intended to be used to recommend other values of work zone speed limit. This product may be more reflective of functional classification and type of work, rather than the effect of work zone speed limit and safety of the work zones. Note that Chicago suburban projects on arterials are a prevalent part of the data set. This product should not be adjusted. It must be based on IDOT policy.

The smaller the product value of work zone speed limit and non-work-zone speed limit, the higher the predicted work zone crashes. To illustrate this concept, if the following variables are held constant for $W Z$ length $=5$ miles, $W Z$ duration $=100$ days, and ADT $=50,000$ vpd, the expected total WZ crashes per duration (per Equation 8) for three typical NWZ x WZ SL combinations are shown in Table 5.6.

Table 5.6 Effect of NWZ x WZ SL Product on Total Work Zone Crashes

\begin{tabular}{|l|l|l|}
\hline NWZ SP/ WZ SL Combination & Product of NWZ x WZ SL & $\begin{array}{l}\text { Predicted Total WZ Crashes per } \\
\text { WZ Duration }\end{array}$ \\
\hline $\begin{array}{l}45 \mathrm{mph} / 45 \mathrm{mph} \\
\text { An arterial without a WZ speed limit reduction }\end{array}$ & $2,025 \mathrm{mph}^{2}$ & 7.95 \\
\hline $\begin{array}{l}55 \mathrm{mph} / 45 \mathrm{mph} \\
\text { Highway with } 10 \mathrm{mph} \text { WZ speed limit reduction }\end{array}$ & $2,475 \mathrm{mph}^{2}$ & 6.64 \\
\hline $\begin{array}{l}70 \mathrm{mph} / 55 \mathrm{mph} \\
\text { Freeway with } 15 \mathrm{mph} \text { WZ speed limit reduction }\end{array}$ & $3,850 \mathrm{mph}^{2}$ & 3.83 \\
\hline
\end{tabular}

Thus, according to the work zone crash predictions with all other variables held constant, the higher the product of NWZ x WZ SL, the lower the work zone crashes. Using work zone speed reductions per IDOT policy, this also shows that the predicted number of work zone crashes are lower on freeways than on arterials.

From the final fatal/injury work zone crash model results, fatal/injury work zone crashes were found to increase at an average of $0.81 \%$ for every $1 \%$ increase in work zone duration and at an average of $0.32 \%$ for every $1 \%$ increase in work zone length. Non-work-zone and work zone speed limits had a similar effect on fatal/injury work zone crashes as total work zone crashes. Fatal/injury crashes tend to increase as the work zone speed limit decreases.

\subsubsection{Comparison of Observed and Predicted Work Zone Crashes}

Statistical analysis was conducted using the concocted chi-square tests $\left(\chi^{2} c\right)$ at 95\% LOC and significance level, $\alpha=0.05$. The $\chi^{2}$ c is considered more precise for the Poisson and negative binomial distribution (FHWA, 1998).

The null and alternative hypotheses are as follows:

$H_{o}$ : Work zone crashes observed and predicted (according to the SPF) have the same mean.

$H_{a}$ : Work zone crashes observed have a smaller or larger mean than the predicted mean.

The hypothesis test consists of computing a sample statistic calculated from the total data compared with a critical chi-square statistic (Equation 9). 


$$
\chi_{c}^{2}=\sum_{i=1}^{N} \frac{\left(y_{i}-\widehat{y}_{l}\right)^{2}}{\widehat{y}_{l}+k \widehat{y}_{l}^{2}}
$$

where

$$
\begin{aligned}
& \mathrm{y}_{\mathrm{i}}=\text { observed work zone crashes at site number } \mathrm{i} \\
& \widehat{y}_{l}=\text { predicted work zone crashes at site number } \mathrm{i} \text { (using the SPF) } \\
& \mathrm{k}=\text { overdispersion parameter of the model } \\
& \mathrm{N}=\text { sample size to which the model is applied }
\end{aligned}
$$

The $\chi^{2}$ c test was performed using the total work zone crash model (Model 3) and the fatal/injury work zone crash model with coefficients based on all 384 work zone sites. The test results show a good fit for both the total and fatal/injury work zone crash prediction models with $n=384$ at a 95\% LOC.

Because the calculated chi-square values (428.4 and 263.4 for the total and fatal/injury work zone crash models, respectively) are less than the critical value (429.6), the null hypothesis is accepted for both the total and fatal/injury work zone models. This indicates that the total and fatal/injury work zone crashes observed and predicted (according to the SPFs) have the same mean at a 95\% LOC and that the SPF models are validated and good predictors of work zone traffic crashes.

\subsubsection{Relative Impact of Parameters in SPF Regression Equations-Monte Carlo}

The two SPF models developed in this study, as presented in section 5.3.5, represent an important advancement with respect to predicting the number of work zone crashes under known work zone site-specific conditions. There is value in analyzing the relative contribution of each regression coefficient (for each SPF model) on the number of cashes. Thus, a Monte Carlo simulation was performed to analyze the relative contribution/strength of the parameters used to predict crashes per the two SPF regression equations developed.

Condition numbers (CNs) can be deployed to achieve this objective. The $\mathrm{CN}$ analysis method is a sensitivity analysis technique to evaluate the impact of the regression coefficients on the dependent variable. The $\mathrm{CN}$ analysis begins with the regression equation or the SPF model. For each regression coefficient in a particular regression equation, the $\mathrm{CN}$ is developed using the general formula: $\mathrm{CN}_{\beta \mathrm{x}}=$ $\beta_{x}{ }^{*} f^{\prime}(x) / f(x)$, where $f^{\prime}(x)$ is the partial derivative.

As an example, the SPF model given by Equation 7 is selected.

$$
\mu_{\text {Total }}=e^{\alpha} \times D^{\beta_{1}} \times L^{\beta_{2}} \times A A D T^{\beta_{3}} \times e^{\beta_{4}(N W Z S L \times W Z S L)}
$$

Equation 7 has four regression coefficients or parameters $\left(\beta_{1}, \beta_{2}, \beta_{3}\right.$, and $\left.\beta_{4}\right)$ directly associated with four independent variables (duration, length, AADT, and NWZ SL $\times$ WZ SL), which are used to predict the average annual expected total work zone crashes. The fifth parameter, $\alpha$, yields a value of 1.0 for the CN (Equation 10).

$$
\mathrm{CN}_{\alpha}=\left(\frac{\alpha}{u_{T O T A L}}\right)\left(\frac{\partial \mu_{T O T A L}}{\partial \alpha}\right)=1.0
$$


No further analysis is required for $\alpha$ because this value (i.e., 1.000) remains a constant for all values of the regression coefficient. Essentially, the $\mathrm{CN}$ value for $\alpha$ indicates that any change in the value of $\alpha$ will impact the SPF model significantly. It is more important to evaluate the impact of the coefficients $\beta_{1}, \beta_{2}, \beta_{3}$ and $\beta_{4}$, because they are linked directly to variables that impact the number of crashes. The results from this $\mathrm{CN}$ analysis for these coefficients can yield important insights into the relative impact on the number of work zone crashes predicted by the SPF. Condition numbers for the four parameters $\left(\beta_{1}, \beta_{2}, \beta_{3}\right.$, and $\left.\beta_{4}\right)$ for the Equation 7 SPF are defined in Equations 11-14:

$$
\begin{aligned}
& \mathrm{CN}_{\beta 1}=\left(\frac{\beta_{1}}{\mu_{T O T A L}}\right)\left(\frac{\partial \mu_{T O T A L}}{\partial \beta_{1}}\right)=\left(\beta_{1}\right)\left(\mathrm{x}_{1}\right) \\
& \mathrm{CN}_{\beta 2}=\left(\frac{\beta_{2}}{\mu_{T O T A L}}\right)\left(\frac{\partial \mu_{T O T A L}}{\partial \beta_{2}}\right)=\left(\beta_{2}\right)\left(\mathbf{x}_{2}\right) \\
& \mathrm{CN}_{\beta 3}=\left(\frac{\beta_{3}}{\mu_{T O T A L}}\right)\left(\frac{\partial \mu_{T O T A L}}{\partial \beta_{3}}\right)=\left(\beta_{3}\right)\left(\mathbf{x}_{3}\right) \\
& \mathrm{CN}_{\beta 4}=\left(\frac{\beta_{4}}{\mu_{T O T A L}}\right)\left(\frac{\partial \mu_{T O T A L}}{\partial \beta_{4}}\right)=\left(\beta_{4}\right)\left(\mathbf{x}_{4}\right)
\end{aligned}
$$

The Monte Carlo simulation technique was then applied to analyze the relative contribution of the four variables in Equation 7 on the total number of work zone crashes at a site. To conduct the CN analysis, the average values of the variables' duration, length, AADT, and NWZ SL $\times$ WZ SL were estimated using sample data from the sites included in the model development.

First, an analysis of one randomly selected site was conducted, and the Monte Carlo simulation was performed 1,000 times to estimate the relative impact and contribution of each regression coefficient (e.g., $\beta_{1} \beta_{2}, \beta_{3}$, and $\beta_{4}$ for Equation 7) on the total number of work zone crashes. Once the CNs were obtained from the Monte Carlo simulation (for 1,000 runs per site), the average $\mathrm{CN}$ for each variable was calculated and expressed as a percentage. The resulting CNs from the Monte Carlo analysis, for a single site, are shown in Table 5.6, depicting the maximum, minimum, and average CNs.

The Monte Carlo simulation indicated that the range of $\mathrm{CN}$ values for 1,000 trials for one site for $\beta_{1}$ (work zone duration), for example, was $6.4 \times 10^{-1}$ to $8.6 \times 10^{-1}$, with an average of $7.5 \times 10^{-1}$. The remaining maximum, minimum, and average CNs for the remaining variables for Equations 7 and 8 , based on one site, are shown in Table 5.6. 
Table 5.6. Minimum, Maximum, and Average Condition Numbers for a Single Site

\begin{tabular}{|c|c|c|c|}
\hline & \multicolumn{3}{|c|}{ Condition Numbers (CN) } \\
\hline & Maximum & Minimum & Average \\
\hline \multicolumn{4}{|c|}{$\begin{array}{l}\text { Equation for Predicting Total Work Zone Crashes } \\
e^{\alpha} \times D^{\beta_{1}} \times L^{\beta_{2}} \times A A D T^{\beta_{3}} \times e^{\beta_{4}(N W Z S L \times W Z S L)}\end{array}$} \\
\hline$\beta_{1}$ Duration of $W Z$ & $8.6 \times 10^{-1}$ & $6.4 \times 10^{-1}$ & $7.5 \times 10^{-1}$ \\
\hline$\beta_{2}$ Length of $W Z$ & $1.2 \times 10^{-1}$ & $6.5 \times 10^{-2}$ & $9.6 \times 10^{-2}$ \\
\hline$\beta_{3}$ AADT in WZ & $5.3 \times 10^{-1}$ & $3.4 \times 10^{-1}$ & $4.4 \times 10^{-1}$ \\
\hline$\beta_{4} \mathrm{NWZ} S L \times W Z S L$ & $-8.4 \times 10^{-1}$ & $-18.2 \times 10^{-1}$ & $-13.7 \times 10^{-1}$ \\
\hline \multicolumn{4}{|c|}{$\begin{array}{l}\text { Equation for Predicting Total Work Zone Fatal/Injury Crashes } \\
\text { atal/Iniury }=e^{\alpha} \times D^{\beta_{1}} \times L^{\beta_{2}} \times e^{\beta_{3}(N W Z S L \times W Z S L)}\end{array}$} \\
\hline$\beta_{1}$ Duration of WZ & $8.1 \times 10^{-1}$ & $5.4 \times 10^{-1}$ & $6.8 \times 10^{-1}$ \\
\hline$\beta_{2}$ Length of $W Z$ & $1.4 \times 10^{-1}$ & $6.1 \times 10^{-2}$ & $1.03 \times 10^{-1}$ \\
\hline$\beta_{3} N W Z S L \times W Z S L$ & $-12.6 \times 10^{-1}$ & $-25.7 \times 10^{-1}$ & $-19.2 \times 10^{-1}$ \\
\hline
\end{tabular}

While the results for a single site are interesting, it is more important to analyze the data trends in a larger data set of work zone sites. The first task was to estimate the required number of samples (work zone sites) to analyze as a part of the Monte Carlo analysis. To estimate the number of samples (out of the 384), Equation 15 was used:

$$
n=\left(\frac{Z_{\alpha / 2} \times s}{e}\right)^{2}
$$

where:

$\mathrm{n}=$ Estimated sample size for number of sites at the desired precision and LOC

$\mathrm{s}=$ Preliminary estimate of the population standard deviation for the relative percent impact

$Z_{\alpha / 2}=$ Two-tailed value of the standardized normal deviate associated with the desired LOC (at a $95 \%$ LOC, $\left.Z_{\alpha / 2}=1.96\right)$

$\mathrm{e}=$ Maximum allowable error for the estimate (assumed to be $3 \%$ )

For this study, the maximum percent error " $\mathrm{e}$ " was assumed to be $3 \%$, and a preliminary estimate of standard deviation was conservatively estimated to be $11.50 \%$. The largest standard deviation value among all variables was used to calculate the required sample size, in order to be conservative. Based on these values, a sample size of 56 was needed to conduct the Monte Carlo simulation.

The Monte Carlo simulation results from the 56 sites were further analyzed to determine the relative impact of each variable on predicting the number of work zone total crashes and injury crashes for each SPF equation developed in this study. Each line in Table 5.7 is a summary of 56,000 Monte Carlo simulations. The relative impact in percent and the $95 \%$ confidence interval of the relative impact of each variable $\left(\beta_{1} \beta_{2}, \beta_{3}\right.$, etc.) was obtained. 
Table 5.7. Relative Impact of SPF Variables for 56 Sites

\begin{tabular}{|c|c|c|c|c|c|c|}
\hline & \multirow{2}{*}{$\begin{array}{l}\text { Average } \\
\text { CN }\end{array}$} & \multirow{2}{*}{$\begin{array}{l}\text { Average } \\
\text { Relative } \\
\text { Impact }\end{array}$} & \multirow{2}{*}{$\begin{array}{l}\text { Standard } \\
\text { Deviation }\end{array}$} & \multicolumn{3}{|c|}{ 95\% Confidence Interval } \\
\hline & & & & $\pm 1.96 \mathrm{~s} / \sqrt{\mathrm{n}}$ & $\begin{array}{l}\text { Lower } \\
\text { Limit }\end{array}$ & $\begin{array}{l}\text { Upper } \\
\text { Limit }\end{array}$ \\
\hline \multicolumn{7}{|c|}{$\begin{array}{r}\text { Equation for Predicting Total Work Zone Crashes } \\
\mu_{\text {Total }}=e^{\alpha} \times D^{\beta_{1}} \times L^{\beta_{2}} \times A A D T^{\beta_{3}} \times e^{\beta_{4}(N W Z S L \times W Z S L)}\end{array}$} \\
\hline$\beta_{1}$ Duration of $\mathrm{WZ}$ & 0.64035 & $31.1 \%$ & $7.1 \%$ & $\pm 1.9 \%$ & $29.2 \%$ & $33.0 \%$ \\
\hline$\beta_{2}$ Length of $W Z$ & 0.08075 & $3.8 \%$ & $2.6 \%$ & $\pm 0.7 \%$ & $3.1 \%$ & $4.5 \%$ \\
\hline$\beta_{3}$ AADT in WZ & 0.42964 & $20.7 \%$ & $4.26 \%$ & $\pm 1.1 \%$ & $19.6 \%$ & $21.8 \%$ \\
\hline$\beta_{4} \mathrm{NWZ}$ speed limit $\times$ WZ speed limit & -0.99893 & $44.4 \%$ & $11.4 \%$ & $\pm 3.0 \%$ & $41.4 \%$ & $47.4 \%$ \\
\hline \multicolumn{7}{|c|}{$\begin{array}{l}\text { Equation for Predicting Total Work Zone Fatal/Injury Crashes } \\
\mu_{\text {Fatal/Injury }}=e^{\alpha} \times D^{\beta_{1}} \times L^{\beta_{2}} \times e^{\beta_{3}(N W Z S L \times W Z S L)}\end{array}$} \\
\hline$\beta_{1}$ Duration of $\mathrm{WZ}$ & 0.55910 & $30.5 \%$ & $10.4 \%$ & $\pm 2.7 \%$ & $27.8 \%$ & $33.2 \%$ \\
\hline$\beta_{2}$ Length of WZ & 0.08057 & $4.5 \%$ & $3.3 \%$ & $\pm 0.9 \%$ & $3.6 \%$ & $5.4 \%$ \\
\hline$\beta_{3} N W Z$ speed limit $\times W Z$ speed limit & -1.39173 & $65.0 \%$ & $11.5 \%$ & $\pm 3.0 \%$ & $62.0 \%$ & $68.0 \%$ \\
\hline
\end{tabular}

For the total work zone crash SPF, the relative impact (based on data from 56 sites) for $\beta_{1}$ is $31.1 \%$, indicating that the duration of work zone is an important factor in determining the total number of work zone crashes. The length of the work zone $\left(\beta_{2}\right)$ is important but not as impactful as the duration of the work zone in predicting the total number of crashes, as its relative impact is $3.8 \%$. The relative impact of AADT $\left(\beta_{3}\right)$ is $20.7 \%$, which is logical because higher traffic volumes are likely to result in more crashes. Finally, the new parameter from this research, which is the product of the NWZ and WZ speed limits, appears to have the greatest impact on the prediction of total WZ crashes, with a relative impact of $44.4 \%$.

For the work zone fatal/injury crash SPF, the results of 56,000 Monte Carlo simulations for the variables $\left(\beta_{1}, \beta_{2}, \beta_{3}\right)$ are also presented in Table 5.7 . The duration of the work zone $\left(\beta_{1}\right)$ is again indicated to be an important parameter, with a $30.5 \%$ relative impact on the total number of work zone fatal/injury crashes. As in the case of the total work zone crash analyses, the work zone length had a relative smaller impact $(4.5 \%)$ than the other two variables. Finally, the product of the nonwork-zone (NWZ) and work zone (WZ) speed limits had the greatest relative impact (65\%) on work zone fatal/injury crashes.

In addition to the average relative impact of each parameter for the two parametric equations developed in this research, the $95 \%$ confidence intervals were also estimated for each variable and SPF. For example, in Equation 7 to predict total WZ crashes, $\beta_{1}$ (duration of WZ) has a relative impact between $29.2 \%$ and $33.0 \%$ (average of $31.1 \%$ ). Similarly, the confidence intervals for the other variables in both equations were estimated and are presented in Table 5.7. These data indicate that the $95 \%$ confidence intervals are narrow, suggesting that the variability in the relative impact for each of the parameters is minimal. This further indicates that the data and data analyses were robust.

The above analyses show the relative impact of the different regression coefficients (e.g., $\alpha, \beta_{1}, \beta_{2}$, $\beta_{3}$, and $\beta_{4}$ ) on the dependent variable (e.g., total number of crashes). This method is not intended as a replacement to develop the appropriate regression equation(s) using standard sensitivity methods 
such as a Bayesian analysis using the negative binomial, Poisson, or other applicable distributions. In fact, these methods are necessary to develop the regression equations, which can then further be analyzed using the $\mathrm{CN}$ analysis presented. 


\section{CHAPTER 6: METHODOLOGY FOR WORK ZONE SAFETY}

As a part of this research, SPFs, an Excel tool, and CMFs were developed to help improve work zone safety. The following sections highlight the recommended SPFs and CMFs developed to predict total and fatal/injury work zone crashes. Illustrations are also provided to show how the SPFs and Excel tool may be applied to practical scenarios where IDOT needs to make decisions about work zone length and expected duration in work zone based on safety considerations on state highways. The approach and methodology developed in this research can also serve as a platform to develop crash predictions and compare alternatives at a regional scale.

\subsection{SAFETY PERFORMANCE FUNCTIONS}

A SPF is an equation used to predict the average number of crashes per unit of time at a location as a function of exposure and other characteristics. SPFs are used to predict crash frequency for a given set of site conditions or to compare the safety performance of a specific site under various conditions. Work zone total crashes (K-fatal; A-, B-, and C-injury crashes; and PDO crashes) and fatal/injury crashes $(K, A, B$, and $C)$ can be predicted using the SPFs shown below.

$$
\begin{gathered}
\mu_{\text {Total }}=e^{-7.049} \times D^{0.904} \times L^{0.317} \times A A D T^{0.486} \times e^{-0.0004(N W Z S L \times W Z S L)} \\
\mu_{\text {Fatal/Injury }}=e^{-2.872} \times D^{0.812} \times L^{0.323} \times e^{-0.0005(N W Z S L \times W Z S L)}
\end{gathered}
$$

where:

$\mathrm{D}=$ Work zone duration, in days

$L=$ Work zone length, in miles

AADT = Annual average daily traffic, in vehicles per day

NWZ SL x WZ SL = Product of non-work-zone and work zone speed limits

$\alpha, \beta_{1}, \beta_{2}, \beta_{3}, \beta_{4}=$ Coefficients for the respective variables

The safety performance can be predicted for alternative scenarios for a given roadway section with a known posted speed limit, AADT, and predetermined work zone speed limit according to IDOT policies. The alternative scenarios considered would have differing work zone lengths and durations.

IDOT's policy on establishing work zone speed limits (March 2011) recommends no speed limit reduction in the case of no lane reduction or apparent hazard on all roadway types and on a multilane road with an existing speed limit below $45 \mathrm{mph}$. The policy further recommends a 10-mph reduction in speed from the existing speed limit for work zones established on a multilane with existing speed of $55 \mathrm{mph}$ or more. In case of workers' presence, the policy recommends speed limit reduction to $45 \mathrm{mph}$ from the existing speed limit of 65 or $60 \mathrm{mph}$ for multilane roads. The reduction in excess of $10 \mathrm{mph}$ below the existing speed limit is recommended by IDOT only in special cases such as narrow pavement lane width, drop-offs, high-traffic volumes, inadequate sight distance, and space requirements (IDOT, 2011). 
The WZ speed limit used in the SPF equation to predict work zone crashes must be input as the speed limit according to IDOT's policy for setting work zone speed limits. The SPFs are not intended to be used to recommend other values of speed limit or work zone speed limit. This product may be more reflective of functional classification and type of work, rather than the effect of work zone speed limit and safety of the work zones. This product should not be adjusted. It must be based on IDOT policy.

\subsubsection{SPF Example for Comparison of Work Zone Alternatives}

The following example illustrates how to apply Illinois SPFs that account for work zone duration and length. Engineers involved in work zone design and maintenance of traffic plans can then make more informed decisions during the work zone design process.

For a maintenance project conducted in a 5-mi highway, the Maintenance of Traffic design team can assess the expected change in crashes for three work zone duration and length scenarios. The three proposed scenarios (Figure 6.1) for consideration include: i) one 5-mi work zone in 60 days, ii) two 2.5-mi work zones with total duration of 90 days (with 45 days per segment and 2 segments), and iii) five 1-mi work zone sections with a total duration of 120 days (with 24 days per segment and 5 segments). Assume the AADT on the freeway is 50,000 vpd and the posted speed limit is $65 \mathrm{mph}$. According to IDOT policy, the work zone speed limit is $55 \mathrm{mph}$.
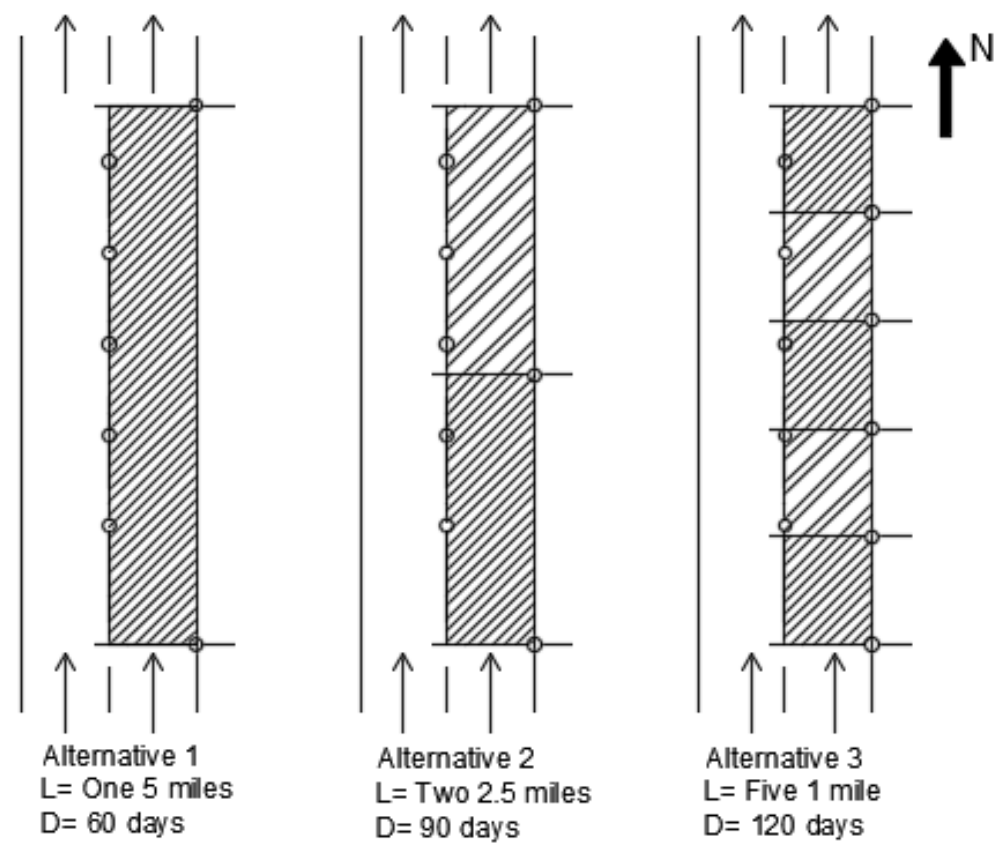

Figure 6.1. Work zone duration and length scenarios for comparison.

Using the SPFs for total and fatal/injury work zone crashes, the predicted crashes would be calculated for each segment and then multiplied by the total number of segments to determine the WZ crashes for the overall project. Sample calculations for total WZ crashes and fatal/injury WZ crashes are as follows for the three alternatives: 


\section{Total Work Zone Crashes (Equation 7)}

Alternative 1 ( $L=5$ miles, $D=60$ days, and 1 segment)

$$
\begin{aligned}
\mu_{\text {Total }} & =e^{-7.049} \times(60 \text { days })^{0.904} \times(5 \text { miles })^{0.317} \times(50,000)^{0.486} \times e^{-0.0004(65 \times 55)} \\
& =2.69 \text { Total work zone crashes per work zone segment duration }
\end{aligned}
$$

There is only one work zone segment in Alternative 1, and the total work zone crashes for the overall project duration (sum of all segments) would be:

$=2.69 \mathrm{WZ}$ crashes per segment $\times 1$ segment $=2.69$ Total WZ crashes for overall project duration

$\therefore$ For Alternative 1: 2.69 Total WZ crashes for overall project duration (for all segments)

Alternative 2 ( $L=2.5$ miles, $D=45$ days, and 2 segments)

$\mu_{\text {Total }}=e^{-7.049} \times(45 \text { days })^{0.904} \times(2.5 \text { miles })^{0.317} \times(50,000)^{0.486} \times e^{-0.0004(65 \times 55)}$

$=1.67$ Total work zone crashes per work zone segment duration

There are two work zone segments in Alternative 2, and the total work zone crashes for the overall project duration (sum of all segments) would be:

$=1.67 \mathrm{WZ}$ crashes per segment $\times 2$ segments $=3.33$ Total WZ crashes for overall project duration

$\therefore$ For Alternative 2: 3.33 Total WZ crashes for overall project duration (for all segments)

Alternative 3 ( $L=1$ mile, $D=24$ days, and 5 segments)

$\mu_{\text {Total }}=e^{-7.049} \times(24 \text { days })^{0.904} \times(1 \text { mile })^{0.317} \times(50,000)^{0.486} \times e^{-0.0004(65 \times 55)}$

$=0.71$ Total work zone crashes per work zone segment duration

There are five work zone segments in Alternative 3, and the total work zone crashes for the overall project duration (sum of all segments) would be:

$=0.71 \mathrm{WZ}$ crashes per segment $\times 5$ segments $=3.53$ Total $\mathrm{WZ}$ crashes for overall project duration

$\therefore$ For Alternative 3: 3.53 Total WZ crashes for overall project duration (for all segments) 


\section{Fatal/Injury Work Zone Crashes (Equation 8)}

Alternative 1 ( $L=5$ miles, $D=60$ days, and 1 segment)

$$
\begin{aligned}
\mu_{\text {Fatal/Injury }} & =e^{-2.872} \times(60 \text { days })^{0.812} \times(5 \text { miles })^{0.323} \times e^{-0.0005(65 \times 55)} \\
& =0.44 \text { Fatal/Injury work zone crashes per work zone segment duration }
\end{aligned}
$$

There is only one work zone segment in Alternative 1, and the fatal/injury work zone crashes for the overall project duration (sum of all segments) would be:

$=0.44 \mathrm{WZ}$ crashes per segment $\times 1$ segment $=0.44$ Fatal/Injury WZ crashes for overall project duration

\section{$\therefore$ For Alternative 1: 0.44 Fatal/Injury WZ crashes for overall project duration (for all segments)}

Alternative 2 ( $L=2.5$ miles, $D=45$ days, and 2 segments)

$$
\begin{aligned}
\mu_{\text {Fatal/Injury }} & =e^{-2.872} \times(45 \text { days })^{0.812} \times(2.5 \text { miles })^{0.323} \times e^{-0.0005(65 \times 55)} \\
& =0.28 \text { Fatal/Injury work zone crashes per work zone segment duration }
\end{aligned}
$$

There are two work zone segments in Alternative 2, and the fatal/injury work zone crashes for the overall project duration (sum of all segments) would be:

$=0.28 \mathrm{WZ}$ crashes per segment $\times 2$ segment $=0.56$ Fatal/Injury WZ crashes for overall project duration

$\therefore$ For Alternative 2: 0.56 Fatal/Injury WZ crashes for overall project duration (for all segments)

Alternative 3 ( $L=1$ mile, $D=24$ days, and 5 segments)

$$
\begin{aligned}
\mu_{\text {Fatal/Injury }} & =e^{-2.872} \times(24 \text { days })^{0.812} \times(1 \text { mile })^{0.323} \times e^{-0.0005(65 \times 55)} \\
& =0.13 \text { Fatal/Injury work zone crashes per work zone segment duration }
\end{aligned}
$$

There are five work zone segments in Alternative 3, and the fatal/injury work zone crashes for the overall project duration (sum of all segments) would be:

$=0.13 \mathrm{WZ}$ crashes per segment $\times 5$ segments $=0.63$ Fatal $/$ Injury WZ crashes for overall project duration

$\therefore$ For Alternative 3: 0.63 Fatal/Injury WZ crashes for overall project duration (for all segments) 
A summary of the results for all three scenarios are shown in Table 6.1.

Table 6.1. Work Zone Crash Predictions Using SPFs for Example Alternatives

\begin{tabular}{|l|c|c|c|}
\hline Work Zone Crash Predictions & $\begin{array}{c}\text { Alternative 1 } \\
(\mathrm{L}=5 \mathrm{mi}, \\
\mathrm{D}=60 \text { days, } \\
1 \text { segment })\end{array}$ & $\begin{array}{c}\text { Alternative 2 } \\
(\mathrm{L}=2.5 \mathrm{mi}, \\
\mathrm{D}=45 \text { days, } \\
2 \text { segments })\end{array}$ & $\begin{array}{c}\text { Alternative 3 } \\
(\mathrm{L}=1 \mathrm{mi}, \\
\mathrm{D}=24 \text { days, } \\
5 \text { segments }\end{array}$ \\
\hline $\begin{array}{l}\text { Predicted total number of work zone crashes per work } \\
\text { zone segment duration }\end{array}$ & 2.69 & 1.67 & 0.71 \\
\hline $\begin{array}{l}\text { Predicted fatal injury work zone crashes per work zone } \\
\text { segment duration }\end{array}$ & 0.44 & 0.28 & 0.13 \\
\hline $\begin{array}{l}\text { Predicted total number of work zone crashes for overall } \\
\text { project duration (for all segments) }\end{array}$ & 2.69 & 3.33 & 3.53 \\
\hline $\begin{array}{l}\text { Predicted fatal/injury work zone crashes for overall } \\
\text { project duration (for all segments) }\end{array}$ & 0.44 & 0.56 & 0.63 \\
\hline
\end{tabular}

The results indicate that Alternative 1, a work zone with one 5-mi length and WZ duration of 60 days, has the lowest overall WZ crashes for total crashes and fatal/injury crashes. Drivers traveling through longer work zones in place over a longer duration may acclimatize themselves to a work zone over time and over longer distances.

\subsection{EXCEL TOOL}

An Excel tool was developed to facilitate the ease of the calculations for the SPFs and assess safety performance of work zones in Illinois. A user can analyze a single work zone, or up to three work zone alternatives at a time. The Excel tool contains:

- A tutorial worksheet that explains the basic components of a work zone and descriptions of the color-coding schemes for data input.

- Yellow-colored cells: input information for a user to manually enter

- Blue-colored cells: input information for a user to enter from a drop-down list

- Green-colored cells: output from the SPF

- Work Zone Safety Performance-Analysis using work zone SPFs. A user would input and receive output for:

- Yellow-colored cells (manually input)

- Route name/number

- Contract number

- Location of road closure (from/to street or miles or other description)

- Type of project (construction, maintenance, utility, other)

- Total number of lanes of roadway

- Number of lanes reduced

- Posted, non-work-zone speed limit

- Work zone speed limit, per IDOT policy

- AADT

- Work zone segment length in miles

- Duration of work zone, in days 
- Blue-colored cells (input from a drop-down list)

- District number

- County name

- Urban or rural

- Functional classification

- Type of road closure

- Green-colored cells (output from the SPF for each alternative for one to three alternatives)

- Predicted total number of work zone crashes per work zone duration

- Predicted fatal/injury work zone crashes per work zone duration

- Predicted total number of work zone crashes per year

- Predicted fatal/injury work zone crashes per year

Screenshots of the Excel tool are included in Appendix D.

\subsection{CRASH MODIFICATION FACTORS}

A CMF is a multiplicative factor used to compute the estimated number of crashes after implementing a given countermeasure at a specific site. "A CMF represents the relative change in estimated average crash frequency due to differences for each specific condition and provides an estimate of the effectiveness of the implementation of a particular countermeasure" (Kolody et al., 2014, p. 2-13).

CMFs are available as a part of this study of Illinois work zones for duration and length for total WZ crashes and fatal/injury WZ crashes. Typically, one would use an SPF to estimate the number of crashes at a site, given traffic volumes, roadway geometry, etc. Then, CMFs would be used to determine the impact on crashes of various safety treatments or alternatives. Because the SPFs developed through this research also contain the variable of work zone duration and length and serve as the basis for the CMFs, using both the SPFs and CMFs together is not recommended.

Thus, it is recommended to use the SPFs to assess work zone total and fatal/injury crashes for different combinations of work zone duration and length. The Excel Tool developed through this research will help facilitate the ease of calculations for WZ total fatal/injury crashes.

To use CMFs, the expected number of crashes under the base condition is required. If the base expected crashes are known or can be estimated, then an analyst may use the CMFs.

If the SPF is used to determine the safety effect of a change in work zone duration from $D_{1}$ to $D_{2}$, then the CMF for a change in duration can be calculated in Equation 16 as:

$$
C M F=\frac{e^{\alpha} \times D_{2} \beta_{1} \times L^{\beta_{2}} \times A A D T^{\beta_{3}} \times e^{\beta_{4} *(N W Z \times W Z S L)}}{e^{\alpha} \times D_{1} \beta_{1} \times L^{\beta_{2}} \times A A D T^{\beta_{3}} \times e^{\beta_{4} *(N W Z \times W Z S L)}}
$$

The equation above can be simplified to: 


$$
C M F=\left(\frac{D_{2}}{D_{1}}\right)^{\beta_{1}}
$$

The CMF is a function of original duration $D_{1}$ and change in duration to $D_{2}$ and variable coefficient $\beta_{1}$. So, for a $1 \%$ increase in work zone duration from the base condition, $\beta_{1} \%$ increase in crashes would occur. The same would apply for determining the safety effect of changing the length of the work zone.

This method was used in the HSM to extract the work zone CMFs from Khattak's model (AASHTO, 2010; Khattak et al., 2002). Equations 18 and 19 below are the two CMFs illustrated in HSM, based on the California data, with a minimum duration of 16 days, minimum length of $0.51 \mathrm{mi}$, WZ duration CMF of 1.11, and WZ length CMF of 0.67 (AASHTO, 2010; Khattak et al., 2002).

$$
\begin{aligned}
& C M F_{\text {Duration for Total } W Z \text { Crashes }}=1.0+\frac{(\% \text { increase in duration from } 16 \text { days } * 1.11)}{100} \\
& C M F_{\text {Length for Total } W Z \text { Crashes }}=1.0+\frac{(\% \text { increase in length from } 0.51 \text { miles } * 0.67)}{100}
\end{aligned}
$$

Equations 18 and 19 from the HSM (AASHTO, 2010; Kolody et al., 2014) were then modified as Equations 20 and 21 for the Illinois study for total WZ crashes, and as Equations 22 and 23 for fatal/injury WZ crashes, for duration and length as shown below.

$$
\begin{aligned}
& C M F_{\text {Duration for Total } W Z \text { Crashes }}=1.0+\frac{(\% \text { increase in duration from } 3 \text { days } * 0.904)}{100} \\
& C M F_{\text {Length for Total } W Z \text { Crashes }}=1.0+\frac{(\% \text { increase in length from 0.1 miles } * 0.317)}{100} \\
& C M F_{\text {Duration for Fatal/Injury } W Z \text { Crashes }}=1.0+\frac{(\% \text { increase in duration from } 3 \text { days } * 0.812)}{100} \\
& C M F_{\text {Length for Fatal/Injury } W Z \text { Crashes }}=1.0+\frac{(\% \text { increase in length from } 0.1 \text { miles } * 0.323)}{100}
\end{aligned}
$$

Table 6.2 shows the comparison of effects of work zone duration and length found from this study in Illinois with that from the HSM and other states.

Table 6.2. Comparison of Effects of Work Zone Duration and Length from Studies

\begin{tabular}{ccccccc}
\hline \multirow{2}{*}{\begin{tabular}{c} 
Variable \\
\cline { 2 - 8 }
\end{tabular}} & \multicolumn{1}{c}{ California } & Missouri & Indiana & Michigan & \multicolumn{2}{c}{ Illinois } \\
\cline { 2 - 8 } & & \multicolumn{2}{c}{ Total WZ CMF } & & $\begin{array}{c}\text { Total WZ } \\
\text { CMF }\end{array}$ & $\begin{array}{c}\text { Fatal/Injury } \\
\text { WZ CMF }\end{array}$ \\
\hline Duration (Days) & 1.11 & 1.01 & 1.00 & 0.90 & 0.904 & 0.812 \\
\hline Length (Miles) & 0.67 & 0.58 & 0.80 & 0.82 & 0.317 & 0.323 \\
\hline
\end{tabular}


Direct comparison shows that the difference between the magnitude of HSM estimate and Illinois estimate for duration was 0.206 and 0.353 for length. This difference could be due to the minimum length and duration considered in the data samples. The 384 work zone sites used for calibrating the Illinois estimate included a work zone duration minimum of three days and a work zone length minimum of $0.1 \mathrm{mi}$, while the base condition for the HSM of work zone duration was 16 days and work zone length was $0.51 \mathrm{mi}$. "The Michigan work zones included a number of projects with shorter durations (a minimum of 3 days) than those in the California and Missouri studies, both of which established minimum project durations of 15 to 16 days. The Indiana study compared per-month averages for longer-duration work zones" (Rista et al., 2017, p. 91). 


\section{CHAPTER 7: WORK ZONE DATA NEEDS}

At the inception of this research project, IDOT expressed concern with its work zone data quality and thus added an objective to the research project to perform a needs assessment and recommend strategies for improving work zone data in Illinois. Lack of quality work zone data is an issue for many DOTs and transportation agencies in the US. FHWA states that "currently, work zone activity data (WZAD) collection is ad-hoc and limited in scope to address a specific need within agency workflows. Accordingly, it is not easily shared outside of proprietary or agency-specific systems and is difficult to use for purposes other than which it was originally designed" (FHWA, 2018, p. 1).

There is a current nationwide need to standardize work zone information so that it can be shared across jurisdictional boundaries for a variety of applications, including safety, operations, and preparing the highway system for connected and autonomous vehicles.

In response to this need, the FHWA has commissioned the Work Zone Data Initiative (WZDI). The purpose of the WZDI is to "develop a recommended practice for managing WZAD and to create a consistent language, through the development of a data dictionary and supporting implementation documents, for communicating information on work zone activity across jurisdictional and organizational boundaries" (FHWA, 2018, p. 1).

There are various uses of work zone data by many different professionals, some of which include (FHWA, 2018):

- Work zone safety analysis

- Work zone planning and design, maintenance of traffic plan development

- Work zone traffic control devices and Intelligent Transportation System (ITS) technologies

- Construction management, quality assurance, and inspection

- Transportation management center, traveler information, and restrictions

- Work zone mobility and impact analysis

- Law enforcement in work zones

- Oversized vehicle permitting

- Connected and autonomous vehicle integration

- Historical records and historical work zone patterns

Considering the needs of work zone data, the following tasks were performed to accomplish the work zone data needs assessment objective.

- Identify current IDOT data collection methods for work zone variables.

- Review FHWA's Work Zone Data Initiative (WZDI).

- Provide recommendations on how work zone variables should be collected and maintained by IDOT that are consistent with FHWA's WZDI. 


\subsection{IDOT'S EXISTING DATA FOR WORK ZONE INFORMATION}

IDOT's current work zone information is gathered via the OPER 2410 form, which documents restrictions on IDOT roads. This information is primarily used for issuance of permit loads. It is also the source used to inform the Illinois motoring public of road obstructions and restrictions at any given time and is available on GIS maps. The data from this form is housed in databases for segments and points. IDOT's OPER 2410 Road Restriction Information form (Appendix E) contains the following data and instructions for completing the form, extracted directly from IDOT's OPER 2410 (IDOT OPER 2410, Rev 06/08/16):

\subsubsection{Location Information}

- District/County Name: District and county for construction location.

- Route Type: Type of route at construction location (interstate, US route, Illinois route, street, county road, or other).

- Route Number or Street: Route number (e.g., 90 for Interstate 90) or roadway name. Do not use FAP, FAU, etc.

- Near Town: Name of the town the construction zone is in or nearest to.

- Direction of Route: Official direction the route travels. Do not use cardinal direction. Example: INT 55 travels south to north, and INT 24 travels west to east. (north, south, north and south, east, west, east and west).

- From/to Location or Mile: Always use mile posts or exit numbers for interstate projects, e.g., MP 177 to 184 or MP 39 for a specific structure at MP 39. For all other roadways use intersecting streets, distance from state roadway, etc., e.g., "Elm St. to First Ave.," "2 miles south IL29 at BNSF RR," "Auburn Rd. to 5 miles north of Sydney." Do not use station numbers.

\subsubsection{Road Restriction Information}

- Start/Stop Dates: "These should be the dates which will affect motorists and not necessarily the official contract starting and stopping dates. The start and stop dates are in $\mathrm{mm} / \mathrm{dd} / \mathrm{yyyy}$ format. The Stop Date is the day the motoring public will stop being affected. If you are not sure of the Stop Date make it longer and revise at a later date. Construction zones will be removed on the Stop Date, if not revised prior to. Projects not requiring roadway closures or dimensional restrictions on vehicles should be submitted within 7 days of start date. Projects requiring roadway/ramp closures or oversize vehicle permit dimensional restrictions (maximum width or length restrictions on vehicles) should submit restrictions 21 days prior to the actual start date the roadway will be closed or a dimensional restriction will be in place to give motorists and oversize overweight permit loads advance notice.

Stop dates should be revised or modified as necessary during the life of the project" (IDOT OPER 2410, Rev 06/08/16).

- Contract Number: If no contract number exists, a reason should be specified, such as an emergency. In those cases, a contract number will be assigned.

- New, Revised, Delete: Describes what kind of temporary restriction is being submitted. New-never submitted prior. Revised-for changing something submitted prior. Delete-to remove an active construction zone, prior to the stop date. (Restrictions will automatically be removed from the website after the stop date.) 
- Contractor: Name of contractor or entity doing the work.

- Contract Value: Value of the construction work performed. (Some districts use this form to provide data for press releases.)

- Type of Construction: Lane reduction/lane closure, intermittent road work, intersection restrictions, temporary changes, one-way traffic with temporary signals, one-way traffic with flaggers, shoulder work, road closed, bridge closed, shoulder closed, ramp closed, railroad closure, weight station closed, rest area closed, or closed due to flooding.

- Lanes/Ramp Closed: Information on the number of lanes closed or if a ramp or shoulder is closed or restricted.

- Suggestions to Motorists: Information that would be helpful to motorists. Examples: Traffic restricted to one lane in each direction, road closed to place beams expect 15-min closures, expect lane closures with narrow lanes, traffic restricted to one lane directed by temporary traffic signals. Include general information on such things as delays, time of day, or days of week, etc. This is an input text line.

- Traffic Alert: Any special information, including special delays such as "Expect intermittent 20minute delays on May 17," "INT 57 SB ramp to IL 17 EB ramp closed," etc.

- Detour Route: Detour route for standard vehicles and truck detour, if needed.

- Current Structure Number: Current structure number in the construction zone. Oversize vehicle permit restrictions will be placed on route specified at the structure only. If restrictions are needed on the crossing roadway as well, please specify. Enter what the structure is crossing to right under crossing (roadway, river, creek, etc.).

- New Structure Number: New structure number replacing the current structure in the construction zone.

- Crossing: When working at a structure/specific feature, enter what the structure is crossing like the Illinois River or Mud Creek. Please enter the current structure number, not the new structure number.

- Oversize Vehicle Permit Restrictions: This section is for submitting width or length restrictions placed on vehicles for construction zones. These restrictions are based on the limitations of the construction zone, not the dimensions of the construction zone. Max Width measurements shall be $1^{\prime} 6^{\prime \prime}$ less than the actual opening (e.g., if actual opening measures 13', width restriction should be reported as $11^{\prime} 6^{\prime \prime}$ and signed as $11^{\prime} 6^{\prime \prime}$ ). Max Length restriction measurements shall be determined by the turning radius and traffic patterns in the construction zone. Note: Length restrictions are usually not submitted unless you identify long vehicles are using the route, e.g., a windmill blade with overall length of vehicle at $205 \mathrm{ft}$. Max length is also used with permanent restrictions to report permanent turning radius issues.

Examples: Report start and stop dates for restrictions if different than general construction start and stop dates, identify additional structures/locations with width restrictions and dates of, start and stop dates for Stage 1 or 2. (STR \# 013-4569 6/15/2013-12/1/14 [Useful when from/to Location for paving is $5 \mathrm{mi}$ long with width restriction at structure] or Stage $110^{\prime} 6^{\prime \prime}$ on 5/15 Stage II 9'6" on 7/7/13-11/1/13.) Do not consider marked detours when reporting restrictions. Permit loads cannot use detours. If this will be a permanent restriction ignore the start and stop dates. 
- Crossover: Indicate if a crossover is being utilized and provide a description. The description should include where both crossovers are, especially in relation to vertical clearance issues, e.g., "East of Elm St. west of IC RR." The description must also include which direction the traffic is traveling on, e.g., "Traffic on NB lanes." Revise form 21 days prior to traffic moving to opposite direction of travel.

- Web Address: Specific website established for the project, if available.

- Data Verification: The accuracy of the information posted on the Road Construction Map and Weekly Restriction List should be verified. Discrepancies can be resolved by submitting a revised OPER 2410.

- Road Construction Map

- Weekly Restriction List

The two critical variables currently being collected by IDOT that are in dire need for increased level of accuracy are start/stop dates for WZ duration and begin/end locations for work zone length.

\subsection{RECOMMENDATIONS FOR WORK ZONE DATA COLLECTION}

To develop recommendations on how work zone data should be collected by IDOT in the future, the following FHWA Work Zone Data Initiative guidelines were used:

- Work Zone Activity Data (WZAD) -WZAD Needs and Opportunities (Draft), January 28, 2019 (Ullman and Finley, 2019)

- Work Zone Activity Data (WZAD) -Data Dictionary Report (Draft), March 15, 2019 (Okunieff et al., 2019)

- Guidance of Data Needs, Availability, and Opportunities for Work Zone Performance Measures (FHWA, 2013)

- A Framework for Work Zone Activity Data Collection and Management (Draft), January 11, 2019 (Stephens et al., 2019)

The following work zone data items are recommended to be collected by IDOT for work zones per the FHWA guidelines (Ullman \& Finley, 2019; Okunieff et al., 2019; FHWA, 2013) for identifier, location, time, and impact attributes:

\begin{tabular}{|c|c|}
\hline Title & Description \\
\hline Identifier $^{2}$ & Machine-generated ID number, permit number \\
\hline Project ID ${ }^{1}$ & Nomenclature for overall project \\
\hline Owner Agency ${ }^{1}$ & Agency primarily responsible for project oversight \\
\hline Funding Allocation ${ }^{1}$ & $\begin{array}{l}\text { Status of funding allocation (e.g., planned, requested, pending, partially } \\
\text { funded, or fully funded) }\end{array}$ \\
\hline Owner Agency Project Manager ${ }^{1}$ & Primary day-to-day project contact within the owner agency \\
\hline Contractor ${ }^{1}$ & Prime contractor responsible for project \\
\hline Subcontractor ${ }^{1}$ & Subcontractor(s) responsible for project \\
\hline
\end{tabular}


Expected Number of Phases ${ }^{1}$

Actual Number of Phases ${ }^{1}$

Project Event ID

Phase $^{1}$

Activity $^{1,2}$

Event $^{2}$
Expected number of project phases

Actual number of project phases

A unique identifier associated with one or more project event identifier types and other associated references identifier such as contract number

Nomenclature for project phase(s)

Nomenclature for project activity(ies) ${ }^{1}$

General description of event/subevent, description about maintenance of traffic approach, expected geometrics associated with each event/subevent, expected traffic control device(s) associated with each event/subevent, actual geometrics associated with each event/subevent, Actual traffic control device(s) associated with each event/subevent, indication that the maintenance of traffic requires coordination between the projects, reference to projects that need to coordinated with, planned number of lanes to be closed, description of planned lanes to be closed, total number of lanes, planned number of lanes to be open ${ }^{2}$

Work type (construction, maintenance, utility work), purpose or scope of work, planned versus actual work

(Source: ${ }^{1}$ Ullman \& Finley, 2019; ${ }^{2}$ Okunieff et al., 2019)

\section{Location Attributes}

Title

Roadway Name ${ }^{1}$

Direction of Travel ${ }^{1}$

Roadway Assigned Direction of Travel ${ }^{2}$

Road Classification ${ }^{2}$

Facility ${ }^{2}$

Planned Begin Location ${ }^{1,2}$

Actual Begin Location ${ }^{1,2}$

\section{Description}

Roadway(s) where project/phase/activity will occur

Cardinal/compass direction of roadway

Route direction of road

Functional classification of road

Description of geometric element affected (e.g., connector, main lanes, or exit ramp)

Planned begin location where project/phase/activity is planned ${ }^{1}$ Latitude/longitude coordinate, state plane coordinates, state linear referencing system (mile points, mile markers), address, cross-street, a spatial point feature (typically described in freeform text). ${ }^{2}$ The Begin Location should be referenced to the location nearest to the first advanced warning sign for the work zone.

Actual begin location where project/phase/activity is occurring/occurred $^{1}$ Latitude/longitude coordinate, state plane coordinates, state linear referencing system (mile points, mile markers), address, cross-street, a spatial point feature (typically described in freeform text). ${ }^{2}$ The Begin Location should be referenced to the location nearest to the first advanced warning sign for the work zone. 
Planned end location where project/phase/activity is planned ${ }^{1}$ Latitude/longitude coordinate, state plane coordinates, state linear Planned End Location ${ }^{1}$ referencing system (mile points, mile markers), address, cross-street, a spatial point feature (typically described in freeform text). ${ }^{2}$ The End Location should be referenced to the location nearest to the last work zone warning sign.

Actual end location where project/phase/activity is occurring/occurred ${ }^{1}$ Latitude/longitude coordinate, state plane coordinates, state linear

Actual End Location ${ }^{1}$ referencing system (mile points, mile markers), address, cross-street, a spatial point feature (typically described in freeform text) ${ }^{2}$ The End Location should be referenced to the location nearest to the last work zone warning sign.

(Source: ${ }^{1}$ Ullman \& Finley, 2019; ${ }^{2}$ Okunieff et al., 2019)

\section{Time Attributes}

\section{Title}

Planned Start Date/Time ${ }^{1}$

Planned End Date/Time ${ }^{1}$

Planned Duration ${ }^{1}$

Level of Confidence in Planned Start Date ${ }^{1}$

Recurring $^{1}$

Date/Time Advanced Notice Received ${ }^{1}$

Actual Start Date/Time ${ }^{1}$

Actual End Date/Time ${ }^{1}$

Estimated Close $^{2}$

Cancel Time ${ }^{2}$

Status $^{1}$

\section{Description}

Start date/time/day of planned project/phase/activity

End date/time/day of planned project/phase/activity

Planned duration of project/phase/activity

Indicator for the level of confidence that the project will start as planned Indicator that activity is a recurring event

Actual date/time advance notice for a lane closure or other activity received

Start date/time when project/phase/activity is occurring/occurred

End date/time when project/phase/activity is occurring/occurred

General description of estimated time project/phase/activity is closed

Description that the project/phase/activity is cancelled

Descriptor of project/phase/activity status (e.g., planned, active, completed, cancelled)

(Source: ${ }^{1}$ Ullman \& Finley, 2019; ${ }^{2}$ Okunieff et al., 2019)

\section{Impact Attributes}

Title

Description of Work ${ }^{1}$

Description of Planned Geometric Changes ${ }^{1}$

Description of Planned Temporary Traffic

Control (TTC) ${ }^{1}$

Estimated Impact(s) $)^{1,2}$

Coordination Flag ${ }^{1}$

Project(s) to Coordinate with ${ }^{1}$

Planned Number of Lanes Closed ${ }^{1}$

\section{Description}

General description of project/phase/activity that impacts coordination General description of planned geometric changes to roadway(s)

General description of planned TTC

General description of estimated impact(s) ${ }^{1}$

Text descriptors of traffic conditions (e.g., heavy, congested, light), expected delay, current travel time on route ${ }^{2}$ Indication that work requires coordination

Project nomenclature of project(s) to coordinate with

Number of lanes planned to be closed 


\begin{tabular}{|c|c|}
\hline Title & Description \\
\hline Description of Planned Lanes to Be Closed $^{1}$ & Description of the lanes planned to be closed \\
\hline Planned Number Lanes To Be Open ${ }^{1}$ & Number of lanes planned to be open \\
\hline Total Number of Lanes ${ }^{1}$ & Total number of lanes \\
\hline $\begin{array}{l}\text { Planned Number of Temporary Lane } \\
\text { Closures }^{1}\end{array}$ & Number of temporary lane closures planned for a project or phase \\
\hline Description of Actual Geometric Changes ${ }^{1}$ & General description of actual geometric changes implemented \\
\hline Description of Actual TTC ${ }^{1}$ & General description of actual TTC implemented \\
\hline Actual Number of Lanes Closed & Number of lanes actually closed \\
\hline Description of Actual Lanes to Be Closed $^{1}$ & Description of the lanes actually closed \\
\hline Actual Number Lanes to Be Open ${ }^{1}$ & Number of lanes actually open \\
\hline Expected Effect on Mobility ${ }^{1}$ & Impact on mobility (e.g., travel time delay) \\
\hline Lane Closure Permit Number ${ }^{1}$ & Lane closure permit number issued by owner agency \\
\hline Pavement Cut ${ }^{1}$ & $\begin{array}{l}\text { Indication that work involves cutting or otherwise affecting the } \\
\text { pavement }\end{array}$ \\
\hline Temporary Restrictions ${ }^{1,2}$ & $\begin{array}{l}\text { General description of temporary restrictions (e.g., height, width, } \\
\text { weight })^{1} \\
\text { A type of restriction that applies to the work zone road segment which is } \\
\text { bounded by the begin / end locations }{ }^{2}\end{array}$ \\
\hline Reduce Speed Limit $^{1}$ & $\begin{array}{l}\text { Indication that the project/phase/activity had a reduced speed limit or } \\
\text { variable speed limit system }\end{array}$ \\
\hline Feature Modified ${ }^{1}$ & Name of the feature being modified in the field \\
\hline Description of Feature Modification ${ }^{1}$ & General description of the change to the feature in the field \\
\hline Infrastructure Devices Impacted ${ }^{1}$ & $\begin{array}{l}\text { General description of existing infrastructure device impact by } \\
\text { project/phase/activity }\end{array}$ \\
\hline Signal Timing Change ${ }^{1}$ & Indication that the signal timing has changed \\
\hline Description of Signal Time Change ${ }^{1}$ & General description of the signal timing change \\
\hline Detour Route ${ }^{1}$ & Detour route information \\
\hline Enforcement Presence $^{1}$ & Indication that law enforcement was present \\
\hline Type of Enforcement Support ${ }^{1}$ & General description of the type of law enforcement support \\
\hline Law Enforcement Needed ${ }^{1}$ & $\begin{array}{l}\text { Number of work activities requiring law enforcement support or an } \\
\text { indication that law enforcement support is required }\end{array}$ \\
\hline Worker Present in Work Zone ${ }^{2}$ & $\begin{array}{l}\text { Agency documents and archives when workers are present in work zones } \\
\text { to support contested citations }\end{array}$ \\
\hline Posted Speed Limits ${ }^{2}$ & $\begin{array}{l}\text { Agency documents and archives posted speed limits in work zones to } \\
\text { support contested citations }\end{array}$ \\
\hline Mobility ${ }^{3}$ & $\begin{array}{l}\text { Throughput, travel time delay, average speed, travel time reliability, } \\
\text { queue length and duration }\end{array}$ \\
\hline Safety ${ }^{3}$ & $\begin{array}{l}\text { Traffic crashes, traffic operation and surrogate measures, worker } \\
\text { accidents }\end{array}$ \\
\hline Customer Satisfaction ${ }^{3}$ & Driver ratings, complaints, contractor work efficiency \\
\hline WZ-Geometry ${ }^{2}$ & $\begin{array}{l}\text { A set of attributes associated with the work zone geometry including but } \\
\text { required not limited to begin and end locations }\end{array}$ \\
\hline Annual Average Daily Traffic & ADT or AADT of road under normal conditions in vehicles per day \\
\hline Work Zone Average Daily Traffic & ADT measured while work zone is in place, vehicles per day \\
\hline
\end{tabular}

(Source: ${ }^{1}$ Ullman \& Finley, 2019; ${ }^{2}$ Okunieff et al., 2019; ${ }^{3}$ FHWA, 2013) 
It is recommended that a tiered approach by priority be used to begin improving the quality of work zone data in Illinois, based on ease of implementing the suggested changes. Some changes may be easier to implement than others, especially if the work zone data is currently being collected. Other variables suggested here and by FHWA may take a longer period to implement, as they are new variables not currently being collected by IDOT and additional forms or processes may need to be created to obtain them.

The following is the suggested priority list for improving the quality of work zone data in Illinois.

\section{Priority 1 Work Zone Variables}

- For number of work zones: Identifier, Project ID, Project event ID

- For work zone duration: Actual start date/time, Actual end date/time

- For work zone length: Actual begin location, Actual end location

- Other critical exposure variables:
○ AADT
- Work zone average daily traffic
- Speed limit of road under normal conditions
- Work zone speed limit
- Functional classification of road

\section{Priority 2 Work Zone Variables}

- Remaining variables listed in the identifier table

- Remaining variables listed in the time attributes table

- Remaining variables listed in the location attributes table

\section{Priority 3 Work Zone Variables}

- Remaining variables listed in the impact attributes table 


\section{CHAPTER 8: CONCLUSIONS AND RECOMMENDATIONS}

Similar to the recent trends in the US, IDOT faces challenges in understanding the causes of increased work zone crashes. Although the direct safety metrics such as the number of work zone fatal and Ainjury crashes are available, they do not completely reflect work zone safety performance measures. Three objectives were established for this research. The first objective is to more clearly quantify and report yearly trends on work zone crashes and injuries with an emphasis on fatal and A-injury crashes with respect to work zone exposure variables such as number of work zones, work zone length, and work zone duration. The second objective is to conduct an in-depth analysis of site-specific work zone sites and characteristics in Illinois to develop prediction tools such as SPFs and CMFs to assess work zone safety. The third objective is to identify gaps in existing work zone data in Illinois and make recommendations on data needs. Overall, it is expected that this research will aid in assessing safety aspects of work zones, which will enable IDOT to make progress towards achieving zero fatalities in work zones.

\subsection{WORK ZONE SAFETY PERFORMANCE MEASURES}

The three performance measures that were used to quantify the work zone safety in Illinois are traffic crash frequencies, exposure variables, and crash rate measures.

Data from three main sources were obtained from IDOT to analyze work zone safety performance in Illinois from 2013 to 2017. They are the traffic crash, lane closure, and roadway network databases. The three databases were fused to obtain work zone information in terms of traffic crash frequencies and work zone exposure variables in Illinois. Annual work zone frequencies were obtained and trend analyses were prepared for all roads and for IDOT roads for the following crash types: total work zone (WZ) crashes, WZ fatal (K) and A-injury crashes, WZ fatal and injury $(K, A, B, C)$ crashes, and WZ fatalities and injuries.

Exposure variables were only available for IDOT roads. Thus, annual trends of work zone exposure variables were quantified for IDOT roads only for 2013 to 2017 for the following: number of IDOT work zones, WZ miles, WZ-days, and WZ day-miles.

Crash rates were then calculated for the four work zone crash types and four exposure variables. Annual trend analyses were then prepared for the following 16 crash rates for IDOT roads from 2013 to 2017. The following observations can be made for IDOT work zone crash frequencies, exposure variables, and crash rates.

\subsubsection{Annual Work Zone Crash Frequency Trends}

- Observation of the work zone crash trends show that work zone crash frequency increased from 2013 to 2015 and then decreased for 2016 and 2017 across all crash categories and roads (IDOT and all roads). The lowest work zone crash and injury frequencies were observed in 2017.

- A comparison of the proportion of work zone crashes occurring on IDOT roads versus all roads from 2013 to 2017 range from 55\% to 64\% for total crashes and 64\% to 92\% for K-A crashes. 


\subsubsection{Annual Work Zone Exposure Variable Trends}

- The work zone exposure trends reveal that the annual number of IDOT work zones increased steadily from 690 in 2013 to 1,058 in 2017. The annual number of IDOT work zone miles was relatively constant from 2014 to 2016 at 2,250 to 2,247 mi, while in 2017, the work zone miles decreased to 1,835 .

- In terms of total annual work zone duration, the number of work zone days increased from 2013 to 2015 and decreased in 2016 and 2017.

- The trends for annual IDOT work zone day-miles also increased from 2013 to 2015 and decreased in 2016 and 2017.

\subsubsection{Annual Work Zone Crash Rate Trends}

- For work zone crashes per number of work zones, in general, an increasing trend was observed for the four crash severity categories from 2013 to 2015, with decreasing rates in 2016 and 2017. The lowest annual rates over the analysis period were observed in 2017 for fatalities and injuries per work zone, fatal and injury crashes per work zone, and K-A crashes per work zone.

- For work zone crashes per work zone mile, the total work zone crash rate increased from 0.93 in 2013 to 1.90 in 2015 . The rate decreased to 1.73 in 2016 and then increased to 1.88 in 2017. The rates based on fatalities and injuries per work zone mile and fatal and injury crashes per work zone mile increased from 2013 to 2015 and then decreased in 2016 and 2017. The KA work zone crashes per work zone mile increased from 2013 to 2016 but decreased in 2017.

- For work zone crashes per work zone day, the total work zone crash rate increased from 2013 to 2015 (from 0.028 to 0.048 ) and then decreased slightly to 0.046 and 0.045 in 2016 and 2017, respectively. The rates based on fatalities and injuries per work zone day and fatal and injury crashes per work zone day increased from 2013 to 2015, remained constant in 2016, and then decreased in 2017. The K-A work zone crashes per work zone day increased from 2013 to 2016 but then decreased in 2017.

- For work zone crashes per 100,000 work zone day-miles, the total work zone crash rate increased from 2013 to 2015 (from 1.45 to 2.15), decreased 2.04 in 2016, and increased again to 2.43 in 2017. The rates based on fatalities and injuries per 100,000 work zone day-miles, and fatal and injury crashes per 100,000 work zone day-miles increased from 2013 to 2015 and then decreased in 2016 and 2017. The K-A work zone crashes per 100,000 work zone daymiles increased from 2013 to 2016 but then decreased in 2017.

- Overall, from 2016 to 2017, 14 of the 16 of the work zone crash and injury rates decreased. The two exceptions where increases were observed from 2016 to 2017 were for total work zone crashes per work zone mile and total work zone crashes per 100,000 day-miles.

The trend analysis of work zone crash frequencies and crash rates reveals that the work zone exposure variables do provide additional insights into work zone safety performance and should continue to be collected in the future. Even though the lane closure databases contained imperfect data, it was still possible to find exposure measures from them through the manual process 
documented in this report. Improvements to collecting more accurate work zone exposure variables will help in automating the extraction of work zone crash and exposure data and make the process easier to conduct in the future.

\subsection{SITE-SPECIFIC WORK ZONE ANALYSIS}

For the site-specific work zone analysis, data for 384 work zone sites were used in a model calibration and validation study, using multiple statewide databases. SPFs were developed assuming an underlying Poisson/negative binomial distribution to predict total work zone crashes (for all crash severities-K, A, B, C, and PDO) and work zone fatal/injury crashes (K-fatal and A-, B-, and C-injury crashes).

\subsubsection{Safety Performance Functions}

Twelve data elements for each of the 384 work zone sites were queried from the three IDOT databases: the traffic crash, lane closure, and road network (base map) databases. The 12 data elements included work zone crash, operational and characteristic data, and non-work-zone crashes, geometry, and characteristics. The characteristics of the 384 work zone sites were compiled and analyzed using the IBM SPSS statistical analysis software. Assuming an underlying Poisson/negative binomial distribution, which is a common assumption in modeling traffic crashes per the HSM, SPF models were then developed to predict crashes using variables that were found to have a statistically significant influence on work zone crashes.

Three statistically significant models were developed for total work zone crashes and one for work zone fatal/injury crashes. Statistically significant results for a work zone K-A crash model specifically could not be developed, and thus was not able to be included in this research.

The 384 work zone sites were initially divided into a calibration group or a validation group. The calibration data set included 256 randomly selected work zone sites. Of the 12 variables considered, the resulting variables that were found to have a statistically significant impact on crashes were work zone duration (D), work zone length (L), annual average daily traffic (AADT), and the product of nonwork-zone speed limit and work zone speed limit (NWZ SL x WZSL).

The remaining 128 sites were used to develop validation models. Analyses were conducted to confirm the models developed with the calibration data set through comparisons with the validation models. Such analyses included:

- Analysis of cumulative residual (CURE) plots

- Goodness-of-fit statistics

- Comparison of individual variable coefficients, standard errors, and p-values between the calibration and validation data sets

The results of these analyses identified which of the three resulting total work zone crash SPF models was superior and that the fatal/injury work zone model was validated. Once the general form of the total and fatal/injury work zone models were validated, the two subsets were combined to develop the final values of the coefficients for the SPF variables in each model, using the pooled set consisting 
of all 384 sites. A statistical analysis of the observed and predicted work zone crashes was conducted to determine if there were significant differences. The results indicated a nonsignificant difference, which means that the models are accurately able to predict work zone crashes and injuries. All statistical analyses were conducted at 95\% LOC. The recommended SPF models for predicting work zone total and fatal/injury crashes on IDOT highways and roads are as follows:

$$
\begin{gathered}
\mu_{\text {Total }}=e^{-7.049} \times D^{0.904} \times L^{0.317} \times A A D T^{0.486} \times e^{-0.0004(N W Z S L \times W Z S L)} \\
\mu_{\text {Fatal/Injury }}=e^{-2.872} \times D^{0.812} \times L^{0.323} \times e^{-0.0005(N W Z S L \times W Z S L)}
\end{gathered}
$$

Although the SPFs include the variable NWZ SL $x$ WZ SL, it is expected that IDOT's policy for setting work zone speed limits be used. The SPFs are not intended to be used to recommend other values of work zone speed limit.

Additional analyses were conducted to further explore the total and fatal/injury work zone SPFs, including a Monte Carlo simulation analysis to determine the relative impact of the variables in each model. Both the total and fatal/injury work zone crash models revealed that the variable with the highest relative impact is NWZ SL x WZ SL, followed by work zone duration.

\subsubsection{Excel Tool for SPF Calculations}

An Excel tool was developed to facilitate the ease of the calculations for the SPFs and assess safety performance of work zones in Illinois. A user can analyze a single work zone, or up to three work zone alternatives at a time. It includes a tutorial worksheet that explains the basic components of a work zone and descriptions of the color-coding schemes for data input and a Work Zone Safety Performance-Analysis using work zone SPFs worksheet. In the latter worksheet, a user would input data and the results would be generated for total and fatal/injury work zone crashes per WZ duration.

\subsubsection{Crash Modification Factors}

CMFs were extracted from the SPF coefficients for total crashes for work zone length (0.317) and work zone duration (0.904), and fatal/injury WZ crashes for work zone length (0.323) and duration (0.812). Comparisons of the CMFs developed for Illinois roads were compared with those developed in the past, which revealed similarities for duration. Differences in the CMF for WZ length were observed, which may be due to the minimum length and duration considered in the data samples. Methodologies and examples on how to use the SPFs developed as a part of this research are presented in the report.

The SPF models developed in this research may be applied to practical scenarios where IDOT can make decisions about work zone length and duration in work zones based on safety considerations on state highways. The approach and methodology developed in this research may serve as a platform to develop crash predictions and compare alternatives at a regional scale as well.

These methodologies and tools can be used by work zone planners when designing the MOT plans to identify which work zone layout and staging will result in fewer work zone crashes and injuries. 


\subsection{WORK ZONE DATA NEEDS}

Several issues with the work zone data currently collected by IDOT were identified. FHWA's Work Zone Data Initiative reports provide recommended practice for collecting and managing uniform work zone activity data across jurisdictional and organizational boundaries. These reports were used as the basis for developing recommendations in a tiered priority list of work zone data improvement needs in Illinois.

The following is the suggested priority list for improving the quality of work zone data in Illinois.

\subsubsection{Priority 1 Work Zone Variables}

- For number of work zones: Identifier, Project ID, Project event ID

- For work zone duration: Actual start date/time, Actual end date/time

- For work zone length: Actual begin location, Actual end location

- Other critical exposure variables
○ AADT
- Work zone average daily traffic
- Speed limit of road under normal conditions
○ Work zone speed limit
- Functional classification of road

The results of this research will provide IDOT with a better understanding of the causes of increased work zone crashes, which will then lead to recommended steps toward making data-driven and systematic enhancements to work zone safety at an agency level. It will aid in determining how a specific work zone design feature or combination of features, operating strategy, etc., affects the safety performance of a work zone, so that future decisions about the work zone design or maintenance of traffic plans are improved. This research will assist in the development of optimal strategies for alleviating work zone crash and fatal/injury problems and help meet future statewide goals in Illinois. 


\section{REFERENCES}

Akepati, S. R., \& Dissanayake, S. (2011). Characteristics and contributory factors of work zone crashes. Proceedings of the $90^{\text {th }}$ Annual Meeting, Transportation Research Board, Washington, DC.

American Association of State Highway and Transportation Officials (AASHTO). (2010). Highway safety manual, 1st ed. Washington, DC: AASHTO.

Cheng, Y., Parker, S. T., Ran, B., \& Noyce, D. A. (2012). Enhanced analysis of work zone safety through integration of statewide crash and lane closure system data. Transportation Research Record: Journal of the Transportation Research Board, 2291, 17-25. https://doi.org/10.3141\%2F2291-03

Cheng, Y., Parker, S. T., Ran, B., \& Noyce, D. A. (2015). Integrating crash, real time traffic and lane closure data for statewide highway work zone safety analysis. Proceedings of the $97^{\text {th }}$ Annual Meeting, Transportation Research Board, Washington, DC.

Clark, J. B., \& Fontaine, M. D. (2015). Exploration of work zone crash causes and implications for safety performance measurement programs. Transportation Research Record: Journal of the Transportation Research Board, 2485, 61-69. https://doi.org/10.3141\%2F2485-08

Federal Highway Administration (FHWA). (1998). Accident models for two-lane rural roads: Segment and intersections (Report No. FHWA-RD-98-133). Retrieved from https://www.fhwa.dot.gov/publications/research/safety/98133/ch06 01.cfm

Federal Highway Administration (FHWA). (2013). Guidance on data needs, availability and opportunities for work zone performance measures (Report No. FHWA-HOP-13-011). U.S. Department of Transportation.

Federal Highway Administration (FHWA). (2018). Work zone management program-Join the work zone data initiative (Report No. FHWA-HOP-18-083). U.S. Department of Transportation.

Federal Highway Administration (FHWA). (2019a, July). Facts and statistics-Work zone safety. Retrieved from https://ops.fhwa.dot.gov/wz/resources/facts stats.htm

Federal Highway Administration (FHWA). (2019b, July). National highway work zone safety program. Retrieved from https://safety.fhwa.dot.gov/wz/wz natl pro.cfm

Garber, J., \& Rivera, G. (2010). Safety performance functions for intersections on highways maintained by the Virginia Department of Transportation (Report No. VTRC 11-CR1). Virginia Department of Transportation and FHWA.

Hauer, E. (2004). Statistical road safety modeling. Transportation Research Record: Journal of the Transportation Research Board, 1897, 81-87. https://doi.org/10.3141\%2F1897-11

Illinois Department of Transportation (IDOT). (2011, March). Policy on establishing and posting speed limits on the state highway system. IDOT.

Illinois Department of Transportation (IDOT). (revised 06/08/2016) Road restriction information form OPER 2410. IDOT. 
Khattak, A., Khattak A., \& Council, F. (2002). Effects of work zone presence on injury and non-injury crashes. Accident Analysis and Prevention, 34(1), 19-29. https://doi.org/10.1016/S00014575(00)00099-3

Kolody, K., Perex-Bravo, D., Zhao, J., \& Neuman, T. R. (2014). Highway safety manual user guide. National Cooperative Highway Research Program 17-50. Lead States Initiative for Implementing the Highway Safety Manual. Transportation Research Board, Washington, DC.

Kweon, Y. J., Lim, I. K., \& Fontaine, M. D. (2016). Work zone safety performance measures for Virginia. FHWA/Virginia Transportation Research Council 16- R10.

Kweon, Y. J., Lim, I. K., \& Fontaine, M. D. (2017). Development of rate-based statewide safety performance measures of work zones using imperfect exposure data: A Virginia case study. Proceedings of the $96^{\text {th }}$ Annual Meeting, Transportation Research Board, Washington, DC.

Li, Y., \& Bai, Y. (2008). Development of crash-severity-index models for the measurement of work zone risk levels. Accident Analysis and Prevention, 40, 1724-1731.

https://doi.org/10.1016/i.aap.2008.06.012

Li, Y., \& Bai, Y. (2009). Highway work zone risk factors and their impact on crash severity. Journal of Transportation Engineering, 135(10). https://doi.org/10.1061/(ASCE)TE.1943-5436.0000055

McAvoy, D. S., Duffy, S., \& Whiting II, H. S. (2011). Simulator study of primary and precipitating factors in work zone crashes. Transportation Research Record: Journal of the Transportation Research Board, 2258, 32-39. https://doi.org/10.3141\%2F2258-04

Okunieff, P., Stephens, D., \& Ostroff, R. (2019, March 15). Work zone activity data (WZAD)_Data dictionary report (Version 2). Federal Highway Administration, U.S. Department of Transportation, Washington, DC.

Rista, E., Barrette, T., Hamzeie, R., Savolainen, P., \& Gates, T. J. (2017). Work zone safety performance: Comparison of alternative traffic control strategies. Transportation Research Record: Journal of the Transportation Research Board, 2617, 87-93. http://doi.org/10.3141/2617-11

Srinivasan, R., \& Bauer, K. (2013). Safety performance function development guide: Developing jurisdiction-specific SPFs (Report No. FHWA-SA-14-005). FHWA, U.S. Department of Transportation.

Stephens, D., Schroeder, J., Creek, A., \& Ostroff, R. (2019, January 11). A framework for work zone activity data collection and management (Version 3). Federal Highway Administration, U.S. Department of Transportation, Washington, DC.

Sun, C., Edara, P., Brown, C., Zhu, Z., \& Rahmani, R. (2014). Calibration of highway safety manual work zone crash modification factors (InTrans Project 06-277). Smart Work Zone Deployment Initiative and FHWA, U.S. Department of Transportation.

Ullman, J., \& Finley, M. (2019, January 28). Work zone activity data (WZAD)-WZAD needs and opportunities (Draft). Federal Highway Administration, U.S. Department of Transportation, Washington, DC. 
Ullman, G. L., Pesti, G., \& Klein, R. (2013). Guidance on data needs, availability and opportunities for work zone performance measures (Report No. FHWA-HOP-13-011). FHWA, U.S. Department of Transportation.

Ullman, G. L., Finley, M. D., Bryden, J. E., Srinivasan, R., \& Council, F. M. (2008). Traffic safety evaluation of nighttime and daytime work zones (NCHRP Report 627). Transportation Research Board, Washington, DC.

Venugopal, S., \& Tarko, A. (2000). Safety models for rural freeway work zones. Transportation Research Record: Journal of the Transportation Research Board, 1715, 1-9. https://doi.org/10.3141/1715-01

Yang, H., Ozbay, K., Ozturk, O., \& Yildirimoglu, M. (2013). Modeling work zone crash frequency by quantifying measurement errors in work zone length. Accident Analysis and Prevention, 55, 192201. https://doi.org/10.1016/j.aap.2013.02.031 


\section{APPENDIX A: ILLUSTRATIONS OF ISSUES AND ASSUMPTIONS FOR NO. WORK ZONES, LENGTH, AND DURATION FOR SEGMENT AND POINT DATABASES}




\section{Segment Work Zone Situations Issues and Assumptions for Counts}




\section{Situation 1}

Situation: One entry- one contract ID, one length, one duration

Assumption: Count as one work zone, with recorded length and duration

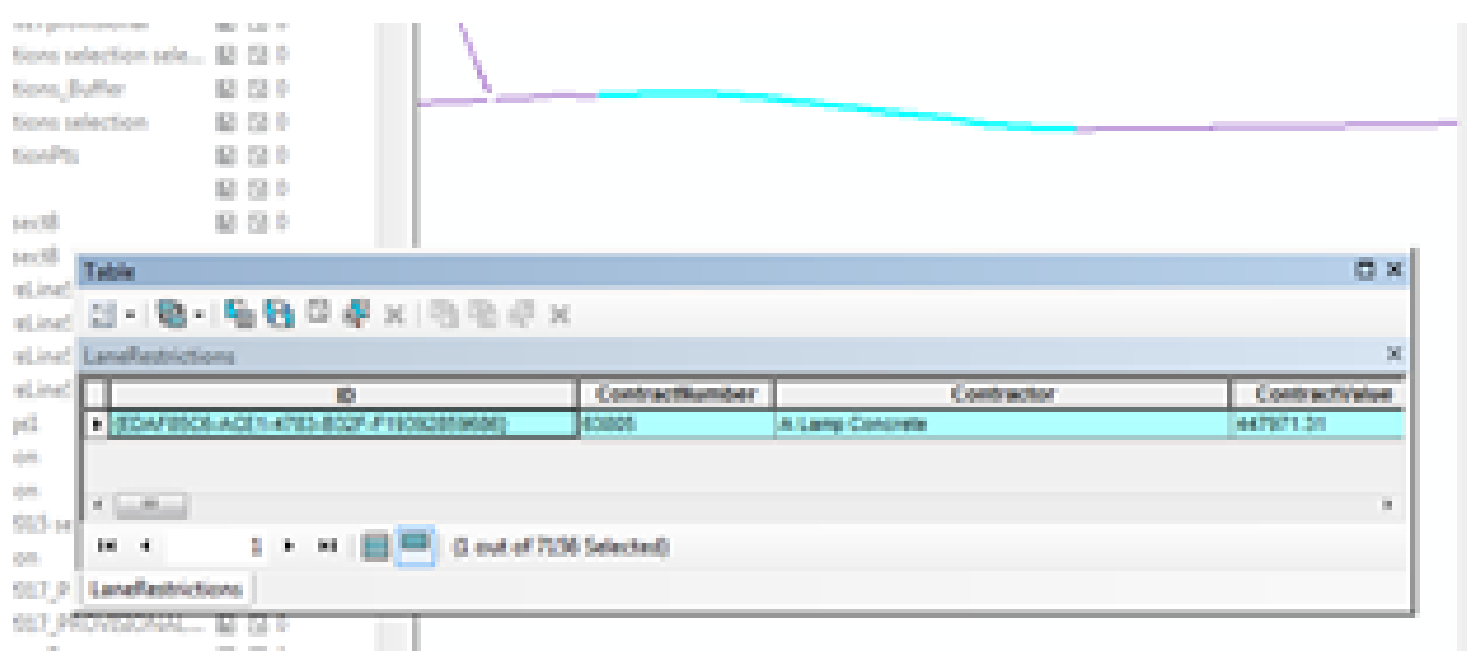




\section{Situation 2}

Situation: Two entries- same contract ID, same route, different route direction (i.e. EB \& WB), same location, same duration, and same length Assumption: Count as one work zone, with recorded length and duration

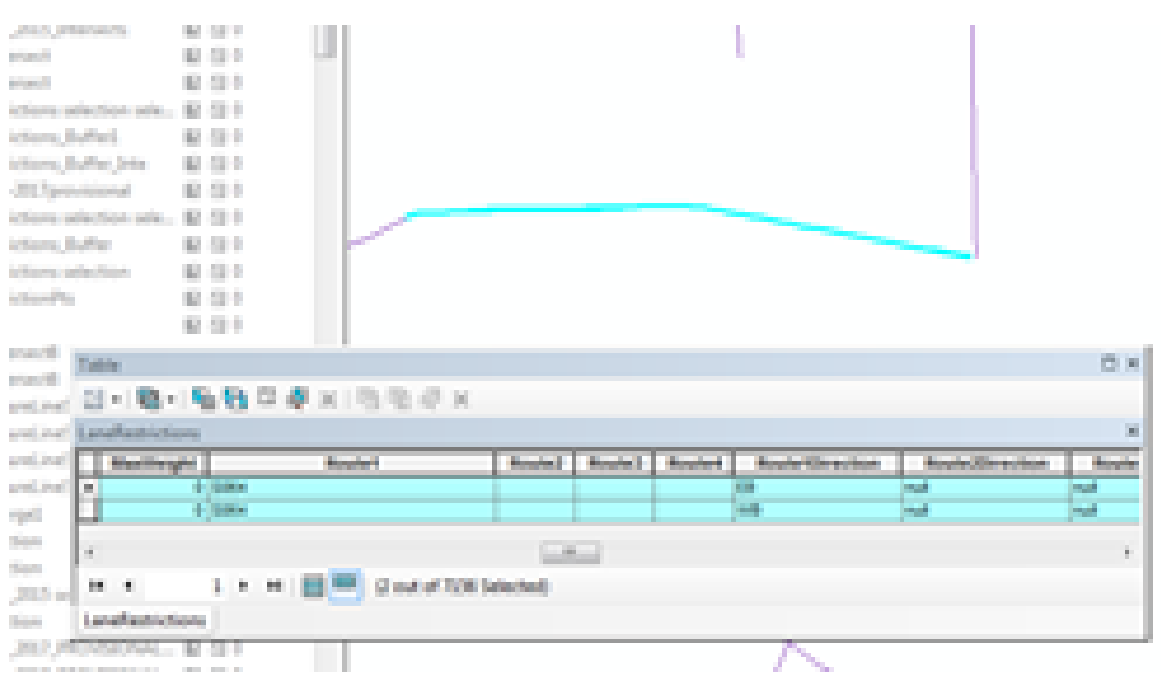




\section{Situation 3}

Situation: Two or more entries- same contract ID, same route, same route direction, different location/different lengths, same duration

Assumption:

- If the multiple entries are adjacent to each other: count as one work zone, sum the individual lengths, and recorded duration.

- If the multiple entries have a gap between them: treat them as separate work zones.
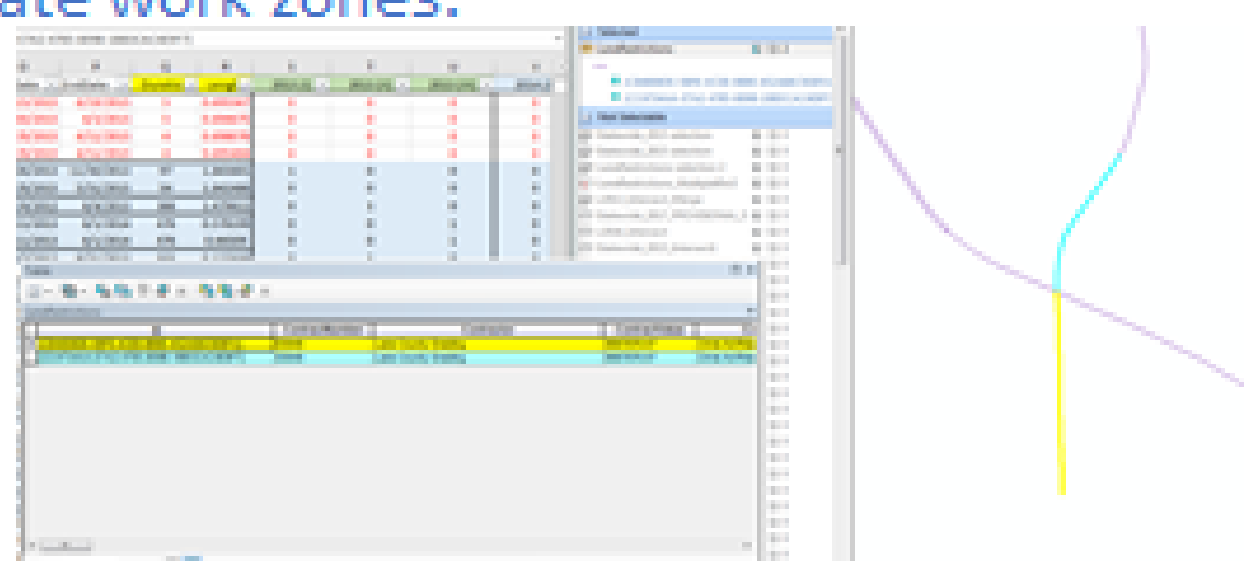


\section{Situation 4}

Situation: Multiple entries- Same contract ID, same contractor, different routes/locations, different dates/durations

Assumption: Count each as separate work zones with recorded lengths and durations for each
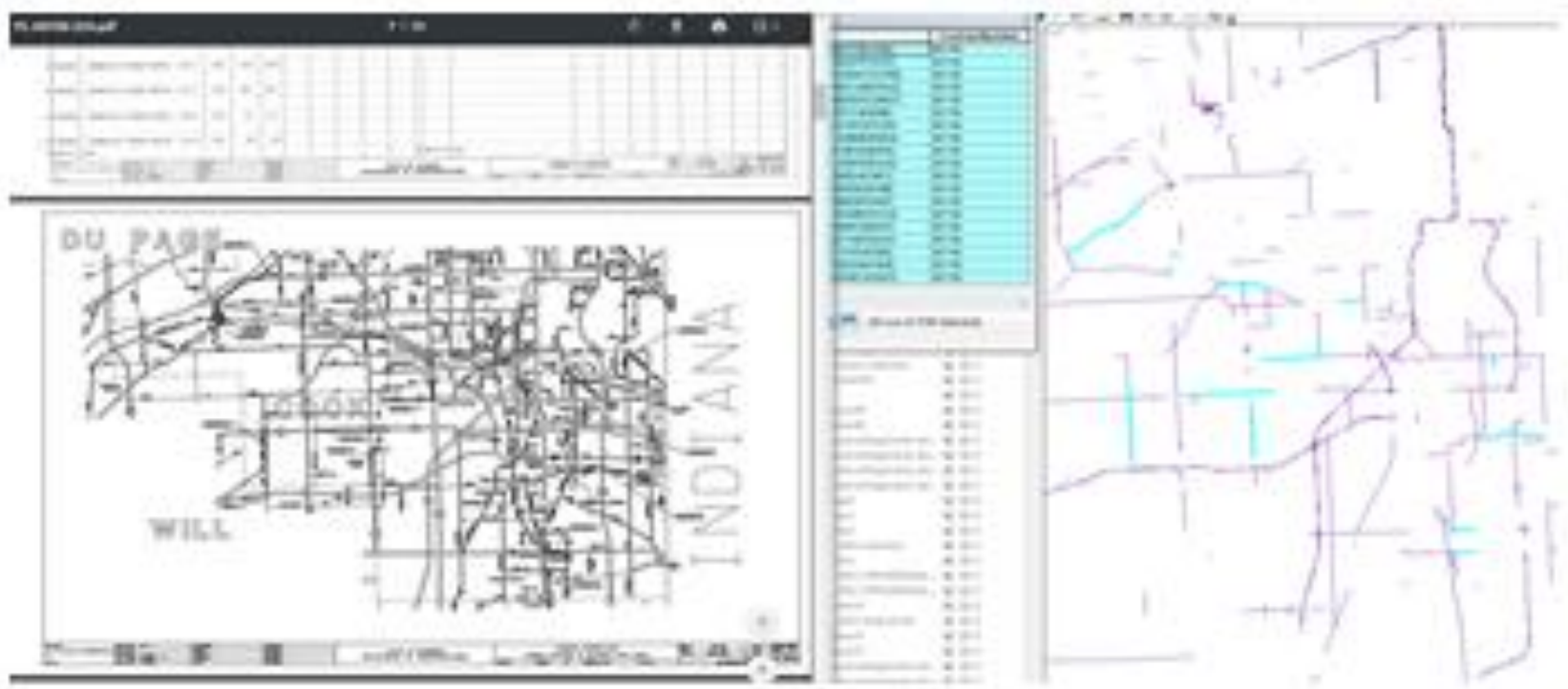


\section{Situation 5}

Situation: Two or more entries- same contract ID, same route/location, different durations

Assumption: Count as two separate work zones unless the end date of one is the start date of the next

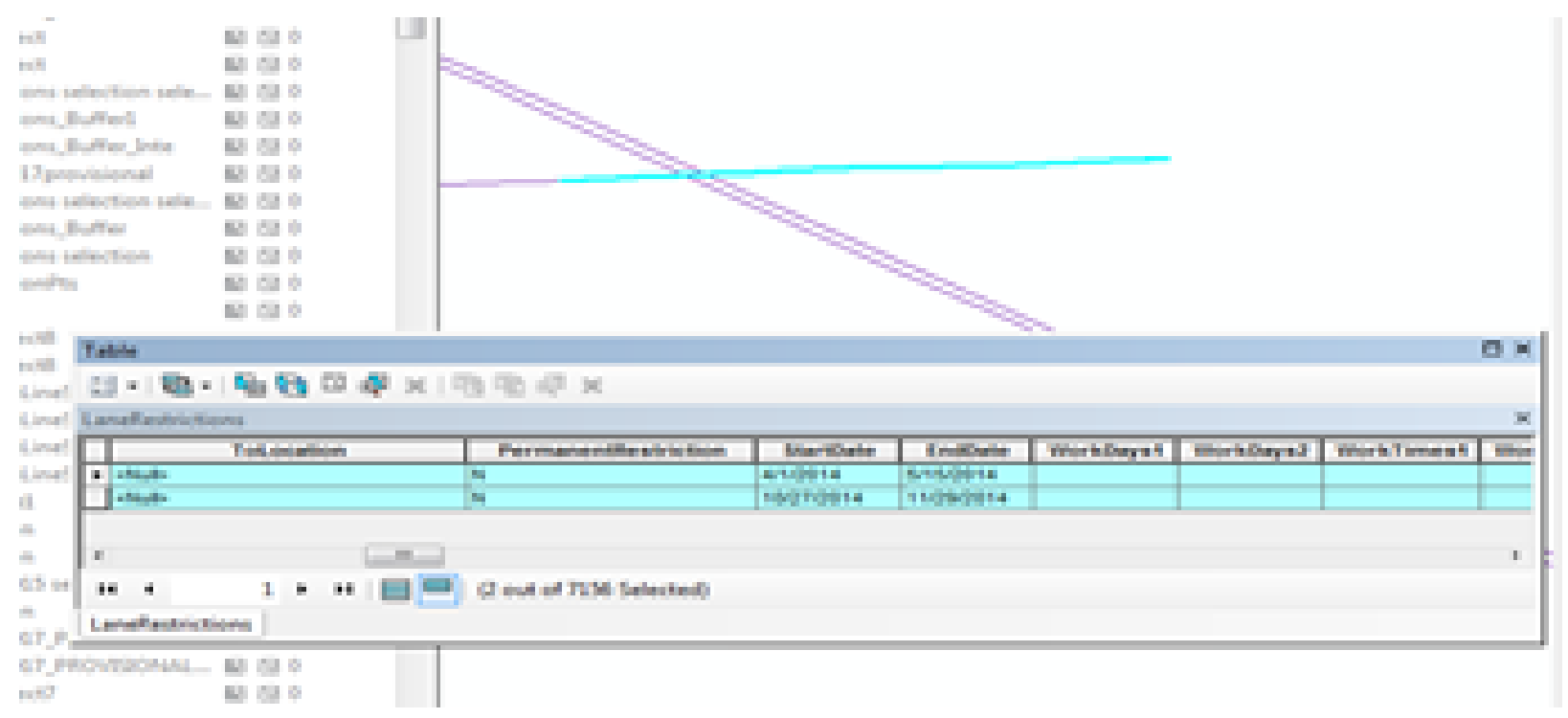




\section{Situation 6}

Situation: "Ramp closure"- same contract ID, different durations

Assumption: Do not take the length of the ramps into consideration but note that the roadway work zone has ramp closures
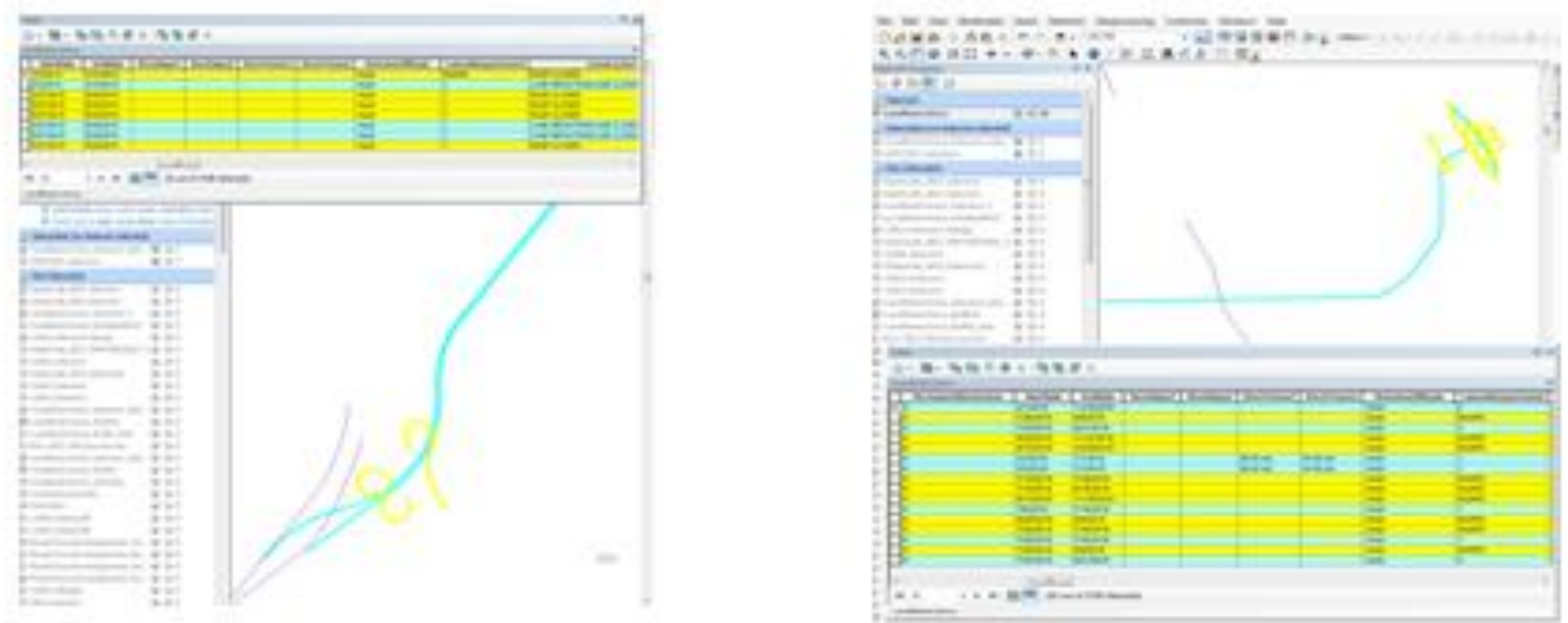


\section{Point Work Zone Situations Issues and Assumptions for Counts}




\section{Situation 1}

Situation: 2 or more points close in distance (a mile or less a part)

Assumption: Count as one work zone, add the lengths and take one duration

- Multiple points should be considered a single work zone only if the durations match up, otherwise count as different work zones.
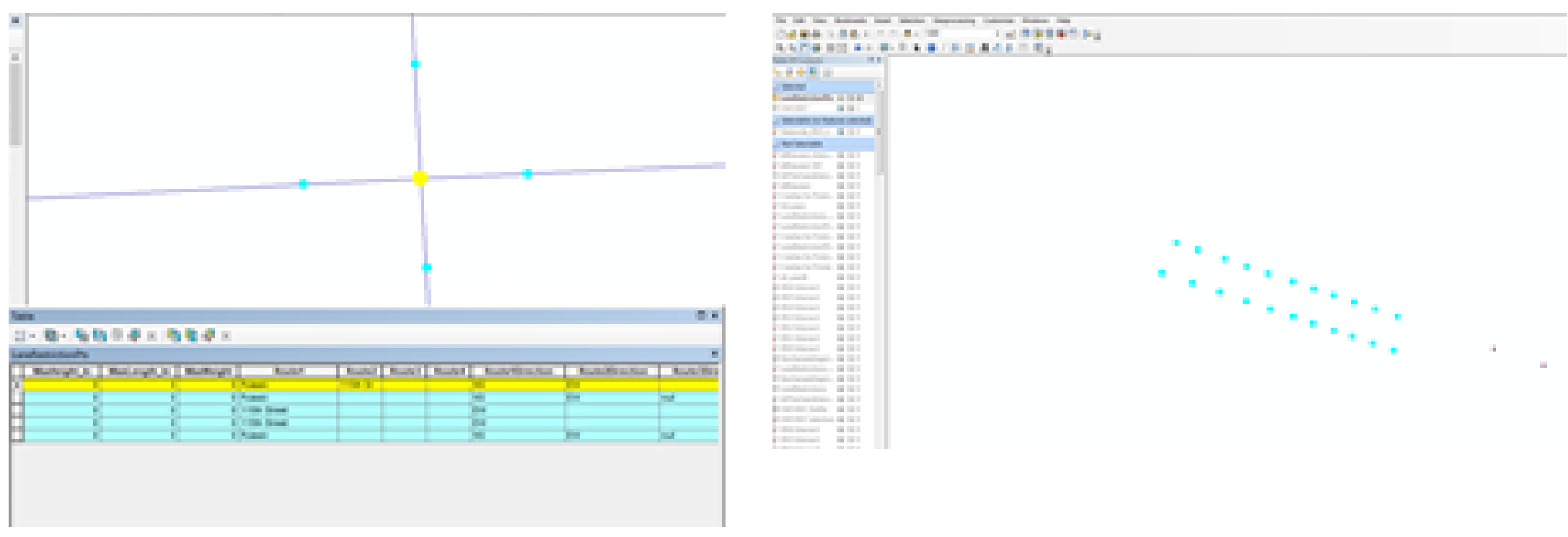


\section{Situation 2}

Situation: Two or more points more than a mile a part

Assumption: Count as multiple work zones, take their individual lengths and take their individual durations

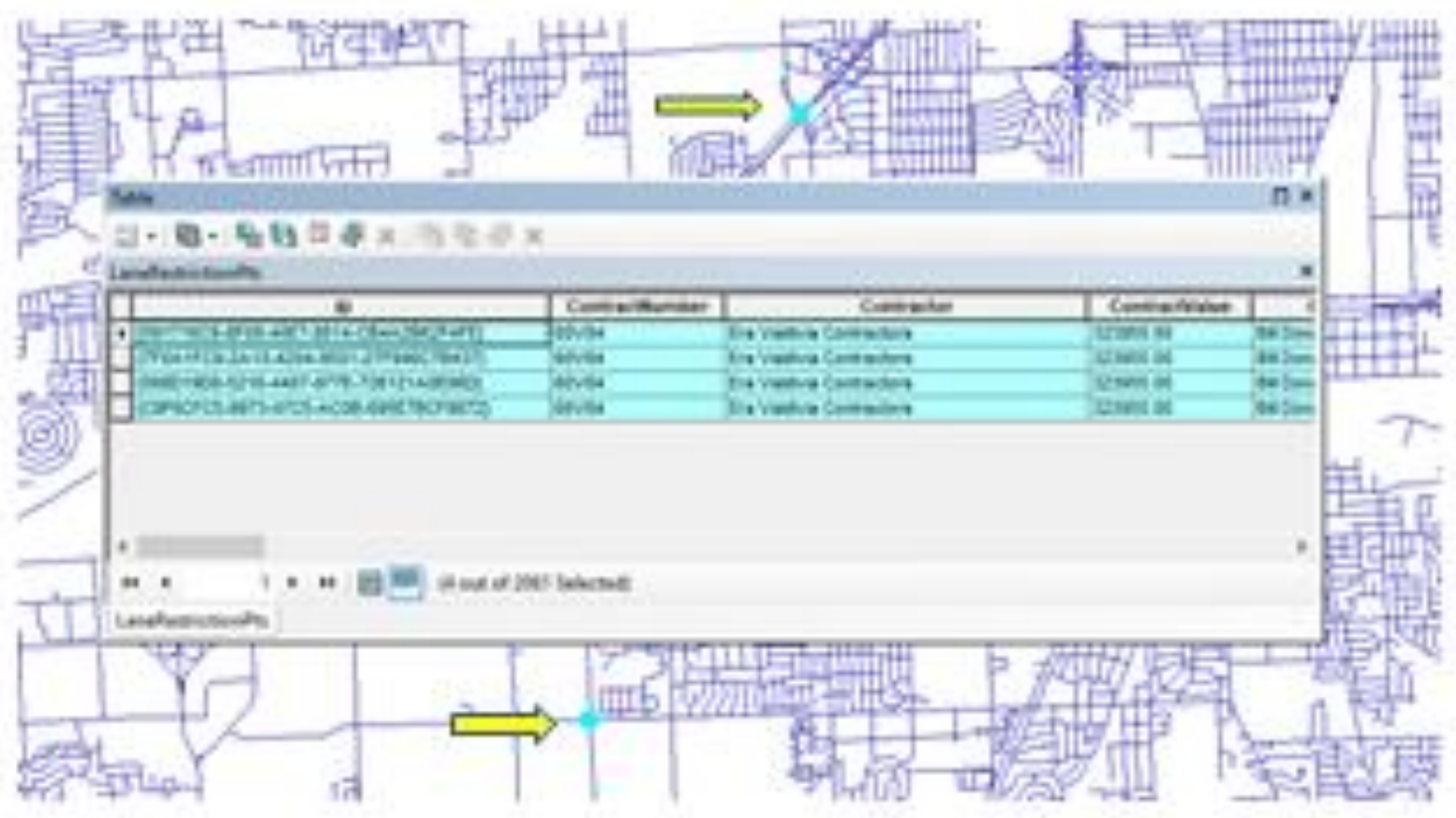




\section{Situation 3}

Situation: The length of the point work zone is not provided in GIS

Assumption:

- If the eplans have a length: take that as the length of the work zone.

- If the eplans do not have a length, follow situations $3 a, 3 b$, or $3 c$
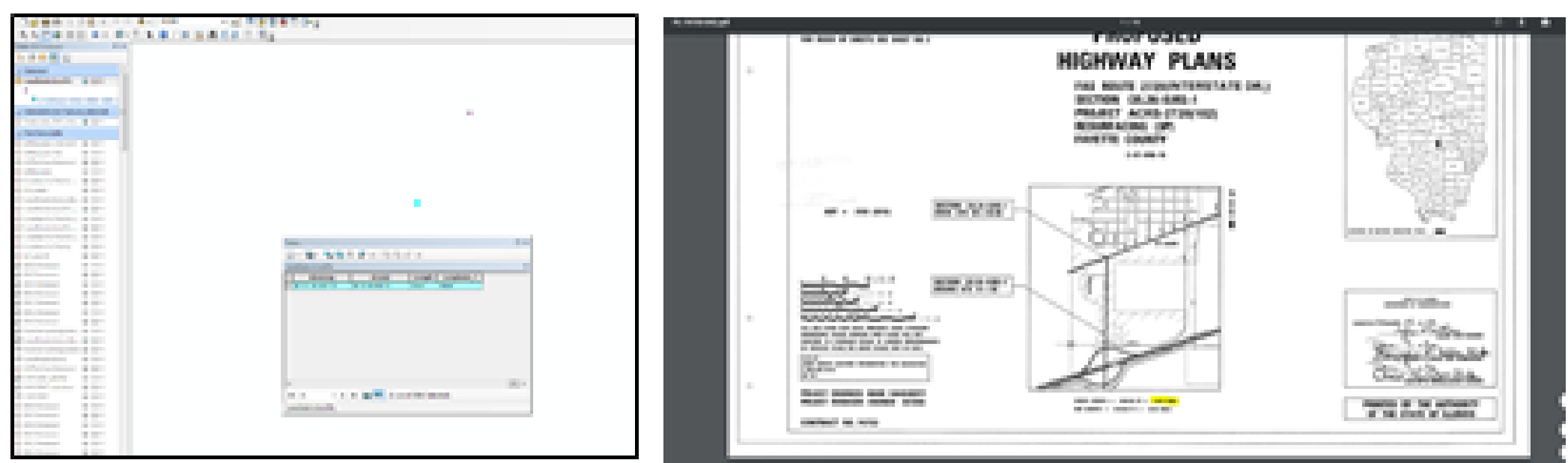


\section{Situation 3a}

Situation: the point has no length in the eplans and shows up as a bridge in Google Earth Assumption: take the length of the bridge plus 0.25 miles upstream and downstream as the length of the work zone
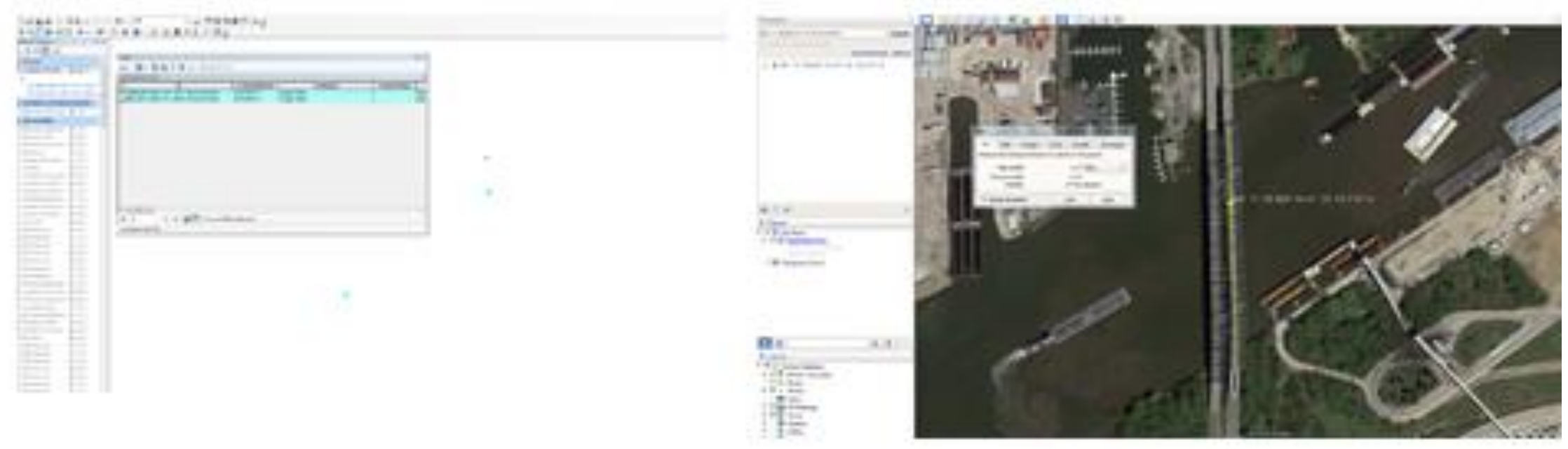


\section{Situation $3 b$}

Situation: the point has no length in the eplans and shows up as a road in Google Earth

Assumption: length assumed as $1,000^{\prime}$ if located on an Interstate, and $500^{\prime}$ for non-Interstate

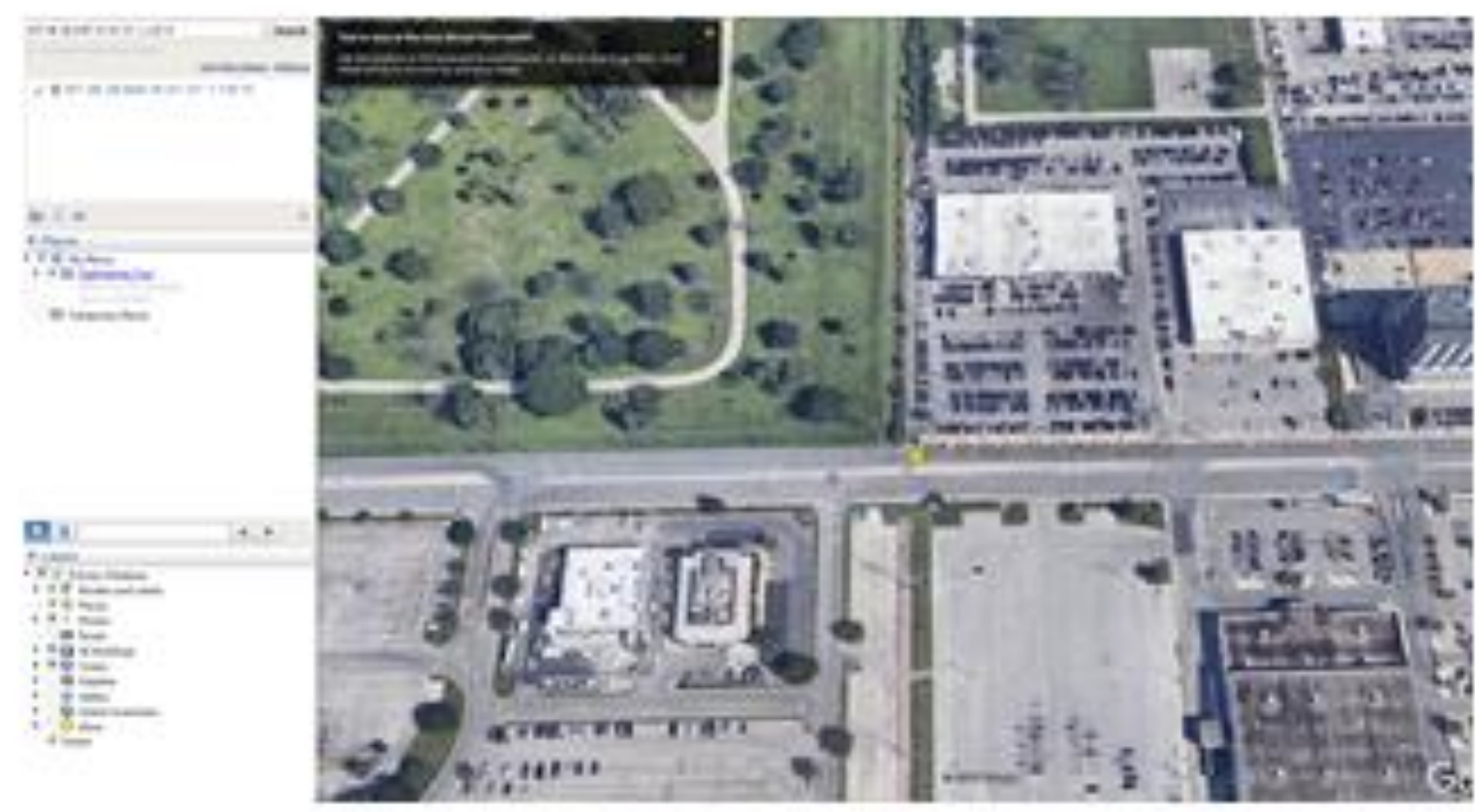


Situation 3c

Situation: the point has no length in the eplans and shows up as a railroad in Google Earth Assumption: length assumed as $500^{\prime}$

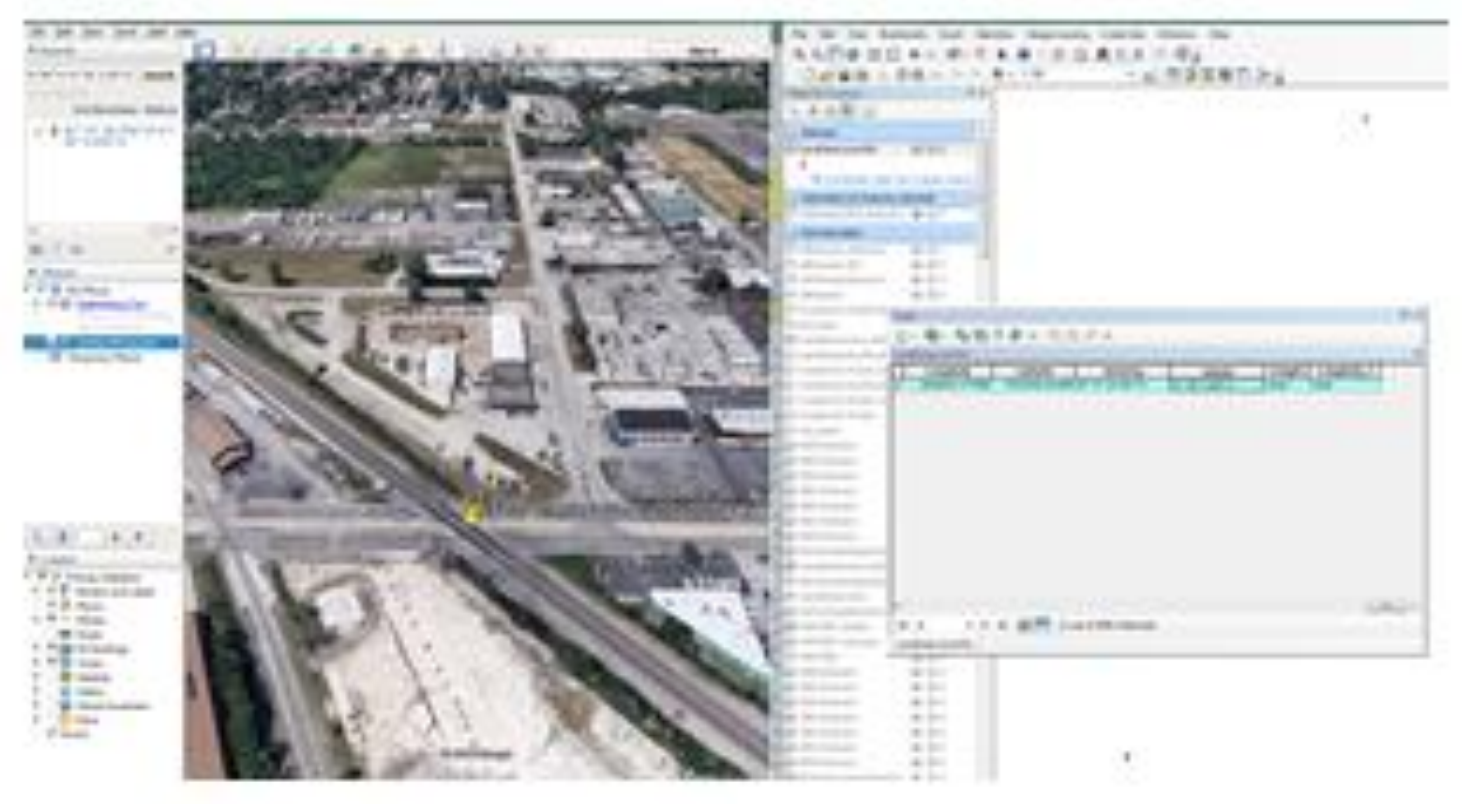


APPENDIX B: ANNUAL WORK ZONE CRASH FREQUENCIES, EXPOSURE VARIABLES, AND CRASH RATES FOR IDOT ROADS 2013-2017 


\begin{tabular}{|c|c|c|c|c|c|c|}
\hline \multirow{2}{*}{\multicolumn{2}{|c|}{ Description }} & \multicolumn{5}{|c|}{ Years } \\
\hline & & 2013 & 2014 & 2015 & 2016 & 2017 \\
\hline \multirow{9}{*}{$\begin{array}{l}\text { Work Zone } \\
\text { Crash } \\
\text { Frequencies } \\
\text { (IDOT } \\
\text { Roads) }\end{array}$} & No. of Work Zone (WZ) Crashes & 1,794 & 2,749 & 4,197 & 3,882 & 3,457 \\
\hline & No. of Fatal (K) WZ Crashes & 15 & 13 & 33 & 32 & 11 \\
\hline & No. of A-Injury WZ crashes & 60 & 93 & 121 & 127 & 97 \\
\hline & No. of K-A WZ Crashes & 75 & 106 & 154 & 159 & 108 \\
\hline & No. of Injury WZ Crashes $(A, B, C)$ & 414 & 694 & 868 & 830 & 599 \\
\hline & No. of Fatal and Injury $(K, A, B, C) W Z$ crashes & 429 & 707 & 901 & 862 & 610 \\
\hline & No. of WZ Fatalities & 17 & 18 & 41 & 27 & 11 \\
\hline & No. of WZ Injuries & 576 & 991 & 1,308 & 1,245 & 853 \\
\hline & No. of WZ Fatalities and Injuries & 593 & 1,009 & 1,349 & 1,272 & 864 \\
\hline \multirow{4}{*}{$\begin{array}{c}\text { Wok Zone } \\
\text { Exposure } \\
\text { Measures } \\
\text { (IDOT } \\
\text { Roads) }\end{array}$} & No. of Work Zones & 690 & 857 & 914 & 962 & 1,058 \\
\hline & Work Zone Length (Miles) & 1,938 & 2,250 & 2,208 & 2,247 & 1,835 \\
\hline & Work Zone Duration (Days) & 63,925 & 73,011 & 88,217 & 84,804 & 77,400 \\
\hline & Work Zone Day-Miles & $123,916,677$ & $164,261,705$ & $194,762,335$ & $190,521,730$ & $142,054,002$ \\
\hline \multirow{16}{*}{$\begin{array}{c}\text { Work Zone } \\
\text { Crash Rates } \\
\text { (IDOT } \\
\text { Roads) }\end{array}$} & WZ Crashes per Work Zone & 2.60 & 3.21 & 4.59 & 4.04 & 3.27 \\
\hline & WZ Crashes per Work Zone-Day & 0.028 & 0.038 & 0.048 & 0.046 & 0.045 \\
\hline & WZ Crashes per Work Zone-Mile & 0.93 & 1.22 & 1.90 & 1.73 & 1.88 \\
\hline & WZ Crashes per 100,000 Work Zone-Day-Mile & 1.45 & 1.67 & 2.15 & 2.04 & 2.43 \\
\hline & Fatal and Injury WZ Crashes per Work Zone & 0.62 & 0.82 & 0.99 & 0.90 & 0.58 \\
\hline & Fatal and Injury WZ Crashes per Work Zone-Day & 0.0067 & 0.0097 & 0.0102 & 0.0102 & 0.0079 \\
\hline & Fatal and Injury WZ Crashes per Work Zone-Mile & 0.22 & 0.31 & 0.41 & 0.38 & 0.33 \\
\hline & Fatal and Injury WZ Crashes per 100,000 Work Zone-Day-Mile & 0.35 & 0.43 & 0.46 & 0.45 & 0.43 \\
\hline & WZ Fatalities and Injuries per Work Zone & 0.86 & 1.18 & 1.48 & 1.32 & 0.82 \\
\hline & WZ Fatalities and Injuries per Work Zone-Day & 0.009 & 0.014 & 0.015 & 0.015 & 0.011 \\
\hline & WZ Fatalities and Injuries per Work Zone-Mile & 0.31 & 0.45 & 0.61 & 0.57 & 0.47 \\
\hline & WZ Fatalities and Injuries per 100,000 Work Zone-Day-Mile & 0.48 & 0.61 & 0.69 & 0.67 & 0.61 \\
\hline & K-A WZ Crashes per No. Work Zones & 0.11 & 0.12 & 0.17 & 0.17 & 0.10 \\
\hline & K-A WZ Crashes per Work Zone Days & 0.0012 & 0.0015 & 0.0017 & 0.0019 & 0.0014 \\
\hline & K-A WZ Crashes per Work Zone Miles & 0.039 & 0.047 & 0.070 & 0.071 & 0.059 \\
\hline & K-A WZ Crashes per 100,000 Work Zone-Day-Mile & 0.061 & 0.065 & 0.079 & 0.083 & 0.076 \\
\hline
\end{tabular}


APPENDIX C: DETAILS OF 384 SITE-SPECIFIC WORK ZONES 


\begin{tabular}{|c|c|c|c|c|c|c|c|c|c|c|c|}
\hline \multirow{2}{*}{$\begin{array}{l}\text { Site } \\
\text { No. }\end{array}$} & \multirow{2}{*}{$\begin{array}{l}\text { IDOT } \\
\text { District } \\
\text { No. }\end{array}$} & \multirow{2}{*}{$\begin{array}{l}\text { Functional } \\
\text { Classification }\end{array}$} & \multirow{2}{*}{ Duration (days) } & \multirow{2}{*}{ Length (miles) } & \multirow{2}{*}{$\begin{array}{c}\text { Annual Average } \\
\text { Daily Traffic } \\
\text { (vehicles/day) }\end{array}$} & \multirow{2}{*}{$\begin{array}{l}\text { No. of Lanes } \\
\text { Reduced }\end{array}$} & \multirow{2}{*}{$\begin{array}{l}\text { Speed Limit } \\
\quad(\mathrm{mph})\end{array}$} & \multirow{2}{*}{$\begin{array}{l}\text { Work Zone } \\
\text { Speed Limit } \\
\text { (mph) }\end{array}$} & \multicolumn{3}{|c|}{$\begin{array}{l}\text { Work Zone Crash Frequency by Severity per } \\
\text { Work Zone Days (Confirmed, Likely, Probable) }\end{array}$} \\
\hline & & & & & & & & & KA Crashes & $\begin{array}{c}\text { Injury Crashes } \\
(\mathrm{K}, \mathrm{A}, \mathrm{B}, \mathrm{C})\end{array}$ & $\begin{array}{c}\text { Total } \\
\text { Crashes }\end{array}$ \\
\hline 1 & 1 & Interstate & 158 & 3.2762 & 122,500 & 1 & 55 & 45 & 2 & 14 & 60 \\
\hline 2 & 1 & Interstate & 108 & 2.5678 & 100,300 & 0 & 55 & 45 & 2 & 2 & 6 \\
\hline 3 & 1 & $\begin{array}{c}\text { Other Principal } \\
\text { Arterial }\end{array}$ & 1,043 & 2.5068 & 38,000 & 4 & 45 & 45 & 2 & 20 & 87 \\
\hline 4 & 1 & $\begin{array}{l}\text { Other Principal } \\
\text { Arterial }\end{array}$ & 372 & 0.6210 & 43,700 & 1 & 45 & 35 & 3 & 15 & 67 \\
\hline 5 & 1 & $\begin{array}{c}\text { Other Principal } \\
\text { Arterial }\end{array}$ & 237 & 2.5960 & 23,100 & 2 & 40 & 35 & 1 & 8 & 27 \\
\hline 6 & 1 & $\begin{array}{c}\text { Other Principal } \\
\text { Arterial }\end{array}$ & 232 & 0.7927 & 22,200 & 1 & 45 & 35 & 1 & 3 & 20 \\
\hline 7 & 1 & $\begin{array}{l}\text { Freeway and } \\
\text { Expressway }\end{array}$ & 594 & 0.8168 & 9,100 & 1 & 55 & 40 & 1 & 6 & 20 \\
\hline 8 & 1 & $\begin{array}{c}\text { Other Principal } \\
\text { Arterial }\end{array}$ & 244 & 1.1429 & 45,900 & 1 & 45 & 45 & 2 & 9 & 22 \\
\hline 9 & 1 & $\begin{array}{c}\text { Other Principal } \\
\text { Arterial }\end{array}$ & 353 & 0.4844 & 20,100 & 2 & 40 & 30 & 2 & 6 & 19 \\
\hline 10 & 1 & Minor Arterial & 594 & 0.2852 & 18,500 & 1 & 40 & 35 & 1 & 5 & 15 \\
\hline 11 & 1 & $\begin{array}{l}\text { Other Principal } \\
\text { Arterial }\end{array}$ & 244 & 1.1431 & 45,900 & 1 & 45 & 35 & 1 & 5 & 16 \\
\hline 12 & 1 & $\begin{array}{c}\text { Other Principal } \\
\text { Arterial }\end{array}$ & 113 & 1.1453 & 45,900 & 1 & 45 & 45 & 2 & 4 & 14 \\
\hline 13 & 1 & Minor Arterial & 484 & 0.8073 & 24,100 & 1 & 45 & 35 & 2 & 4 & 13 \\
\hline 14 & 1 & $\begin{array}{l}\text { Other Principal } \\
\text { Arterial }\end{array}$ & 130 & 2.3569 & 26,400 & 1 & 40 & 40 & 3 & 7 & 16 \\
\hline 15 & 1 & $\begin{array}{c}\text { Other Principal } \\
\text { Arterial }\end{array}$ & 209 & 0.9034 & 22,300 & 1 & 35 & 30 & 1 & 6 & 13 \\
\hline 16 & 1 & $\begin{array}{c}\text { Other Principal } \\
\text { Arterial }\end{array}$ & 494 & 1.2869 & 19,400 & 1 & 40 & 35 & 1 & 1 & 12 \\
\hline 17 & 1 & $\begin{array}{c}\text { Other Principal } \\
\text { Arterial }\end{array}$ & 237 & 1.5004 & 23,100 & 2 & 40 & 35 & 1 & 2 & 8 \\
\hline 18 & 1 & $\begin{array}{l}\text { Other Principal } \\
\text { Arterial }\end{array}$ & 281 & 0.2062 & 25,000 & 1 & 40 & 30 & 2 & 6 & 11 \\
\hline 19 & 1 & $\begin{array}{c}\text { Other Principal } \\
\text { Arterial }\end{array}$ & 344 & 0.4045 & 28,100 & 0 & 40 & 40 & 1 & 3 & 29 \\
\hline 20 & 1 & $\begin{array}{c}\text { Other Principal } \\
\text { Arterial }\end{array}$ & 131 & 0.4808 & 20,100 & 2 & 40 & 30 & 1 & 2 & 7 \\
\hline 21 & 1 & Minor Arterial & 237 & 0.9686 & 29,600 & 1 & 45 & 35 & 1 & 2 & 18 \\
\hline 22 & 1 & Minor Arterial & 425 & 0.4742 & 13,400 & 4 & 40 & 35 & 1 & 3 & 8 \\
\hline 23 & 1 & $\begin{array}{c}\begin{array}{c}\text { Other Principal } \\
\text { Arterial }\end{array} \\
\end{array}$ & 118 & 6.5237 & 33,500 & 1 & 55 & 45 & 1 & 1 & 5 \\
\hline 24 & 1 & Minor Arterial & 321 & 1.9482 & 10,600 & 1 & 55 & 45 & 1 & 5 & 9 \\
\hline 25 & 1 & $\begin{array}{l}\text { Other Principal } \\
\text { Arterial }\end{array}$ & 248 & 1.7597 & 38,600 & 1 & 55 & 40 & 1 & 2 & 5 \\
\hline
\end{tabular}




\begin{tabular}{|c|c|c|c|c|c|}
\hline $\begin{array}{l}\text { Site } \\
\text { No. }\end{array}$ & $\begin{array}{c}\text { Pre-Construction Crash Frequency } \\
\text { (Same Duration as WZ with No Overlap) }\end{array}$ & $\begin{array}{l}\text { No. of Intersections/Ramps in } \\
\text { Work Zone }\end{array}$ & Type of Road Closure & $\begin{array}{l}\text { WZ Crash Frequency per WZ Days } \\
\text { Workers Not Present }\end{array}$ & $\begin{array}{c}\text { WZ Crash Frequency per WZ } \\
\text { Days } \\
\text { Workers Present }\end{array}$ \\
\hline 1 & 25 & 8 & Lane Reduction/Closure & 34 & 24 \\
\hline 2 & 10 & 9 & Lane Reduction/Closure & 4 & 0 \\
\hline 3 & 164 & 4 & Lane Reduction/Closure & 66 & 18 \\
\hline 4 & 112 & 10 & Lane Reduction/Closure & 40 & 12 \\
\hline 5 & 72 & 12 & Lane Reduction/Closure & 18 & 8 \\
\hline 6 & 16 & 12 & Lane Reduction/Closure & 10 & 9 \\
\hline 7 & 61 & 5 & Lane Reduction/Closure & 17 & 2 \\
\hline 8 & 15 & 6 & Lane Reduction/Closure & 11 & 11 \\
\hline 9 & 22 & 4 & Lane Reduction/Closure & 16 & 2 \\
\hline 10 & 13 & 2 & Lane Reduction/Closure & 12 & 3 \\
\hline 11 & 18 & 6 & Lane Reduction Closure & 8 & 7 \\
\hline 12 & 15 & 9 & Lane Reduction/Closure & 11 & 3 \\
\hline 13 & 40 & 3 & Intermittent Roadwork & 11 & 3 \\
\hline 14 & 37 & 12 & Intermittent Roadwork & 11 & 4 \\
\hline 15 & 24 & 2 & Lane Reduction/Closure & 7 & 6 \\
\hline 16 & 30 & 4 & Lane Reduction/Closure & 4 & 4 \\
\hline 17 & 60 & 7 & Lane Reduction/Closure & 6 & 2 \\
\hline 18 & 16 & 2 & Intersection Restrictions & 8 & 3 \\
\hline 19 & 0 & 2 & Intermittent Roadwork & 5 & 3 \\
\hline 20 & 3 & 4 & Lane Reduction/Closure & 2 & 5 \\
\hline 21 & 43 & 7 & Lane Reduction/Closure & 4 & 3 \\
\hline 22 & 15 & 0 & Lane Reduction/Closure & 6 & 1 \\
\hline 23 & 20 & 13 & Lane Reduction/Closure & 4 & 1 \\
\hline 24 & 5 & 3 & Lane Reduction/Closure & 5 & 4 \\
\hline 25 & 11 & 7 & Lane Reduction/Closure & 0 & 5 \\
\hline
\end{tabular}




\begin{tabular}{|c|c|c|c|c|c|c|c|c|c|c|c|}
\hline \multirow{2}{*}{$\begin{array}{l}\text { Site } \\
\text { No. }\end{array}$} & \multirow{2}{*}{$\begin{array}{l}\text { IDOT } \\
\text { District } \\
\text { No. }\end{array}$} & \multirow{2}{*}{$\begin{array}{l}\text { Functional } \\
\text { Classification }\end{array}$} & \multirow{2}{*}{ Duration (days) } & \multirow{2}{*}{ Length (miles) } & \multirow{2}{*}{$\begin{array}{c}\text { Annual Average } \\
\text { Daily Traffic } \\
\text { (vehicles/day) }\end{array}$} & \multirow{2}{*}{$\begin{array}{l}\text { No. of Lanes } \\
\text { Reduced }\end{array}$} & \multirow{2}{*}{$\begin{array}{l}\text { Speed Limit } \\
\quad(\mathrm{mph})\end{array}$} & \multirow{2}{*}{$\begin{array}{l}\text { Work Zone } \\
\text { Speed Limit } \\
\text { (mph) }\end{array}$} & \multicolumn{3}{|c|}{$\begin{array}{l}\text { Work Zone Crash Frequency by Severity per } \\
\text { Work Zone Days (Confirmed, Likely, Probable) }\end{array}$} \\
\hline & & & & & & & & & KA Crashes & $\begin{array}{c}\text { Injury Crashes } \\
(\mathrm{K}, \mathrm{A}, \mathrm{B}, \mathrm{C})\end{array}$ & $\begin{array}{c}\text { Total } \\
\text { Crashes }\end{array}$ \\
\hline 26 & 1 & $\begin{array}{c}\text { Other Principal } \\
\text { Arterial } \\
\end{array}$ & 299 & 0.5038 & 15,700 & 1 & 40 & 40 & 1 & 1 & 4 \\
\hline 27 & 1 & $\begin{array}{c}\text { Other Principal } \\
\text { Arterial }\end{array}$ & 122 & 5.6486 & 11,400 & 0 & 55 & 55 & 1 & 3 & 9 \\
\hline 28 & 1 & $\begin{array}{c}\text { Other Principal } \\
\text { Arterial } \\
\end{array}$ & 124 & 4.2304 & 43,100 & 1 & 45 & 45 & 3 & 2 & 7 \\
\hline 29 & 1 & $\begin{array}{c}\text { Other Principal } \\
\text { Arterial }\end{array}$ & 406 & 0.7411 & 11,100 & 0 & 50 & 45 & 1 & 2 & 4 \\
\hline 30 & 1 & $\begin{array}{c}\text { Other Principal } \\
\text { Arterial }\end{array}$ & 84 & 4.5258 & 9,350 & 1 & 55 & 55 & 1 & 2 & 5 \\
\hline 31 & 1 & $\begin{array}{c}\text { Other Principal } \\
\text { Arterial }\end{array}$ & 436 & 0.6060 & 15,300 & 1 & 45 & 45 & 1 & 1 & 4 \\
\hline 32 & 1 & Interstate & 65 & 12.0361 & 120,300 & 0 & 55 & 45 & 2 & 1 & 4 \\
\hline 33 & 1 & $\begin{array}{c}\text { Other Principal } \\
\text { Arterial }\end{array}$ & 217 & 0.2197 & 33,500 & 0 & 40 & 40 & 1 & 2 & 4 \\
\hline 34 & 1 & Major Collector & 64 & 0.7403 & 3,550 & 1 & 20 & 20 & 1 & 1 & 1 \\
\hline 35 & 1 & Minor Arterial & 345 & 0.4931 & 12,200 & 2 & 35 & 35 & 1 & 1 & 4 \\
\hline 36 & 1 & Minor Arterial & 99 & 0.9990 & 16,500 & 1 & 40 & 35 & 1 & 1 & 1 \\
\hline 37 & 1 & Minor Arterial & 82 & 3.2441 & 14,100 & 1 & 50 & 40 & 1 & 1 & 1 \\
\hline 38 & 1 & $\begin{array}{c}\text { Other Principal } \\
\text { Arterial }\end{array}$ & 103 & 0.4816 & 33,000 & 1 & 35 & 35 & 1 & 1 & 1 \\
\hline 39 & 1 & $\begin{array}{c}\text { Other Principal } \\
\text { Arterial }\end{array}$ & 138 & 5.9790 & 33,100 & 1 & 35 & 35 & 2 & 4 & 4 \\
\hline 40 & 1 & Interstate & 31 & 0.5748 & 11,300 & 0 & 65 & 45 & 1 & 2 & 2 \\
\hline 41 & 1 & $\begin{array}{c}\text { Other Principal } \\
\text { Arterial }\end{array}$ & 73 & 2.8299 & 24,300 & 1 & 45 & 45 & 1 & 1 & 4 \\
\hline 42 & 1 & Minor Arterial & 173 & 8.3460 & 5,050 & 1 & 55 & 55 & 1 & 1 & 2 \\
\hline 43 & 1 & $\begin{array}{c}\text { Other Principal } \\
\text { Arterial }\end{array}$ & 794 & 1.4832 & 33,700 & 1 & 45 & 35 & 1 & 11 & 43 \\
\hline 44 & 1 & Interstate & 430 & 3.0524 & 33,412 & 1 & 65 & 45 & 0 & 1 & 25 \\
\hline 45 & 1 & $\begin{array}{c}\text { Other Principal } \\
\text { Arterial }\end{array}$ & 1,370 & 1.9921 & 36,300 & 1 & 35 & 35 & 0 & 9 & 75 \\
\hline 46 & 1 & $\begin{array}{c}\text { Other Principal } \\
\text { Arterial }\end{array}$ & 724 & 2.4317 & 17,500 & 1 & 40 & 35 & 0 & 5 & 28 \\
\hline 47 & 1 & Interstate & 430 & 3.1413 & 49,000 & 1 & 65 & 45 & 0 & 3 & 29 \\
\hline 48 & 1 & $\begin{array}{c}\text { Other Principal } \\
\text { Arterial }\end{array}$ & 712 & 1.2113 & 43,700 & 1 & 45 & 35 & 0 & 4 & 27 \\
\hline 49 & 1 & Interstate & 232 & 0.9808 & 132,900 & 0 & 65 & 45 & 0 & 1 & 13 \\
\hline 50 & 1 & Minor Arterial & 345 & 1.2823 & 30,550 & 2 & 35 & 30 & 0 & 9 & 24 \\
\hline
\end{tabular}




\begin{tabular}{|c|c|c|c|c|c|}
\hline $\begin{array}{l}\text { Site } \\
\text { No. }\end{array}$ & $\begin{array}{l}\text { Pre-Construction Crash Frequency } \\
\text { (Same Duration as WZ with No Overlap) }\end{array}$ & $\begin{array}{l}\text { No. of Intersections/Ramps in } \\
\text { Work Zone }\end{array}$ & Type of Road Closure & $\begin{array}{l}\text { WZ Crash Frequency per WZ Days } \\
\text { Workers Not Present }\end{array}$ & $\begin{array}{c}\text { WZ Crash Frequency per WZ } \\
\text { Days } \\
\text { Workers Present }\end{array}$ \\
\hline 26 & 12 & 1 & Lane Reduction/Closure & 3 & 1 \\
\hline 27 & 5 & 7 & Lane Reduction/Closure & 5 & 1 \\
\hline 28 & 18 & 25 & Lane Reduction/Closure & 3 & 1 \\
\hline 29 & 15 & 1 & Intersection Restriction & 1 & 3 \\
\hline 30 & 2 & 8 & One-Way Traffic with Flaggers & 2 & 2 \\
\hline 31 & 7 & 2 & Lane Reduction/Closure & 2 & 0 \\
\hline 32 & 39 & 15 & Shoulder Closed & 0 & 2 \\
\hline 33 & 7 & 13 & Intersection Restrictions & 3 & 0 \\
\hline 34 & 1 & 7 & Lane Reduction/Closure & 1 & 0 \\
\hline 35 & 6 & 3 & Lane Reduction/Closure & 1 & 0 \\
\hline 36 & 6 & 2 & Lane Reduction/Closure & 1 & 0 \\
\hline 37 & 15 & 13 & One-Way Traffic with Flaggers & 1 & 0 \\
\hline 38 & 48 & 3 & Intersection Restrictions & 0 & 1 \\
\hline 39 & 54 & 32 & Lane Reduction/Closure & 4 & 0 \\
\hline 40 & 3 & 2 & Lane Reduction/Closure & 2 & 0 \\
\hline 41 & 11 & 5 & Lane Reduction/Closure & 1 & 0 \\
\hline 42 & 3 & 9 & Lane Reduction/Closure & 0 & 1 \\
\hline 43 & 69 & 4 & Lane Reduction/Closure & 30 & 10 \\
\hline 44 & 39 & 4 & Lane Reduction/Closure & 19 & 3 \\
\hline 45 & 720 & 8 & Lane Reduction/Closure & 24 & 5 \\
\hline 46 & 95 & 13 & Lane Reduction/Closure & 19 & 3 \\
\hline 47 & 23 & 4 & Lane Reduction/Closure & 18 & 2 \\
\hline 48 & 171 & 7 & Lane Reduction/Closure & 13 & 4 \\
\hline 49 & 32 & 6 & Lane Reduction/Closure & 6 & 7 \\
\hline 50 & 28 & 16 & Lane Reduction/Closure & 16 & 4 \\
\hline
\end{tabular}




\begin{tabular}{|c|c|c|c|c|c|c|c|c|c|c|c|}
\hline \multirow{2}{*}{$\begin{array}{l}\text { Site } \\
\text { No. }\end{array}$} & \multirow{2}{*}{$\begin{array}{l}\text { IDOT } \\
\text { District } \\
\text { No. }\end{array}$} & \multirow{2}{*}{$\begin{array}{l}\text { Functional } \\
\text { Classification }\end{array}$} & \multirow{2}{*}{ Duration (days) } & \multirow{2}{*}{ Length (miles) } & \multirow{2}{*}{$\begin{array}{c}\text { Annual Average } \\
\text { Daily Traffic } \\
\text { (vehicles/day) }\end{array}$} & \multirow{2}{*}{$\begin{array}{l}\text { No. of Lanes } \\
\text { Reduced }\end{array}$} & \multirow{2}{*}{$\begin{array}{l}\text { Speed Limit } \\
\text { (mph) }\end{array}$} & \multirow{2}{*}{$\begin{array}{l}\text { Work Zone } \\
\text { Speed Limit } \\
\text { (mph) }\end{array}$} & \multicolumn{3}{|c|}{$\begin{array}{l}\text { Work Zone Crash Frequency by Severity per } \\
\text { Work Zone Days (Confirmed, Likely, Probable) }\end{array}$} \\
\hline & & & & & & & & & KA Crashes & $\begin{array}{l}\text { Injury Crashes } \\
(\mathrm{K}, \mathrm{A}, \mathrm{B}, \mathrm{C})\end{array}$ & $\begin{array}{c}\text { Total } \\
\text { Crashes }\end{array}$ \\
\hline 51 & 1 & $\begin{array}{c}\text { Other Principal } \\
\text { Arterial }\end{array}$ & 372 & 1.3083 & 55,000 & 1 & 40 & 35 & 0 & 2 & 11 \\
\hline 52 & 1 & $\begin{array}{l}\text { Other Principal } \\
\text { Arterial }\end{array}$ & 864 & 1.3748 & 41,000 & 1 & 50 & 40 & 0 & 3 & 13 \\
\hline 53 & 1 & $\begin{array}{c}\text { Other Principal } \\
\text { Arterial }\end{array}$ & 724 & 0.7986 & 33,700 & 1 & 40 & 30 & 0 & 3 & 10 \\
\hline 54 & 1 & $\begin{array}{c}\text { Other Principal } \\
\text { Arterial }\end{array}$ & 409 & 0.1180 & 22,300 & 0 & 35 & 30 & 0 & 2 & 10 \\
\hline 55 & 1 & Minor Arterial & 296 & 2.0539 & 19,700 & 2 & 35 & 30 & 0 & 3 & 10 \\
\hline 56 & 1 & Interstate & 158 & 3.2753 & 122,500 & 1 & 55 & 45 & 0 & 2 & 8 \\
\hline 57 & 1 & Interstate & 847 & 2.0569 & 257,000 & 1 & 55 & 45 & 0 & 1 & 6 \\
\hline 1058 & 1 & $\begin{array}{l}\text { Other Principal } \\
\text { Arterial }\end{array}$ & 409 & 1.2992 & 55,000 & 1 & 40 & 30 & 0 & 1 & 10 \\
\hline 579 & 1 & $\begin{array}{c}\text { Other Principal } \\
\text { Arterial }\end{array}$ & 139 & 5.0874 & 16,500 & 1 & 55 & 30 & 0 & 3 & 7 \\
\hline 650 & 1 & $\begin{array}{l}\text { Other Principal } \\
\text { Arterial }\end{array}$ & 411 & 2.1205 & 15,300 & 0 & 45 & 35 & 0 & 2 & 5 \\
\hline 61 & 1 & $\begin{array}{c}\text { Other Principal } \\
\text { Arterial }\end{array}$ & 182 & 0.1142 & 22,900 & 2 & 40 & 35 & 0 & 1 & 3 \\
\hline 62 & 1 & Minor Arterial & 409 & 0.0912 & 19,100 & 1 & 40 & 30 & 0 & 3 & 5 \\
\hline 63 & 1 & Interstate & 199 & 2.4212 & 68,900 & 0 & 70 & 55 & 0 & 2 & 4 \\
\hline 64 & 1 & Minor Arterial & 61 & 6.7434 & 7,800 & 1 & 55 & 55 & 0 & 1 & 2 \\
\hline 65 & 1 & Interstate & 151 & 3.1524 & 65,600 & 1 & 65 & 45 & 0 & 1 & 18 \\
\hline 66 & 1 & $\begin{array}{l}\text { Other Principal } \\
\text { Arterial }\end{array}$ & 442 & 1.6173 & 18,400 & 1 & 45 & 35 & 0 & 4 & 32 \\
\hline 67 & 1 & $\begin{array}{c}\text { Other Principal } \\
\text { Arterial }\end{array}$ & 223 & 0.3466 & 37,700 & 1 & 40 & 35 & 0 & 1 & 6 \\
\hline 768 & 1 & $\begin{array}{c}\text { Other Principal } \\
\text { Arterial }\end{array}$ & 503 & 3.9599 & 37,300 & 1 & 45 & 45 & 0 & 1 & 7 \\
\hline 69 & 1 & $\begin{array}{c}\text { Other Principal } \\
\text { Arterial }\end{array}$ & 835 & 5.0076 & 19,900 & 1 & 50 & 45 & 0 & 2 & 5 \\
\hline 70 & 1 & Minor Arterial & 533 & 0.9797 & 27,100 & 1 & 35 & 30 & 0 & 4 & 8 \\
\hline 71 & 1 & $\begin{array}{c}\text { Other Principal } \\
\text { Arterial }\end{array}$ & 85 & 2.1334 & 36,900 & 1 & 35 & 35 & 0 & 1 & 3 \\
\hline 72 & 1 & $\begin{array}{c}\text { Other Principal } \\
\text { Arterial }\end{array}$ & 124 & 3.8917 & 52,500 & 1 & 50 & 45 & 0 & 2 & 5 \\
\hline 73 & 1 & $\begin{array}{c}\text { Other Principal } \\
\text { Arterial }\end{array}$ & 115 & 0.7889 & 18,800 & 1 & 40 & 40 & 0 & 1 & 3 \\
\hline 74 & 1 & $\begin{array}{l}\text { Other Principal } \\
\text { Arterial }\end{array}$ & 98 & 3.7132 & 22,600 & 0 & 45 & 45 & 0 & 1 & 2 \\
\hline 75 & 1 & $\begin{array}{l}\text { Other Principal } \\
\text { Arterial }\end{array}$ & 141 & 3.2285 & 29,900 & 1 & 40 & 25 & 0 & 0 & 9 \\
\hline
\end{tabular}




\begin{tabular}{|c|c|c|c|c|c|}
\hline $\begin{array}{l}\text { Site } \\
\text { No. }\end{array}$ & $\begin{array}{l}\text { Pre-Construction Crash Frequency } \\
\text { (Same Duration as WZ with No Overlap) }\end{array}$ & $\begin{array}{l}\text { No. of Intersections/Ramps in } \\
\text { Work Zone }\end{array}$ & Type of Road Closure & $\begin{array}{l}\text { WZ Crash Frequency per WZ Days } \\
\text { Workers Not Present }\end{array}$ & $\begin{array}{c}\text { WZ Crash Frequency per WZ } \\
\text { Days } \\
\text { Workers Present }\end{array}$ \\
\hline 51 & 60 & 3 & Lane Reduction/Closure & 10 & 1 \\
\hline 52 & 27 & 6 & Lane Reduction/Closure & 11 & 0 \\
\hline 53 & 42 & 1 & Lane Reduction/Closure & 6 & 4 \\
\hline 54 & 24 & 1 & Temporary Changes & 5 & 4 \\
\hline 55 & 53 & 19 & Lane Reduction/Closure & 6 & 4 \\
\hline 56 & 30 & 10 & Lane Reduction/Closure & 3 & 5 \\
\hline 57 & 545 & 3 & Lane Reduction/Closure & 3 & 3 \\
\hline 58 & 57 & 3 & Lane Reduction/Closure & 2 & 3 \\
\hline 59 & 27 & 22 & One-Way Traffic with Flaggers & 6 & 1 \\
\hline 60 & 10 & 8 & Lane Reduction/Closure & 4 & 1 \\
\hline 61 & 15 & 1 & Lane Reduction/Closure & 3 & 0 \\
\hline 62 & 24 & 1 & Temporary Changes & 4 & 1 \\
\hline 63 & 3 & 2 & Lane Reduction/Closure & 4 & 0 \\
\hline 64 & 0 & 9 & One-Way Traffic with Flaggers & 2 & 0 \\
\hline 65 & 17 & 4 & Lane Reduction/Closure & 14 & 1 \\
\hline 66 & 53 & 3 & Lane Reduction/Closure & 13 & 2 \\
\hline 67 & 15 & 5 & Lane Reduction/Closure & 4 & 2 \\
\hline 68 & 54 & 14 & Lane Reduction/Closure & 4 & 1 \\
\hline 69 & 48 & 7 & Lane Reduction/Closure & 3 & 2 \\
\hline 70 & 56 & 5 & Lane Reduction/Closure & 5 & 2 \\
\hline 71 & 44 & 15 & Lane Reduction/Closure & 3 & 0 \\
\hline 72 & 13 & 26 & Lane Reduction/Closure & 2 & 2 \\
\hline 73 & 11 & 4 & Lane Reduction/Closure & 2 & 1 \\
\hline 74 & 13 & 11 & Lane Reduction/Closure & 2 & 0 \\
\hline 75 & 65 & 21 & Intermittent Roadwork & 6 & 2 \\
\hline
\end{tabular}




\begin{tabular}{|c|c|c|c|c|c|c|c|c|c|c|c|}
\hline \multirow{2}{*}{$\begin{array}{l}\text { Site } \\
\text { No. }\end{array}$} & \multirow{2}{*}{$\begin{array}{l}\text { IDOT } \\
\text { District } \\
\text { No. }\end{array}$} & \multirow{2}{*}{$\begin{array}{l}\text { Functional } \\
\text { Classification }\end{array}$} & \multirow{2}{*}{ Duration (days) } & \multirow{2}{*}{ Length (miles) } & \multirow{2}{*}{$\begin{array}{l}\text { Annual Average } \\
\text { Daily Traffic } \\
\text { (vehicles/day) }\end{array}$} & \multirow{2}{*}{$\begin{array}{l}\text { No. of Lanes } \\
\text { Reduced }\end{array}$} & \multirow{2}{*}{$\begin{array}{l}\text { Speed Limit } \\
\quad(\mathrm{mph})\end{array}$} & \multirow{2}{*}{$\begin{array}{l}\text { Work Zone } \\
\text { Speed Limit } \\
\text { (mph) }\end{array}$} & \multicolumn{3}{|c|}{$\begin{array}{l}\text { Work Zone Crash Frequency by Severity per } \\
\text { Work Zone Days (Confirmed, Likely, Probable) }\end{array}$} \\
\hline & & & & & & & & & KA Crashes & $\begin{array}{c}\text { Injury Crashes } \\
(\mathrm{K}, \mathrm{A}, \mathrm{B}, \mathrm{C})\end{array}$ & $\begin{array}{c}\text { Total } \\
\text { Crashes }\end{array}$ \\
\hline 76 & 1 & $\begin{array}{l}\text { Freeway and } \\
\text { Expressway }\end{array}$ & 594 & 0.7812 & 38,000 & 1 & 40 & 35 & 0 & 0 & 8 \\
\hline 77 & 1 & $\begin{array}{c}\text { Other Principal } \\
\text { Arterial }\end{array}$ & 345 & 0.3076 & 12,000 & 2 & 40 & 40 & 0 & 0 & 8 \\
\hline 78 & 1 & Minor Arterial & 414 & 0.5556 & 16,300 & 1 & 45 & 35 & 0 & 0 & 5 \\
\hline 79 & 1 & Interstate & 577 & 0.4505 & 36,500 & 0 & 55 & 45 & 0 & 0 & 5 \\
\hline 80 & 1 & $\begin{array}{c}\text { Other Principal } \\
\text { Arterial }\end{array}$ & 201 & 0.3727 & 25,100 & 2 & 35 & 35 & 0 & 0 & 5 \\
\hline 81 & 1 & $\begin{array}{l}\text { Freeway and } \\
\text { Expressway }\end{array}$ & 852 & 2.1288 & 31,700 & 1 & 55 & 45 & 0 & 0 & 4 \\
\hline 82 & 1 & Interstate & 65 & 12.0059 & 147,100 & 0 & 55 & 45 & 0 & 0 & 6 \\
\hline 83 & 1 & $\begin{array}{c}\text { Other Principal } \\
\text { Arterial }\end{array}$ & 94 & 2.5015 & 38,500 & 0 & 45 & 35 & 0 & 0 & 4 \\
\hline 84 & 1 & Interstate & 712 & 0.5789 & 20,200 & 1 & 45 & 45 & 0 & 0 & 3 \\
\hline 85 & 1 & $\begin{array}{c}\text { Other Principal } \\
\text { Arterial }\end{array}$ & 54 & 1.9892 & 11,500 & 1 & 50 & 50 & 0 & 0 & 3 \\
\hline 86 & 1 & Interstate & 107 & 2.5842 & 139,600 & 0 & 55 & 50 & 0 & 0 & 3 \\
\hline 87 & 1 & $\begin{array}{c}\text { Other Principal } \\
\text { Arterial }\end{array}$ & 531 & 0.8428 & 22,500 & 1 & 35 & 30 & 0 & 0 & 4 \\
\hline 88 & 1 & $\begin{array}{c}\text { Freeway and } \\
\text { Expressway }\end{array}$ & 853 & 2.1531 & 43,800 & 1 & 55 & 45 & 0 & 0 & 4 \\
\hline 89 & 1 & Interstate & 67 & 0.1184 & 194,400 & 4 & 45 & 45 & 0 & 0 & 2 \\
\hline 90 & 1 & $\begin{array}{c}\text { Other Principal } \\
\text { Arterial }\end{array}$ & 243 & 0.2588 & 23,000 & 1 & 45 & 40 & 0 & 0 & 2 \\
\hline 91 & 1 & $\begin{array}{c}\text { Other Principal } \\
\text { Arterial }\end{array}$ & 125 & 0.2937 & 26,100 & 0 & 40 & 40 & 0 & 0 & 2 \\
\hline 92 & 1 & $\begin{array}{c}\text { Other Principal } \\
\text { Arterial }\end{array}$ & 131 & 0.0534 & 17,400 & 0 & 40 & 35 & 0 & 0 & 2 \\
\hline 93 & 1 & $\begin{array}{c}\text { Other Principal } \\
\text { Arterial }\end{array}$ & 148 & 3.5225 & 27,500 & 1 & 40 & 35 & 0 & 0 & 2 \\
\hline 94 & 1 & $\begin{array}{l}\text { Other Principal } \\
\text { Arterial }\end{array}$ & 256 & 2.0505 & 27,500 & 1 & 50 & 45 & 0 & 0 & 5 \\
\hline 95 & 1 & $\begin{array}{c}\text { Other Principal } \\
\text { Arterial }\end{array}$ & 135 & 1.2519 & 26,000 & 2 & 35 & 35 & 0 & 0 & 2 \\
\hline 96 & 1 & $\begin{array}{c}\text { Other Principal } \\
\text { Arterial }\end{array}$ & 67 & 7.5306 & 17,500 & 1 & 45 & 45 & 0 & 0 & 2 \\
\hline 97 & 1 & Minor Arterial & 342 & 0.1106 & 12,000 & 5 & 30 & 30 & 0 & 0 & 2 \\
\hline 98 & 1 & Collector & 122 & 0.9396 & 8,500 & 0 & 35 & 35 & 0 & 0 & 2 \\
\hline 99 & 1 & $\begin{array}{c}\text { Other Principal } \\
\text { Arterial }\end{array}$ & 283 & 1.9167 & 43,000 & 1 & 50 & 40 & 0 & 0 & 1 \\
\hline 100 & 1 & Interstate & 144 & 0.2365 & 45,500 & 3 & 35 & 35 & 0 & 0 & 1 \\
\hline
\end{tabular}




\begin{tabular}{|c|c|c|c|c|c|}
\hline $\begin{array}{l}\text { Site } \\
\text { No. }\end{array}$ & $\begin{array}{l}\text { Pre-Construction Crash Frequency } \\
\text { (Same Duration as WZ with No Overlap) }\end{array}$ & $\begin{array}{l}\text { No. of Intersections/Ramps in } \\
\text { Work Zone }\end{array}$ & Type of Road Closure & $\begin{array}{l}\text { WZ Crash Frequency per WZ Days } \\
\text { Workers Not Present }\end{array}$ & $\begin{array}{c}\text { WZ Crash Frequency per WZ } \\
\text { Days } \\
\text { Workers Present }\end{array}$ \\
\hline 76 & 36 & 2 & Lane Reduction/Closure & 4 & 3 \\
\hline 77 & 21 & 2 & Lane Reduction/Closure & 5 & 0 \\
\hline 78 & 20 & 2 & Lane Reduction/Closure & 3 & 1 \\
\hline 79 & 226 & 4 & Lane Reduction/Closure & 3 & 1 \\
\hline 80 & 32 & 4 & Lane Reduction/Closure & 3 & 1 \\
\hline 81 & 42 & 2 & Lane Reduction/Closure & 2 & 1 \\
\hline 82 & 49 & 21 & Shoulder Closed & 3 & 0 \\
\hline 83 & 13 & 6 & Lane Reduction/Closure & 3 & 0 \\
\hline 84 & 85 & 4 & Lane Reduction/Closure & 2 & 1 \\
\hline 85 & 7 & 12 & Lane Reduction/Closure & 0 & 3 \\
\hline 86 & 5 & 14 & Lane Reduction/Closure & 3 & 0 \\
\hline 87 & 51 & 7 & Lane Reduction/Closure & 2 & 1 \\
\hline 88 & 38 & 1 & Lane Reduction/Closure & 1 & 1 \\
\hline 89 & 23 & 3 & Lane Reduction/Closure & 0 & 2 \\
\hline 90 & 6 & 1 & Lane Reduction/Closure & 2 & 0 \\
\hline 91 & 7 & 2 & Lane Reduction/Closure & 0 & 2 \\
\hline 92 & 7 & 2 & Lane Reduction/Closure & 2 & 0 \\
\hline 93 & 30 & 18 & Lane Reduction/Closure & 1 & 1 \\
\hline 94 & 56 & 4 & Lane Reduction/Closure & 2 & 0 \\
\hline 95 & 33 & 17 & Lane Reduction/Closure & 2 & 0 \\
\hline 96 & 9 & 14 & Lane Reduction/Closure & 0 & 2 \\
\hline 97 & 42 & 5 & Bridge Closed & 2 & 0 \\
\hline 98 & 6 & 6 & Lane Reduction/Closure & 1 & 0 \\
\hline 99 & 20 & 7 & Lane Reduction/Closure & 0 & 1 \\
\hline 100 & 5 & 3 & Lane Reduction/Closure & 1 & 0 \\
\hline
\end{tabular}




\begin{tabular}{|c|c|c|c|c|c|c|c|c|c|c|c|}
\hline \multirow{2}{*}{$\begin{array}{l}\text { Site } \\
\text { No. }\end{array}$} & \multirow{2}{*}{$\begin{array}{l}\text { IDOT } \\
\text { District } \\
\text { No. }\end{array}$} & \multirow{2}{*}{$\begin{array}{l}\text { Functional } \\
\text { Classification }\end{array}$} & \multirow{2}{*}{ Duration (days) } & \multirow{2}{*}{ Length (miles) } & \multirow{2}{*}{$\begin{array}{c}\text { Annual Average } \\
\text { Daily Traffic } \\
\text { (vehicles/day) }\end{array}$} & \multirow{2}{*}{$\begin{array}{l}\text { No. of Lanes } \\
\text { Reduced }\end{array}$} & \multirow{2}{*}{$\begin{array}{l}\text { Speed Limit } \\
\quad(\mathrm{mph})\end{array}$} & \multirow{2}{*}{$\begin{array}{l}\text { Work Zone } \\
\text { Speed Limit } \\
\text { (mph) }\end{array}$} & \multicolumn{3}{|c|}{$\begin{array}{l}\text { Work Zone Crash Frequency by Severity per } \\
\text { Work Zone Days (Confirmed, Likely, Probable) }\end{array}$} \\
\hline & & & & & & & & & KA Crashes & $\begin{array}{c}\text { Injury Crashes } \\
(\mathrm{K}, \mathrm{A}, \mathrm{B}, \mathrm{C})\end{array}$ & $\begin{array}{c}\text { Total } \\
\text { Crashes }\end{array}$ \\
\hline 101 & 1 & Collector & 193 & 1.4914 & 6,700 & 1 & 30 & 25 & 0 & 0 & 2 \\
\hline 102 & 1 & $\begin{array}{c}\text { Other Principal } \\
\text { Arterial }\end{array}$ & 64 & 0.9638 & 15,210 & 0 & 35 & 25 & 0 & 0 & 1 \\
\hline 103 & 1 & Minor Arterial & 394 & 2.4594 & 20,600 & 1 & 45 & 45 & 0 & 0 & 10 \\
\hline 104 & 1 & Collector & 183 & 1.6117 & 30,700 & 1 & 45 & 35 & 0 & 0 & 2 \\
\hline 105 & 1 & $\begin{array}{c}\text { Other Principal } \\
\text { Arterial }\end{array}$ & 3 & 0.9975 & 11,000 & 4 & 45 & 45 & 0 & 0 & 1 \\
\hline 106 & 1 & $\begin{array}{c}\text { Other Principal } \\
\text { Arterial } \\
\end{array}$ & 723 & 2.4323 & 22,400 & 1 & 35 & 35 & 0 & 0 & 20 \\
\hline 107 & 1 & $\begin{array}{c}\text { Other Principal } \\
\text { Arterial } \\
\end{array}$ & 120 & 7.1521 & 17,800 & 1 & 55 & 35 & 0 & 0 & 1 \\
\hline 108 & 1 & Interstate & 222 & 2.9777 & 46,500 & 0 & 55 & 45 & 0 & 0 & 1 \\
\hline 109 & 1 & $\begin{array}{c}\text { Other Principal } \\
\text { Arterial }\end{array}$ & 143 & 2.0365 & 33,100 & 0 & 40 & 40 & 0 & 0 & 1 \\
\hline 110 & 1 & $\begin{array}{l}\text { Other Principal } \\
\text { Arterial }\end{array}$ & 96 & 1.8436 & 26,400 & 1 & 35 & 35 & 0 & 0 & 1 \\
\hline 111 & 1 & $\begin{array}{c}\text { Other Principal } \\
\text { Arterial }\end{array}$ & 247 & 2.5034 & 32,200 & 1 & 45 & 45 & 0 & 0 & 3 \\
\hline 112 & 1 & Interstate & 90 & 14.7429 & 50,200 & 0 & 70 & 55 & 1 & 1 & 2 \\
\hline 113 & 1 & Interstate & 608 & 0.4770 & 31,000 & 0 & 45 & 45 & 2 & 18 & 136 \\
\hline 114 & 1 & $\begin{array}{c}\text { Other Principal } \\
\text { Arterial } \\
\end{array}$ & 794 & 1.4901 & 33,700 & 1 & 45 & 35 & 1 & 38 & 97 \\
\hline 115 & 1 & $\begin{array}{c}\text { Other Principal } \\
\text { Arterial }\end{array}$ & 724 & 0.8024 & 33,700 & 1 & 45 & 40 & 6 & 36 & 75 \\
\hline 116 & 1 & $\begin{array}{c}\text { Other Principal } \\
\text { Arterial }\end{array}$ & 409 & 0.7256 & 37,100 & 1 & 45 & 35 & 2 & 2 & 30 \\
\hline 117 & 1 & $\begin{array}{c}\text { Other Principal } \\
\text { Arterial } \\
\end{array}$ & 1,043 & 1.9955 & 36,300 & 4 & 35 & 35 & 3 & 70 & 320 \\
\hline 118 & 1 & $\begin{array}{c}\text { Other Principal } \\
\text { Arterial }\end{array}$ & 372 & 1.3001 & 55,000 & 1 & 40 & 35 & 1 & 14 & 40 \\
\hline 119 & 1 & $\begin{array}{l}\text { Other Principal } \\
\text { Arterial }\end{array}$ & 906 & 0.6387 & 22,000 & 1 & 50 & 35 & 2 & 7 & 33 \\
\hline 120 & 1 & Minor Arterial & 481 & 0.8023 & 24,100 & 1 & 45 & 35 & 2 & 8 & 21 \\
\hline 121 & 1 & $\begin{array}{c}\text { Other Principal } \\
\text { Arterial }\end{array}$ & 1,370 & 1.4966 & 35,600 & 1 & 45 & 35 & 1 & 32 & 178 \\
\hline 122 & 1 & $\begin{array}{c}\text { Other Principal } \\
\text { Arterial }\end{array}$ & 409 & 1.3051 & 55,000 & 1 & 40 & 35 & 1 & 15 & 61 \\
\hline 123 & 1 & $\begin{array}{c}\text { Other Principal } \\
\text { Arterial }\end{array}$ & 716 & 3.3013 & 14,700 & 1 & 50 & 45 & 1 & 6 & 21 \\
\hline 124 & 1 & Interstate & 969 & 0.9879 & 37,500 & 0 & 50 & 45 & 1 & 1 & 10 \\
\hline 125 & 1 & $\begin{array}{l}\text { Other Principal } \\
\text { Arterial }\end{array}$ & 275 & 2.4878 & 31,100 & 1 & 40 & 40 & 1 & 3 & 10 \\
\hline
\end{tabular}




\begin{tabular}{|c|c|c|c|c|c|}
\hline $\begin{array}{l}\text { Site } \\
\text { No. }\end{array}$ & $\begin{array}{c}\text { Pre-Construction Crash Frequency } \\
\text { (Same Duration as WZ with No Overlap) }\end{array}$ & $\begin{array}{l}\text { No. of Intersections/Ramps in } \\
\text { Work Zone }\end{array}$ & Type of Road Closure & $\begin{array}{l}\text { WZ Crash Frequency per WZ Days } \\
\text { Workers Not Present }\end{array}$ & $\begin{array}{c}\text { WZ Crash Frequency per WZ } \\
\text { Days } \\
\text { Workers Present }\end{array}$ \\
\hline 101 & 8 & 14 & Lane Reduction/Closure & 1 & 0 \\
\hline 102 & 2 & 14 & Lane Reduction/Closure & 1 & 0 \\
\hline 103 & 36 & 3 & Intermittent Roadwork & 0 & 1 \\
\hline 104 & 37 & 9 & Lane Reduction/Closure & 0 & 1 \\
\hline 105 & 0 & 6 & Road Closed & 1 & 0 \\
\hline 106 & 88 & 13 & Lane Reduction/Closure & 1 & 0 \\
\hline 107 & 14 & 13 & One-Way Traffic with Flaggers & 1 & 0 \\
\hline 108 & 10 & 2 & Lane Reduction/Closure & 0 & 1 \\
\hline 109 & 44 & 12 & Intermittent Roadwork & 1 & 0 \\
\hline 110 & 14 & 12 & Lane Reduction/Closure & 0 & 1 \\
\hline 111 & 99 & 10 & Lane Reduction/Closure & 0 & 1 \\
\hline 112 & 16 & 8 & Lane Reduction/Closure & 0 & 1 \\
\hline 113 & 233 & 2 & Lane Reduction/Closure & 86 & 50 \\
\hline 114 & 120 & 4 & Lane Reduction/Closure & 66 & 17 \\
\hline 115 & 74 & 1 & Lane Reduction/Closure & 55 & 16 \\
\hline 116 & 92 & 6 & Lane Reduction/Closure & 11 & 6 \\
\hline 117 & 534 & 8 & Lane Reduction/Closure & 270 & 50 \\
\hline 118 & 52 & 3 & Lane Reduction/Closure & 28 & 7 \\
\hline 119 & 50 & 1 & Lane Reduction/Closure & 14 & 7 \\
\hline 120 & 40 & 2 & Intermittent Roadwork & 12 & 9 \\
\hline 121 & 314 & 7 & Lane Reduction/Closure & 136 & 42 \\
\hline 122 & 59 & 3 & Lane Reduction/Closure & 43 & 14 \\
\hline 123 & 67 & 6 & One-Way Traffic with Flaggers & 12 & 9 \\
\hline 124 & 127 & 10 & Lane Reduction/Closure & 7 & 3 \\
\hline 125 & 124 & 15 & Lane Reduction/Closure & 5 & 4 \\
\hline
\end{tabular}




\begin{tabular}{|c|c|c|c|c|c|c|c|c|c|c|c|}
\hline \multirow{2}{*}{$\begin{array}{l}\text { Site } \\
\text { No. }\end{array}$} & \multirow{2}{*}{$\begin{array}{l}\text { IDOT } \\
\text { District } \\
\text { No. }\end{array}$} & \multirow{2}{*}{$\begin{array}{l}\text { Functional } \\
\text { Classification }\end{array}$} & \multirow{2}{*}{ Duration (days) } & \multirow{2}{*}{ Length (miles) } & \multirow{2}{*}{$\begin{array}{c}\text { Annual Average } \\
\text { Daily Traffic } \\
\text { (vehicles/day) }\end{array}$} & \multirow{2}{*}{$\begin{array}{l}\text { No. of Lanes } \\
\text { Reduced }\end{array}$} & \multirow{2}{*}{$\begin{array}{l}\text { Speed Limit } \\
\quad(\mathrm{mph})\end{array}$} & \multirow{2}{*}{$\begin{array}{l}\text { Work Zone } \\
\text { Speed Limit } \\
\text { (mph) }\end{array}$} & \multicolumn{3}{|c|}{$\begin{array}{l}\text { Work Zone Crash Frequency by Severity per } \\
\text { Work Zone Days (Confirmed, Likely, Probable) }\end{array}$} \\
\hline & & & & & & & & & KA Crashes & $\begin{array}{c}\text { Injury Crashes } \\
(\mathrm{K}, \mathrm{A}, \mathrm{B}, \mathrm{C})\end{array}$ & $\begin{array}{c}\text { Total } \\
\text { Crashes }\end{array}$ \\
\hline 126 & 1 & Minor Arterial & 810 & 1.0707 & 22,500 & 1 & 35 & 35 & 4 & 17 & 81 \\
\hline 127 & 1 & $\begin{array}{l}\text { Other Principal } \\
\text { Arterial }\end{array}$ & 122 & 5.6202 & 11,100 & 0 & 55 & 45 & 1 & 2 & 3 \\
\hline 128 & 1 & $\begin{array}{l}\text { Other Principal } \\
\text { Arterial }\end{array}$ & 807 & 1.7295 & 22,000 & 2 & 30 & 30 & 4 & 16 & 172 \\
\hline 129 & 1 & Interstate & 713 & 0.4035 & 116,400 & 1 & 50 & 50 & 0 & 2 & 48 \\
\hline 130 & 1 & Interstate & 754 & 3.4912 & 137,136 & 1 & 55 & 45 & 3 & 4 & 25 \\
\hline 131 & 1 & $\begin{array}{c}\text { Other Principal } \\
\text { Arterial }\end{array}$ & 772 & 2.2374 & 14,300 & 1 & 50 & 30 & 0 & 3 & 14 \\
\hline 132 & 1 & Minor Arterial & 68 & 2.2439 & 22,500 & 1 & 35 & 35 & 0 & 1 & 3 \\
\hline 133 & 1 & $\begin{array}{c}\text { Other Principal } \\
\text { Arterial } \\
\end{array}$ & 102 & 4.0008 & 11,600 & 1 & 55 & 30 & 0 & 1 & 2 \\
\hline 134 & 1 & $\begin{array}{l}\text { Other Principal } \\
\text { Arterial }\end{array}$ & 409 & 1.2064 & 45,000 & 1 & 45 & 35 & 0 & 8 & 69 \\
\hline 135 & 1 & $\begin{array}{l}\text { Other Principal } \\
\text { Arterial }\end{array}$ & 216 & 0.9306 & 39,088 & 2 & 35 & 35 & 0 & 9 & 29 \\
\hline 136 & 1 & $\begin{array}{c}\text { Other Principal } \\
\text { Arterial } \\
\end{array}$ & 1,043 & 2.5012 & 38,000 & 4 & 45 & 45 & 0 & 2 & 10 \\
\hline 137 & 1 & Minor Arterial & 469 & 0.1515 & 19,500 & 4 & 30 & 30 & 1 & 2 & 22 \\
\hline 138 & 1 & $\begin{array}{l}\text { Other Principal } \\
\text { Arterial }\end{array}$ & 97 & 0.4681 & 26,800 & 0 & 35 & 35 & 0 & 2 & 8 \\
\hline 139 & 1 & $\begin{array}{c}\text { Other Principal } \\
\text { Arterial } \\
\end{array}$ & 133 & 4.5410 & 32,800 & 0 & 35 & 35 & 0 & 1 & 4 \\
\hline 140 & 1 & $\begin{array}{c}\text { Other Principal } \\
\text { Arterial }\end{array}$ & 716 & 3.3037 & 14,700 & 1 & 50 & 45 & 0 & 2 & 3 \\
\hline 141 & 1 & Interstate & 303 & 0.6799 & 10,600 & 0 & 35 & 45 & 0 & 1 & 26 \\
\hline 142 & 1 & Minor Arterial & 232 & 0.0979 & 19,000 & 1 & 40 & 35 & 0 & 1 & 7 \\
\hline 143 & 1 & $\begin{array}{c}\text { Other Principal } \\
\text { Arterial }\end{array}$ & 937 & 1.7372 & 46,000 & 1 & 50 & 45 & 0 & 1 & 7 \\
\hline 144 & 1 & Interstate & 741 & 0.6781 & 206,700 & 1 & 55 & 45 & 0 & 1 & 2 \\
\hline 145 & 1 & $\begin{array}{c}\text { Other Principal } \\
\text { Arterial }\end{array}$ & 223 & 0.4099 & 37,700 & 2 & 40 & 35 & 0 & 0 & 9 \\
\hline 146 & 1 & $\begin{array}{c}\text { Other Principal } \\
\text { Arterial }\end{array}$ & 299 & 0.1602 & 11,100 & 1 & 40 & 40 & 0 & 0 & 4 \\
\hline 147 & 1 & Minor Arterial & 208 & 0.0835 & 28,600 & 0 & 35 & 35 & 0 & 0 & 3 \\
\hline 148 & 1 & $\begin{array}{c}\text { Other Principal } \\
\text { Arterial }\end{array}$ & 39 & 5.3349 & 18,300 & 1 & 40 & 30 & 0 & 0 & 2 \\
\hline 149 & 1 & $\begin{array}{l}\text { Other Principal } \\
\text { Arterial }\end{array}$ & 495 & 0.6078 & 32,200 & 1 & 35 & 35 & 0 & 0 & 8 \\
\hline 150 & 1 & Interstate & 576 & 0.1224 & 61,100 & 0 & 50 & 45 & 0 & 0 & 3 \\
\hline
\end{tabular}




\begin{tabular}{|c|c|c|c|c|c|}
\hline $\begin{array}{l}\text { Site } \\
\text { No. }\end{array}$ & $\begin{array}{l}\text { Pre-Construction Crash Frequency } \\
\text { (Same Duration as WZ with No Overlap) }\end{array}$ & $\begin{array}{l}\text { No. of Intersections/Ramps in } \\
\text { Work Zone }\end{array}$ & Type of Road Closure & $\begin{array}{l}\text { WZ Crash Frequency per WZ Days } \\
\text { Workers Not Present }\end{array}$ & $\begin{array}{c}\text { WZ Crash Frequency per WZ } \\
\text { Days } \\
\text { Workers Present }\end{array}$ \\
\hline 126 & 169 & 10 & Lane Reduction/Closure & 50 & 28 \\
\hline 127 & 10 & 6 & Lane Reduction/Closure & 2 & 1 \\
\hline 128 & 118 & 16 & Lane Reduction/Closure & 56 & 26 \\
\hline 129 & 102 & 7 & Lane Reduction/Closure & 29 & 18 \\
\hline 130 & 119 & 11 & Lane Reduction/Closure & 15 & 9 \\
\hline 131 & 66 & 7 & One-Way Traffic with Flaggers & 10 & 4 \\
\hline 132 & 15 & 26 & Lane Reduction/Closure & 2 & 1 \\
\hline 133 & 9 & 3 & One-Way Traffic with Flaggers & 1 & 1 \\
\hline 134 & 302 & 9 & Lane Reduction/Closure & 24 & 13 \\
\hline 135 & 53 & 9 & Lane Reduction/Closure & 17 & 7 \\
\hline 136 & 139 & 4 & Lane Reduction/Closure & 7 & 2 \\
\hline 137 & 186 & 10 & Lane Reduction/Closure & 13 & 2 \\
\hline 138 & 9 & 1 & Lane Reduction/Closure & 4 & 4 \\
\hline 139 & 29 & 21 & Lane Reduction/Closure & 1 & 2 \\
\hline 140 & 16 & 4 & One-Way Traffic with Flaggers & 1 & 2 \\
\hline 141 & 61 & 16 & Lane Reduction/Closure & 13 & 13 \\
\hline 142 & 13 & 1 & Intersection Restrictions & 5 & 2 \\
\hline 143 & 15 & 5 & Lane Reduction/Closure & 4 & 0 \\
\hline 144 & 30 & 4 & Lane Reduction/Closure & 0 & 2 \\
\hline 145 & 24 & 4 & Lane Reduction/Closure & 9 & 0 \\
\hline 146 & 7 & 1 & Lane Reduction/Closure & 3 & 1 \\
\hline 147 & 18 & 2 & Intersection Restrictions & 0 & 3 \\
\hline 148 & 12 & 26 & Lane Reduction/Closure & 2 & 0 \\
\hline 149 & 72 & 11 & Lane Reduction/Closure & 8 & 0 \\
\hline 150 & 190 & 1 & Lane Reduction/Closure & 2 & 1 \\
\hline
\end{tabular}




\begin{tabular}{|c|c|c|c|c|c|c|c|c|c|c|c|}
\hline \multirow{2}{*}{$\begin{array}{l}\text { Site } \\
\text { No. }\end{array}$} & \multirow{2}{*}{$\begin{array}{l}\text { IDOT } \\
\text { District } \\
\text { No. }\end{array}$} & \multirow{2}{*}{$\begin{array}{l}\text { Functional } \\
\text { Classification }\end{array}$} & \multirow{2}{*}{ Duration (days) } & \multirow{2}{*}{ Length (miles) } & \multirow{2}{*}{$\begin{array}{c}\text { Annual Average } \\
\text { Daily Traffic } \\
\text { (vehicles/day) }\end{array}$} & \multirow{2}{*}{$\begin{array}{l}\text { No. of Lanes } \\
\text { Reduced }\end{array}$} & \multirow{2}{*}{$\begin{array}{l}\text { Speed Limit } \\
\quad(\mathrm{mph})\end{array}$} & \multirow{2}{*}{$\begin{array}{l}\text { Work Zone } \\
\text { Speed Limit } \\
\text { (mph) }\end{array}$} & \multicolumn{3}{|c|}{$\begin{array}{l}\text { Work Zone Crash Frequency by Severity per } \\
\text { Work Zone Days (Confirmed, Likely, Probable) }\end{array}$} \\
\hline & & & & & & & & & KA Crashes & $\begin{array}{c}\text { Injury Crashes } \\
(\mathrm{K}, \mathrm{A}, \mathrm{B}, \mathrm{C})\end{array}$ & $\begin{array}{c}\text { Total } \\
\text { Crashes }\end{array}$ \\
\hline 151 & 1 & $\begin{array}{l}\text { Other Principal } \\
\text { Arterial }\end{array}$ & 294 & 4.0734 & 37,600 & 1 & 50 & 35 & 0 & 0 & 2 \\
\hline 152 & 1 & $\begin{array}{c}\text { Other Principal } \\
\text { Arterial } \\
\end{array}$ & 60 & 0.4941 & 30,000 & 1 & 45 & 40 & 0 & 0 & 2 \\
\hline 153 & 1 & Interstate & 366 & 0.1782 & 60,400 & 0 & 70 & 55 & 0 & 0 & 2 \\
\hline 154 & 1 & Minor Arterial & 547 & 0.1480 & 21,00 & 1 & 45 & 45 & 0 & 0 & 1 \\
\hline 155 & 1 & $\begin{array}{l}\text { Other Principal } \\
\quad \text { Arterial } \\
\end{array}$ & 137 & 0.2616 & 22,400 & 1 & 40 & 35 & 0 & 0 & 1 \\
\hline 156 & 1 & $\begin{array}{c}\text { Other Principal } \\
\text { Arterial }\end{array}$ & 98 & 2.4253 & 15,000 & 1 & 35 & 35 & 0 & 0 & 1 \\
\hline 157 & 1 & Interstate & 54 & 0.1837 & 23,700 & 0 & 40 & 35 & 0 & 0 & 1 \\
\hline 158 & 1 & Interstate & 198 & 2.4595 & 85,400 & 0 & 70 & 55 & 0 & 0 & 2 \\
\hline 159 & 1 & $\begin{array}{c}\text { Other Principal } \\
\text { Arterial }\end{array}$ & 182 & 0.0338 & 41,900 & 1 & 35 & 35 & 0 & 0 & 1 \\
\hline 160 & 1 & $\begin{array}{c}\text { Other Principal } \\
\text { Arterial }\end{array}$ & 123 & 4.2301 & 45,900 & 1 & 45 & 45 & 0 & 0 & 4 \\
\hline 161 & 1 & Local & 65 & 0.7276 & 10,400 & 1 & 45 & 25 & 0 & 0 & 2 \\
\hline 162 & 1 & $\begin{array}{c}\text { Other Principal } \\
\text { Arterial }\end{array}$ & 33 & 0.6627 & 31,700 & 2 & 40 & 40 & 0 & 0 & 1 \\
\hline 163 & 1 & Interstate & 215 & 22.2101 & 30,500 & 1 & 70 & 55 & 2 & 3 & 7 \\
\hline 164 & 2 & Interstate & 580 & 37.1387 & 45,700 & 1 & 65 & 45 & 7 & 34 & 302 \\
\hline 165 & 2 & $\begin{array}{l}\text { Other Principal } \\
\text { Arterial }\end{array}$ & 600 & 3.3447 & 12,700 & 1 & 45 & 45 & 1 & 13 & 25 \\
\hline 166 & 2 & $\begin{array}{c}\text { Other Principal } \\
\text { Arterial }\end{array}$ & 172 & 1.7459 & 14,200 & 2 & 30 & 30 & 1 & 5 & 15 \\
\hline 167 & 2 & Interstate & 579 & 22.2442 & 30,300 & 1 & 70 & 55 & 3 & 2 & 17 \\
\hline 168 & 2 & Interstate & 181 & 22.2458 & 30,500 & 1 & 70 & 55 & 2 & 4 & 16 \\
\hline 169 & 2 & $\begin{array}{c}\text { Other Principal } \\
\text { Arterial }\end{array}$ & 626 & 0.8287 & 7,250 & 1 & 45 & 45 & 1 & 1 & 5 \\
\hline 170 & 2 & Interstate & 255 & 17.9531 & 18,800 & 1 & 70 & 55 & 3 & 4 & 9 \\
\hline 171 & 2 & Interstate & 153 & 12.2476 & 21,300 & 1 & 70 & 55 & 1 & 1 & 9 \\
\hline 172 & 2 & $\begin{array}{c}\text { Other Principal } \\
\text { Arterial }\end{array}$ & 135 & 0.4908 & 11,800 & 2 & 30 & 30 & 1 & 1 & 7 \\
\hline 173 & 2 & $\begin{array}{c}\text { Other Principal } \\
\text { Arterial }\end{array}$ & 66 & 4.3416 & 5,750 & 1 & 55 & 55 & 1 & 2 & 3 \\
\hline 174 & 2 & Interstate & 209 & 3.2671 & 28,800 & 1 & 70 & 55 & 1 & 1 & 1 \\
\hline 175 & 2 & Interstate & 47 & 18.5559 & 12,600 & 1 & 70 & 70 & 1 & 1 & 1 \\
\hline
\end{tabular}




\begin{tabular}{|c|c|c|c|c|c|}
\hline $\begin{array}{l}\text { Site } \\
\text { No. }\end{array}$ & $\begin{array}{l}\text { Pre-Construction Crash Frequency } \\
\text { (Same Duration as WZ with No Overlap) }\end{array}$ & $\begin{array}{l}\text { No. of Intersections/Ramps in } \\
\text { Work Zone }\end{array}$ & Type of Road Closure & $\begin{array}{l}\text { WZ Crash Frequency per WZ Days } \\
\text { Workers Not Present }\end{array}$ & $\begin{array}{c}\text { WZ Crash Frequency per WZ } \\
\text { Days } \\
\text { Workers Present }\end{array}$ \\
\hline 151 & 43 & 103 & Lane Reduction/Closure & 2 & 0 \\
\hline 152 & 3 & 3 & Lane Reduction/Closure & 2 & 0 \\
\hline 153 & 21 & 1 & Lane Reduction/Closure & 2 & 0 \\
\hline 154 & 17 & 1 & Intersection Restrictions & 1 & 0 \\
\hline 155 & 6 & 3 & Lane Reduction/Closure & 0 & 1 \\
\hline 156 & 14 & 13 & Lane Reduction/Closure & 0 & 1 \\
\hline 157 & 4 & 13 & Ramp Closed & 1 & 0 \\
\hline 158 & 3 & 4 & Lane Reduction/Closure & 1 & 0 \\
\hline 159 & 18 & 1 & Intermittent Roadwork & 0 & 1 \\
\hline 160 & 18 & 37 & Lane Reduction/Closure & 0 & 1 \\
\hline 161 & 4 & 9 & One-Way Traffic with Flaggers & 1 & 0 \\
\hline 162 & 9 & 4 & Lane Reduction/Closure & 0 & 1 \\
\hline 163 & 93 & 22 & Lane Reduction/Closure & 6 & 1 \\
\hline 164 & 318 & 35 & Lane Reduction/Closure & 5 & 0 \\
\hline 165 & 60 & 9 & Lane Reduction/Closure & 22 & 3 \\
\hline 166 & 39 & 15 & Lane Reduction/Closure & 9 & 5 \\
\hline 167 & 72 & 22 & Lane Reduction/Closure & 8 & 3 \\
\hline 168 & 17 & 19 & Lane Reduction/Closure & 9 & 3 \\
\hline 169 & 6 & 2 & Lane Reduction/Closure & 4 & 1 \\
\hline 170 & 23 & 12 & Lane Reduction/Closure & 5 & 3 \\
\hline 171 & 2 & 11 & Lane Reduction/Closure & 5 & 0 \\
\hline 172 & 11 & 5 & Lane Reduction/Closure & 2 & 0 \\
\hline 173 & 11 & 6 & Lane Reduction/Closure & 0 & 1 \\
\hline 174 & 6 & 4 & Lane Reduction/Closure & 1 & 0 \\
\hline 175 & 2 & 16 & Lane Reduction/Closure & 0 & 1 \\
\hline
\end{tabular}




\begin{tabular}{|c|c|c|c|c|c|c|c|c|c|c|c|}
\hline \multirow{2}{*}{$\begin{array}{l}\text { Site } \\
\text { No. }\end{array}$} & \multirow{2}{*}{$\begin{array}{l}\text { IDOT } \\
\text { District } \\
\text { No. }\end{array}$} & \multirow{2}{*}{$\begin{array}{l}\text { Functional } \\
\text { Classification }\end{array}$} & \multirow{2}{*}{ Duration (days) } & \multirow{2}{*}{ Length (miles) } & \multirow{2}{*}{$\begin{array}{c}\text { Annual Average } \\
\text { Daily Traffic } \\
\text { (vehicles/day) }\end{array}$} & \multirow{2}{*}{$\begin{array}{l}\text { No. of Lanes } \\
\text { Reduced }\end{array}$} & \multirow{2}{*}{$\begin{array}{l}\text { Speed Limit } \\
\text { (mph) }\end{array}$} & \multirow{2}{*}{$\begin{array}{l}\text { Work Zone } \\
\text { Speed Limit } \\
\text { (mph) }\end{array}$} & \multicolumn{3}{|c|}{$\begin{array}{l}\text { Work Zone Crash Frequency by Severity per } \\
\text { Work Zone Days (Confirmed, Likely, Probable) }\end{array}$} \\
\hline & & & & & & & & & KA Crashes & $\begin{array}{c}\text { Injury Crashes } \\
(\mathrm{K}, \mathrm{A}, \mathrm{B}, \mathrm{C})\end{array}$ & $\begin{array}{c}\text { Total } \\
\text { Crashes }\end{array}$ \\
\hline 176 & 2 & Interstate & 579 & 22.2248 & 31,263 & 1 & 70 & 70 & 0 & 1 & 1 \\
\hline 177 & 2 & $\begin{array}{c}\text { Other Principal } \\
\text { Arterial } \\
\end{array}$ & 467 & 0.8604 & 14,500 & 1 & 45 & 15 & 0 & 1 & 1 \\
\hline 178 & 2 & Interstate & 267 & 5.3062 & 24,851 & 1 & 65 & 55 & 0 & 0 & 5 \\
\hline 179 & 2 & Interstate & 234 & 18.0803 & 16,100 & 1 & 70 & 55 & 0 & 0 & 4 \\
\hline 180 & 2 & Interstate & 59 & 18.2488 & 16,100 & 1 & 70 & 55 & 0 & 0 & 3 \\
\hline 181 & 2 & Interstate & 159 & 11.8066 & 16,100 & 1 & 70 & 55 & 0 & 0 & 3 \\
\hline 182 & 2 & $\begin{array}{c}\text { Other Principal } \\
\text { Arterial }\end{array}$ & 250 & 2.0045 & 26,200 & 1 & 55 & 45 & 0 & 0 & 2 \\
\hline 183 & 2 & $\begin{array}{l}\text { Freeway and } \\
\text { Expressway }\end{array}$ & 269 & 1.8741 & 34,300 & 1 & 65 & 45 & 0 & 0 & 1 \\
\hline 184 & 2 & Interstate & 87 & 6.6690 & 23,800 & 1 & 70 & 45 & 0 & 0 & 1 \\
\hline 185 & 2 & Interstate & 47 & 18.5311 & 15,700 & 1 & 70 & 45 & 0 & 0 & 1 \\
\hline 186 & 2 & Interstate & 258 & 9.2566 & 20,200 & 1 & 70 & 65 & 0 & 0 & 1 \\
\hline 187 & 2 & Interstate & 262 & 4.9360 & 21,100 & 1 & 70 & 45 & 2 & 2 & 7 \\
\hline 188 & 2 & $\begin{array}{c}\text { Other Principal } \\
\text { Arterial }\end{array}$ & 423 & 1.7595 & 9,450 & 2 & 45 & 45 & 1 & 5 & 12 \\
\hline 189 & 2 & Interstate & 580 & 37.2252 & 45,700 & 1 & 65 & 45 & 3 & 34 & 290 \\
\hline 190 & 2 & $\begin{array}{c}\text { Other Principal } \\
\text { Arterial }\end{array}$ & 217 & 0.4907 & 11,800 & 5 & 30 & 30 & 1 & 3 & 4 \\
\hline 191 & 2 & Interstate & 217 & 9.0979 & 20,200 & 1 & 70 & 55 & 1 & 1 & 5 \\
\hline 91392 & 3 & Interstate & 217 & 9.1792 & 20,100 & 1 & 70 & 55 & 0 & 3 & 9 \\
\hline 193 & 3 & Interstate & 255 & 17.9531 & 17,700 & 1 & 65 & 55 & 0 & 0 & 3 \\
\hline 194 & 3 & $\begin{array}{c}\text { Other Principal } \\
\text { Arterial }\end{array}$ & 236 & 3.3452 & 19,000 & 1 & 45 & 35 & 0 & 0 & 2 \\
\hline 195 & 3 & Interstate & 152 & 18.5590 & 18,600 & 1 & 70 & 45 & 0 & 0 & 1 \\
\hline 196 & 3 & Interstate & 743 & 0.5085 & 31,800 & 0 & 70 & 45 & 1 & 2 & 5 \\
\hline 197 & 3 & Interstate & 743 & 0.5106 & 31,800 & 0 & 70 & 55 & 1 & 1 & 1 \\
\hline 198 & 3 & Interstate & 192 & 12.9703 & 18,900 & 1 & 70 & 55 & 1 & 1 & 3 \\
\hline 199 & 3 & Major Collector & 75 & 5.0203 & 3,400 & 1 & 55 & 55 & 1 & 1 & 1 \\
\hline 200 & 3 & Interstate & 89 & 31.9647 & 22,300 & 1 & 70 & 70 & 1 & 1 & 1 \\
\hline
\end{tabular}




\begin{tabular}{|c|c|c|c|c|c|}
\hline $\begin{array}{l}\text { Site } \\
\text { No. }\end{array}$ & $\begin{array}{l}\text { Pre-Construction Crash Frequency } \\
\text { (Same Duration as WZ with No Overlap) }\end{array}$ & $\begin{array}{l}\text { No. of Intersections/Ramps in } \\
\text { Work Zone }\end{array}$ & Type of Road Closure & $\begin{array}{l}\text { WZ Crash Frequency per WZ Days } \\
\text { Workers Not Present }\end{array}$ & $\begin{array}{c}\text { WZ Crash Frequency per WZ } \\
\text { Days } \\
\text { Workers Present }\end{array}$ \\
\hline 176 & 93 & 23 & Lane Reduction/Closure & 1 & 0 \\
\hline 177 & 9 & 5 & Lane Reduction/Closure & 1 & 0 \\
\hline 178 & 7 & 3 & Lane Reduction/Closure & 2 & 1 \\
\hline 179 & 11 & 16 & Lane Reduction/Closure & 4 & 0 \\
\hline 180 & 8 & 17 & Lane Reduction/Closure & 3 & 0 \\
\hline 181 & 3 & 9 & Lane Reduction/Closure & 2 & 1 \\
\hline 182 & 29 & 5 & Lane Reduction/Closure & 1 & 1 \\
\hline 183 & 19 & 2 & Lane Reduction/Closure & 1 & 0 \\
\hline 184 & 4 & 7 & Lane Reduction/Closure & 0 & 1 \\
\hline 185 & 1 & 15 & Lane Reduction/Closure & 1 & 0 \\
\hline 186 & 19 & 3 & Lane Reduction/Closure & 1 & 0 \\
\hline 187 & 2 & 3 & Lane Reduction/Closure & 7 & 0 \\
\hline 188 & 15 & 7 & Lane Reduction/Closure & 9 & 1 \\
\hline 189 & 339 & 38 & Lane Reduction/Closure & 147 & 25 \\
\hline 190 & 20 & 6 & Lane Reduction/Closure & 5 & 1 \\
\hline 191 & 10 & 2 & Lane Reduction/Closure & 196 & 21 \\
\hline 192 & 8 & 5 & Lane Reduction/Closure & 3 & 6 \\
\hline 193 & 23 & 11 & Lane Reduction/Closure & 2 & 1 \\
\hline 194 & 23 & 11 & Lane Reduction/Closure & 2 & 0 \\
\hline 195 & 9 & 15 & Lane Reduction/Closure & 1 & 0 \\
\hline 196 & 2 & 1 & Shoulder Work & 4 & 1 \\
\hline 197 & 2 & 1 & Shoulder Work & 1 & 0 \\
\hline 198 & 12 & 8 & Lane Reduction/Closure & 1 & 0 \\
\hline 199 & 2 & 16 & One-Way Traffic with Flaggers & 1 & 0 \\
\hline 200 & 34 & 33 & Lane Reduction/Closure & 1 & 0 \\
\hline
\end{tabular}




\begin{tabular}{|c|c|c|c|c|c|c|c|c|c|c|c|}
\hline \multirow{2}{*}{$\begin{array}{l}\text { Site } \\
\text { No. }\end{array}$} & \multirow{2}{*}{$\begin{array}{l}\text { IDOT } \\
\text { District } \\
\text { No. }\end{array}$} & \multirow{2}{*}{$\begin{array}{l}\text { Functional } \\
\text { Classification }\end{array}$} & \multirow{2}{*}{ Duration (days) } & \multirow{2}{*}{ Length (miles) } & \multirow{2}{*}{$\begin{array}{c}\text { Annual Average } \\
\text { Daily Traffic } \\
\text { (vehicles/day) }\end{array}$} & \multirow{2}{*}{$\begin{array}{l}\text { No. of Lanes } \\
\text { Reduced }\end{array}$} & \multirow{2}{*}{$\begin{array}{l}\text { Speed Limit } \\
\quad(\mathrm{mph})\end{array}$} & \multirow{2}{*}{$\begin{array}{l}\text { Work Zone } \\
\text { Speed Limit } \\
\text { (mph) }\end{array}$} & \multicolumn{3}{|c|}{$\begin{array}{l}\text { Work Zone Crash Frequency by Severity per } \\
\text { Work Zone Days (Confirmed, Likely, Probable) }\end{array}$} \\
\hline & & & & & & & & & KA Crashes & $\begin{array}{c}\text { Injury Crashes } \\
(\mathrm{K}, \mathrm{A}, \mathrm{B}, \mathrm{C})\end{array}$ & $\begin{array}{c}\text { Total } \\
\text { Crashes }\end{array}$ \\
\hline 201 & 3 & Interstate & 426 & 4.9866 & 17,200 & 1 & 70 & 55 & 2 & 5 & 15 \\
\hline 202 & 3 & Interstate & 185 & 6.9104 & 16,800 & 1 & 70 & 55 & 1 & 1 & 11 \\
\hline 203 & 3 & Minor Arterial & 560 & 2.0111 & 8,450 & 0 & 55 & 45 & 1 & 1 & 10 \\
\hline 204 & 3 & Minor Arterial & 78 & 13.6292 & 2,000 & 1 & 55 & 50 & 1 & 1 & 3 \\
\hline 205 & 3 & $\begin{array}{l}\text { Other Principal } \\
\text { Arterial }\end{array}$ & 121 & 0.6580 & 23,400 & 0 & 35 & 35 & 1 & 2 & 2 \\
\hline 206 & 3 & $\begin{array}{l}\text { Other Principal } \\
\text { Arterial }\end{array}$ & 507 & 3.9076 & 7,150 & 1 & 55 & 45 & 0 & 2 & 5 \\
\hline 207 & 3 & $\begin{array}{c}\text { Other Principal } \\
\text { Arterial }\end{array}$ & 643 & 0.1366 & 9,400 & 0 & 45 & 35 & 0 & 3 & 4 \\
\hline 208 & 3 & Interstate & 92 & 5.9861 & 17,200 & 1 & 70 & 55 & 0 & 2 & 3 \\
\hline 209 & 3 & Interstate & 36 & 36.9698 & 17,200 & 1 & 70 & 55 & 0 & 1 & 1 \\
\hline 210 & 3 & $\begin{array}{l}\text { Other Principal } \\
\text { Arterial }\end{array}$ & 84 & 1.9985 & 21,100 & 1 & 45 & 35 & 0 & 1 & 4 \\
\hline 211 & 3 & $\begin{array}{l}\text { Other Principal } \\
\text { Arterial }\end{array}$ & 292 & 3.3034 & 17,100 & 1 & 35 & 35 & 0 & 1 & 3 \\
\hline 212 & 3 & $\begin{array}{l}\text { Other Principal } \\
\text { Arterial }\end{array}$ & 121 & 2.0626 & 21,700 & 0 & 45 & 35 & 0 & 1 & 2 \\
\hline 213 & 3 & $\begin{array}{l}\text { Other Principal } \\
\text { Arterial }\end{array}$ & 108 & 0.2986 & 13,900 & 1 & 45 & 45 & 0 & 1 & 2 \\
\hline 214 & 3 & Interstate & 435 & 2.0000 & 30,800 & 1 & 70 & 55 & 0 & 0 & 6 \\
\hline 215 & 3 & Interstate & 426 & 4.9915 & 17,200 & 1 & 70 & 55 & 0 & 0 & 3 \\
\hline 216 & 3 & Interstate & 281 & 4.9916 & 17,200 & 1 & 70 & 55 & 0 & 0 & 3 \\
\hline 217 & 3 & Interstate & 182 & 5.9880 & 17,200 & 1 & 70 & 55 & 0 & 0 & 3 \\
\hline 218 & 3 & $\begin{array}{c}\text { Other Principal } \\
\text { Arterial } \\
\end{array}$ & 174 & 0.2275 & 11,500 & 1 & 45 & 45 & 0 & 0 & 3 \\
\hline 219 & 3 & Interstate & 362 & 4.8634 & 33,100 & 1 & 70 & 55 & 0 & 0 & 2 \\
\hline 220 & 3 & Interstate & 26 & 12.9879 & 24,600 & 1 & 70 & 45 & 0 & 0 & 1 \\
\hline 221 & 3 & Interstate & 38 & 4.7479 & 17,400 & 1 & 70 & 55 & 0 & 0 & 1 \\
\hline 222 & 3 & Interstate & 195 & 0.4701 & 17,600 & 1 & 70 & 55 & 0 & 0 & 1 \\
\hline 223 & 3 & $\begin{array}{l}\text { Other Principal } \\
\text { Arterial }\end{array}$ & 84 & 2.0199 & 26,600 & 1 & 35 & 35 & 0 & 0 & 1 \\
\hline 224 & 3 & $\begin{array}{l}\text { Other Principal } \\
\text { Arterial }\end{array}$ & 495 & 2.6429 & 25,600 & 1 & 55 & 45 & 3 & 19 & 49 \\
\hline 225 & 3 & $\begin{array}{l}\text { Other Principal } \\
\text { Arterial }\end{array}$ & 464 & 3.4264 & 22,400 & 1 & 35 & 30 & 3 & 7 & 32 \\
\hline
\end{tabular}




\begin{tabular}{|c|c|c|c|c|c|}
\hline $\begin{array}{l}\text { Site } \\
\text { No. }\end{array}$ & $\begin{array}{l}\text { Pre-Construction Crash Frequency } \\
\text { (Same Duration as WZ with No Overlap) }\end{array}$ & $\begin{array}{l}\text { No. of Intersections/Ramps in } \\
\text { Work Zone }\end{array}$ & Type of Road Closure & $\begin{array}{l}\text { WZ Crash Frequency per WZ Days } \\
\text { Workers Not Present }\end{array}$ & $\begin{array}{c}\text { WZ Crash Frequency per WZ } \\
\text { Days } \\
\text { Workers Present }\end{array}$ \\
\hline 201 & 11 & 3 & Lane Reduction/Closure & 11 & 4 \\
\hline 202 & 3 & 6 & Lane Reduction/Closure & 10 & 1 \\
\hline 203 & 18 & 1 & Lane Reduction/Closure & 5 & 1 \\
\hline 204 & 3 & 17 & One-Way Traffic with Flaggers & 1 & 2 \\
\hline 205 & 8 & 5 & Lane Reduction/Closure & 1 & 1 \\
\hline 206 & 22 & 14 & Lane Reduction/Closure & 2 & 3 \\
\hline 207 & 12 & 1 & Intersection Restrictions & 3 & 1 \\
\hline 208 & 2 & 6 & Lane Reduction/Closure & 3 & 0 \\
\hline 209 & 0 & 35 & Lane Reduction/Closure & 1 & 0 \\
\hline 210 & 8 & 16 & Lane Reduction/Closure & 2 & 2 \\
\hline 211 & 11 & 17 & Lane Reduction/Closure & 3 & 0 \\
\hline 212 & 5 & 19 & Lane Reduction/Closure & 0 & 2 \\
\hline 213 & 1 & 3 & Lane Reduction/Closure & 0 & 2 \\
\hline 214 & 26 & 4 & Lane Reduction/Closure & 4 & 0 \\
\hline 215 & 13 & 6 & Lane Reduction/Closure & 2 & 1 \\
\hline 216 & 8 & 4 & Lane Reduction/Closure & 2 & 1 \\
\hline 217 & 7 & 6 & Lane Reduction/Closure & 2 & 1 \\
\hline 218 & 4 & 2 & Lane Reduction/Closure & 3 & 0 \\
\hline 219 & 25 & 3 & Lane Reduction/Closure & 1 & 1 \\
\hline 220 & 1 & 15 & Lane Reduction/Closure & 0 & 1 \\
\hline 221 & 2 & 7 & Lane Reduction/Closure & 1 & 0 \\
\hline 222 & 0 & 1 & Lane Reduction/Closure & 0 & 1 \\
\hline 223 & 8 & 17 & Lane Reduction/Closure & 1 & 0 \\
\hline 224 & 112 & 4 & Lane Reduction/Closure & 35 & 5 \\
\hline 225 & 71 & 26 & Lane Reduction/Closure & 17 & 7 \\
\hline
\end{tabular}




\begin{tabular}{|c|c|c|c|c|c|c|c|c|c|c|c|}
\hline \multirow{2}{*}{$\begin{array}{l}\text { Site } \\
\text { No. }\end{array}$} & \multirow{2}{*}{$\begin{array}{l}\text { IDOT } \\
\text { District } \\
\text { No. }\end{array}$} & \multirow{2}{*}{$\begin{array}{l}\text { Functional } \\
\text { Classification }\end{array}$} & \multirow{2}{*}{ Duration (days) } & \multirow{2}{*}{ Length (miles) } & \multirow{2}{*}{$\begin{array}{c}\text { Annual Average } \\
\text { Daily Traffic } \\
\text { (vehicles/day) }\end{array}$} & \multirow{2}{*}{$\begin{array}{l}\text { No. of Lanes } \\
\text { Reduced }\end{array}$} & \multirow{2}{*}{$\begin{array}{l}\text { Speed Limit } \\
\quad(\mathrm{mph})\end{array}$} & \multirow{2}{*}{$\begin{array}{l}\text { Work Zone } \\
\text { Speed Limit } \\
\text { (mph) }\end{array}$} & \multicolumn{3}{|c|}{$\begin{array}{l}\text { Work Zone Crash Frequency by Severity per } \\
\text { Work Zone Days (Confirmed, Likely, Probable) }\end{array}$} \\
\hline & & & & & & & & & KA Crashes & $\begin{array}{c}\text { Injury Crashes } \\
(\mathrm{K}, \mathrm{A}, \mathrm{B}, \mathrm{C})\end{array}$ & $\begin{array}{c}\text { Total } \\
\text { Crashes }\end{array}$ \\
\hline 226 & 3 & $\begin{array}{c}\text { Other Principal } \\
\text { Arterial }\end{array}$ & 742 & 4.8141 & 4,550 & 1 & 55 & 45 & 1 & 4 & 17 \\
\hline 227 & 3 & Interstate & 281 & 4.9877 & 17,200 & 1 & 70 & 55 & 2 & 5 & 15 \\
\hline 228 & 3 & Interstate & 19 & 3.9888 & 22,300 & 1 & 70 & 55 & 1 & 1 & 1 \\
\hline 229 & 3 & $\begin{array}{l}\text { Other Principal } \\
\text { Arterial }\end{array}$ & 174 & 0.2263 & 12,400 & 1 & 45 & 45 & 1 & 1 & 2 \\
\hline 230 & 3 & $\begin{array}{c}\text { Other Principal } \\
\text { Arterial } \\
\end{array}$ & 137 & 5.5640 & 4,950 & 1 & 55 & 45 & 1 & 2 & 3 \\
\hline 231 & 3 & $\begin{array}{c}\text { Other Principal } \\
\text { Arterial }\end{array}$ & 938 & 2.3397 & 22,400 & 0 & 45 & 25 & 0 & 6 & 20 \\
\hline 232 & 3 & $\begin{array}{l}\text { Other Principal } \\
\text { Arterial }\end{array}$ & 495 & 2.0481 & 27,500 & 1 & 45 & 45 & 0 & 2 & 12 \\
\hline 233 & 3 & $\begin{array}{c}\text { Other Principal } \\
\text { Arterial }\end{array}$ & 731 & 2.3401 & 15,500 & 1 & 45 & 35 & 0 & 4 & 10 \\
\hline 234 & 3 & Interstate & 92 & 5.9889 & 17,200 & 1 & 70 & 55 & 0 & 0 & 2 \\
\hline 235 & 3 & $\begin{array}{l}\text { Other Principal } \\
\text { Arterial }\end{array}$ & 1,390 & 0.7029 & 18,100 & 1 & 35 & 35 & 0 & 0 & 3 \\
\hline 236 & 3 & Interstate & 122 & 4.8249 & 32,900 & 1 & 70 & 55 & 0 & 0 & 1 \\
\hline 237 & 3 & Interstate & 284 & 2.9784 & 34,100 & 1 & 70 & 45 & 0 & 0 & 1 \\
\hline 238 & 3 & Interstate & 76 & 2.9683 & 29,200 & 1 & 65 & 55 & 0 & 1 & 1 \\
\hline 239 & 4 & Interstate & 681 & 3.3158 & 54,300 & 1 & 70 & 45 & 0 & 3 & 18 \\
\hline 240 & 4 & Interstate & 681 & 1.3461 & 23,200 & 1 & 65 & 45 & 0 & 2 & 5 \\
\hline 241 & 4 & Interstate & 219 & 35.3903 & 37,400 & 1 & 70 & 55 & 0 & 0 & 8 \\
\hline 242 & 4 & Minor Arterial & 124 & 8.4842 & 5,750 & 1 & 45 & 45 & 0 & 0 & 3 \\
\hline 243 & 4 & Interstate & 512 & 7.7478 & 1,700 & 0 & 70 & 45 & 0 & 0 & 1 \\
\hline 244 & 4 & Interstate & 681 & 1.5668 & 8,900 & 1 & 65 & 45 & 1 & 2 & 3 \\
\hline 245 & 4 & Interstate & 166 & 11.7066 & 13,400 & 1 & 70 & 45 & 0 & 0 & 1 \\
\hline 246 & 4 & Interstate & 213 & 8.2147 & 31,600 & 1 & 70 & 55 & 1 & 1 & 13 \\
\hline 247 & 4 & Interstate & 151 & 7.0061 & 22,200 & 1 & 70 & 55 & 1 & 1 & 4 \\
\hline 248 & 5 & Interstate & 109 & 10.9816 & 26,200 & 1 & 70 & 70 & 1 & 1 & 1 \\
\hline 249 & 5 & Interstate & 213 & 8.2067 & 31,600 & 1 & 70 & 55 & 2 & 3 & 8 \\
\hline 250 & 5 & Interstate & 2132.56 & 8.1771 & 31,600 & 1 & 70 & 55 & 2 & 3 & 8 \\
\hline
\end{tabular}




\begin{tabular}{|c|c|c|c|c|c|}
\hline $\begin{array}{l}\text { Site } \\
\text { No. }\end{array}$ & $\begin{array}{c}\text { Pre-Construction Crash Frequency } \\
\text { (Same Duration as WZ with No Overlap) }\end{array}$ & $\begin{array}{l}\text { No. of Intersections/Ramps in } \\
\text { Work Zone }\end{array}$ & Type of Road Closure & $\begin{array}{l}\text { WZ Crash Frequency per WZ Days } \\
\text { Workers Not Present }\end{array}$ & $\begin{array}{c}\text { WZ Crash Frequency per WZ } \\
\text { Days } \\
\text { Workers Present }\end{array}$ \\
\hline 226 & 33 & 5 & One-Way Traffic with Flaggers & 11 & 5 \\
\hline 227 & 17 & 3 & Lane Reduction/Closure & 11 & 4 \\
\hline 228 & 0 & 2 & Lane Reduction/Closure & 0 & 1 \\
\hline 229 & 2 & 3 & Lane Reduction/Closure & 2 & 0 \\
\hline 230 & 7 & 4 & One-Way Traffic with Flaggers & 2 & 1 \\
\hline 231 & 66 & 8 & Lane Reduction/Closure & 17 & 1 \\
\hline 232 & 75 & 6 & Lane Reduction/Closure & 9 & 3 \\
\hline 233 & 66 & 7 & Lane Reduction/Closure & 7 & 3 \\
\hline 234 & 3 & 6 & Lane Reduction/Closure & 1 & 1 \\
\hline 235 & 121 & 4 & Lane Reduction/Closure & 1 & 2 \\
\hline 236 & 1 & 3 & Lane Reduction/Closure & 0 & 1 \\
\hline 237 & 8 & 3 & Lane Reduction/Closure & 0 & 1 \\
\hline 238 & 6 & 6 & Lane Reduction/Closure & 1 & 0 \\
\hline 239 & 30 & 9 & Lane Reduction/Closure & 6 & 10 \\
\hline 240 & 5 & 6 & Lane Reduction/Closure & 5 & 0 \\
\hline 241 & 28 & 24 & One-Way Traffic with Flaggers & 0 & 1 \\
\hline 242 & 5 & 13 & One-Way Traffic with Flaggers & 0 & 1 \\
\hline 243 & 13 & 8 & Lane Reduction/Closure & 0 & 1 \\
\hline 244 & 5 & 2 & Lane Reduction/Closure & 0 & 3 \\
\hline 245 & 2 & 12 & Intermittent Roadwork & 0 & 1 \\
\hline 246 & 20 & 7 & Lane Reduction/Closure & 5 & 3 \\
\hline 247 & 1 & 8 & Lane Reduction/Closure & 3 & 1 \\
\hline 248 & 16 & 14 & Lane Reduction/Closure & 1 & 0 \\
\hline 249 & 8 & 6 & Lane Reduction/Closure & 5 & 3 \\
\hline 250 & 8 & 6 & Lane Reduction/Closure & 5 & 3 \\
\hline
\end{tabular}




\begin{tabular}{|c|c|c|c|c|c|c|c|c|c|c|c|}
\hline \multirow{2}{*}{$\begin{array}{l}\text { Site } \\
\text { No. }\end{array}$} & \multirow{2}{*}{$\begin{array}{l}\text { IDOT } \\
\text { District } \\
\text { No. }\end{array}$} & \multirow{2}{*}{$\begin{array}{l}\text { Functional } \\
\text { Classification }\end{array}$} & \multirow{2}{*}{ Duration (days) } & \multirow{2}{*}{ Length (miles) } & \multirow{2}{*}{$\begin{array}{c}\text { Annual Average } \\
\text { Daily Traffic } \\
\text { (vehicles/day) }\end{array}$} & \multirow{2}{*}{$\begin{array}{l}\text { No. of Lanes } \\
\text { Reduced }\end{array}$} & \multirow{2}{*}{$\begin{array}{l}\text { Speed Limit } \\
\quad(\mathrm{mph})\end{array}$} & \multirow{2}{*}{$\begin{array}{c}\text { Work Zone } \\
\text { Speed Limit } \\
\text { (mph) }\end{array}$} & \multicolumn{3}{|c|}{$\begin{array}{l}\text { Work Zone Crash Frequency by Severity per } \\
\text { Work Zone Days (Confirmed, Likely, Probable) }\end{array}$} \\
\hline & & & & & & & & & KA Crashes & $\begin{array}{l}\text { Injury Crashes } \\
(\mathrm{K}, \mathrm{A}, \mathrm{B}, \mathrm{C})\end{array}$ & $\begin{array}{c}\text { Total } \\
\text { Crashes }\end{array}$ \\
\hline 251 & 5 & Interstate & 213 & 8.1771 & 31,600 & 1 & 70 & 55 & 2 & 3 & 8 \\
\hline 252 & 5 & Major Collector & 213 & 6.8386 & 4,000 & 1 & 55 & 55 & 1 & 1 & 3 \\
\hline 253 & 5 & Minor Arterial & 138 & 2.2255 & 5,300 & 1 & 55 & 45 & 2 & 1 & 2 \\
\hline 254 & 5 & Interstate & 212 & 10.9933 & 24,100 & 1 & 70 & 45 & 0 & 1 & 4 \\
\hline 255 & 5 & Interstate & 213 & 9.9849 & 29,000 & 1 & 70 & 45 & 0 & 1 & 2 \\
\hline 256 & 5 & $\begin{array}{l}\text { Other Principal } \\
\text { Arterial }\end{array}$ & 383 & 2.0120 & 10,250 & 1 & 55 & 35 & 0 & 0 & 2 \\
\hline 257 & 5 & $\begin{array}{c}\text { Other Principal } \\
\text { Arterial }\end{array}$ & 129 & 4.5967 & 13,500 & 1 & 55 & 45 & 0 & 0 & 1 \\
\hline 258 & 5 & $\begin{array}{c}\text { Other Principal } \\
\text { Arterial }\end{array}$ & 212 & 2.7594 & 19,000 & 1 & 45 & 35 & 0 & 0 & 1 \\
\hline 259 & 5 & Interstate & 272 & 7.9390 & 23,100 & 1 & 70 & 70 & 0 & 0 & 13 \\
\hline 260 & 5 & Interstate & 272 & 2.1011 & 36,100 & 1 & 70 & 55 & 1 & 2 & 5 \\
\hline 261 & 5 & Interstate & 212 & 10.9584 & 26,200 & 1 & 70 & 55 & 1 & 3 & 15 \\
\hline 262 & 5 & Interstate & 151 & 6.9600 & 22.200 & 1 & 70 & 55 & 1 & 2 & 6 \\
\hline 263 & 5 & Major Collector & 35 & 2.0057 & 4,650 & 2 & 55 & 50 & 1 & 1 & 1 \\
\hline 264 & 5 & Interstate & 127 & 5.9512 & 20,700 & 0 & 70 & 45 & 0 & 1 & 2 \\
\hline 265 & 5 & Minor Arterial & 136 & 3.8525 & 11,000 & 1 & 55 & 55 & 0 & 1 & 1 \\
\hline 266 & 5 & Minor Arterial & 141 & 4.7413 & 8,400 & 1 & 50 & 40 & 0 & 1 & 1 \\
\hline 267 & 5 & Interstate & 272 & 12.9891 & 25,000 & 1 & 70 & 55 & 0 & 0 & 17 \\
\hline 268 & 5 & Interstate & 272 & 12.9731 & 23,100 & 1 & 70 & 70 & 0 & 0 & 24 \\
\hline 269 & 5 & Interstate & 127 & 5.9395 & 20,700 & 0 & 65 & 55 & 0 & 0 & 1 \\
\hline 270 & 6 & Interstate & 716 & 17.9678 & 23,500 & 1 & 70 & 55 & 2 & 5 & 30 \\
\hline 271 & 6 & Interstate & 790 & 10.4308 & 23,500 & 1 & 70 & 55 & 1 & 3 & 12 \\
\hline 272 & 6 & Minor Arterial & 96 & 2.6136 & 7,700 & 1 & 55 & 55 & 1 & 1 & 2 \\
\hline 273 & 6 & $\begin{array}{c}\text { Other Principal } \\
\text { Arterial }\end{array}$ & 114 & 4.5846 & 2,500 & 1 & 55 & 55 & 1 & 1 & 1 \\
\hline 274 & 6 & Interstate & 201 & 13.2398 & 17,600 & 1 & 70 & 70 & 1 & 1 & 2 \\
\hline 275 & 6 & Minor Arterial & 122 & 8.8673 & 2,300 & 1 & 55 & 55 & 1 & 1 & 1 \\
\hline
\end{tabular}




\begin{tabular}{|c|c|c|c|c|c|}
\hline $\begin{array}{l}\text { Site } \\
\text { No. }\end{array}$ & $\begin{array}{c}\text { Pre-Construction Crash Frequency } \\
\text { (Same Duration as WZ with No Overlap) }\end{array}$ & $\begin{array}{l}\text { No. of Intersections/Ramps in } \\
\text { Work Zone }\end{array}$ & Type of Road Closure & $\begin{array}{l}\text { WZ Crash Frequency per WZ Days } \\
\text { Workers Not Present }\end{array}$ & $\begin{array}{c}\text { WZ Crash Frequency per WZ } \\
\text { Days } \\
\text { Workers Present }\end{array}$ \\
\hline 251 & 8 & 6 & Lane Reduction/Closure & 5 & 3 \\
\hline 252 & 6 & 13 & Lane Reduction/Closure & 0 & 3 \\
\hline 253 & 3 & 6 & One-Way Traffic with Flaggers & 1 & 0 \\
\hline 254 & 27 & 16 & Lane Reduction/Closure & 3 & 1 \\
\hline 255 & 13 & 13 & Lane Reduction/Closure & 1 & 1 \\
\hline 256 & 8 & 3 & Lane Reduction/Closure & 2 & 0 \\
\hline 257 & 5 & 27 & Lane Reduction/Closure & 1 & 0 \\
\hline 258 & 4 & 6 & Lane Reduction/Closure & 1 & 0 \\
\hline 259 & 12 & 8 & Lane Reduction/Closure & 1 & 0 \\
\hline 260 & 11 & 4 & Lane Reduction/Closure & 3 & 1 \\
\hline 261 & 32 & 14 & Lane Reduction/Closure & 6 & 9 \\
\hline 262 & 4 & 6 & Lane Reduction/Closure & 3 & 1 \\
\hline 263 & 0 & 2 & Road Closed & 0 & 1 \\
\hline 264 & 3 & 6 & Lane Reduction/Closure & 1 & 1 \\
\hline 265 & 7 & 8 & Lane Reduction/Closure & 0 & 1 \\
\hline 266 & 3 & 16 & Lane Reduction/Closure & 1 & 0 \\
\hline 267 & 31 & 23 & Lane Reduction/Closure & 1 & 7 \\
\hline 268 & 27 & 17 & Lane Reduction/Closure & 1 & 0 \\
\hline 269 & 2 & 8 & Lane Reduction/Closure & 1 & 0 \\
\hline 270 & 51 & 6 & Lane Reduction/Closure & 21 & 5 \\
\hline 271 & 22 & 7 & Lane Reduction/Closure & 9 & 2 \\
\hline 272 & 5 & 4 & Lane Reduction/Closure & 1 & 1 \\
\hline 273 & 1 & 7 & Lane Reduction/Closure & 1 & 0 \\
\hline 274 & 13 & 13 & Lane Reduction/Closure & 1 & 0 \\
\hline 275 & 0 & 10 & Lane Reduction/Closure & 1 & 0 \\
\hline
\end{tabular}




\begin{tabular}{|c|c|c|c|c|c|c|c|c|c|c|c|}
\hline \multirow{2}{*}{$\begin{array}{l}\text { Site } \\
\text { No. }\end{array}$} & \multirow{2}{*}{$\begin{array}{l}\text { IDOT } \\
\text { District } \\
\text { No. }\end{array}$} & \multirow{2}{*}{$\begin{array}{l}\text { Functional } \\
\text { Classification }\end{array}$} & \multirow{2}{*}{ Duration (days) } & \multirow{2}{*}{ Length (miles) } & \multirow{2}{*}{$\begin{array}{c}\text { Annual Average } \\
\text { Daily Traffic } \\
\text { (vehicles/day) }\end{array}$} & \multirow{2}{*}{$\begin{array}{l}\text { No. of Lanes } \\
\text { Reduced }\end{array}$} & \multirow{2}{*}{$\begin{array}{l}\text { Speed Limit } \\
\quad(\mathrm{mph})\end{array}$} & \multirow{2}{*}{$\begin{array}{l}\text { Work Zone } \\
\text { Speed Limit } \\
\text { (mph) }\end{array}$} & \multicolumn{3}{|c|}{$\begin{array}{l}\text { Work Zone Crash Frequency by Severity per } \\
\text { Work Zone Days (Confirmed, Likely, Probable) }\end{array}$} \\
\hline & & & & & & & & & KA Crashes & $\begin{array}{c}\text { Injury Crashes } \\
(\mathrm{K}, \mathrm{A}, \mathrm{B}, \mathrm{C})\end{array}$ & $\begin{array}{c}\text { Total } \\
\text { Crashes }\end{array}$ \\
\hline 276 & 6 & Interstate & 150 & 5.5826 & 15,900 & 0 & 70 & 55 & 1 & 3 & 3 \\
\hline 277 & 6 & Interstate & 209 & 1.0732 & 37,000 & 1 & 70 & 45 & 0 & 1 & 4 \\
\hline 278 & 6 & Interstate & 177 & 3.3625 & 54,000 & 0 & 70 & 70 & 0 & 0 & 8 \\
\hline 279 & 6 & Interstate & 76 & 3.9845 & 37,000 & 1 & 70 & 45 & 0 & 0 & 2 \\
\hline 280 & 6 & Interstate & 27 & 30.5220 & 34,600 & 1 & 70 & 45 & 0 & 0 & 2 \\
\hline 281 & 6 & Interstate & 165 & 5.3864 & 17,000 & 1 & 70 & 70 & 0 & 0 & 1 \\
\hline 282 & 6 & Interstate & 71 & 38.9809 & 32,200 & 1 & 70 & 55 & 1 & 1 & 3 \\
\hline 283 & 6 & $\begin{array}{l}\text { Other Principal } \\
\text { Arterial }\end{array}$ & 456 & 3.3716 & 18,000 & 1 & 35 & 35 & 0 & 0 & 2 \\
\hline 284 & 6 & Interstate & 790 & 18.1401 & 23,500 & 1 & 70 & 45 & 0 & 0 & 19 \\
\hline 285 & 6 & $\begin{array}{c}\text { Other Principal } \\
\text { Arterial }\end{array}$ & 746 & 0.3084 & 23,800 & 0 & 40 & 40 & 0 & 0 & 1 \\
\hline 286 & 6 & Interstate & 201 & 13.2453 & 40,000 & 1 & 70 & 45 & 0 & 0 & 1 \\
\hline 287 & 7 & Interstate & 233 & 8.5659 & 21,600 & 1 & 70 & 45 & 2 & 3 & 16 \\
\hline 288 & 7 & Interstate & 103 & 36.9816 & 21,700 & 1 & 70 & 55 & 2 & 3 & 14 \\
\hline 289 & 7 & Interstate & 260 & 8.9861 & 21,600 & 1 & 70 & 55 & 1 & 1 & 3 \\
\hline 290 & 7 & Minor Arterial & 270 & 3.8547 & 6,250 & 1 & 55 & 45 & 1 & 1 & 2 \\
\hline 291 & 7 & $\begin{array}{c}\text { Other Principal } \\
\text { Arterial }\end{array}$ & 113 & 8.3583 & 3,900 & 0 & 55 & 55 & 0 & 1 & 0 \\
\hline 292 & 7 & Interstate & 844 & 4.0694 & 2,250 & 1 & 70 & 45 & 3 & 5 & 23 \\
\hline 293 & 7 & Interstate & 576 & 4.9405 & 42,100 & 1 & 70 & 45 & 1 & 3 & 14 \\
\hline 294 & 7 & Interstate & 173 & 3.9765 & 22,000 & 1 & 70 & 45 & 1 & 1 & 4 \\
\hline 295 & 7 & Minor Arterial & 78 & 14.9044 & 4,300 & 1 & 55 & 55 & 1 & 1 & 1 \\
\hline 296 & 7 & Minor Arterial & 418 & 0.0551 & 3,700 & 1 & 55 & 40 & 1 & 1 & 4 \\
\hline 297 & 7 & Interstate & 260 & 8.9913 & 22,000 & 1 & 70 & 55 & 0 & 2 & 2 \\
\hline 298 & 7 & Interstate & 577 & 9.9777 & 62,500 & 1 & 70 & 55 & 1 & 2 & 14 \\
\hline 299 & 7 & Interstate & 258 & 8.9942 & 21,800 & 1 & 70 & 55 & 0 & 0 & 4 \\
\hline 300 & 7 & Interstate & 283 & 4.9947 & 19,600 & 1 & 70 & 55 & 0 & 0 & 4 \\
\hline
\end{tabular}




\begin{tabular}{|c|c|c|c|c|c|}
\hline $\begin{array}{l}\text { Site } \\
\text { No. }\end{array}$ & $\begin{array}{l}\text { Pre-Construction Crash Frequency } \\
\text { (Same Duration as WZ with No Overlap) }\end{array}$ & $\begin{array}{l}\text { No. of Intersections/Ramps in } \\
\text { Work Zone }\end{array}$ & Type of Road Closure & $\begin{array}{l}\text { WZ Crash Frequency per WZ Days } \\
\text { Workers Not Present }\end{array}$ & $\begin{array}{c}\text { WZ Crash Frequency per WZ } \\
\text { Days } \\
\text { Workers Present }\end{array}$ \\
\hline 276 & 6 & 3 & Lane Reduction/Closure & 3 & 0 \\
\hline 277 & 5 & 4 & Lane Reduction/Closure & 1 & 3 \\
\hline 278 & 16 & 4 & Lane Reduction/Closure & 1 & 0 \\
\hline 279 & 1 & 2 & Lane Reduction/Closure & 1 & 0 \\
\hline 280 & 2 & 18 & Lane Reduction/Closure & 1 & 0 \\
\hline 281 & 3 & 4 & Lane Reduction/Closure & 1 & 0 \\
\hline 282 & 27 & 37 & Lane Reduction/Closure & 1 & 2 \\
\hline 283 & 0 & 21 & Lane Reduction/Closure & 1 & 1 \\
\hline 284 & 73 & 16 & Intersection Restriction & 1 & 0 \\
\hline 285 & 4 & 6 & Lane Reduction/Closure & 1 & 0 \\
\hline 286 & 7 & 13 & Lane Reduction/Closure & 0 & 1 \\
\hline 287 & 11 & 8 & Lane Reduction/Closure & 9 & 4 \\
\hline 288 & 27 & 34 & Lane Reduction/Closure & 7 & 5 \\
\hline 289 & 10 & 7 & Lane Reduction/Closure & 2 & 1 \\
\hline 290 & 15 & 12 & Lane Reduction/Closure & 0 & 2 \\
\hline 291 & 3 & 12 & Intermittent Roadwork & 1 & 0 \\
\hline 292 & 12 & 5 & Lane Reduction/Closure & 9 & 12 \\
\hline 293 & 31 & 5 & Lane Reduction/Closure & 9 & 5 \\
\hline 294 & 3 & 5 & Lane Reduction/Closure & 3 & 0 \\
\hline 295 & 4 & 21 & Lane Reduction/Closure & 0 & 1 \\
\hline 296 & 1 & 0 & One-Way Traffic with Temporary Signals & 1 & 0 \\
\hline 297 & 3 & 8 & Lane Reduction/Closure & 1 & 1 \\
\hline 298 & 31 & 12 & Lane Reduction/Closure & 9 & 2 \\
\hline 299 & 8 & 9 & Lane Reduction/Closure & 4 & 0 \\
\hline 300 & 7 & 4 & Lane Reduction/Closure & 3 & 0 \\
\hline
\end{tabular}




\begin{tabular}{|c|c|c|c|c|c|c|c|c|c|c|c|}
\hline \multirow{2}{*}{$\begin{array}{l}\text { Site } \\
\text { No. }\end{array}$} & \multirow{2}{*}{$\begin{array}{l}\text { IDOT } \\
\text { District } \\
\text { No. }\end{array}$} & \multirow{2}{*}{$\begin{array}{l}\text { Functional } \\
\text { Classification }\end{array}$} & \multirow{2}{*}{ Duration (days) } & \multirow{2}{*}{ Length (miles) } & \multirow{2}{*}{$\begin{array}{c}\text { Annual Average } \\
\text { Daily Traffic } \\
\text { (vehicles/day) }\end{array}$} & \multirow{2}{*}{$\begin{array}{l}\text { No. of Lanes } \\
\text { Reduced }\end{array}$} & \multirow{2}{*}{$\begin{array}{l}\text { Speed Limit } \\
\quad(\mathrm{mph})\end{array}$} & \multirow{2}{*}{$\begin{array}{l}\text { Work Zone } \\
\text { Speed Limit } \\
\text { (mph) }\end{array}$} & \multicolumn{3}{|c|}{$\begin{array}{l}\text { Work Zone Crash Frequency by Severity per } \\
\text { Work Zone Days (Confirmed, Likely, Probable) }\end{array}$} \\
\hline & & & & & & & & & KA Crashes & $\begin{array}{c}\text { Injury Crashes } \\
(\mathrm{K}, \mathrm{A}, \mathrm{B}, \mathrm{C})\end{array}$ & $\begin{array}{c}\text { Total } \\
\text { Crashes }\end{array}$ \\
\hline 301 & 7 & Interstate & 516 & 9.9765 & 36,000 & 1 & 70 & 45 & 0 & 0 & 3 \\
\hline 302 & 7 & $\begin{array}{c}\text { Other Principal } \\
\text { Arterial }\end{array}$ & 105 & 1.0120 & 12,400 & 1 & 35 & 30 & 0 & 0 & 2 \\
\hline 303 & 7 & Interstate & 214 & 2.1744 & 22,900 & 1 & 70 & 55 & 0 & 0 & 1 \\
\hline 304 & 7 & Interstate & 435 & 8.9959 & 21,800 & 1 & 70 & 55 & 2 & 3 & 13 \\
\hline 305 & 7 & Interstate & 103 & 36.9887 & 21,700 & 1 & 70 & 55 & 2 & 2 & 5 \\
\hline 306 & 7 & Interstate & 173 & 7.9854 & 21,700 & 0 & 70 & 55 & 1 & 1 & 8 \\
\hline 307 & 7 & Interstate & 258 & 8.9819 & 21,800 & 1 & 70 & 55 & 1 & 2 & 18 \\
\hline 308 & 7 & Interstate & 270 & 7.9686 & 20,300 & 1 & 70 & 55 & 1 & 1 & 13 \\
\hline 309 & 7 & Interstate & 173 & 7.9980 & 21,700 & 0 & 70 & 55 & 1 & 2 & 5 \\
\hline 310 & 7 & Interstate & 275 & 2.9772 & 22,900 & 1 & 70 & 45 & 2 & 2 & 9 \\
\hline 311 & 7 & Interstate & 270 & 8.0060 & 17,870 & 1 & 70 & 45 & 0 & 0 & 4 \\
\hline 312 & 7 & Interstate & 844 & 3.9204 & 37,900 & 1 & 70 & 45 & 0 & 0 & 5 \\
\hline 313 & 8 & Interstate & 1,149 & 7.9783 & 38,000 & 1 & 70 & 55 & 3 & 5 & 50 \\
\hline 314 & 8 & Interstate & 979 & 7.9911 & 38,000 & 1 & 70 & 55 & 3 & 6 & 43 \\
\hline 315 & 8 & Interstate & 228 & 10.9822 & 23,500 & 1 & 70 & 45 & 2 & 3 & 11 \\
\hline 316 & 8 & $\begin{array}{c}\text { Other Principal } \\
\text { Arterial }\end{array}$ & 103 & 7.1164 & 3,600 & 1 & 55 & 55 & 1 & 1 & 2 \\
\hline 317 & 8 & Interstate & 170 & 2.0474 & 49,300 & 2 & 50 & 50 & 1 & 1 & 10 \\
\hline 318 & 8 & Interstate & 979 & 3.9838 & 38,000 & 1 & 70 & 55 & 1 & 1 & 16 \\
\hline 319 & 8 & Interstate & 228 & 10.9840 & 23,500 & 1 & 70 & 55 & 3 & 5 & 17 \\
\hline 320 & 8 & Interstate & 168 & 3.9758 & 71,300 & 1 & 65 & 55 & 1 & 3 & 9 \\
\hline 321 & 8 & Minor Arterial & 176 & 16.1616 & 5,150 & 1 & 55 & 55 & 1 & 1 & 5 \\
\hline 322 & 8 & Interstate & 168 & 3.9869 & 71,300 & 1 & 65 & 55 & 1 & 1 & 3 \\
\hline 323 & 8 & Interstate & 329 & 7.5351 & 34,500 & 1 & 70 & 55 & 1 & 1 & 4 \\
\hline 324 & 8 & Interstate & 114 & 10.0002 & 26,700 & 1 & 70 & 55 & 2 & 3 & 5 \\
\hline 325 & 8 & Interstate & 18 & 7.5804 & 54,600 & 1 & 65 & 65 & 1 & 1 & 3 \\
\hline
\end{tabular}




\begin{tabular}{|c|c|c|c|c|c|}
\hline $\begin{array}{l}\text { Site } \\
\text { No. }\end{array}$ & $\begin{array}{l}\text { Pre-Construction Crash Frequency } \\
\text { (Same Duration as WZ with No Overlap) }\end{array}$ & $\begin{array}{l}\text { No. of Intersections/Ramps in } \\
\text { Work Zone }\end{array}$ & Type of Road Closure & $\begin{array}{l}\text { WZ Crash Frequency per WZ Days } \\
\text { Workers Not Present }\end{array}$ & $\begin{array}{c}\text { WZ Crash Frequency per WZ } \\
\text { Days } \\
\text { Workers Present }\end{array}$ \\
\hline 326 & 2 & 2 & Lane Reduction/Closure & 0 & 1 \\
\hline 327 & 0 & 2 & Lane Reduction/Closure & 0 & 1 \\
\hline 328 & 11 & 9 & Lane Reduction/Closure & 12 & 2 \\
\hline 329 & 16 & 8 & Lane Reduction/Closure & 4 & 2 \\
\hline 330 & 13 & 6 & Lane Reduction/Closure & 12 & 2 \\
\hline 331 & 1 & 9 & Lane Reduction/Closure & 0 & 0 \\
\hline 332 & 3 & 8 & Lane Reduction/Closure & 2 & 2 \\
\hline 333 & 13 & 7 & Lane Reduction/Closure & 3 & 1 \\
\hline 334 & 24 & 3 & Lane Reduction/Closure & 2 & 0 \\
\hline 335 & 19 & 5 & Lane Reduction/Closure & 2 & 0 \\
\hline 336 & 18 & 6 & Lane Reduction/Closure & 2 & 0 \\
\hline 337 & 10 & 35 & Lane Reduction/Closure & 1 & 1 \\
\hline 338 & 21 & 9 & Lane Reduction/Closure & 0 & 1 \\
\hline 339 & 2 & 3 & Lane Reduction/Closure & 1 & 0 \\
\hline 340 & 6 & 8 & Lane Reduction/Closure & 1 & 0 \\
\hline 341 & 8 & 5 & Lane Reduction/Closure & 1 & 0 \\
\hline 342 & 80 & 6 & Lane Reduction/Closure & 33 & 12 \\
\hline 343 & 2 & 11 & Lane Reduction/Closure & 1 & 0 \\
\hline 344 & 6 & 0 & Lane Reduction/Closure & 32 & 15 \\
\hline 345 & 36 & 2 & Lane Reduction/Closure & 20 & 7 \\
\hline 346 & 18 & 4 & Lane Reduction/Closure & 4 & 1 \\
\hline 347 & 3 & 10 & Lane Reduction/Closure & 2 & 1 \\
\hline 348 & 246 & 23 & Lane Reduction/Closure & 74 & 16 \\
\hline 349 & 17 & 6 & Lane Reduction/Closure & 18 & 2 \\
\hline 350 & 0 & 20 & One-Way Traffic with Flaggers & 1 & 0 \\
\hline
\end{tabular}




\begin{tabular}{|c|c|c|c|c|c|c|c|c|c|c|c|}
\hline \multirow{2}{*}{$\begin{array}{l}\text { Site } \\
\text { No. }\end{array}$} & \multirow{2}{*}{$\begin{array}{l}\text { IDOT } \\
\text { District } \\
\text { No. }\end{array}$} & \multirow{2}{*}{$\begin{array}{l}\text { Functional } \\
\text { Classification }\end{array}$} & \multirow{2}{*}{ Duration (days) } & \multirow{2}{*}{ Length (miles) } & \multirow{2}{*}{$\begin{array}{l}\text { Annual Average } \\
\text { Daily Traffic } \\
\text { (vehicles/day) }\end{array}$} & \multirow{2}{*}{$\begin{array}{l}\text { No. of Lanes } \\
\text { Reduced }\end{array}$} & \multirow{2}{*}{$\begin{array}{l}\text { Speed Limit } \\
\quad(\mathrm{mph})\end{array}$} & \multirow{2}{*}{$\begin{array}{l}\text { Work Zone } \\
\text { Speed Limit } \\
\text { (mph) }\end{array}$} & \multicolumn{3}{|c|}{$\begin{array}{l}\text { Work Zone Crash Frequency by Severity per } \\
\text { Work Zone Days (Confirmed, Likely, Probable) }\end{array}$} \\
\hline & & & & & & & & & KA Crashes & $\begin{array}{c}\text { Injury Crashes } \\
(\mathrm{K}, \mathrm{A}, \mathrm{B}, \mathrm{C})\end{array}$ & $\begin{array}{c}\text { Total } \\
\text { Crashes }\end{array}$ \\
\hline 351 & 8 & Interstate & 426 & 0.3482 & 3,500 & 0 & 65 & 55 & 1 & 1 & 1 \\
\hline 352 & 8 & Minor Arterial & 254 & 0.5201 & 11,200 & 1 & 45 & 45 & 2 & 1 & 3 \\
\hline 353 & 8 & $\begin{array}{l}\text { Other Principal } \\
\text { Arterial }\end{array}$ & 692 & 0.2495 & 550 & 0 & 55 & 55 & 1 & 2 & 2 \\
\hline 354 & 8 & Interstate & 1,066 & 0.4714 & 20,108 & 1 & 55 & 45 & 1 & 1 & 7 \\
\hline 355 & 8 & $\begin{array}{c}\text { Freeway and } \\
\text { Expressway }\end{array}$ & 96 & 5.5947 & 16,000 & 1 & 65 & 45 & 1 & 1 & 1 \\
\hline 356 & 8 & Other Principal & 110 & 15.8023 & 5,081 & 1 & 55 & 55 & 0 & 1 & 1 \\
\hline 357 & 8 & Interstate & 243 & 2.5157 & 95,298 & 1 & 50 & 45 & 0 & 0 & 16 \\
\hline 358 & 8 & Interstate & 1,066 & 0.4620 & 50,108 & 1 & 55 & 45 & 0 & 0 & 8 \\
\hline 359 & 8 & Interstate & 426 & 4.7591 & 36,000 & 0 & 65 & 55 & 0 & 0 & 8 \\
\hline 360 & 8 & Interstate & 52 & 19.9653 & 26,512 & 1 & 65 & 45 & 0 & 0 & 3 \\
\hline 361 & 8 & Interstate & 81 & 10.6419 & 22,600 & 1 & 65 & 55 & 0 & 0 & 2 \\
\hline 362 & 8 & Interstate & 194 & 13.1566 & 34,105 & 1 & 70 & 45 & 0 & 0 & 2 \\
\hline 363 & 8 & Minor Arterial & 127 & 4.5332 & 3,250 & 1 & 55 & 55 & 0 & 0 & 1 \\
\hline 364 & 9 & Interstate & 172 & 10.4854 & 30,900 & 1 & 70 & 45 & 3 & 11 & 36 \\
\hline 365 & 9 & $\begin{array}{c}\text { Other Principal } \\
\text { Arterial }\end{array}$ & 1,182 & 2.2435 & 20,200 & 1 & 55 & 45 & 2 & 3 & 21 \\
\hline 366 & 9 & $\begin{array}{c}\text { Other Principal } \\
\text { Arterial } \\
\end{array}$ & 59 & 4.0497 & 4,000 & 1 & 55 & 55 & 1 & 1 & 2 \\
\hline 367 & 9 & Interstate & 165 & 4.8874 & 22,600 & 1 & 70 & 55 & 1 & 1 & 4 \\
\hline 368 & 9 & Minor Arterial & 180 & 11.1759 & 1,550 & 1 & 55 & 55 & 1 & 1 & 2 \\
\hline 369 & 9 & Interstate & 48 & 4.9226 & 30,900 & 1 & 70 & 45 & 1 & 1 & 10 \\
\hline 370 & 9 & Interstate & 195 & 11.0368 & 11,900 & 1 & 70 & 55 & 1 & 1 & 5 \\
\hline 371 & 9 & Interstate & 8 & 0.9732 & 39,100 & 0 & 70 & 55 & 1 & 1 & 2 \\
\hline 372 & 9 & Interstate & 86 & 4.9867 & 38,500 & 1 & 70 & 45 & 0 & 1 & 3 \\
\hline 373 & 9 & $\begin{array}{c}\text { Other Principal } \\
\text { Arterial }\end{array}$ & 1,182 & 2.2576 & 24,300 & 1 & 55 & 55 & 0 & 1 & 6 \\
\hline 374 & 9 & Interstate & 540 & 2.2003 & 37,500 & 1 & 70 & 45 & 0 & 1 & 8 \\
\hline 375 & 9 & Interstate & 225 & 9.6675 & 13,400 & 1 & 70 & 55 & 0 & 1 & 4 \\
\hline
\end{tabular}




\begin{tabular}{|c|c|c|c|c|c|}
\hline $\begin{array}{l}\text { Site } \\
\text { No. }\end{array}$ & $\begin{array}{l}\text { Pre-Construction Crash Frequency } \\
\text { (Same Duration as WZ with No Overlap) }\end{array}$ & $\begin{array}{l}\text { No. of Intersections/Ramps in } \\
\text { Work Zone }\end{array}$ & Type of Road Closure & $\begin{array}{l}\text { WZ Crash Frequency per WZ Days } \\
\text { Workers Not Present }\end{array}$ & $\begin{array}{c}\text { WZ Crash Frequency per WZ } \\
\text { Days } \\
\text { Workers Present }\end{array}$ \\
\hline 351 & 2 & 1 & Lane Reduction/Closure & 1 & 0 \\
\hline 352 & 5 & 6 & Lane Reduction/Closure & 2 & 0 \\
\hline 353 & 0 & 1 & Ramp Closed & 0 & 2 \\
\hline 354 & 36 & 2 & Lane Reduction/Closure & 6 & 0 \\
\hline 355 & 0 & 8 & Lane Reduction/Closure & 0 & 1 \\
\hline 356 & 5 & 16 & Lane Reduction/Closure & 0 & 1 \\
\hline 357 & 39 & 5 & Lane Reduction/Closure & 8 & 1 \\
\hline 358 & 16 & 2 & Lane Reduction/Closure & 4 & 0 \\
\hline 359 & 17 & 5 & Lane Reduction/Closure & 6 & 0 \\
\hline 360 & 8 & 42 & Lane Reduction/Closure & 2 & 1 \\
\hline 361 & 5 & 14 & Lane Reduction/Closure & 2 & 0 \\
\hline 362 & 20 & 14 & Lane Reduction/Closure & 1 & 1 \\
\hline 363 & 1 & 12 & One-Way Traffic with Flaggers & 0 & 1 \\
\hline 364 & 16 & 9 & Lane Reduction/Closure & 17 & 16 \\
\hline 365 & 34 & 4 & Lane Reduction/Closure & 18 & 3 \\
\hline 366 & 2 & 3 & Intermittent Roadwork & 0 & 2 \\
\hline 367 & 6 & 6 & Lane Reduction/Closure & 7 & 0 \\
\hline 368 & 3 & 24 & Intermittent Roadwork & 0 & 2 \\
\hline 369 & 1 & 3 & Lane Reduction/Closure & 4 & 6 \\
\hline 370 & 4 & 13 & Lane Reduction/Closure & 3 & 2 \\
\hline 371 & 0 & 1 & Lane Reduction/Closure & 2 & 0 \\
\hline 372 & 4 & 3 & Lane Reduction/Closure & 1 & 2 \\
\hline 373 & 32 & 5 & Lane Reduction/Closure & 2 & 0 \\
\hline 374 & 14 & 7 & Lane Reduction/Closure & 4 & 1 \\
\hline 375 & 6 & 11 & Lane Reduction/Closure & 1 & 2 \\
\hline
\end{tabular}




\begin{tabular}{|c|c|c|c|c|c|c|c|c|c|c|c|}
\hline \multirow{2}{*}{$\begin{array}{l}\text { Site } \\
\text { No. }\end{array}$} & \multirow{2}{*}{$\begin{array}{l}\text { IDOT } \\
\text { District } \\
\text { No. }\end{array}$} & \multirow{2}{*}{$\begin{array}{l}\text { Functional } \\
\text { Classification }\end{array}$} & \multirow{2}{*}{ Duration (days) } & \multirow{2}{*}{ Length (miles) } & \multirow{2}{*}{$\begin{array}{c}\text { Annual Average } \\
\text { Daily Traffic } \\
\text { (vehicles/day) }\end{array}$} & \multirow{2}{*}{$\begin{array}{l}\text { No. of Lanes } \\
\text { Reduced }\end{array}$} & \multirow{2}{*}{$\begin{array}{l}\text { Speed Limit } \\
\quad(\mathrm{mph})\end{array}$} & \multirow{2}{*}{$\begin{array}{l}\text { Work Zone } \\
\text { Speed Limit } \\
\text { (mph) }\end{array}$} & \multicolumn{3}{|c|}{$\begin{array}{l}\text { Work Zone Crash Frequency by Severity per } \\
\text { Work Zone Days (Confirmed, Likely, Probable) }\end{array}$} \\
\hline & & & & & & & & & KA Crashes & $\begin{array}{c}\text { Injury Crashes } \\
(\mathrm{K}, \mathrm{A}, \mathrm{B}, \mathrm{C})\end{array}$ & $\begin{array}{c}\text { Total } \\
\text { Crashes }\end{array}$ \\
\hline 376 & 9 & Interstate & 618 & 1.9069 & 25,600 & 1 & 55 & 45 & 0 & 1 & 4 \\
\hline 377 & 9 & Interstate & 43 & 0.2241 & 34,500 & 0 & 70 & 45 & 0 & 0 & 3 \\
\hline 378 & 9 & Interstate & 618 & 2.9718 & 43,000 & 1 & 70 & 45 & 0 & 0 & 4 \\
\hline 379 & 9 & Interstate & 144 & 7.0025 & 11,001 & 1 & 65 & 45 & 0 & 0 & 2 \\
\hline 380 & 9 & $\begin{array}{c}\text { Other Principal } \\
\text { Arterial }\end{array}$ & 180 & 10.7344 & 5,100 & 1 & 55 & 55 & 1 & 2 & 3 \\
\hline 381 & 9 & Major Collector & 334 & 2.9900 & 5,700 & 1 & 55 & 55 & 0 & 1 & 4 \\
\hline 382 & 9 & Interstate & 75 & 2.2873 & 43,000 & 1 & 65 & 45 & 0 & 1 & 4 \\
\hline 383 & 9 & $\begin{array}{c}\text { Other Principal } \\
\text { Arterial }\end{array}$ & 213 & 4.8540 & 12,500 & 1 & 55 & 45 & 0 & 1 & 3 \\
\hline 384 & 9 & Interstate & 75 & 33.9710 & 6,550 & 1 & 70 & 55 & 1 & 0 & 23 \\
\hline 385 & 9 & Interstate & 436 & 7.9407 & 10,500 & 1 & 70 & 45 & 0 & 0 & 4 \\
\hline
\end{tabular}

\begin{tabular}{|c|c|c|c|c|c|}
\hline $\begin{array}{l}\text { Site } \\
\text { No. }\end{array}$ & $\begin{array}{l}\text { Pre-Construction Crash Frequency } \\
\text { (Same Duration as WZ with No Overlap) }\end{array}$ & $\begin{array}{l}\text { No. of Intersections/Ramps in } \\
\text { Work Zone }\end{array}$ & Type of Road Closure & $\begin{array}{l}\text { WZ Crash Frequency per WZ Days } \\
\text { Workers Not Present }\end{array}$ & $\begin{array}{c}\text { WZ Crash Frequency per WZ } \\
\text { Days } \\
\text { Workers Present }\end{array}$ \\
\hline 376 & 10 & 2 & Lane Reduction/Closure & 3 & 0 \\
\hline 377 & 1 & 1 & Ramp Closed & 1 & 2 \\
\hline 378 & 34 & 3 & Lane Reduction/Closure & 2 & 0 \\
\hline 379 & 1 & 4 & Lane Reduction/Closure & 1 & 0 \\
\hline 380 & 19 & 14 & One-Way Traffic with Flaggers & 1 & 0 \\
\hline 381 & 14 & 4 & One-Way Traffic with Flaggers & 0 & 2 \\
\hline 382 & 5 & 3 & Lane Reduction/Closure & 3 & 0 \\
\hline 383 & 18 & 15 & One-Way Traffic with Flaggers & 0 & 1 \\
\hline 384 & 27 & 8 & Lane Reduction/Closure & 3 & 0 \\
\hline 385 & 12 & 7 & Lane Reduction/Closure & 1 & 0 \\
\hline
\end{tabular}


APPENDIX D: SCREEN CAPTURES OF THE EXCEL TOOL 


\section{(2) Minnos Dopatmentot Tansportation

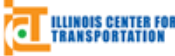 \\ $\underset{\text { University }}{\text { BRADLE }}$}

\section{Derviex}

This spreadsheet has been developed to assess the safety performance

of work zones in llinois

The page tab displayed at the bottom of the file allow the user to

Therk zone

also contain buttons to allow user to navigate easily between them.

This worksheet contains the following:

Horkshees

Tutorial

Work Zone Safety

Performance

\section{Contents}

Current spreadsheet including descriptions of Cons

Prediction of crashes for a given work zone based on information entered by the user.

This spreadsheet also allows the user to input data for up to 3 work zone alternatives, and compares

\section{Work Zone Safety Performance Tool - Tutorial Page}

\section{Color Coding in Horksheets}

The following worksheet contains different color codings to help users identify where data inputis required. Some cells require specitic data to be entered by the user. In other cases, he user wil be given a drop down listlo choose from, or a

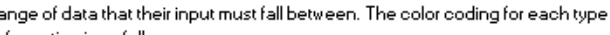

Colors Used

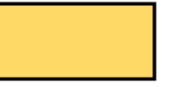

\section{Information Required from User}

Information required for user to input.

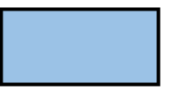

Information required that is required from the user, but is restricted to a range of values or a drop down list.

Data Output from the Program.

Output from the SPFs

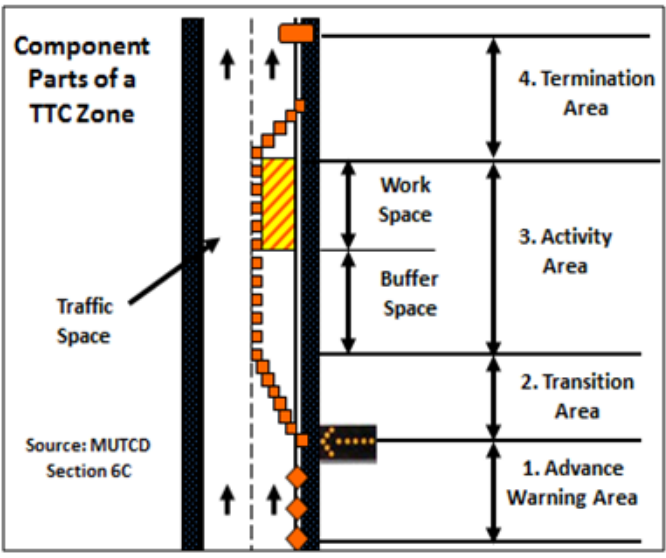

Temporary Traffic Control (TTC) Zone 


\section{Work Zone Analysis using Safety Performance Functions}

\section{- Mmens CEnTER Fon}

inois Department of Transportation

圆BRADLEY
A safety performance function (SPF) is an equation used to predict the average number of crashes per unit of time, typically one vear at a location as a function of exposure and other characteristics. SPFs are used to predict crash frequency for a given set of site conditions or to compare the safety performance of a specific site under various conditions. Work Zone total crashes (K, A, B, C \& O severity crashes) and injury crashes (K, A, B \& C) can be predicted using this Excel Tool for three Alternatives with differing Work Zone lengths and durations.

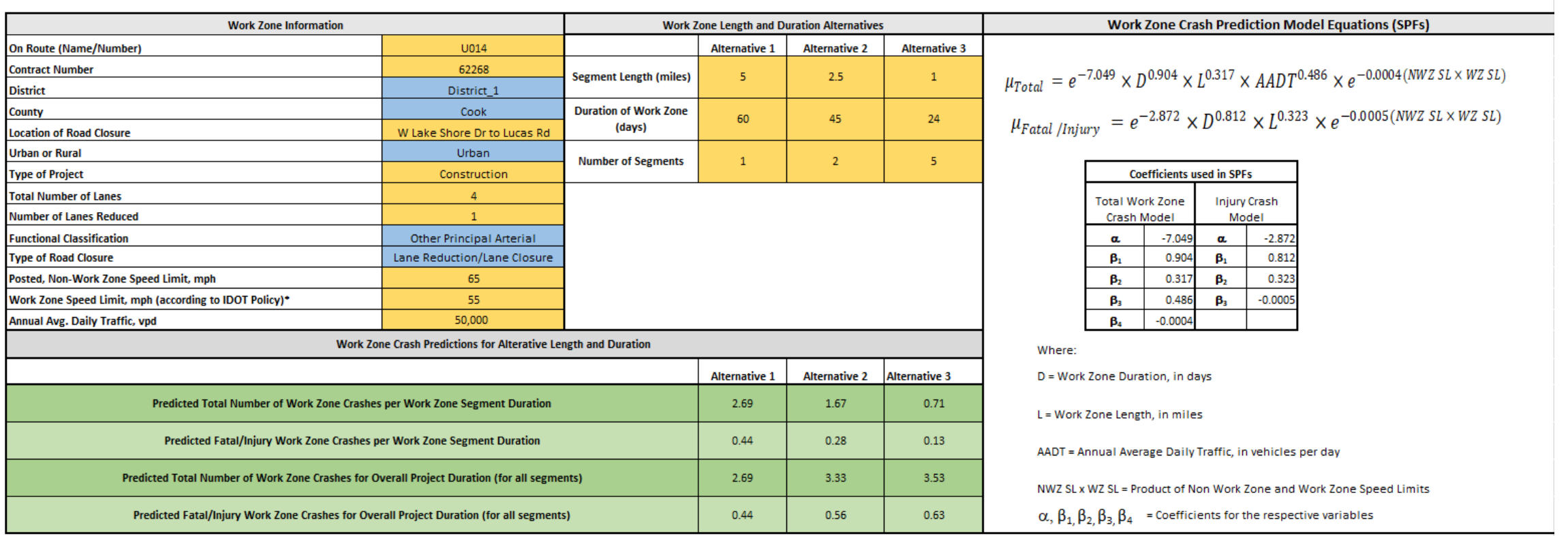

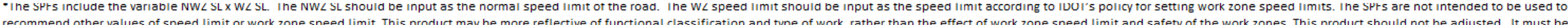
based on IDOT polic. 
APPENDIX E: IDOT'S ROAD RESTRICTION INFORMATION FORM OPER 2410 


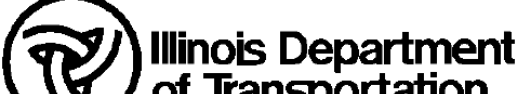 of Transportation}

Name:

Phone \#:

County Name:

Location Information: District:

Road Restriction Information

Route Type:

Route Number or Street:

Near Town:

Direction of Route

Bound

From Location or Mile:

To Location or Mile:

Road Restriction Information:

Start Date:

Stop Date:

Contract \#

New

Revised

Delete

Contract Value:

Contractor:

Type of Construction: Lanes/Ramp Closed

Suggestions to Motorists:

Traffic Alert (Special Comments):

Detour Route:

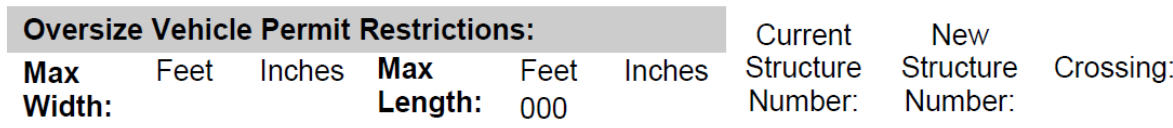

Crossover: $\square$ Yes $\square$ No

Web Address:

Send to: DOT.ROADINFO@Illinois.gov or in the Global Address Book under DOT.Roadlnfo 


\section{OPER 2410: ROAD RESTRICTION INFORMATION FORM INSTRUCTIONS (USE A SEPARATE FORM FOR EACH LOCATION)}

Name: Please enter the name of person responsible for this restriction, who will answer all questions about restrictions.

Phone \#: Please enter the phone number for the person responsible for this restriction.

Permanent or Emergency: Please mark box - Emergency - To report a restriction after informing Station 1, due to an unplanned event. Permanent - To identify a permanent roadway restriction not due to construction. Example: Max length 100 feet due to turning radius at intersection or 14 feet wide at a narrow structure. All narrow structures with actual openings of less than 17' 6" should be reported. For Permanent Restrictions you only need to fill out the location and Max Width or Length. This restriction will be placed on our Permanent Restriction List at:

Permanent Restriction List $\quad$ http://www.idot.illinois.gov/Assets/uploads/files/Doing-Business/SpecialtyLists/Highways/Permits/Permanentrestrictedroads.pdf

\section{Location Information:}

District/ County Name: Please select District and identify County for construction location.

Route Type: Please select type of route at Construction Location. (Interstate, US Route, Illinois Route, Street, County Road, or other.)

Route Number or Street: Identify Route, e.g. 90 for Interstate 90 or roadway name. Do not use FAP, FAU, etc.

Near Town: Enter name of the town construction zone is in or nearest to.

Direction of Route: Use the official direction the route travels. Do not use cardinal direction. Example INT 55 travels south to north and INT 24 travels west to east. (North, South, North and South, East, West, East and West).

From / To Location or Mile: Always use mile posts or Exit Numbers for Interstate projects, e.g. MP 177 to 184 or MP 39 for a specific structure at MP 39. For all other roadways use intersecting streets, distance from state roadway, etc., e.g. "Elm St. to First Ave.," "2 miles south IL29 at BNSF RR," "Auburn Rd. to 5 miles north of Sydney." Do not use Station Numbers.

\section{Road Restriction Information:}

Start / Stop Dates: These should be the dates which will affect motorists and not necessarily the official contract starting and stopping dates. The start and stop dates are in $\mathrm{mm} / \mathrm{dd} / \mathrm{yyyy}$ format. The Stop Date is the day the motoring public will stop being affected. If you are not sure of the Stop Date make it longer and revise at a later date. Construction zones will be removed on the Stop Date, if not revised prior to. Projects not requiring roadway closures or dimensional restrictions on vehicles should be submitted within 7 days of start date. Projects requiring roadway/ramp closures or oversize vehicle permit dimensional restrictions (maximum width or length restrictions on vehicles) should submit restrictions 21 days prior to the actual start date the roadway will be closed or a dimensional restriction will be in place to give motorists and oversize overweight permit loads advance notice. Stop dates should be revised or modified as necessary during the life of the project.

Contract \#: Please enter contract number. If no contract number, specify reason like CN RR, Day Labor, Bridge Office, or Emergency. In those cases a contract number will be assigned.

New, Revised, Delete: Please mark box that describes what kind of temporary restriction you are submitting. New Never submitted prior. Revised - For changing something submitted prior. Delete - To remove an active construction zone, prior to the Stop Date. (You do not have to submit a delete form when past the Stop Date. Restrictions will automatically be removed after the Stop Date.)

Contractor: Please provide name of contractor or entity doing the work. 
Contract Value: Please provide value of work performed. (Some Districts use this form to provide data for Press Releases).

Type of Construction: Select what describes your construction zone the best. Use one of the following: Lane Reduction/Lane Closure, Intermittent Road Work, Intersection Restrictions, Temporary Changes, One Way Traffic with Temporary Signals, One Way Traffic with Flaggers, Shoulder Work, Road Closed, Bridge Closed, Shoulder Closed, Ramp Closed, Railroad Closure, Weight Station Closed, Rest Area Closed, or Closed Due to Flooding. This is a pull down box selection.

Lanes / Ramp Closed: Provide information on the number of lanes closed or if a ramp or shoulder is closed or restricted.

Suggestions to Motorists: Please enter information that would be helpful to motorists. Examples: Traffic restricted to one lane in each direction, Road closed to place beams expect 15 minute closures, Expect lane closures with narrow lanes, Traffic restricted to one lane directed by temporary traffic signals. Include general information on such things as delays, time of day or days of week, etc. This is an input text line.

Traffic Alert: Any special information, including special delays such as "Expect intermittent 20-minute delays on May 17," "INT 57 SB ramp to IL 17 EB ramp closed," etc. This is an input text line.

Detour Route: Enter detour route for standard vehicles and truck detour if needed. This is an input text line.

Current Structure Number: Enter the current structure number in the construction zone. Oversize vehicle permit restrictions will be placed on route specified at the structure only. If you need restrictions on the crossing roadway as well, please specify. Enter what the structure is crossing to right under Crossing. (Roadway, River, Creek, etc.)

New Structure Number: Enter the new structure number replacing the current structure in the construction zone.

Crossing: When working at a structure/specific feature, enter what the structure is crossing like Illinois River or Mudd Creek. Please enter the current structure number, not the new structure number in column to left.

Oversize Vehicle Permit Restrictions: This section is for submitting width or length restrictions placed on vehicles for construction zones. These restrictions are based on the limitations of the construction zone, not the dimensions of the Construction Zone. Max Width measurements shall be 1' 6" less than the actual opening, e.g. (If actual opening measures 13', width restriction should be reported as 11' 6" and signed as 11' 6"). Max Length restriction measurements shall be determined by the turning radius and traffic patterns in the construction zone. Note: Length restrictions are usually not submitted unless you identify long vehicles are using the route, e.g. a wind mill blade with overall length of vehicle at 205 feet. Max length is also used with permanent restrictions to report permanent turning radius issues.

The blank entry field below the max width and length fields is for additional info. Examples: Report start and stop dates for restrictions if different than general construction start and stop dates, identify additional structures/locations with width restrictions and dates of, Start and Stop dates for Stage 1 or 2. (STR \# 013-4569 6/15/2013-12/1/14 (Useful when From/To Location for paving is 5 miles long with width restriction at structure) or Stage $110^{\prime \prime}$ " on $5 / 15$ Stage II 9' 6" on 7/7/13-11/1/13.) Do not consider marked detours when reporting restrictions. Permit loads can't use detours. If this will be a Permanent Restriction please mark the box in the upper right corner of the form and remind us in this field as well, so we will ignore the start and stop dates.

Crossover: If a crossover is being utilized, mark the Yes box and provide a description below. The description should include where both crossovers are, especially in relation to vertical clearance issues, e.g. "East of Elm St. west of IC RR." The description must also include which direction the traffic is traveling on, e.g. "Traffic on NB lanes." Revise form 21 days prior to traffic moving to opposite direction of travel.

Web Address: Enter the address if you have a specific website established for the project.

Data Verification: Please verify the accuracy of the information posted for your area of the State on the Road Construction Map and Weekly Restriction List. Please bring all discrepancies to our attention by issuing a revised OPER 2410 .

Road Construction Map $\quad$ http://www.gettingaroundillinois.com/gai.htm?mt=cons

Weekly Restriction List $\quad$ http://truckpermits.dot.illinois.gov/road/restrlst.rtf 


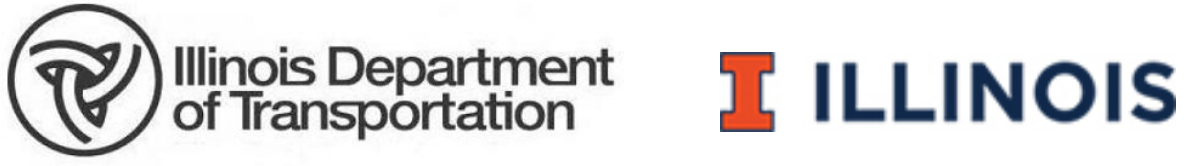

